\title{
ASSESSING THE IMPACT OF SOCIAL CAPABILITY, TECHNICAL CAPABILITY, AND THEIR FIT ON SOFTWARE DEVELOPMENT TEAM PERFORMANCE: AN EMPIRICAL STUDY
}

MANJARI MAHESHWARI, B.E. (Chemical), M.B.E., M.B.A.

A thesis submitted to the Faculty of Graduate Studies and Research in partial fulfillment of the requirements for the degree of

Doctor of Philosophy in Management

Eric Sprott School of Business

Carleton University

Ottawa, Ontario

(C) Copyright Manjari Maheshwari, 2010 


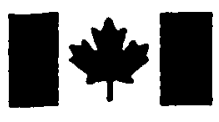

\author{
Library and Archives \\ Canada \\ Published Heritage \\ Branch \\ 395 Wellington Street \\ Ottawa ON K1A ON4 \\ Canada
}

Bibliothèque et

Archives Canada

Direction du

Patrimoine de l'édition

395, rue Wellington

Ottawa ON K1A 0N4

Canada
Your file Votre référence
ISBN: $978-0-494-67892-3$
Our file Notre reférence
ISBN: $978-0-494-67892-3$

\section{NOTICE:}

The author has granted a nonexclusive license allowing Library and Archives Canada to reproduce, publish, archive, preserve, conserve, communicate to the public by telecommunication or on the Internet, loan, distribute and sell theses worldwide, for commercial or noncommercial purposes, in microform, paper, electronic and/or any other formats.

The author retains copyright ownership and moral rights in this thesis. Neither the thesis nor substantial extracts from it may be printed or otherwise reproduced without the author's permission.
AVIS:

L'auteur a accordé une licence non exclusive permettant à la Bibliothèque et Archives Canada de reproduire, publier, archiver, sauvegarder, conserver, transmettre au public par télécommunication ou par l'Internet, prêter, distribuer et vendre des thèses partout dans le monde, à des fins commerciales ou autres, sur support microforme, papier, électronique et/ou autres formats.

L'auteur conserve la proprièté du droit d'auteur et des droits moraux qui protège cette thèse. $\mathrm{Ni}$ la thèse ni des extraits substantiels de celle-ci ne doivent être imprimés ou autrement reproduits sans son autorisation.
In compliance with the Canadian Privacy Act some supporting forms may have been removed from this thesis.

While these forms may be included in the document page count, their removal does not represent any loss of content from the thesis.
Conformément à la loi canadienne sur la protection de la vie privée, quelques formulaires secondaires ont été enlevés de cette thèse.

Bien que ces formulaires aient inclus dans la pagination, il n'y aura aucun contenu manquant. 


\begin{abstract}
The purpose of this study was to examine the effect of social capability, technical capability, and their fit on software development team performance. We hypothesized that a team's social and technical capabilities positively impacts its performance. Further, we hypothesized that the fit between social and technical capabilities also impacts team performance. Fit was conceptualized using three different approaches of moderation, matching, and profile deviation.
\end{abstract}

Socio-technical systems perspective, which is the theoretical argument behind building sociotechnical systems adopts a holistic view of how the social and technical factors are interweaved in the way people work in an organization. We applied this perspective to study how social and technical capabilities interact within the software development team context, and eventually studied their impact on team performance. Basic premise of our research is that in order to build the socio-technical systems enough emphasis should be given on how the social and technical capabilities interact within the system. We found that progress in the area is hindered by 1) lack of validated measures for the social and technical capability construct within a software development team and 2) lack of measures for assessing the socio-technical capability fit. We addressed these two gaps in our research. We developed the constructs of social and technical capability and further state that social and technical capabilities are second order constructs.

The research model was tested using data from software product development managers and team leaders of 192 software development teams. Three different analytical techniques of structural equation modeling (SEM), deviation score, and profile deviation were used to test the hypotheses in three different fit perspectives. The findings indicate that matching and moderation approaches are more suitable for the micro-level fit analysis and profile deviation is more suited for the macro level fit analysis. 


\section{Acknowledgements}

Completion of this thesis was made possible by efforts, support and encouragement of many people. My supervisor, Dr. Uma Kumar was the pillar of strength and support for me and stood by me at all times. She kept faith in me during difficult times and her financial support provided me a way to sustain myself during my graduate student days.

I would like to thank all the members of my committee who individually and collectively contributed to the thesis. I have come to admire the efforts of Dr. Vinod Kumar, Dr. Raili Pollanen, and Dr. Shaobo Ji and have formed a special bonding with them, which I expect to continue for years. Their constructive comments helped me immensely in improving my work.

I would like to extend my thank you to all my respondents for answering the survey for my thesis without which this work could not be finished.

I must specially acknowledge all my friends in Ottawa specially Vedmani and Aareni who helped me and provided me support when I needed it the most.

Finally, no word can express the unconditional love and extraordinary support my family extended to me that made the completion of this thesis a reality. I would like to thank my spouse, my kids, and my parents for being less demanding on my time.

I would like to dedicate this work to my father who once said to me "I was not able to do a $\mathrm{PhD}$ and I want you to do it." 


\section{Table of Contents}

Abstract

Acknowledgements ................................................................................................................ ii

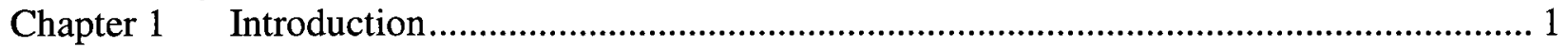

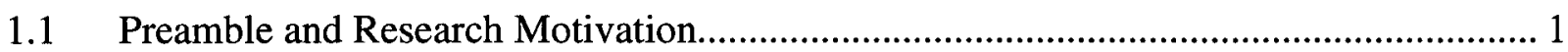

1.2 Research Objectives and Research Questions.............................................................. 7

1.3 Organization of the Thesis ..................................................................................... 10

Chapter 2 Theoretical Background .................................................................................. 11

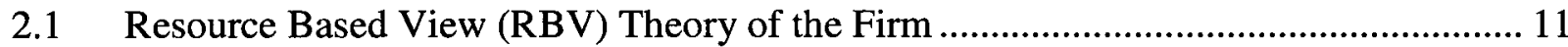

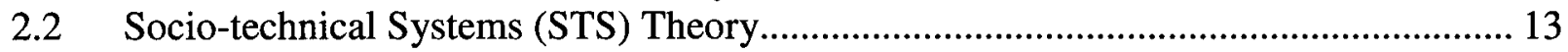

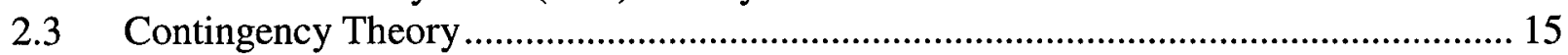

2.4 Related Literature on Software Development ................................................................. 17

Chapter 3 Research Model and Hypotheses .............................................................................. 23

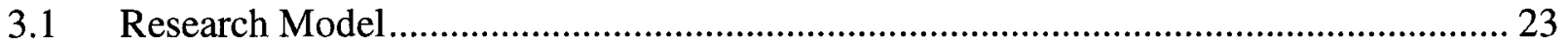

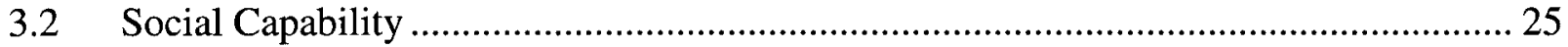

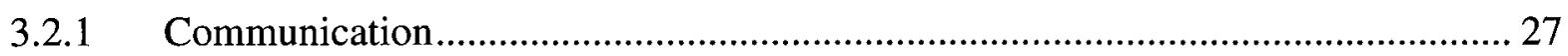

3.2.2 Conflict resolution ............................................................................................ 29

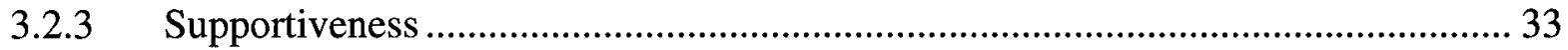

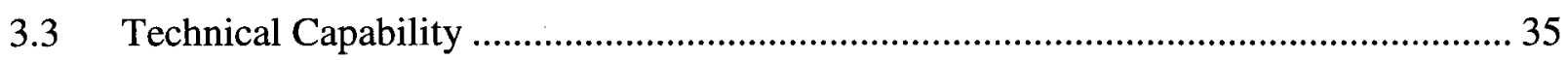

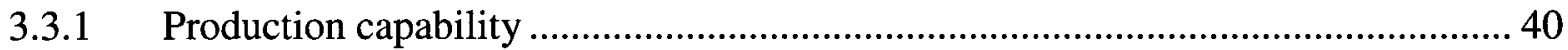

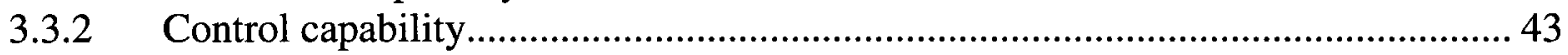

3.3.3 IT infrastructure capability ……………….......................................................... 46

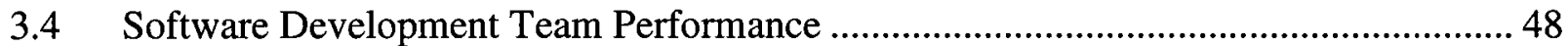

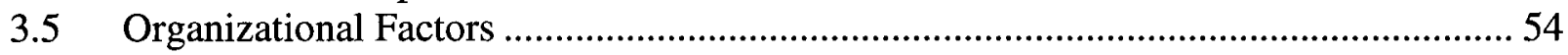

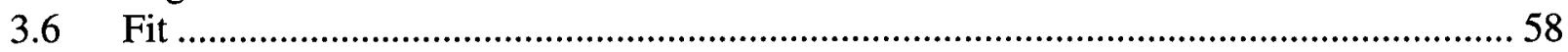

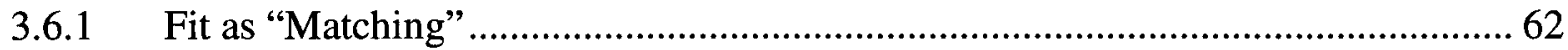

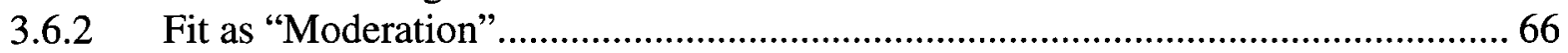

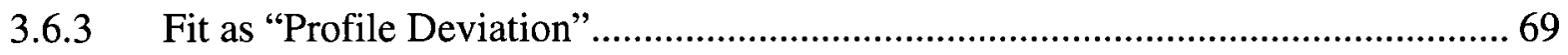

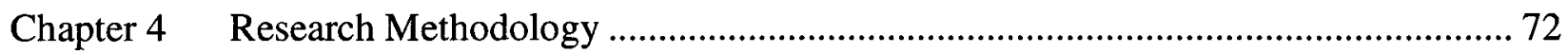

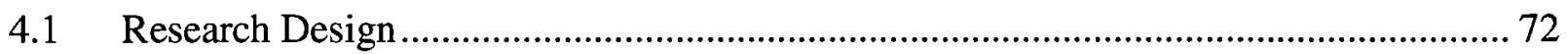

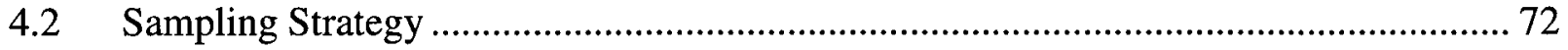




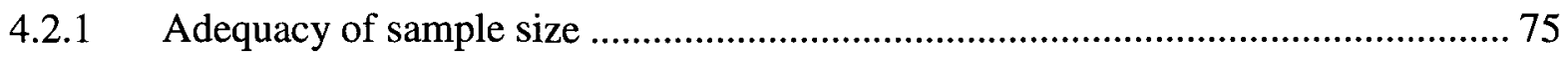

4.2.2 Data collection and unit of analysis ..................................................................... 76

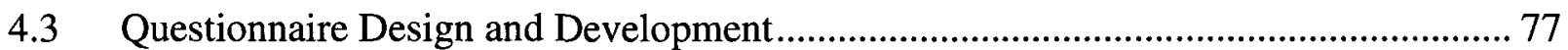

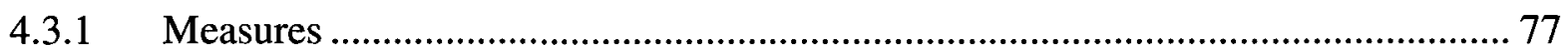

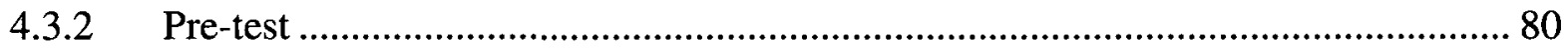

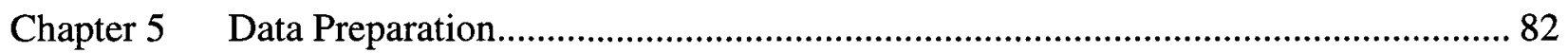

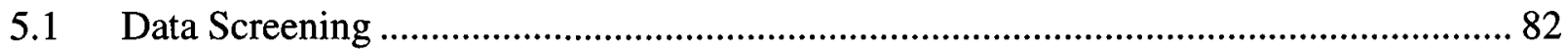

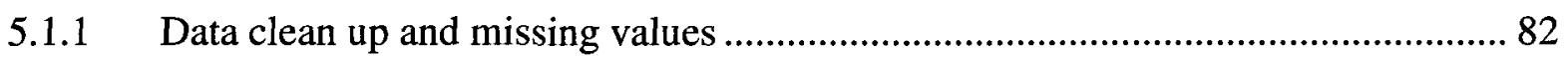

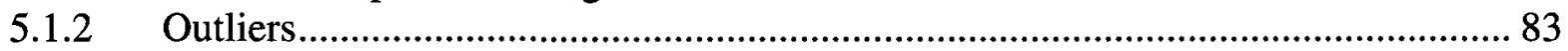

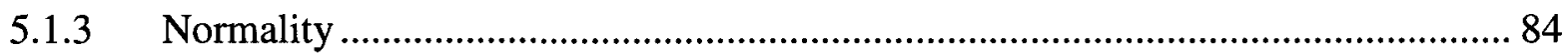

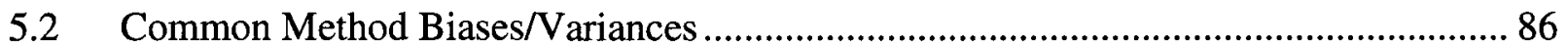

5.3 Non Response Bias and Response Rate ………......................................................... 87

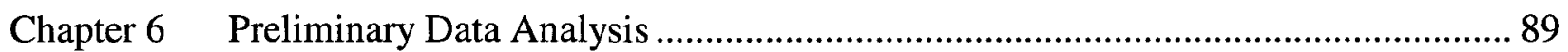

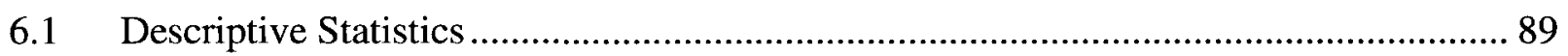

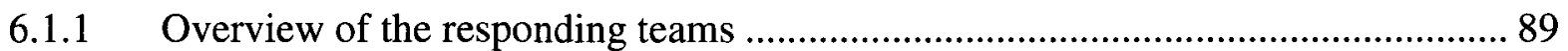

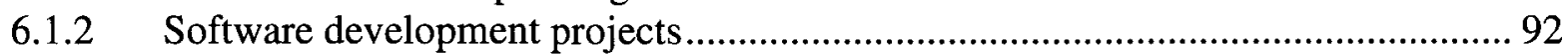

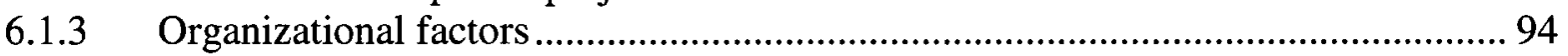

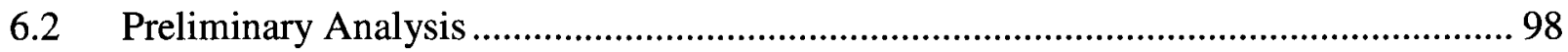

6.2.1 Impact of perceived fit on performance............................................................. 99

6.2.2 Capabilities differences across team size, region, and between virtual and co-

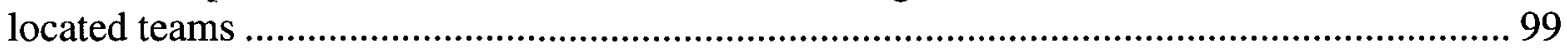

Chapter 7 Analysis using Structural Equation Modeling .................................................... 103

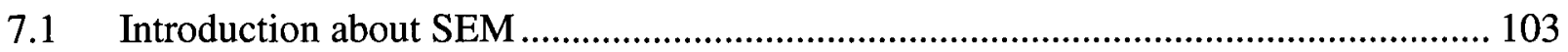

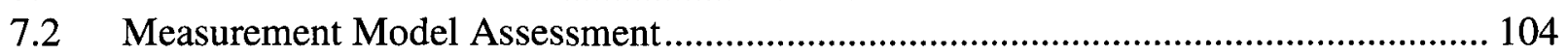

7.2.1 Assessing uni-dimensionality: First order CFA................................................. 105

7.2.2 Assessing uni-dimensionality: Second order CFA …...................................... 116

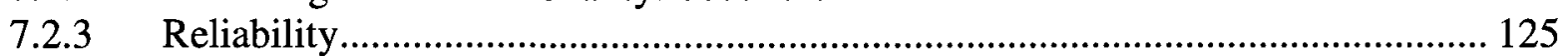

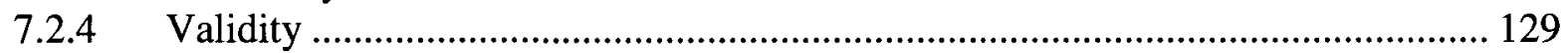

7.3 Structural Model Assessment of Capabilities on Team Performance............................ 132 


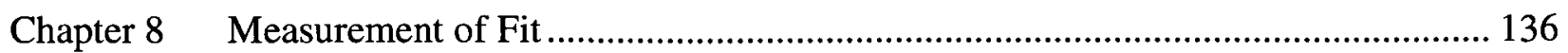

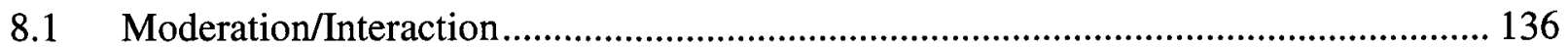

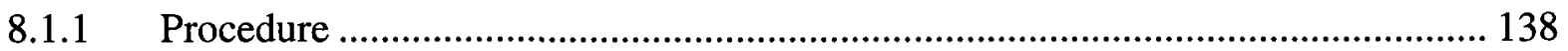

8.1.2 Impact of fit between communication and technical capability variables on

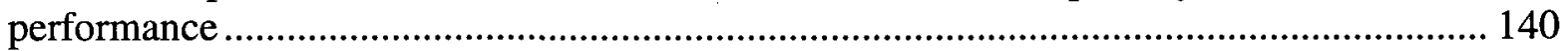

8.1.3 Impact of fit between conflict resolution and technical capability variables on performance

8.1.4 Impact of fit between supportiveness and technical capability variables on

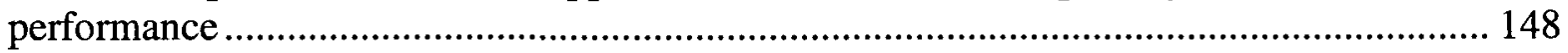

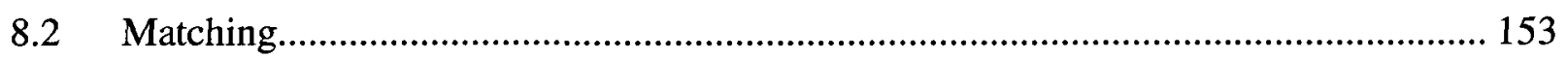

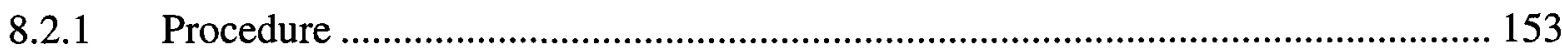

8.2.2 Impact of fit between communication and technical capability variables on team

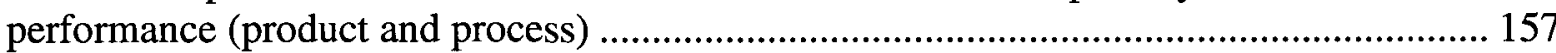

8.2.3 Impact of fit between conflict resolution and technical capability variables on performance (product and process) ................................................................................ 160 8.2.4 Impact of fit between supportiveness and technical capability variables on performance (product and process) .................................................................................. 162

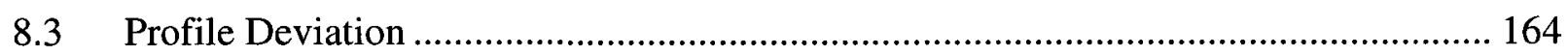

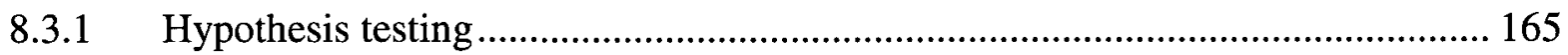

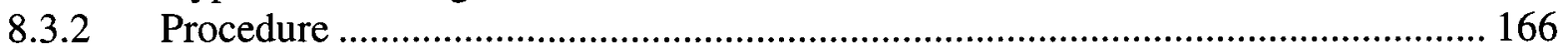

Chapter 9 Impact of Moderating Variables …………..................................................... 172

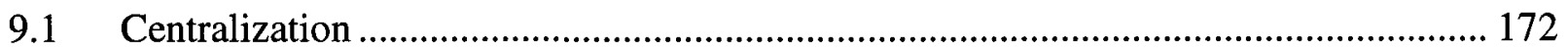

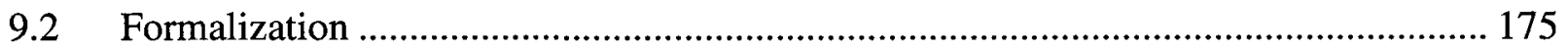

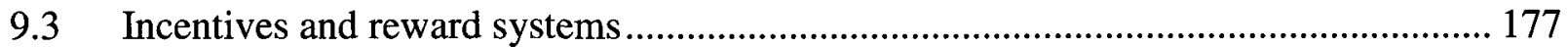

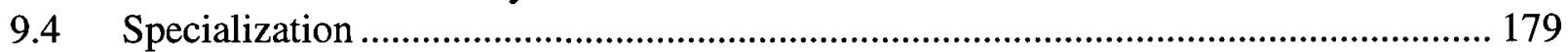

9.5 Team Size

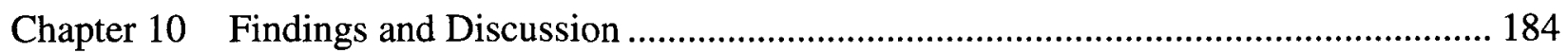

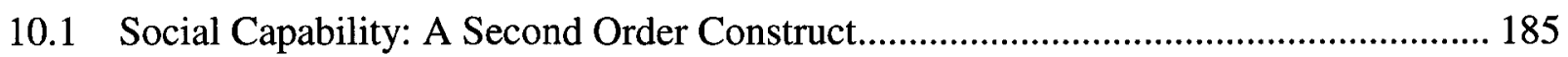

10.2 Technical Capability: A Second Order Construct.......................................................... 188

10.3 Relationship between Social and Technical Capability and Team Performance......... 190

10.4 The Measurement of Fit ................................................................................. 192

10.4.1 Fit between communication and technical capability variables ............................ 193

10.4.2 Fit between conflict resolution and technical capability variables ...................... 194

10.4.3 Fit between supportiveness and technical capability variables.............................. 195 


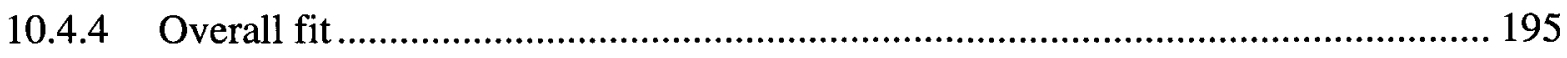

10.5 Comparing the Three Fit Measurement Approaches .......................................... 196

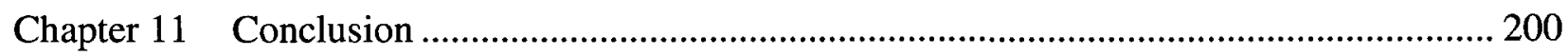

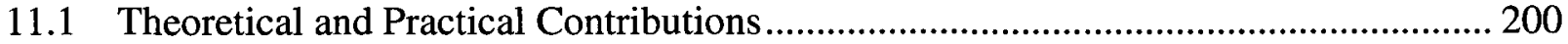

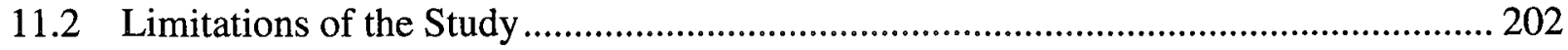

11.3 Recommendations for Future Research ............................................................ 204

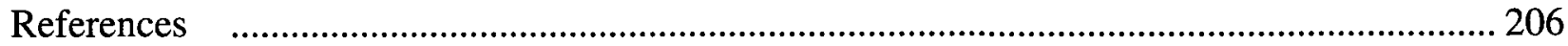




\section{List of Tables}

Table 2-1 Summary of socio-technical studies within software development teams .................... 21

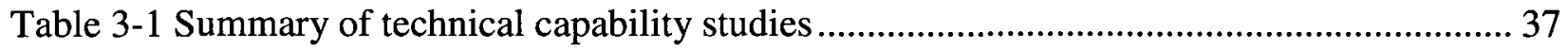

Table 3-2 Summary of software development team performance studies..................................... 50

Table 4-1 List of Industries in publishing sub-sector (NAICS Code 511) .................................... 73

Table 4-2 List of Industries in computer and electronic product manufacturing sub-sector ......... 74

Table 5-1 Descriptive statistics of the independent and dependent variables ................................ 85

Table 6-1 Correlations of perceived fit and performance ............................................................ 99

Table 6-2 Independent samples t-test for capability differences across the two regions............. 100

Table 6-3 Independent sample test for capability differences across virtual and co-located teams

Table 6-4 Independent samples test for capability differences across team size......................... 102

Table 7-1 Summary of modified measurement models .............................................................. 116

Table 7-2 Alternative models for social capability ....................................................................... 118

Table 7-3 Alternative models for technical capability.............................................................. 122

Table 7-4 Reliability statistics of first order constructs .............................................................. 127

Table 7-5 Reliability statistics of second order constructs ........................................................ 129

Table 7-6 Average variance extracted (AVE) ................................................................ 130

Table 7-7 Correlation matrix and average variance extracted (on the diagonal)....................... 132

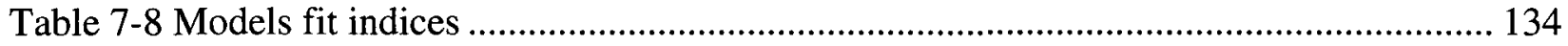

Table 8-1 Interaction term starting values and reliability ......................................................... 141

Table 8-2 Model fit indices for communication and technical capability dimensions ............... 142

Table 8-3 Interaction term starting values and reliability ...................................................... 145

Table 8-4 Model fit indices for conflict resolution and technical capability dimensions........... 146

Table 8-5 Interaction term starting values and reliability.......................................................... 149

Table 8-6 Model fit indices for supportiveness and technical capability dimensions ................. 150

Table 8-7 Correlations of fit variables with product performance ............................................... 156

Table 8-8 Correlations of fit variables with process performance................................................ 157

Table 8-9 Mean values for social capability dimensions....................................................... 168

Table 8-10 Mean values for social capability dimensions........................................................ 170

Table 8-11 Correlations between performance measures and profile distance scores ................ 171

Table 9-1 More centralization group .......................................................................................... 173

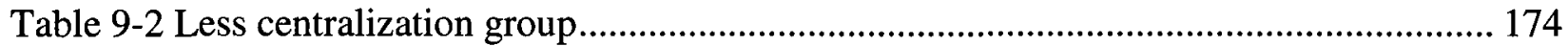

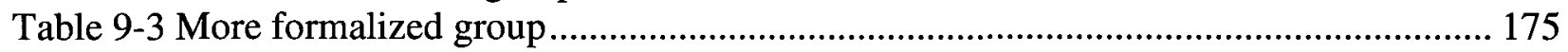

Table 9-4 Less formalized group .............................................................................................. 176

Table 9-5 More incentives and rewards group ………............................................................ 177

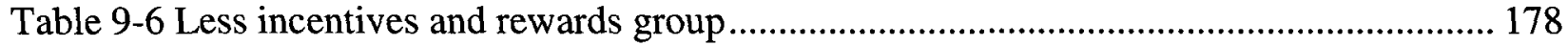

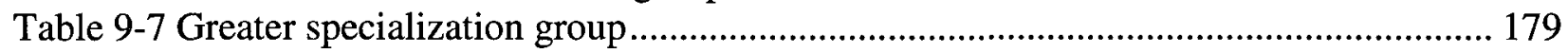

Table 9-8 Less specialization group ………………............................................................. 180

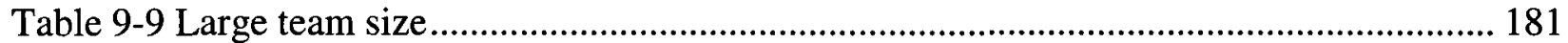

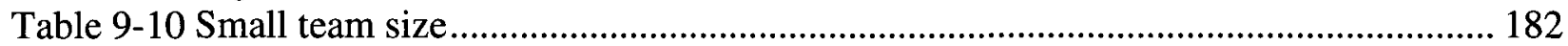

Table 10-1 Aggregate findings linking fit with product and process performance ..................... 198 


\section{List of Figures}

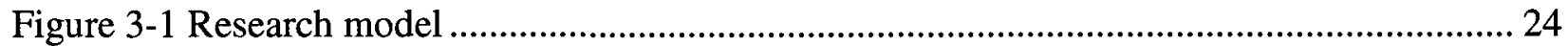

Figure 3-2 Phases of software development (Clegg et al. 1997) ............................................. 41

Figure 3-3 A classification scheme for fit measurement approaches (Venkataraman, 1989)...........60

Figure 3-4 A schematic diagram of fit as matching ......................................................6 63

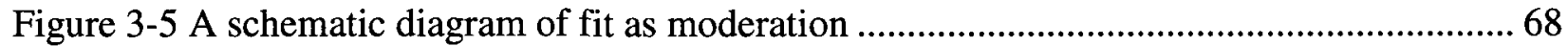

Figure 6-1 Distribution of the dataset by the type of software developed..............................90

Figure 6-2 Distribution of the dataset by the location of the respondent................................ 91

Figure 6-3 Distribution of the dataset by team size .................................................... 92

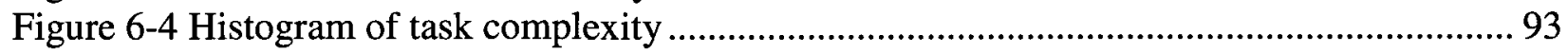

Figure 6-5 Histogram of task interdependence ........................................................ 94

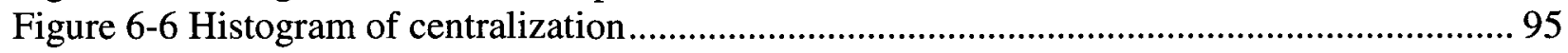

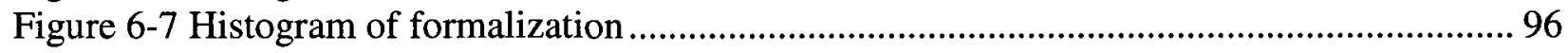

Figure 6-8 Histogram of incentives and reward systems ................................................... 97

Figure 6-9 Histogram of specialization................................................................... 98

Figure 7-1 Road map for measure validation in SEM ................................................. 105

Figure 7-2 Measurement model of communication (com) .............................................. 107

Figure 7-3 Measurement model of conflict resolution (cr) ................................................ 108

Figure 7-4 Measurement model of supportiveness (sup) .................................................. 109

Figure 7-5 Measurement model of production capability $(\mathrm{pc})$......................................... 110

Figure 7-6 Measurement model of control (performance) capability (cop) ........................... 111

Figure 7-7 Measurement model of control (standardization) capability (cos) ......................... 112

Figure 7-8 Measurement model of IT infrastructure capability (it)....................................... 114

Figure 7-9 Measurement model of product performance (prod) .......................................... 115

Figure 7-10 Measurement model of social capability (sc) .................................................. 120

Figure 7-11 Measurement model of technical capability (tc) ............................................. 124

Figure 7-12 Structural model of social and technical capability and performance .................. 133

Figure 8-1 Schematic diagram of communication and technical capability dimensions under the

moderation approach.................................................................................................. 140

Figure 8-2 Schematic diagram of conflict resolution and technical capability dimensions under the moderation approach ........................................................................................... 145

Figure 8-3 Schematic diagram of supportiveness and technical capability dimensions under the

moderation approach. 


\section{List of Appendices}

Appendix I Letter of Invitation to Participate in the Study ............................................... 228

Appendix II Questionnaire......................................................................................... 230

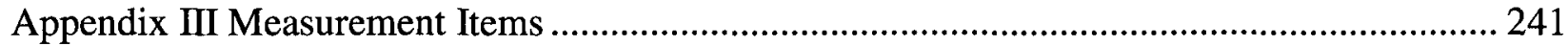

Appendix IV Descriptive Statistics for Measured Items .................................................. 246

Appendix V Interaction Term Analysis with Procedure, SIMPLIS Code and Starting Values . 249

Appendix VI Alterative Models for Social Capability ........................................................ 260

Appendix VII Alternative Models for Technical Capability ................................................ 263

Appendix VIII Team Satisfaction Analysis using Profile Deviation....................................... 266 


\section{Chapter 1 Introduction}

This chapter provides an introduction about the study. In this chapter first the research motivation is discussed and then the research objectives are outlined. Finally, organization of the thesis is presented.

\subsection{Preamble and Research Motivation}

Software development today is one of the largest and most prominent high growth industries. Software development is also a major activity for many other industries which package their products with software-supported innovations. For example, for mobile device manufacturer Nokia, the end product is a physical device but the majority of its research and development investment is focused on software development. From a global perspective, the size of the worldwide software industry in 2008 was US $\$ 303.8$ billion, which was an increase in $6.5 \%$, compared to 2007 . The size of the global software market by 2013 is estimated to increase by $50.5 \%$ since 2008 , with a value of US $\$ 457$ billion $^{1}$. Even in 2008 with the global economic crisis at its peak, software industry continued its progress and software remains an important component of the global economy. Concepts such as digital convergence, cloud computing, virtualization, and SOA bring in new challenges for the software enterprises. Given the pressures to constantly innovate and yet remain flexible in the software development and the software

\footnotetext{
${ }^{1}$ http://www.infoedge.com/product type.asp?product=DO-4959
} 
supported industries along with the accelerating costs associated with developing the software, organizations are always looking for ways to improve their software development team capabilities and team performance.

Failure is a common occurrence in the software development industry, and it is a common concern across the research studies in system development/software development ${ }^{2}$ (e.g., Robey and Newman, 1996; Guinan et al., 1998; Patnayakuni et al., 2006). Despite huge expenditures, prevalence of sophisticated tools and techniques, and the organizational insights provided by many years of academic research, software development remains problematic and stories of failure abound. It is a well recognized fact that managing a software development project from the requirements determination stage through to its implementation is a complex task. Examples of software development projects gone awry and the fiascos associated with them are plentiful; they include the Hudson Bay Company's $\$ 33.3$ million loss on an inventory system and the Ford Motor company's $\$ 400$ million loss on a purchasing system (Charette, 2005). Software development failures result in operational consequences, which may not be always dramatic, but the financial consequences of failure are generally quite heavy (Tiwana and Keil, 2006). These problems are increasing with the growth in the software industry; however, we are of the opinion that software failure, for the most part, is predictable and avoidable.

Academic research has provided many insights into improving the software development processes and performance and reducing the failure rate. Several researchers in both the

2 At the beginning, it is necessary to ensure that the terms used are clear. In the IS literature, the use of the terms system development and software development are often confused and often overlap. In our understanding, system development is a broader term than software development and we used the term software development because it is more appropriate to the research objectives of the study. 
information systems (IS) and software engineering fields have studied the performance of software development teams with a focus on various theoretical constructs, such as project management constructs (Keil et al., 2003), user participation (Barki and Hartwick, 1994), knowledge integration (Patnayakuni et al., 2006), control (Henderson and Lee, 1992; Nidumolu and Subramani, 2003), software processes (Deephouse et al., 1996), teamwork quality (Hoegl and Gemuenden, 2001), and coordination (Andres and Zmud, 2001). Despite more than 25 years of research in the software development domain, researchers have argued for the presence of deficiencies in the knowledge related to the successful management of complex software development processes (e.g., Sambamurthy and Kirsch, 2000). To keep pace with the changing face of the software industry, new theoretical ideas and methodological principles are needed in the software development domain (Kang et al., 2006). This research provides a fresh theoretical perspective for understanding the software development domain by focusing on the software development team capabilities and how they impact the performance of the project development teams. We did not find any academic research in the IS literature dealing with capabilities and their impact on software development team performance.

Software development requires input from numerous stakeholders and team members with diverse skill-sets and backgrounds (Robey et al., 2001; Clegg, 2000). It is mainly a team effort, and the performance of software development teams is a prime concern for IS/IT managers. Managing software projects efficiently while promoting team performance is also a long-standing concern in the IS research community (Robey et al., 1993). Traditionally, researchers have attempted to reduce the probability of software project failure by addressing the technical aspects and processes within the software development team. Despite that, however, software development failures have increased. One explanation that the literature provides for 
increase in failure rate is the lack of recognition given to the social processes that take place within in a software development team (Barki et al., 1993).

The focus on the social processes aspect in software development has received limited attention and has only come into the forefront of software development research in the '90s (Sawyer, 2001; Robey and Newman, 1996; Hirschheim et al., 1991). The social view stresses the importance of the social context within which team members operate and interact with each other. The social perspective may be able to provide a better explanation in dealing with the complex and confounding effects of system development (Hirschheim et al. 1996). The social action perspective suggests that all design activities take place in a "historical context under specific social influences" (c.f. Hirschheim et al., 1996), and research focusing on development problems must take into consideration the practices that are shared within the community. A few studies within a software development team context indicate that social processes do provide an explanatory value for team performance (Guinan et al., 1998; Sawyer and Guinan, 1998). One of the prominent studies within the software engineering field (Walz et al., 1993) identified communication breakdowns as a key factor affecting project outcomes, suggesting the importance of studying software development teams from a social perspective.

The present study calls for a more holistic view in studying software development team performance. We argue that rather than studying only the technical aspects of the development process (such as the tools and the techniques) or the social processes (such as the communication and conflict resolution) it is more appropriate to examine the underlying dynamics of the software development team performance by focusing on both technical and social aspects. Software development is not just a technical process of building a technical product, i.e., software, but also a social process involving various stakeholders (Kirsch, 1997). 
Developers work together to produce software which involves learning, communication, and negotiation processes (Curtis et al., 1988). A few researchers have recognized software development as a socio-technical process (Robey and Newman, 1996; Sawyer, 2001). While the social and technical aspects in developing software can be examined separately, literature suggests that they are mutually interdependent (Guinan et al., 1998; Sawyer, 2004). This mutual interdependence makes it difficult for researchers to understand either aspect independently (Sawyer, 2004). We focus on social and technical capabilities of a software development team for understanding the mutual interdependence among the social and technical elements. The purpose of this study is to further our understanding of the software development team capabilities and their effect on the success of software development team. The research model developed in this study incorporates both social and technical aspects of developing software by focusing on social and technical team capabilities. Building social and technical capabilities within a team are crucial for providing social and technical support to the team members respectively. The theoretical basis of our model rests on the resource-based view (RBV), sociotechnical systems (STS), and the contingency theory.

RBV theory posits that rare, valuable, imperfectly imitable, and non-substitutable resources and capabilities provide sustainable competitive advantage to a firm (Wernerfelt, 1984; Barney, 1991; Grant, 1996). Though mostly applied at the firm level, RBV has been recently applied to teams and work groups (Haas, 2006). It is argued that higher group capabilities result in higher performance (Lakhanpal, 1993; Boehm and Ross, 1989). To be sustainable, teams must maintain access to the pool of resources and at the same time be able to convert those resources by means of the various team processes to generate value for the team members (Perez et al., 2004). Processes refer to the way things are carried out and along with the resources collectively 
form the capabilities (Teece and Pisano, 1994). Focusing on internal capabilities (both social and technical) at the software development team level may provide an explanation for why some teams perform better than others. Although the primary focus of this research is on internal capabilities of a team but organizational factors, such as, centralization, formalization, specialization, and incentive and reward systems which may influence team capabilities and performance are also explored.

Proponents of STS theory argue that any work system can be considered as a sociotechnical system. Design and performance of a work system can be improved when the social and technical sub-systems are examined as interdependent aspects of the overall work system (Clegg, 2000). Building socio-technical systems has gained importance for the past few decades in the IS community. Within the field, researchers have focused on how to build the systems and the benefits of building such systems. STS perspective, which is the theoretical argument behind building socio-technical systems adopts a holistic view of how the social and technical factors are interweaved in the way people work to develop such systems. The main premise of the STS theory is that a fit is needed between the technical and social sub-systems of a work system (Cherns, 1976). We apply this perspective to study how social and technical capabilities interact within the software development team context, and eventually study their impact on team performance. The use of STS in studying software development team performance is not new. For example, within the software development risk domain, Wallace et al. (2004), looked at the impact of social sub-system and technical sub-system risk on team performance. Guided by STS theory and software development literature, we conceptualize the software development team as a socio-technical system and assess the fit between the social and technical capabilities within the team. 
Contingency theory is used to measure the fit. We adopt three different perspectives of fit, and hypothesize that software development team performance is influenced by the fit between the social and technical capabilities of the team. The present study examined previous efforts in IS research where researchers have compared different perspectives of fit (Bergeron et al. 2001; Nidumolu, 1996) and have applied multiple analysis techniques in their research. The use of multiple analysis techniques and use of the multiple perspectives of fit to study the same model are considered robust ways of testing the research model where fit is a key factor (Venkataraman, 1989).

\subsection{Research Objectives and Research Questions}

The research explores four research objectives and addresses five research questions. The socio-technical view highlights the importance of exploring the domain and context of the phenomenon under study. As previously mentioned, our extensive literature review shows that software development team capabilities and their impact on software development team performance is an under researched area in the IS literature. Progress in the area is hindered by 1) lack of validated measures for social and technical capability of a software development team and 2) lack of measures for assessing the socio-technical capability fit ${ }^{3}$. Our research objectives address these concerns and also focus on how the capabilities impact software development team performance.

\footnotetext{
${ }^{3}$ We use the term fit to represent socio-technical capability fit further in the document.
} 
First, we develop the constructs of social and technical capabilities within a software development team context. Second, we study their impact on software development team performance. Third, we measure the fit from three perspectives of matching, moderation, and profile deviation in the same context. Our argument is that in order to improve the team's performance, technical capability needs to vary according to the team's social capability or vice versa. Finally, we compare and contrast the three fit perspectives. Our unit of analysis in the study is the software development project team developing new products/modules within a given time frame. Team performance is a multi-dimensional construct. Consistent with the software development literature, the performance measures used in this research include both product and process dimensions.

The first two research questions address the first research objective.

1. What are the dimensions of social capability of a software development team?

2. What are the dimensions of technical capability of a software development team?

Based on the IS literature we develop the construct of social capability. It consists of three dimensions: communication, conflict resolution, and supportiveness. These dimensions have been found to play an important role in impacting software development team performance (Robey et al., 1989; Barki and Hartwick, 1994; Sawyer, 2001; Sawyer and Guinan, 1998; Hoegl and Gemuenden, 2001). The dimensions of technical capability, developed from IS and technology management literature, include production capability, control capability, and IT infrastructure capability.

The third and fourth research questions address the second and third research objectives. 
3. What are the contributions of social and technical capabilities on software development team performance?

4. Does the fit between social and technical capability impact software development team performance?

It is well understood in the literature that coherence in corporate capabilities reinforce the competitive advantage of firms (Teece et al, 1994; Robins and Wiersema, 1995). Studying the fit within a software development team becomes important as it is difficult to separate how the team members interact with each other and with both the technical methods and computing technologies. In the software development context, a few studies have suggested that a sociotechnical congruence/fit is beneficial for software development performance (Valetto et al., 2007; Cataldo et al., 2006). Valetto et al. (2007) used social network theory and mathematically formalized socio-technical congruence using data from software repositories. However, coherence of capabilities at the team level in software development has not been addressed in the literature, which is one of the aims of this research. Given the mutual influence of social and technical aspects in software development we saw a need to study both of these aspects jointly and use the contingency theory to measure the fit. Exploring the fit of social and technical capabilities presented a challenge to the researchers since established measures for the construct for social capability and technical capability were not available in the literature.

Finally, the fifth research question/fourth research objective relates to the comparison of the three approaches used in the measurement of fit.

5. Is one fit measurement approach better than the other in explaining the impact of fit on team performance? 
The classification scheme given by Venkataraman (1989) provides a comprehensive way for understanding the various fit conceptualization methods. Some approaches (e.g., matching) are more suitable for studying phenomenon at micro level and other approaches (e.g., profile deviation) are more suited for studying macro level phenomenon. Previous studies in IS have used more than one approach to conceptualize and measure fit (Nidumolu, 1996; Bergeron et al., 2001). Thus, we pursue a similar strategy in our research and study fit from multiple perspectives involving multiple analytical techniques.

\subsection{Organization of the Thesis}

The thesis is divided into 11 chapters. The next chapter discusses the theoretical backgrounds used to develop the model and provides a review of the socio-technical nature of the software development process. Chapter 3 presents the research model, including the definition of constructs and the research hypotheses for the three fit measurement approaches. Chapter 4 is about research design, which includes variable measures, sampling, and data collection details. Chapter 5 is about preparing data for analysis purposes. Chapter 6 presents the descriptive statistics of the data and some preliminary analysis involving t-tests. Chapter 7 presents the data analysis using structural equation modeling. Chapter 8 discusses the three fit measurement techniques. Chapter 9 presents the results of moderating variables analysis. Chapter 10 discusses the results and findings of the research. Finally, Chapter 11 lists the contributions, limitations, and future research directions of the study. 


\section{Chapter 2 Theoretical Background}

This chapter provides the theoretical background and the rationale for this study by reviewing some of the key concepts and theories from the relevant literature. The chapter is divided into four sections. The first three sections discuss the literature on RBV theory, STS theory, and contingency theory. The discussion provides an overview of the theories, including the origin, importance, relevance to IS literature in particular, and how they were applied in this study. The last section provides an overview of software development and why it is important to study both the social and technical aspects jointly in a software development team setting.

\subsection{Resource Based View (RBV) Theory of the Firm}

The RBV Theory is credited to Penrose (1959). The RBV theory posits that rare, valuable, imperfectly imitable, and non-substitutable resources and capabilities are the basis for sustainable competitive advantage for a firm (e.g., Wernerfelt, 1984; Barney, 1991; Grant, 1996). In strategy research, RBV has become a standard explanation for achieving competitive advantage for a firm (Hoopes et al., 2003). Recent studies (Verona, 1999; Dutta et al., 1999; Eithraj et al., 2005) have shown that RBV can be used to explain the organizational performance and success of any firm.

Improved organizational performance is attributed to the unique bundle of resources and capabilities that each firm possesses (Grant, 1996). A resource is an observable entity (not necessarily tangible) that can be valued or traded, such as a patent, land, machine, or a brand (Makadok, 2001). Capability, on the other hand, is not observable (i.e., it is intangible) and cannot be valued; hence, it can only be transferred/traded as part of a team/entire unit such as 
Intel's product platforms (Makadok, 2001) ${ }^{4}$. This is one of the best explanations of the differences between resources and capabilities in the literature. Capabilities rely on the firm's ability to create, exchange, develop, and utilize the information needed to realize the desired organizational outcomes using the firm's human resources (Amit and Schoemaker, 1993). Commonly, organizational capabilities - such as organizational culture, learning, routines, and entrepreneurship - are considered to be key sources of sustainable competitive advantage (Lado and Wilson, 1994).

Many studies in IS literature have used RBV theory to explain a firm's performance. Ravichandran and Lertwongsatien (2005) studied the impact of IS resources and capabilities on firm performance. Bharadwaj (2000) extended the notion of organizational capability to the IT function and studied the impact of IT capability on the performance of the firm. Capabilities in team environment have not received much attention in the IS literature. Capabilities can readily be conceptualized at the team level as evident in the argument: "to be capable of something is to have a generally reliable capacity to bring that thing about as a result of intended action" (Dosi et $a l ., 2000$ p. 2). Applying RBV to work groups and teams, we argue that performance of software development teams can be improved by focusing on their internal capabilities. In this research, we focus on the social and technical capabilities in the software development team environment. The team capabilities view developed here proposes that performance of software development teams should be examined from the social and technical capabilities point of view. These capabilities are important in any organizational context, but they are especially critical for addressing the problems of knowledge-intensive, complex and interdependent work, such as the development of software.

\footnotetext{
${ }^{4}$ A few key papers on RBV for readers such as Mahoney and Pandian, 1992; Makadok, 2001
} 


\subsection{Socio-technical Systems (STS) Theory}

The term "STS," coined by Trist and Bamforth in the early 1950s, has its base in the open systems theory. Since then, a number of researchers have made significant contributions in this field (e.g. Emery, 1982; Passmore et al. 1982; Mumford, 2000). The ten socio-technical design principles defined by Cherns (1976) and further refined by Cherns (1987) form the basis of much of the thinking in studies that follow the STS approach. The main premise of the STS theory is that a fit is needed between the technical and social sub-systems by means of exploiting the adaptability and innovativeness of the people to attain the fit (Cherns, 1976). Coakes (2000) described socio-technical research as "the study of the relationships and inter-relationships between the social and technical parts of any system." The design and performance of new systems can be improved if social and technical elements are brought together and examined as interdependent aspects of the overall work system (Clegg, 2000). The socio-technical perspective views organizations as socio-technical systems made of two independent, but linked, subsystems: a social sub-system and a technical sub-system (Shani et al., 1992).

The socio-technical perspective has been widely used to study organizational changes and design of work systems (Shani et al., 1992; Mumford, 2003). Studies have indicated that a neglect of socio-technical issues results in a negative impact on productivity and performance of employees that ultimately affects their quality of life (Land, 2000). In this paper our focus is not on the design aspect of the STS approach, though the results of the study may help in improving the design of the work system (software development team).

Building socio-technical systems is an important research stream in the IS community (Mumford, 1995; Davis et al., 1992). STS perspective, which is the theoretical argument behind building socio-technical systems, adopt a holistic view of how the social and technical factors are 
interweaved in the way people work in an organization. Several researchers have used the STS approach, applying the concepts to the design and implementation of IS (Bostrom and Heinen, 1977; Mumford, 1995, Davis et al., 1992; Lyytinen et al., 1998; Ivari and Hirschheim, 1996). Within the software development field, researchers have focused on how to build the systems and the benefits of building such systems.

Theoretically, every work system can be modeled as a socio-technical system and the software development team is no exception. The social sub-system includes two components actors and the social interactions (Cummings, 1978; Lee and Xia, 2005). Within the software development context, actor means the various stakeholders - such as users, managers, and developers - and social interaction indicates activities that are determined by the interaction between the various stakeholders (Lee and Xia, 2005; Gruhn, 1992). Effective management of the various interactions (such as communication and conflict resolution) among the various stakeholders is critical for software development teams (Kirsch, 1996). The technical sub-system generally consists of the tools, equipment, and skills and the methods of operation for producing goods and services (Cummings, 1978). Within the software development context, a technical sub-system includes the infrastructure and the skills needed to develop the software (Cooprider and Henderson, 1990). Researchers have suggested that system development failures could be attributed more to the social and organizational factors than technical factors (Doherty and King, 1998; Lee and Xia, 2005). Therefore, organizations must take both the social and technical dimensions into account in an IS development process. However, very few researchers have actually combined both views (social and technical) in their system development studies (Sawyer and Guinan, 1998). We apply STS theory to study how social and technical capabilities interact within the software development team context, and eventually study their impact on team 
performance. Consistent with the STS approach, we argue that there are two capability elements that must be simultaneously managed in a software development team in order to improve team performance. We label these two elements as social capability and technical capability. Basic premise of our research is that in order to build the socio-technical systems enough emphasis should be given on how the social and technical capabilities interact within the system.

\subsection{Contingency Theory}

The contingency approach, developed in the late 1960s, is the dominant approach to organization design. Different environments place differing requirements on organizations as there is no best way to design a structure (Lawrence and Lorsch, 1967). Contingency theory emphasizes a fit between the type of work performed and the specific situation at hand for achieving organizational objectives effectively (Scott, 1998). Galbraith (1977) provides an information processing view to explain the contingency theory. He argued for an appropriate fit between the structural arrangement and information processing requirements of the task (Galbraith, 1977). Over time, the contingency theory has been applied frequently to explain many management and organizational phenomena.

A fit, or a match, between two or more factors is the key concept in contingency theory studies. The terminology used varies from congruence, match, and similarity to co-alignment; compatibility, or fit, which is the most common term used. Purpose of contingency theory is to understand and explain the inter-relationships within and among the various organizational subsystems (Szilyagi and Wallace, 1980). It assumes that a better fit among the contingency variables results in better performance (Weill and Olson, 1989). A number of studies have examined fit in the management literature such as the task-technology fit (Goodhue and 
Thompson, 1995), the technology-structure fit (Hoffman et al., 1992; Alexander and Randolph, 1985), the strategy-environment fit (Venkataraman and Prescott, 1990), and technologyinformation processing fit (Keller, 1994). Another point to be noted is that the level of analysis in studying the fit has been mostly at the organizational level with very few studies looking at the project/group/team level (Barki et al., 2001).

A number of IS researchers have used this theory to investigate the contingent effect of one variable on another with varying conceptualizations of fit (e.g., Hardgrave et al., 1999; Raymond et al., 1994; Bergeron et al., 2001). Raymond et al. (1994) tested the contingent relations of IT management on structural sophistication and organizational performance. Bergeron et al. (2001) studied strategic orientation and strategic IT management on a firm's performance using multiple perspectives of fit. Barki et al. (2001) looked at the influence of fit between software development project risk and the management of that risk on the performance of the project. However, its application in assessing the performance of a software development team is rather limited, with a few exceptions (Kim and Umanath, 1993; Barki et al., 2001). Literature has given little attention to the fact that the performance of a team could be contingent upon the fit between their social and technical capabilities. Based on the fit conceptualization classification scheme given by Venkataraman (1989) we use three conceptualizations of fit Matching, Moderation, and Profile Deviation - to address the research in the paper. Our purpose is not to test the contingency theory, but rather to use it as a framework to understand the impact of socio-technical fit in enhancing the software development team performance. 


\subsection{Related Literature on Software Development}

Fast technological change and global growth, short product cycles, fierce competition, new ways of developing software (the Open Source phenomenon), evolving business models, and high failure rates are some of the characteristics describing today's software industry. Software industry that depends on hardware industry has another big challenge to face. As evident in Moore's Law, hardware technology has improved exponentially over the years along with rapid price reductions for the computer hardware (Liang et al., 2007). Adapting software development to this rapidly changing environment is a challenge for the software industry in general and for software development firms and software professionals in particular.

Development of successful software is an exception rather than a rule. There is no standard way of developing software as each development is application specific. It is difficult to identify all the uncertainties that will be encountered during the development process. Although this can be the case for any kind of work in organizations, software development faces large number of contingencies since it has to deal with complex technologies. Software development is an innovative and knowledge-intensive activity where the degree of innovativeness depends not only on the firm's ability but also on the requirements of the customer (Torrisi, 1998). The multidisciplinary nature of software development requires an understanding of a variety of scholarly literature from IS, software engineering, project management, technology management, sociology, psychology, and other fields. We mostly focused on IS, software engineering, and technology management literature but at times knowledge from the other related literature provided important insights for developing the model for this research. The next section describes the socio-technical nature of software development that is relevant for the study. 
The common view prevalent in the literature is that the software development process is a collection of interrelated methods and practices and that technology plays a crucial role in the overall development process. Previous studies have shown that difficulties or trends associated with software development can be solved by following software engineering principles, such as establishing more formalized production methods (e.g., Henderson and Cooprider, 1990; Yourdan, 1989; Patnayakuni et al., 2006). The Software Engineering Institute (SEI)-Capability Maturity Model (CMM) framework for software process improvement is one such attempt. The technical view related to methodologies, techniques, and tools associated with software development has dominated the research on software development team performance for a long time.

A focus on the social view, considering software development as a social process, came into the forefront of research in the 1990s and has received limited attention (Sawyer, 2001; Robey and Newman, 1996; Hirschhiem et al., 1991). Clegg (2000), who revised the sociotechnical principles given by Cherns $(1976,1987)$ for system design and development, argued in his work that design is socially shaped and is an extended social process. Tracing the IS development literature, Hirscheim et al. (1991) argued that viewing software development as a technical process or a technical process with behavioural consequences is not adequate. They proposed a social action perspective that considers software development as a social process that relies on technology rather than as a purely technical process.

There is another stream of literature that views software development as a complex sociotechnical activity (Robey and Newman, 1996; Sawyer, 2001; Scacchi, 2005). The main premise of this stream of literature is that development is not just a technical process of building some technical product, i.e., a system or software, but a social process involving various 
actors/stakeholders with different backgrounds and orientations working together on a complex task (Robey, 1994; Kirsch, 1997; Sawyer and Guinan, 1998). Software development needs to be treated as a learning, communication, and negotiation process (Curtis et al., 1988). The dichotomy between technical and social aspects can be very well seen in the field of software development. Software development processes and the tools and techniques used come from the field of engineering and computer sciences, which are known to ignore the human-centric social issues. On the other hand, it is well established that software development is a human-centric process - as software is made by the people for the people - and their issues cannot be ignored.

Sawyer and Guinan (1998), in their research, examined the effects of technical methods and social processes on software development team performance and discovered that social processes - such as communication, conflict management, and supportiveness - accounted for more variation in performance measures (e.g., product quality) as compared to the technical methods. In an extensive study involving a number of years, Guinan et al. (1997) concluded that the use of automated tools in software development may not necessarily result in improved performance unless other social factors - such as coordination and training - are taken into account. In another research, Guinan et al. (1998) studied the impact of behavioural (e.g., team skill) and technical (e.g., structured methods) factors on software development team performance in the requirements determination stage. They concluded that behavioural factors have a more positive impact on group processes and, ultimately, team performance than do the technical factors. In a software development project risk study, Wallace et al. (2004) divided the risks into social and technical sub-systems risk and concluded that social sub-system risk influenced technical sub-system risk, which impacted performance. These four studies focused on both social and technical aspects of software development. Table 2.1 summarizes these four studies. 
Our study is similar in approach to the above mentioned studies as we examine both social and technical aspects for a software development project team.

In this research, we take the socio-technical view of software development and study the capabilities of the software development team. While the social and technical aspects of a sociotechnical system can be explicitly characterized, they are mutually interdependent. This mutual interdependence makes it difficult to understand either aspect independently (Sawyer, 2004). We argue that performance of a software development team may be improved by adopting a joint view of both the social and technical aspects. To be sustainable, teams should have access to the pool of resources (technical capabilities such as skills and infrastructure) and at the same time should be able to convert those resources by means of the various team processes (social capabilities such as communication and conflict resolution) to generate value for the team members (Perez et al., 2004). 
Table 2-1 Summary of socio-technical studies within software development teams

\begin{tabular}{|l|l|l|l|l|}
\hline $\begin{array}{c}\text { Author } \\
\text { (year) }\end{array}$ & \multicolumn{1}{|c|}{ Focus } & \multicolumn{1}{c|}{$\begin{array}{c}\text { Study } \\
\text { Sample }\end{array}$} & $\begin{array}{l}\text { Dependent/Independent } \\
\text { Variables }\end{array}$ & \multicolumn{1}{c|}{ Findings } \\
\hline $\begin{array}{l}\text { Sawyer } \\
\text { and } \\
\begin{array}{l}\text { Guinan } \\
(1998)\end{array}\end{array}$ & $\begin{array}{l}\text { Production } \\
\text { and social } \\
\text { processes }\end{array}$ & $\begin{array}{l}\text { 40 software } \\
\text { development } \\
\text { teams }\end{array}$ & $\begin{array}{l}\text { Team performance and } \\
\text { software product } \\
\text { quality/production, and } \\
\text { social processes }\end{array}$ & $\begin{array}{l}\text { Social processes play a key } \\
\text { role in team performance }\end{array}$ \\
\hline $\begin{array}{l}\text { Wallace } \text { et } \\
\text { al. }(2004)\end{array}$ & $\begin{array}{l}\text { Social and } \\
\text { technical sub- } \\
\text { system risk }\end{array}$ & $\begin{array}{l}507 \text { project } \\
\text { managers }\end{array}$ & $\begin{array}{l}\text { Product and process } \\
\text { performance/social, } \\
\text { technical and project sub- } \\
\text { system risk }\end{array}$ & $\begin{array}{l}\text { Social sub-system risk } \\
\text { impacts technical sub- } \\
\text { system risk which impacts } \\
\text { performance }\end{array}$ \\
\hline $\begin{array}{l}\text { Guinan } \text { et } \\
\text { al. } \text { (1998) }\end{array}$ & $\begin{array}{l}\text { Group } \\
\text { processes in } \\
\text { requirements } \\
\text { determination } \\
\text { stage }\end{array}$ & $\begin{array}{l}66 \text { teams from } \\
15 \text { companies }\end{array}$ & $\begin{array}{l}\text { Team } \\
\text { performance/relationship, } \\
\text { production, and also } \\
\text { visionary and guard } \\
\text { processes }\end{array}$ & $\begin{array}{l}\text { Group processes impact } \\
\text { team performance and } \\
\text { behavioural factors have an } \\
\text { influence on group } \\
\text { processes. }\end{array}$ \\
\hline $\begin{array}{l}\text { Guinan } \text { et } \\
\text { al. } \text { (1997) }\end{array}$ & $\begin{array}{l}\text { Use of } \\
\text { automated } \\
\text { tools in } \\
\text { software } \\
\text { development }\end{array}$ & $\begin{array}{l}57 \text { projects } \\
\text { from 15 } \\
\text { organizations }\end{array}$ & $\begin{array}{l}\text { Development } \\
\text { performance/case tool } \\
\text { usage }\end{array}$ & $\begin{array}{l}\text { Case tool usage is not } \\
\text { enough to improve } \\
\text { performance. Several other } \\
\text { factors - such as group } \\
\text { coordination and training } \\
\text { provided - may aid in the } \\
\text { case tool usage }\end{array}$ \\
\hline
\end{tabular}

The social capability construct is based on the argument that software development is a social process and is embedded in the social context. The social capability construct is developed as consisting of three underlying dimensions: communication, conflict resolution, and supportiveness. The technical capability construct is based on the argument that software development ultimately results in the creation of a technical artifact: software with lines of code based on a set of requirement initiated by the user/customer. The technical capability construct is represented by three underlying dimensions: production capability, control capability, and IT infrastructural capability. These two capability constructs for a software development team are further developed in the next chapter. 
In summary, this chapter presented a brief overview of the RBV, STS, and contingency theories. These theories provide the needed theoretical foundation to the research purpose and the research questions. Extant literature required to build the research framework was presented. The importance of this chapter to the study cannot be over emphasized, as the theories discussed in the chapter form the basis for the development of the software development team performance model. 


\section{Chapter 3 Research Model and Hypotheses}

This chapter presents the research model of the study and gives an explanation for all the constructs in the model in subsequent sections. The chapter discusses the three dimensions of social capability - communication, conflict resolution, and supportiveness - as they relate to the software development team. The chapter also discusses the three dimensions of technical capability - production, control, and IT infrastructure capability - as they relate to the software development team. A review of software development team performance studies along with the definition of team performance used in this study is also presented. Organizational factors relevant for this study are also discussed. The last section looks at the fit measurement approaches and introduces three perspectives for measuring the fit. Research hypotheses for each fit perspective are provided in the respective sections.

\subsection{Research Model}

The research model designed for the study is depicted in Figure 3.1. The model consists of five blocks: social capability, technical capability, software development team performance, fit, and the moderating variables. These blocks are connected together by the causal relationships. The three main relationships tested in the research include 1) impact of social capability on team performance, 2) impact of technical capability on team performance, and 3) the impact of fit on team performance. 


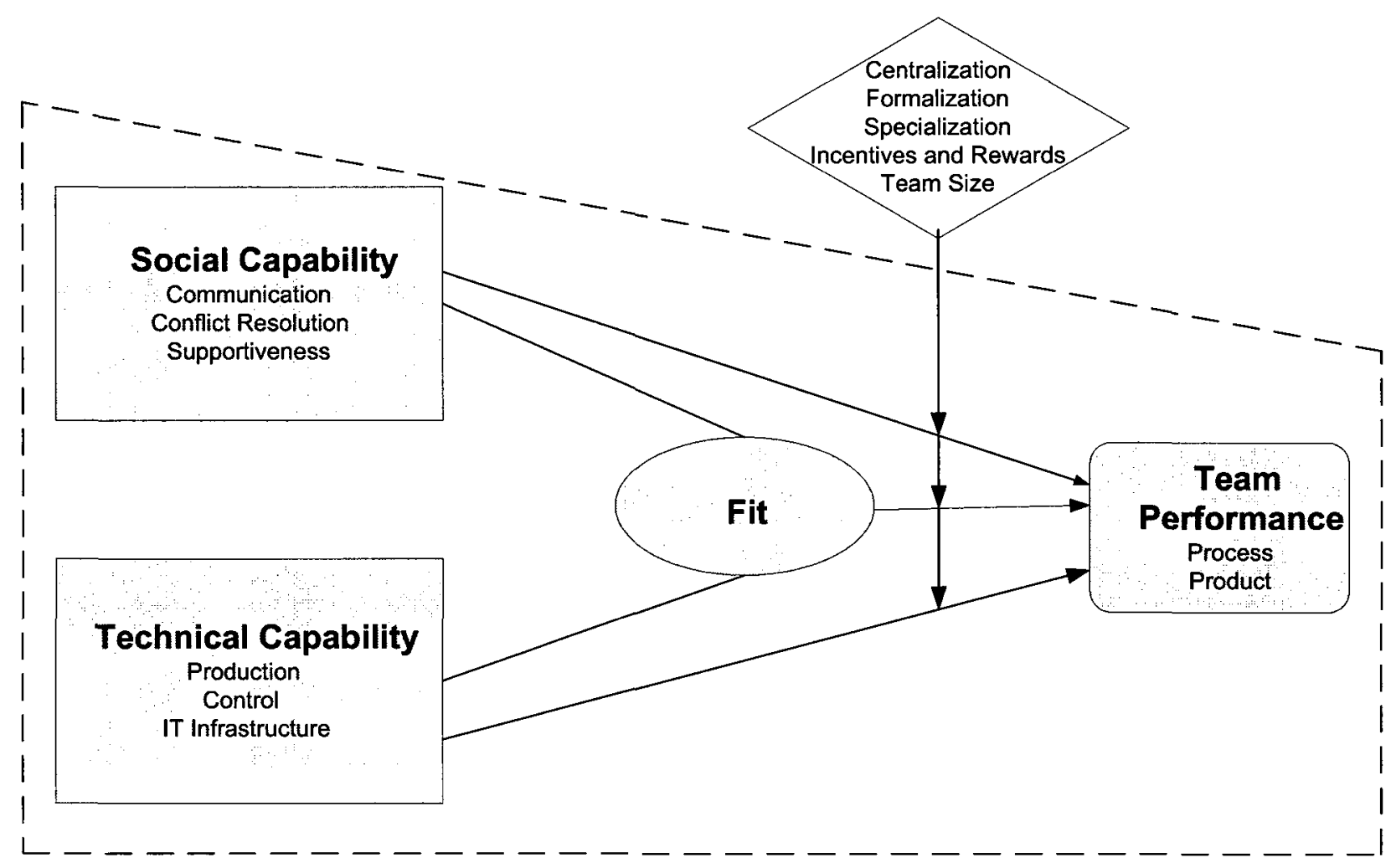

Figure 3-1 Research model

Teams operate within the larger organizational context and previous research has indicated that organizational factors such as centralization, formalization, specialization, and incentives and reward systems play an important role in team performance studies (Jiang et al., 2003). Testing the impact of organizational factors is not possible at all times in team performance studies (Hoegl and Gemuenden, 2001), as it enlarges the scope of the study. Hoegl and Gemuenden (2001) in their study, within the software development context argued that when tasks are routine, organizational factors tend to play more important role in impacting team performance, compared to, when tasks are non-routine. We argue on similar lines but acknowledge the importance of organizational factors for the study. The portion inside the dotted 
lines is the focus of this research. However, we have tested the moderating impact of centralization, formalization, specialization, and incentives and reward systems on the relationship between the overall fit and team performance (Chapter 9). Team size was added in the model after conducting t-test analysis for the small and large teams. Detailed analysis involving the organizational factors and team size is left for future research.

\subsection{Social Capability}

The social capability construct has its origins in social and political institutions (Abramowitz, 1986). The term social capability was first coined by Kasushi Ohkawa and Henry Rosovsky in 1973 (Fagerberg, 1994). According to their definition, social capability refers to "factors constituting a country's ability to import or engage in technological and organizational progress" (c.f. Fagerberg, 1994 p. 1156). The above excerpt suggests that the term social capability has been mainly used in understanding the economic development of societies/nations. The term social capability has rarely been used in the management literature (e.g., Morosini, 2004) and non-existent in the IS literature. This is surprising since researchers have always argued that a firm's capabilities rely on the basic values by which relationships are structured among individuals, within and between groups, and among organizations (Kogut and Zander, 1992). Despite the importance, not much work is available where researchers have empirically tested the construct of social capability within teams. No rigorous studies of model data fit have been conducted to confirm the structure and validity of the social capability construct. In this research, we address this gap and develop and validate the construct of social capability. We develop and validate the construct of social capability in the context of software development teams. 
A team is a social system embedded in the larger organizational context (Hackman, 1987). Growth of a team occurs by building on the social relationships that currently exist (Kogut and Zander, 1992) and the interactions that take place among the members, which represents the capabilities of the team. Morosini (2004) used the term social capability to basically denote the knowledge interactions that take place among the members of a group/team. Hackman (1987) categorized these interactions that take place within a team as the socioemotional processes. The literature also uses terms such as maintenance/behaviour processes, and it includes communication, supportiveness, and conflict resolution as the key sub-processes (Gladstein, 1984; McGrath, 1984). These processes have also been found to impact software development team performance (Guinan et al., 1998). According to the strategic management literature, these processes represent capabilities (Teece and Pisano, 1994). We rely on the argument that performance of a team is determined by the result of interactions among the team members. By building on social capabilities a team may be able to transform these processes into superior products and services (Morosini, 2004).

We concentrate on the social process lens of software development (Robey and Newman, 1996; Hirschheim et al., 1991; Scacchi, 2005) and develop the construct of social capability for the software development team. The social process perspective on software development includes the interpersonal interactions and the rules and norms that define these interactions (Sawyer, 2000). We focus on the interpersonal interactions and the rules and norms aspect that define these interactions. Social capability of the software development team is defined as the ability of a team to communicate, and manage conflict in a manner supportive to the team. According to the definition, the key dimensions of social capability include communication, conflict resolution, and supportiveness. All these variables individually have been found to play 
a significant role within a software development team context. However, for the first time they are being combined under the construct of social capability. We argue that by building on these dimensions of social capability a team can improve its performance. Hence, we have our hypothesis:

Hypothesis 1: Social capability positively influences software development team performance.

The following sub-sections (3.2.1-3.2.3) discuss the dimensions of social capability within the software development team context.

\subsubsection{Communication}

Communication is a process in which information is exchanged among the team members (Pinto and Pinto, 1990). The importance of effective communication for the success of a software development project is well documented (Debrabander and Edstrom, 1977; Curtis et al., 1988; Kraut and Streeler, 1995; Hoegl and Guemendeun, 2001). According to Debrabander and Edstrom (1977), effective communication in IS development projects happens in two cases: first, when the parties involved mutually agree to end the communication after all available information has been exchanged and, second, when there is a mutual agreement to implement a specific information system after the available information has been exchanged. Software development is a complex task where requirements are ill-defined and constantly changing. Communication is found to play a critical role in such innovative projects that involve a lot of uncertainty because ideas can be shared, discussed, and evaluated with other team members in a quicker and effective manner (Kraut and Streeler, 1995; Pinto and Pinto, 1990). The need for communication increases with the increase in complexity and size of the project/team (Herbsleb and Moitra, 2001). 
Communication can be formal or informal. Formal communication requires huge amounts of preparation and planning and occurs through written documents, scheduled meetings, and other non-interactive methods and impersonal communication channels such as emails. In the software development team context, formal communication takes place through various means such as written documents outlining specifications, a formal specification language, review meetings to check the status of the project, and automated reporting and tracking of program errors (Kraut and Streeler, 1995). Researchers have long argued that the communication needs of a team are poorly served by written documentation (Curtis et al., 1988). Informal communication is spontaneous and voluntary and refers to personal, peer-oriented, and interactive communication, such as talks in the hallway, quick phone calls, and short e-mails (Hoegl and Gemuenden, 2001).

Informal communication that is based on collaborative exchange among the team members facilitates knowledge integration among individuals belonging to specialized domains (Patnayakuni et al., 2006). Since verbal communication is the primary medium of informal communication, it is important that team members develop and exhibit good listening skills and be able to translate this verbal or tacit knowledge into a form for later retrieval (Walz et al., 1993). Common understanding and a shared system model is important to develop a common dialect for project argumentation (Curtis et al., 1988). Conditions that foster or facilitate informal communication include spontaneous and voluntary communication, direct communication among the interested parties without a moderator, and the open sharing of information (Hoegl and Gemuenden, 2001; Pinto and Pinto, 1990). Open effective communication depends on trust (Smith and Blanck, 2002; Child, 2001), and holding back information acts as a hindrance to communication (Hoegl and Gemuenden, 2001). 
The technology used in software development is growing exponentially and developers always face information overload and unavoidable obsolescence (Herbsleb and Mockus, 2003). This puts immense pressure on the communication aspects of the software development team. Curtis et al. (1988), in their study of software development projects, found that communication breakdowns are a major bottleneck in successfully developing a software product. One of the major problems faced in effective communication is the presence of semantic gaps. Semantic gaps occur because different members involved in the software development have different perceptions about reality and live in their own thought worlds (Dougherty, 1992). More effort is needed in communication when the semantic gap is greater and the gap may be reduced by training and developing a common knowledge base or shared space (Debranbander and Edstrom, 1977). Walz et al. (1993) argued for developing programs that incorporate communication skills such as team building, negotiation, and teaching skills along with technical skills for software developers. Infrastructure support and effective communication channels aids in improving communication among members of a software development team (Herbsleb and Mockus, 2003).

\subsubsection{Conflict resolution}

Conflict basically indicates a difference in the way that two people think about the meaning of some information (Simmel, 1955). Conflicts within a group are a common phenomenon and there is a vast literature on conflict and its management (e.g., Green and Taber, 1980; Deutsch, 2003). Conflict resolution is regarded as a universal social process through which disagreements between people or groups/teams are addressed and at times resolved (Robey et al., 1989). Our focus is to study conflict management and resolution in a software development team context. 
Conflict is inevitable when people work together and the software development team setting is a fertile place for conflicts to occur (Robey and Newman, 1996; Sawyer, 2001). IS researchers have argued that the potential for conflict in system development is high since it involves high interdependence among the team members (Sawyer, 2001; Andres and Zmud, 2001; Robey and Farrow, 1982). Like any other new product development team, a software development team involves multiple stakeholders with diverse knowledge and background; these include the end users, system designers, and programming specialists. These stakeholders espouse different goals (Kruat and Streeler, 1995; Sawyer, 2001). For example, end users need a robust and user friendly system with lot of functionality, customers look for on-time delivery and a within-budget product, programmers are interested in technical challenges to progress in their careers, and maintenance persons require a product that is well documented and free from bugs (Bohem and Ross, 1989). Reasons for conflict among software developers may range from choices related to design methodology, programming languages, the choice of database server, and meeting deadlines (Walz et al., 1993). Lack of knowledge about the operational domain and the conflicting and ever-changing requirements increase the level of conflict among software developers within a team (Curtis et al., 1988). Robey (1984) summarized the sources of conflict within a software development setting as individual differentiation, sharing of resources, interdependence, and distribution of power. Similarly, Barki and Hartwick (2001) identified interdependence, disagreement, interference, and negative emotion as four characteristics of interpersonal conflict within the software development context.

The presence of conflict creates difficulties at both the strategic level in setting goals and establishing milestones and at the tactical level in resolving day-to-day differences and prioritizing assignments (Bohem and Ross, 1989). At the same time, the presence of conflict in 
software development is also seen as an opportunity for growth and change (Barki and Hartwick, 1994). The proper resolution and management of conflict may stimulate development of new and creative ideas and may avoid group think (Rahim, 2002; Tjoswold, 1984).

Conflict resolution is a means for resolving differences of opinions (Green and Taber, 1980; Sambamurthy and Poole, 1992) and is a critical aspect of team-based software development (Sawyer, 2001). Conflict management facilitates learning and need not be suppressed in the design team (Walz et al., 1993). Rather, it is important to understand the manner in which conflicts are managed (Robey et al., 1993). The aim of conflict resolution should be to reduce the level of irritation and frustration among the team members and resolve differences in a timely manner (Sawyer and Guinan, 1998). Resolution does not mean imposition of a solution; rather it indicates an amicable solution acceptable to the entire group (Robey et al., 1989). In order to take advantage of strengths, conflicts within groups must be handled by taking into account the diverse perspectives, maintaining member commitment, and by building group cohesion (Sambamurthy and Poole, 1992). Constructive conflict resolution is desired to prevent domination and facilitate creativity and innovation (Robey and Farrow, 1982). Our purpose is not to measure the conflict within a team; rather, we measure the conflict resolution ability of the software development team.

Conflict resolution may take place in two phases: 1) differentiation, where members attempt to communicate their initial interpretations or the underlying assumptions and 2) integration, where members attempt to synthesize their interpretations to develop a shared sense among team members (Sambamurthy and Poole, 1992). Different people may use different styles in responding and resolving conflicts. Sillars (1982) identified three common patterns of conflict resolution: integrative, distributive, and avoidance. Integrative strategy identifies and aims to 
achieve outcomes that are mutually satisfying to the interested parties, whereas distributive strategy focuses on the attainment of the outcomes of one party over the other and is based on power differentials to arrive at a solution (Miranda and Bostrom, 1993-94). Avoidance is failure to face the conflict or to resolve the conflict by showing low concern for the outcomes by either party (Miranda and Bostrom, 1993-94). Rahim's (1985) contingency model proposed that an integrative strategy is the most appropriate for complex, undefined, and evolving tasks and when no power differentials exist among group members. Considering the nature of software development, it would make sense to propose the use of integrative strategy for effective conflict resolution.

Within the software development context, Paul et al. (2004-5) and Gobeli et al. (1989) used the term collaborative conflict resolution, which is basically the way integrative strategy works to resolve conflicts. Collaborative conflict management refers to a mechanism by which both parties can satisfy their desires and neither side has to sacrifice considerably. Paul et al. (2004-5) argued that a high concern for others and also for self ultimately results in integrating the views of all to achieve a solution. Gobeli et al. (1989) found that confronting the disagreement and then collaborating to reach a solution was an effective conflict resolution style. Follett (1973) argued that using a collaborative style stabilized the conflict in the group, otherwise conflict might resurface again. One approach can be to smooth over conflicts by minimizing disagreements among members (Robey, 1994). This can reduce conflict, but it may mean that important issues go unaddressed. If conflicts are encouraged to surface and then resolved constructively, there is likely to be greater project success (Gobeli et al. 1989). Our model concentrates only on the collaborative conflict management style. We argue that teams 
that exhibit collaborative conflict resolution styles have a higher social capability compared to teams that do not exhibit such style.

\subsubsection{Supportiveness}

In software development peer-to-peer relationships are as important as manager and subordinate relationships (Kirsch, 1997). It is an accepted argument in the literature that the final design of the software revolves around building a shared and consensus-oriented view among the team members (Walz et al., 1993; Crowston et al., 2005). Reliance on consensus building and shared norms actually solves the problems associated with communication and coordination breakdowns in software development (Curtis et al., 1988). Similarly, Sawyer and Guinan (1998), in their study of software development teams, concluded that problems in communication and coordination arise because of the low degree of shared norms that tie the software developers together. Many research studies have praised the software development practices followed by software development teams at Microsoft that make the development task a unique and satisfying experience for developers (Zachary, 1998; Caramel and Sawyer, 1998).

Norms are the behavioural expectations (Trice and Beyer, 1993); shared norms are the stable behavioural patterns expected by a team's members (Bettenhausen and Murnigham, 1991). Bettenhasuen and Murnigham (1991) referred to these shared norms as a powerful form of control. A clan is a group of individuals who share common goals and some degree of interdependence (Ouchi, 1980). Clan implies a strong sense of belonging and commitment (Kirsh, 1996). Key characteristics, as identified by Kirsch $(1997 ; 1996)$, include common values, common beliefs, and problem solving philosophy, identification and reinforcement of acceptable behaviours and specific tasks and goals evolving over time, and strong commitment to the clan. 
Research within the IS realm indicates that mutual support and cooperation among the developers, is a key ingredient for successful experience for the developers, which ultimately translates into a successful product (Sawyer and Guinan, 1998; Hoegl and Gemuenden, 2001). Mutual support is important for integrating team member expertise and developing a sense of belonging among team members, specifically in software development teams (Hoegl and Gemuenden, 2001). Sawyer and Guinan (1998) argued that software developers within software development teams are tied together by shared norms of loyalty and support. Friendliness and support are crucial for cooperation; team members working on the common objectives should display mutual respect, provide assistance when needed, and develop and support ideas and contributions given by other team members' rather than trying to compete and win among themselves (Tjosvold, 1984).

Clan control is said to occur in teams/groups when shared understanding and norms dictate how people should behave and respond to situations (Kirsch, 1997). Clan control is put into practice through mechanisms that reduce the differences between the controller's and controlee's preferences (Eisenhardt, 1985). Given the similar value set and the desire to work together, an individual's high level of commitment to the group is an indication that clan controls are operating (Gosain et al., 2003). Teams that show high team commitment are more likely to develop a culture of supportiveness and cooperation within the team. Thus, we argue that teams where clan control is operating show a higher social capability compared to others where it is not. 


\subsection{Technical Capability}

Unlike social capability, technical capability is much more researched in the management literature. Commonly called as technological capability, the term technical capability has its roots in RBV theory. According to RBV theory, each firm has a unique bundle of resources generating a different and unique set of capabilities and organizational routines (Barney, 1991; Nelson and Winter, 1982; Grant, 1991). Firms compete on the basis of these capabilities; the firms that exhibit superior capabilities compared to others have superior product offerings (Afua, 2002). Technological capability is a core organizational capability that refers to those abilities that distinguish a firm and are based on the technology (Prahlad and Hamel, 1990; LeonardBarton, 1992; Carayannis and Alexander, 2002). In simple terms, it is the ability of a firm to make effective use of technical knowledge (Westphal et al., 1985).

Technological capability is an essential strategic resource for firms, especially the high technology firms, to stay competitive in the market (Hsieh and Tsai, 2007). It has a direct impact on firm performance (Lee et al., 2001; Henderson and Cockburn, 1994; Tsai, 2004; Aw and Batra, 1998). Researchers have argued that innovation capability rests on technological capability (Tsai, 2004; Hseih and Tsai, 2007). By focusing on technological capability, firms positively affect process or product innovations, resulting in improved efficiency in their new product development process. For example, organizations such as Toyota and Honda have been able to reduce cost, improve quality, and shorten design-to-market cycles. Similarly, Intel is able to design and manufacture ever more powerful microprocessors for PCs by focusing on its technological capability.

Technological capability resides in both human and institutional capital (Westphal et al. 1985). It consists of technological knowledge, trade secrets, know-how generated by R\&D, and 
other technology related intellectual capital (Dollinger, 1995). Knowledge and knowledgecreating activities are the basis for building technological capabilities (Leonard-Barton 1992; Prahalad and Hamel 1990; Teece et al. 1997). Organizations are able to prolong their competitive advantage by focusing on the tacit and intangible nature of technological capabilities (McEvily and Chakravarthy, 2002).

Several classification schemes for technological capabilities exist in the literature. The seminal study by Westphal et al. (1985) identified three major technological capabilities: production, investment, and innovative. The boundaries separating these capabilities are fuzzy and the capabilities depend on the size and nature of the firm, type of industry, type of production organization, and type of ownership (Katz, 1985). Lall (1992) identified investment, production, and linkage capabilities as key technological capabilities. Building upon these initial classifications, a more recent study (Figueiredo, 2001) focussed on four types of technological capabilities: investment capability, process and production organization capability, productcentered capability, and equipment capability. Ramanathan (2007) categorized technological capabilities under three sub-categories: tactical, strategic, and supplementary technological capabilities. Similarly, Isobe et al. (2007) categorized technological capabilities into two types: refinement capability, which relates to the development and improvement of the existing asset portfolio, and reconfiguration capability, which relates to the reorganization of the asset portfolio by integration of the new assets. 
Table 3-1 Summary of technical capability studies

\begin{tabular}{|l|l|}
\hline \multicolumn{1}{|c|}{ Technological/Technical Capability } & $\begin{array}{l}\text { Author (year)/Industry(if } \\
\text { available) }\end{array}$ \\
\hline $\begin{array}{l}\text { Knowledge and skills required to identify, appraise, utilize and } \\
\text { develop technologies relevant to the petroleum industry. }\end{array}$ & $\begin{array}{l}\text { Acha (2000)/Upstream } \\
\text { petroleum industry }\end{array}$ \\
\hline $\begin{array}{l}\text { It is the ability to adapt or assimilate technology imported from } \\
\text { abroad and to incorporate the additional and distinct resources } \\
\text { needed to manage and put to productive use the newly acquired } \\
\text { technology. }\end{array}$ & $\begin{array}{l}\text { Aw and Batra (1998)/ } \\
\text { Manufacturing firms }\end{array}$ \\
\hline $\begin{array}{l}\text { It covers employees processing skills and the associated } \\
\text { procedures and equipment. }\end{array}$ & Wenger and Snyder (2000) \\
\hline $\begin{array}{l}\text { It refers to the availability of technical manpower, state of } \\
\text { production technology, R\&D facilities, etc. }\end{array}$ & $\begin{array}{l}\text { Mandal and Deshmukh } \\
\text { (1994) }\end{array}$ \\
\hline $\begin{array}{l}\text { It is the ability to use technological resources to } \\
\text { combine/recombine components, linkages between the } \\
\text { components, methods, processes and techniques, and underpinning } \\
\text { core concepts to offer products. }\end{array}$ & $\begin{array}{l}\text { Afuah } \\
\text { (2002)/Pharmaceutical } \\
\text { industry }\end{array}$ \\
\hline $\begin{array}{l}\text { It embodies the resources needed to generate and manage } \\
\text { technological change where resources are embodied in individuals } \\
\text { and organizational systems. }\end{array}$ & Bell and Pavitt (1993) \\
\hline $\begin{array}{l}\text { It is the ability of a firm to make effective use of technical } \\
\text { knowledge. }\end{array}$ & $\begin{array}{l}\text { Westphal } \text { et al } \\
\text { (1985)/Korean firms }\end{array}$ \\
\hline $\begin{array}{l}\text { Technology innovation and awareness of future technology } \\
\text { requirements. }\end{array}$ & $\begin{array}{l}\text { Reed and Walsh } \\
\text { (2002)/UK Aerospace } \\
\text { industry }\end{array}$ \\
\hline $\begin{array}{l}\text { The assimilation and application of the technological knowledge } \\
\text { from R\&D activities to production. }\end{array}$ & $\begin{array}{l}\text { Tsai (2004)/Taiwan's } \\
\text { Electronics industry }\end{array}$ \\
\hline $\begin{array}{l}\text { The resources needed to generate and manage improvements in } \\
\text { processes and production organization, products, equipment, and } \\
\text { engineering projects. }\end{array}$ & $\begin{array}{l}\text { Figueiredo (2001)/Steel } \\
\text { industry }\end{array}$ \\
\hline $\begin{array}{l}\text { Technological capabilities are the set of skills the firm has in } \\
\text { building and leveraging different technologies and systems. }\end{array}$ & Zahra and Nielsen (2002) \\
\hline
\end{tabular}


In analyzing Table 3.1, we see that studies focusing on technological capabilities and their accumulation have been mostly undertaken in manufacturing sector industries such as petroleum (Acha, 2000), steel (Figueiredo, 2001), electronics (Tsai, 2004), and aerospace (Reed and Walsh, 2002). We also see that the focus of most of the studies is on international technology transfer with studies done specifically in a developing country context such as India, China, Taiwan, Korea, and Indonesia (Tsai, 2004; Westphal et al., 1985). The core component of most of the definitions on technological capability is the emphasis on the development and application of knowledge and technical skills for achieving competitive advantage.

Over the last few decades, a number of different measures of technological capability have come into existence. Schoenecker and Swanson (2002) placed them into one of the three different categories: financial measures, patent statistics, or statistics on new product introductions. The most commonly used measures for assessing technological capability have been R\&D expenditure (e.g., Hsieh and Tsai, 2007; Schoenecker and Swanson, 2002) and patents (e.g., Dyusters and Hagedoorn, 2000; Lee et al., 2001; Schoenecker and Swanson, 2002). The frameworks and classification in technological capability and its measurement reflect the specifics of the manufacturing sector. Torrisi (1998) argued that patents may not work as indicators of technical capability in the software development context because it becomes difficult to separate the original from other ideas. Reuse of components in software development makes the separation difficult.

For measuring technical capabilities in the software development industry at the team level, the specifics of software development need to be taken into account. A few studies have been undertaken to study capabilities in the software development context but the focus was on late entry firms (Torissi, 1998; Tschang, 2001; Rousseva, 2008). The software development 
industry has some unique characteristics that may have an effect on developing the measures for technological capability for a software development team. Software development is an innovative and knowledge-intensive activity. Rousseva (2008) argued that in analyzing technological capabilities in software development, the distinction between production and innovation capability becomes blurred as the innovation capabilities are part of the production capabilities. Second, the software development industry is a human capital intensive industry, as compared to the industrial sector, which is physical capital intensive. According to the RBV theory, human capital is an important resource of competitive advantage to firms (Grant, 1991; Barney, 1991). Huselid et al. (1997) argued that competitive advantage is only possible when the human resource or the people add value to the production processes and generate a unique set of capabilities that are hard to replicate and substitute. In this paper, we analyze technological capabilities in the software development industry and study their impact on software development team performance. We use the term "technical capability" in this research. The use is to highlight the case for studying the technological capabilities at the team level within the software development context.

We find that the technical capability view in the literature mostly provides a production capability view. However, to get a complete picture we need to look further than production and include other dimensions as well. Based on the technological capability and software development literature, we found the classification by Henderson and Cooprider (1990) to be most suited for studying technological capabilities within a software development team. The functional model for information systems planning and design aids proposed by Henderson and Cooprider (1990) distinguished three dimension of technology: production, coordination, and organization. We adapt their classification to define the technical capability within software 
development team as the ability of the team to deploy the IT infrastructure capability in which the control and production capability can be applied for developing the software. According to the definition, the key dimensions of technical capability include the production capability, control capability, and IT infrastructural capability. The combined strength of a team's technical capability, rather than brilliance in a single dimension, results in superior team performance (Zahra et al., 2007). Hence, we have our hypothesis:

Hypothesis 2: Technical capability positively influences software development team performance.

The following sub-sections (3.3.1-3.3.3) discuss the dimensions of technical capability within the software development team context.

\subsubsection{Production capability}

Production processes in software development have a direct influence on the development of a software artifact or the task at hand. They influence the capacity of the individual to generate the planning and design decisions related to the development of the software product (Henderson and Coprider, 1990; Vitalari, 1985). In the production view, input factors of labor, the programming team skills and capital, and the techniques and tools are transformed into outputs (Banker et al., 1998). In a study of software development team performance, Henderson and Lee (1992) found that production processes affected performance. However, research indicates that very few studies in IS literature have looked at production capabilities from a team perspective.

Software development process is a collection of interrelated methods and practices to produce software products (Humphrey, 1988). Team members need to use various methodologies, techniques/methods, and tools for developing a software product (Sawyer and 
Guinan, 1998). The purpose of the team is to follow a proper method and use the techniques and tools in support of that project. This involves going through a number of software development phases related to the construction and maintenance of the software. A generic software development process model is shown in Figure 3.2. The figure is only an example of waterfall model, one of the traditional software development methodologies. Other software development methodologies such as extreme programming, scrum, agile, and object oriented are equally popular in the software community. Each organization may have a unique software production process with added complexity in terms of rapid iterations and feedback loops. The maintenance phase is treated separately in many studies, where it is argued that input to the maintenance process is the software that is created by the development process (Banker et al, 1998).

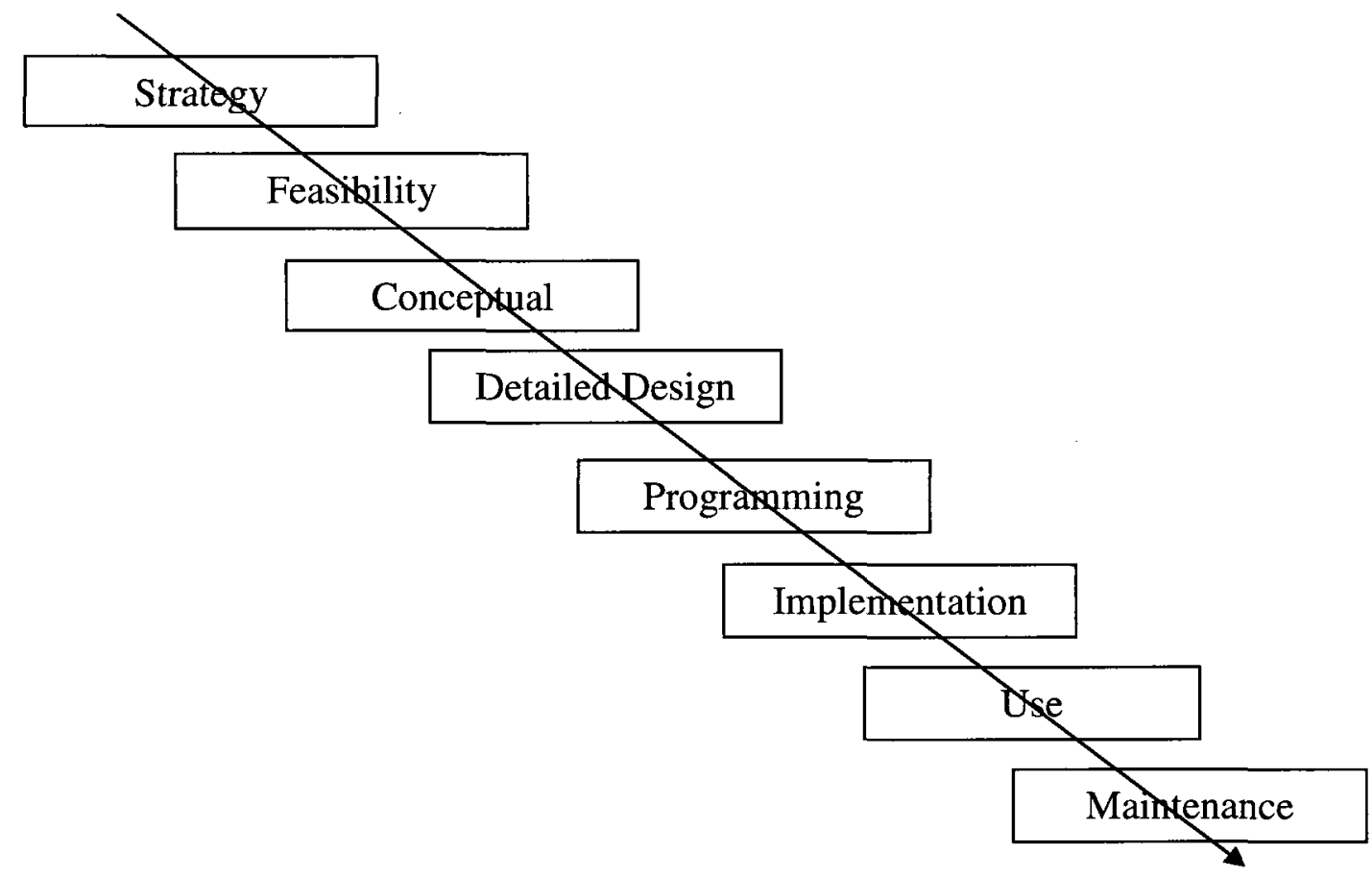

Figure 3-2 Phases of software development (Clegg et al. 1997) 
The software development process is a knowledge-intensive process requiring the expertise and skills of many different people (Curtis et al, 1988; Patnayakuni et al., 2006). Mainly two types of domain knowledge are needed in software development: 1) IS domain knowledge that is related to methods, tools, and techniques that form the scientific base and 2) application domain (context specific) knowledge that is related to the real world problems and solution in a given business area (Khatri et al., 2006). Context specific capabilities are idiosyncratic and are a source of core competence for the team (Malerba and Torrisi, 1992). For example, if software is being developed for the banking industry then knowledge about the nuances of the industry must accompany the technical knowledge.

Many previous studies have addressed the knowledge and skill requirements of IS personnel over the past three decades (Benbasat and Vessey, 1980; Zmud, 1983; Cheny and Lyons, 1980; Nelson, 1991; Lee et al., 1995). Zmud (1983) proposed six general areas of knowledge and skills for IS personnel: organizational overview, organizational skills, target organizational unit, functional general IS knowledge, technical skills, and IS product. A decade later, Lee et al. (1995) took into account the changing role of IS personnel and divided IS knowledge/skills into four categories of technical knowledge, technology management knowledge, business functional knowledge, and interpersonal and management skills. Literature on IS knowledge/skills and critical activities in the software development process suggests that technical and business skills are important aspects of production capabilities in a software development team.

In software development, a breadth of technical skills is required for the successful development of a product (Guinan et al, 1998). Technical skills include methods and techniques required to perform IS-related tasks (Nelson, 1991). Curtis et al. (1988) categorized technical 
skills into six knowledge domains. They are application-specific knowledge, system architecture, machine architecture, algorithmic and data structure, software architecture, and user behaviour. Proficiency in tools and the use of structured programming methods are part of the technical skills. Lee et al. (1995) categorized IS Staffing patterns (i.e., the various roles played by IS personnel in the development team): 1) programmers, 2) technical specialists with knowledge of specific hardware, operating system, communication system, networking, database, etc., 3) system/business analysts with knowledge of planning, analysis, design and implementation of business applications, 4) end user support consultants, and 5) computer operators and clerks. A software development team requires a mix of technical knowledge/skills based on the role played by various personnel. While a software programmer needs to be technically skilled for the most part, a systems analyst requires a more balanced mix of technical and business skills, and the manager needs to possess a higher level of organizational knowledge (Nelson, 1991).

A recent survey of software professionals indicates that innovation and new product areas are the most important priority for software firms (Berryman et al., 2007). Software production is an innovation intensive process and Rouessava (2006) argued that the various skills needed to produce a software solution - i.e., the production capabilities - should also include innovative capabilities. Thus, within the software development context, the dimension of production capability needs to incorporate the innovation-generating capabilities as well.

\subsubsection{Control capability}

Organization has long been the unit of analysis for studies on control in the management literature (Ouchi, 1977; Van de Ven et al., 1976; Eisenhardt, 1985). The term control - like the terms specialization, decentralization, and formalization - is used in many ways (Ouchi, 1979). Ouchi (1977), in his seminal work on the relationship between organization structure and 
organization control, proposed that the control system is primarily a process for monitoring and evaluating performance. The control dimension addresses the need to establish and enforce goals, policy, procedures, standards, and priorities during the design process (Henderson and Copprider, 1990). Managers use control to monitor the progress of members and to impose restrictions within a team to ensure the quality of the product/service and the timely delivery of the product/service to the customer. Control is classified mainly into formal and informal modes. Formal modes include behaviour and outcome control and are primarily performance based (Eisenhardt, 1985). In behavioural control, specific rules and procedures are formulated for the controlees; in outcome control, desired outcomes and/or goals are formulated (Kirsch, 1997). Informal modes include self and clan control. Self control operates at the individual level clan control mechanisms operate at the group level and rely on social norms and shared values (Eisenhardt, 1985, Gosain et al., 2003). Kirsch (1997) argued that control within teams is exercised to make sure that the team member's act in accordance with the various strategies outlined to achieve the desired goals and objectives.

Software development is a highly interdependent process. Coordination is needed when interdependence occurs among business processes (Thompson, 1967). Coordination is needed within the software development projects to fit the various interdependent modules that were built separately. Increased task interdependence requires increased information exchange to clarify task requirements, project assignments, and roles resulting in increased control (Andres and Zmud, 2001). Control is required to coordinate various activities of developing the software. Control, in the coordination sense, refers to "problem of ensuring that scarce development resources are allocated efficiently to the different tasks that must be accomplished, that task deadlines are set appropriately and communicated clearly, and that the sequence of planned 
activities leads to a total project duration that approaches the minimum possible" (Hoopes and Postrel, 1999 p. 841). It refers to the process of sequencing and scheduling activities in any product development process.

Other than for interdependence, control is also needed in software development for dealing with uncertainties associated with ever-changing user requirements, incomplete specification, the very non-routine nature of the development task, and the lack of common view shared by the designers and the analysts (Kraut and Streeler, 1995; Nidumolu, 1996; Zmud, 1980). Control is needed for the team members to agree upon a common task-related goal structure with clear sub-goals for individual team members (Hoegl and Gemuenden, 2001).

The importance of control in enhancing the performance of teams is emphasized in organization theory and, more recently, in IS research (Kirsch, 1996; Henderson and Lee, 1992). Many researchers have studied control within development teams (Orlikowski, 1991; Henderson and Lee 1992; Kirsch 1996; Nidumolu and Subramani, 2003). Henderson and Lee (1992) studied the outcome and behaviour control mechanisms and their impact on team performance in the IS design team context. Orlikowski (1991) conceptualized control in terms of internal and external forms. In her writing, internal form referred to the direct connection between the managers and subordinates within the realm of rules, procedures, and technology, and external form referred to the professional instructions and training. Nidumolu and Subramani (2003) emphasized two perspectives on control especially for system development projects: control through process and control through structure. We focus on control through process for this research. Control through process involves specifying the methods required to perform the various activities and specifying the performance criteria for the output and outcomes in software development (Nidumolu and Subramani, 2003). 


\subsubsection{IT infrastructure capability}

A firm's IT infrastructure is a key source for sustainable competitive advantage (Bhardawaj, 2000; Cibbora and Hanseth, 1998). Establishing standard operating procedures and forcing standards for data and languages for IS have long been argued by organization theorists as necessary to reduce burdens on the information processing capacity of a firm (March and Simon, 1958; Galbriath, 1977). Henderson and Cooprider (1990) argued that IT infrastructure is an important component of organizational technology that provides institutionalized help to individuals/groups/teams to overcome the cognitive burdens of information processing. IT Infrastructure is important for the firm to process and communicate information, to support streamlined processes, and to enhance coordination (Cibbora and Hanseth, 1998). Viewed from the RBV perspective, IT infrastructure capability is needed to develop not only new products but also to continuously improve the existing products (Duncan 1995; Venkatraman, 1991).

Research on IT infrastructure came to the forefront in IS research in the late 1980s, when management researchers realized that it had become one of the top priorities for IS executives (Branchaeu et al., 1996). A number of definitions emerged (Keen, 1991; McKay and Brockway, 1989; Broadbent et al., 1996). The common theme in most of the definitions is that IT infrastructure provides a shared technical foundation for organizations to execute their business processes in an effective and efficient manner. IT infrastructure has long been viewed as the foundation of IT components (such as hardware, software, and networks). Recent conceptualizations expand the notion of IT infrastructure to include various shared services (such as data, information, and standardized applications) that are held together by the human IT infrastructure of knowledge skills and experience (Weill and Vitale, 2002). 
Researchers soon realized that just building an IT infrastructure was not enough for firms to realize the benefits, and the concept of IT infrastructure flexibility was proposed (Duncan, 1995; Byrd and Turner, 2000). More than ever, organizations are faced with ever increasing change in their business environments and IT infrastructure flexibility; a critical aspect of IT infrastructure, allows organizations to respond to new market conditions (Byrd and Turner, 2000). Duncan (1995), through an empirical investigation of the technical aspects of the IT infrastructure flexibility, found that high connectivity, compatibility, and modularity make an IT infrastructure flexible. When the IT infrastructure has a high degree of flexibility, the overall IS function is more effective and efficient in meeting the organization's needs for the development and implementation of IT applications. Bharadwaj (2000) argued that a flexible IT infrastructure, along with the right human IT skills, is a powerful organizational capability.

IT infrastructure capability, a key IT function, is a more recent term used within IT infrastructure research (Broadbent et al., 1999; Bharadwaj 2000; Weill and Vitale, 2002; Mithas et al., 2007). IT infrastructure capability is the combination of IT components (such as hardware, software, data storage, and networks) and information, applications, and utilities provided to the users from the foundation of IT components (Broadbent et al., 1999; Keen, 1997). It is considered as the "integrated set of reliable IT infrastructure services that are available to support both existing applications and new initiatives in firms" (Weill and Vitale, 2002 p. 20). How quickly a firm may be able to implement a new IT initiative depends in part on the firm's IT infrastructure capability (Weill and Vitale, 2002).

A software development team operates within an organizational context. In the technical capability construct, we focus on the technical environment/infrastructure that the organization provides to the software development projects. Software development in most cases is a modular 
process where several design teams are involved before the final product is released. This requires a common platform for coordination and control of multiple teams. Portability of skills and data and a standard structure for representing the knowledge generated in design process increases the ability to share the knowledge with other teams (Cooprider and Henderson, 1991). IT infrastructure enforces the use of consistent techniques and tools throughout the organization (Henderson and Cooprider, 1990).

Broadbent et al., (1996) measured IT infrastructure capability using three measures: 1) the extent of the firm's infrastructure services, 2) the provision of boundary crossing infrastructure services, and 3) the firm's reach and range. Xia and King (2002) measured IT infrastructure capability as the reach of IT infrastructure, the range of shared IT infrastructure services, IS standards and procedures, the flexibility of IT infrastructure, and IS management competence. Marchand et al. (2000) conceptualized IT infrastructure capability as the capability to effectively manage appropriate IT applications and infrastructure in support of operational decision making and communication processes, which is part of the larger construct of information orientation and IT practices.

\subsection{Software Development Team Performance}

A team is a group of two or more people embedded in a larger organizational structure. It is defined in a generic sense by the common goal of its members and the interdependence of their efforts (Thompson, 2003). Teams are viewed as a primary mechanism for leveraging the specialized knowledge of individual team members (Lewis, 2004). Teams are the basic organizational unit through which software development projects are carried out (Faraj and Sambamurthy, 2006). A team in our study is a project team developing new software 
products/modules. The use of the word project team is more common in the IS literature (Kaiser and Bostrom, 1982; White, 1984; Jones and Harrison, 1996; He et al., 2007). For consistency purposes, we use the term software development team for this study.

Software development requires very innovative skills in individuals. The core task for a software development team is very creative, complex, and sometimes unstructured (Kang et al., 2006). Teamwork or team-related issues for software development activity cannot be avoided and IS/IT managers are always concerned with finding the influential factors for successful team performance. Thus, software development team performance has always remained an important topic in the IS domain.

Team performance is a multi-dimensional concept and software development team performance is no exception. The literature search on software development team performance resulted in a number of empirical studies that addressed team performance from a number of theoretical perspectives. Table 3.2 summarizes the various articles on software development team performance that have direct implications for this research. Most of the researchers adopted a two-dimensional view for studying software development team/project performance.

An excellent starting point to understand software development team performance is the article by Henderson and Lee (1992). Henderson and Lee (1992) recognized efficiency and effectiveness as two important aspects of system development group performance by looking at the managerial and team member control behaviour. 
Table 3-2 Summary of software development team performance studies

\begin{tabular}{|c|c|c|}
\hline Performance Measures & Theoretical Constructs & Author (s) (year) \\
\hline $\begin{array}{l}\text { Efficiency and } \\
\text { effectiveness }\end{array}$ & $\begin{array}{l}\text { Managerial control and team } \\
\text { member control; software } \\
\text { development risk; group structural } \\
\text { characteristics and formal } \\
\text { participation; cognitive and } \\
\text { demographic characteristics; } \\
\text { conflict resolution; team cognition; } \\
\text { group related variables such as } \\
\text { cohesion, team member } \\
\text { involvement, user } \\
\text { representativeness etc.; } \\
\text { organizational traits/environment; } \\
\text { conflict management; social } \\
\text { processes; teamwork quality }\end{array}$ & $\begin{array}{l}\text { Henderson and Lee (1992); } \\
\text { Jiang and Klein (2000); } \\
\text { Aladwani et al (2000); Kang } \\
\text { et al. (2006); Robey et al. } \\
\text { (1993); He et al. (2007); } \\
\text { Jones and Harrison (1996); } \\
\text { Jiang et al. (2003); Sawyer } \\
\text { (2001); Sawyer and Guinan } \\
\text { (1998); Hoegl and } \\
\text { Gemuenden (2001) }\end{array}$ \\
\hline $\begin{array}{l}\text { Efficiency and } \\
\text { effectiveness (modified } \\
\text { scale from Henderson and } \\
\text { Lee, 1992) }\end{array}$ & Expertise coordination; leadership & $\begin{array}{l}\text { Faraj and Sproull (2000); } \\
\text { Faraj and Sambamurthy } \\
(2006)\end{array}$ \\
\hline $\begin{array}{l}\text { Process performance (task } \\
\text { and maintenance } \\
\text { behaviours) }\end{array}$ & Participative management & Chung and Guinan (1994); \\
\hline $\begin{array}{l}\text { Process and product } \\
\text { performance }\end{array}$ & $\begin{array}{l}\text { Project uncertainty and } \\
\text { coordination mechanisms; software } \\
\text { project risk; software process } \\
\text { maturity and software development } \\
\text { risk; software development risk; } \\
\text { knowledge diversity }\end{array}$ & $\begin{array}{l}\text { Nidumolu (1995 and 1996); } \\
\text { Wallace et al. (2004); Tuillo } \\
\text { and Bahli (2006); Na et al. } \\
\text { (2007); Liang et al. (2007) }\end{array}$ \\
\hline $\begin{array}{l}\text { Operational performance } \\
\text { and service performance; } \\
\text { system performance and } \\
\text { IS maintenance team } \\
\text { performance. }\end{array}$ & $\begin{array}{l}\text { Shared knowledge; software } \\
\text { system flexibility }\end{array}$ & $\begin{array}{l}\text { Nelson and Cooprider } \\
\text { (1996); Nelson and } \\
\text { Cooprider (2001) }\end{array}$ \\
\hline $\begin{array}{l}\text { Process and product } \\
\text { performance (different } \\
\text { measures than Nidumolu } \\
(1995) \text { ) }\end{array}$ & Software development risk & Barki et al. (2001) \\
\hline
\end{tabular}


A number of studies followed the path provided by Henderson and Lee (1992) and operationalized performance on similar lines of efficiency and effectiveness by adapting their performance measures (e.g., Jiang and Klein, 2000; Aladwani et al., 2000; Kang et al., 2006). Jiang and Klien (2000) studied software development project risk and found that different project risks impacted different aspects of system development to differing extents. Aladwani et al. (2000) reported that the system development group performance is affected by group heterogeneity and group-based rewards; managers should consider the interaction between the various design elements when forming system development project groups. Kang et al. (2006) compared and contrasted the impacts of cognitive characteristics (e.g., shared mental model) and demographic characteristics (e.g., age) on performance and found that a shared mental model construct influenced performance more than the demographic characteristics. Jones and Harrison (1996) also used the scale given by Henderson and Lee (1992) and studied the impact of some group-related variables, such as team member involvement and group cohesion, on team performance. They concluded that management support, user support, and cooperation are the most critical factors of team performance. Jiang et al. (2003) modified the scale by Henderson and Lee (1992) and studied the impact of organizational factors - such as centralization, formalization, and IS maturity - on team performance; they found that teams are more effective in a centralized and mature organizational environment.

Robey et al. (1993) found a positive relationship between conflict resolution and project success. Their success measures were influenced by the project management literature. However, the measures are similar to the ones given by Henderson and Lee (1992). In a recent article, He et al. (2007) used the scale provided by Robey et al. (1993) successfully and studied the impact of team cognition on software development team performance. Sawyer and Guinan (1998) and 
Sawyer (2001) used similar team performance measures and studied the impact of social processes and conflict management, respectively. Similarly, Faraj and colleagues in two different studies studied the efficiency and effectiveness of a software development team, and their scale was a modification of the one used by Henderson and Lee (1992). Faraj and Sproull (2000) found that expertise coordination within knowledge teams (software development teams) played a significant role in explaining team performance. Faraj and Sambamurthy (2006) concluded that IS leadership has no direct impact on team performance and only influences performance when team skills and task characteristics are taken into account. Hoegl and Gemuenden (2001) studied teamwork quality and its impact on team performance. They basically studied the perceptions of team leader, team members, and the manager about the performance of their team and found no statistical differences in their perceptions of team success.

Another stream of IS research used product and process dimensions for studying software development team performance. A good starting point for understanding these two dimensions of performance within a software development team context is the research by Nidumolu (1995) and Nidumolu (1996). Product performance refers to the success of the software that is developed and process performance refers to the success of the development process itself (on schedule and within budget). For the product performance, technical performance, responsiveness (the software responds to the needs of its users) and flexibility (software's ability to adapt to the changing business needs) dimensions were included initially, and the technical performance dimension was subsequently dropped from the analysis (Nidumolu, 1995). Nidumolu (1996) considered product flexibility as the proxy for product performance in his study on software development risk. For the process performance, Nidumolu (1995) included learning, control, and quality of interaction initially; then subsequently dropped learning from the 
final analysis. Nidumolu (1996) used just the control dimension for measuring the process performance in their study on software project risk. Similarly, Wallace et al. (2004) studied software development risk and the control dimension of process performance.

Some other notable research studies on software development performance include the studies by Nelson and Cooprider (1996) and Nelson and Cooprider (2001). Nelson and Cooprider (1996) looked at the operational performance (inward operational activities of development) and service performance (the outward service related to customer satisfaction). In 2001, Nelson and Cooprider examined system performance and team performance as the product and process dimensions of IS performance respectively. Chung and Guinan (1994) operationlized team performance based on process behaviours (task and maintenance) and studied how participative management impacted them. Deephouse et al. (1996) studied the impact of various software development processes on the performance, measuring software quality and meeting targets (schedule and budget) as performance dimensions.

Performance measures tested by Barki et al. (2001) provide a clear understanding that the process/product and efficiency/effectiveness two-dimensional view of performance are actually two sides of the same coin. Their performance construct referred to the efficiency and effectiveness with which a software development project is completed. It takes into account both the process performance, i.e., how well the software development went in terms of schedule and budget (efficiency), and the product performance, i.e., how good the developed product is in terms of quality (effectiveness).

The importance of adopting a two-dimensional view, i.e., process and product, is supported by the fact that there is a trade-off between the efficiency of the process and the quality of the product. For example, software projects may deliver a high quality product but 
may not be efficient in terms of delivering the product on schedule and within budget (Nidumolu, 1995). Conversely, a project that is within budget and on time may deliver a product of poor quality. Nidumolu (1995) argued that performance should be observed in two key aspects, process and product. Process performance reflects how well the software development process was carried out. Product performance refers to the qualities of the resulting product delivered by the project. The two-dimensional view of performance selected for this research is influenced by Nidumolu's (1995) work as it clearly addressed the importance of adopting both the product and process perspectives of performance. At the core of this two-dimensional view (product and process) is that the key goal of performance measurement is not just to improve the final output (i.e., software) but also to consider the processes that are used to obtain that output (Di Tuillo and Bahli, 2006).

\subsection{Organizational Factors}

Organizational factors are the factors that are largely beyond the project team's control. Within the software development context, organizational factors that are found to influence project team performance in the literature include centralization and formalization (Zmud, 1982; Jiang et al., 2003). They refer to the amount of discretion given to the analysts and programmers in conducting their routine activities as part of the software project development team (Zmud, 1982). Specialization does not find enough mention in the software development and team performance literature. However, we include it in our study as it is considered a primary organizational structure variable (Pugh et al., 1968; Child, 1972; Carter and Keon, 1989). These are the organizational structural variables. Based on other organization studies, we also discuss incentive and reward systems as an organizational factor influencing software team performance. 
We do not claim that they are the only four organization related variables. However, they have been studied extensively; literature supports their use and reliable measurement scales exist for them (Jiang et al., 2003). The following paragraphs discuss the four organizational factors of centralization, formalization, specialization, and incentive and reward systems that are relevant for this study.

Centralization is referred to as the extent to which power and control in a system/organization is concentrated in the hands of a few individuals (Rogers, 1983). It is the inverse of delegation of the decision-making authority and the extent to which the organizational members participate in the decision-making process (Jaowrski and Kohli, 1993). In a highly centralized environment pertaining to the software development group, most of the decisions regarding project planning, control, and selection of development methods are generally carried out by the senior management (Zmud, 1982). Project teams hold the ultimate responsibility for their performance. However, the degree of centralization may decide how the resources are allocated or distributed across the various projects in an organization. Within the software development team performance context, Jiang et al. (2003) found that centralized organizational environment positively influences team performance.

Formalization is the degree to which the organization expects its members to follow rules and procedures (Hage and Aiken, 1967; Damanpour, 1991). It represents how the rules and procedures dictate roles, authority, relations, communications, and norms and sanctions (Jawroski and Kohli, 1993). In a highly formalized environment pertaining to the software development group, software standards are specified that determine the rules and procedures to be followed by the software development group in conducting their routine activities (Zmud, 1982). Formalization may increase productivity when the jobs are highly structured (Jiang et al., 
2003). In complex, uncertain, and rapidly changing environments, the highly formalized environment inhibits innovation (Mintzberg, 1979), which may be true in the case of software development, a highly complex and uncertain innovation. However, the project management literature suggests that formal structures tend to promote project team performance. Jiang et al. (2003) in their research did not find much support for the argument that formalization is positively associated with software development team performance. The research by Rai and $\mathrm{Al}$ Hindi (2000) reported a positive association between process modeling and product and process quality. Development process modeling is a key stage in managing the software development process, such as it helps in determining the milestones as the development progresses (Rai and Al-Hindi, 2000). Thus, we argue that process modeling is a way formalization is exercised within the software development context and may positively impact team performance. Formalization may also negate the impact of task uncertainty associated with software development projects.

Specialization or differentiation is another way of saying division of labor within the organization. It is a mechanism to deal with the task complexity and is concerned with the differentiation of activities within each function (Pugh et al., 1968). It has many aspects related to function, role, person, and task (Carter and Keon, 1989). Function relates to the number of divisions (Child, 1972), task relates to the specific activities, role relates to the duties split within a function (Child, 1972), and person relates to the specialization of the person who performs the task. There are cognitive limits to this process of specialization, and division of labor depends on what kinds of problems firms solve, and how they solve them (Brusoni, 2005). Similar to formalization and centralization, specialization is one of the organization structure-related variables. However, compared to centralization and formalization, specialization variable has not 
received as much attention in the management literature. Swanson and Beath (1990) worked on departmentalization which is closely related to the concept of horizontal division of labor and vertical chain of command and control within an organization. They identified three bases for division of labor and departmentalization within the software development organizations: work type where job specialization is related to the work skills (such as system analysis versus programming versus testing), application type where specialization is related to the knowledge associated with the domain of application (such as banking versus networking), and life cycle phases where specialization is related with the skills and management of the phases in software development (such as coding versus maintenance) (Swanson and Beath, 1990). The research concluded that no form is perfect and division of labor within the software development organizations should follow a hybrid strategy.

Incentive and reward systems for teams are part of the larger organizational support system (Lurey and Raisinghani, 2001). Literature on the subject on incentives and rewards varies from finance and economics to human resource management to marketing to IS (though in a limited sense). It suggests that measurement/reward systems are influential in shaping the behaviours of employees (e.g., Jawroski and Kohli, 1993). Over the years, the use of teams as an organizational unit for a number of critical tasks is gaining popularity in contemporary organizations but the popularity is not translated to ways that the organizations reward teams (Shaw and Schneier, 1995). Organizational reward and evaluation structures have not kept pace with the changes in the work environment and outdated reward structures are one of the common reasons for team failure (Sarin and Mahajan, 2001). Measuring and rewarding individuals, instead of teams, remains the most popular reward method within organizations, even for those that rely heavily on teams (Shaw and Schneier, 1995). However, organizations are realizing the 
need to refocus their reward systems to project/team objectives (Ravichandran and Rai, 2000). In an IS context, few studies looked at recognizing and rewarding individual and team accomplishments for improvement in quality (Ravichandran and Rai, 2000; Shrednick et al., 1992). Similarly, research is also undertaken in the knowledge management domain where rewards and incentives are found to encourage knowledge sharing and reuse (Markus, 2001; Kulkarni et al, 2007). Fichman and Kemerer (2001) looked at the impact of incentives on software reuse and found that incentive incompatibility is a major inhibitor for lack of widespread application of software reuse practices within software development teams. We argue that reward systems that focus on teams rather than individual accomplishments may have a positive influence on team performance. Within software development, tasks are highly interdependent (and thus the value of cooperation is high), and reward systems that provide incentives for cooperation will generate better outcomes than those that provide no incentives for cooperation (Wageman and Baker, 1997).

\subsection{Fit}

Fit can be conceptualized in many different ways (Venkataraman, 1989, Drazin and Van de Ven, 1985; Ivari, 1992; Joyce et al., 1982). A number of techniques have been used in the literature to measure the extent of fit. Some researchers have used direct measures of fit where the respondents are asked directly whether a fit exists among the variables in question (e.g., Posner et al., 1985). However, the direct measurement of fit has received a lot of criticism from the researchers; one such criticism is that they prevent estimation of the independent effects (Kristof, 1996). We focus on the indirect measures of fit in this paper, which is the most common 
way of measuring fit in management research. The following paragraphs describe the classification framework for the various ways of measuring fit.

The six perspectives of measuring fit identified by Venkataraman (1989) in his seminal article provide a comprehensive review of fit measurement research. Most of the recent work on fit in IS research use the classification scheme provided by Venkataraman (1989). His classification encompassed the perspectives proposed in some of the other noted studies on fit (e.g., Drazin and Van de Ven, 1985; Joyce et al., 1982). Drazin and Van de Ven (1985) proposed three different approaches to study fit: selection, interaction, and systems. The classification scheme by Venkataraman (1989) covered the classification by Drazin and Van de Ven (1985). Venkataraman (1989) proposed six perspectives for measuring fit: 1) moderation, 2) mediation, 3) matching, 4) profile deviation, 5) covariation, and 6) gestalt. His framework is based on the following three dimensions: 1) presence or absence of a criterion variable, 2) the number of variables in the research, and 3) the degree of specificity of the functional form of fit (Venkataraman, 1989). The conceptualization of fit is critical as it determines the formation of hypotheses and the use of analytical techniques (Drazin and Van de Ven, 1985). These three dimensions aid the researcher in deciding the perspective of fit to be used for their particular study (Figure 3.3). 


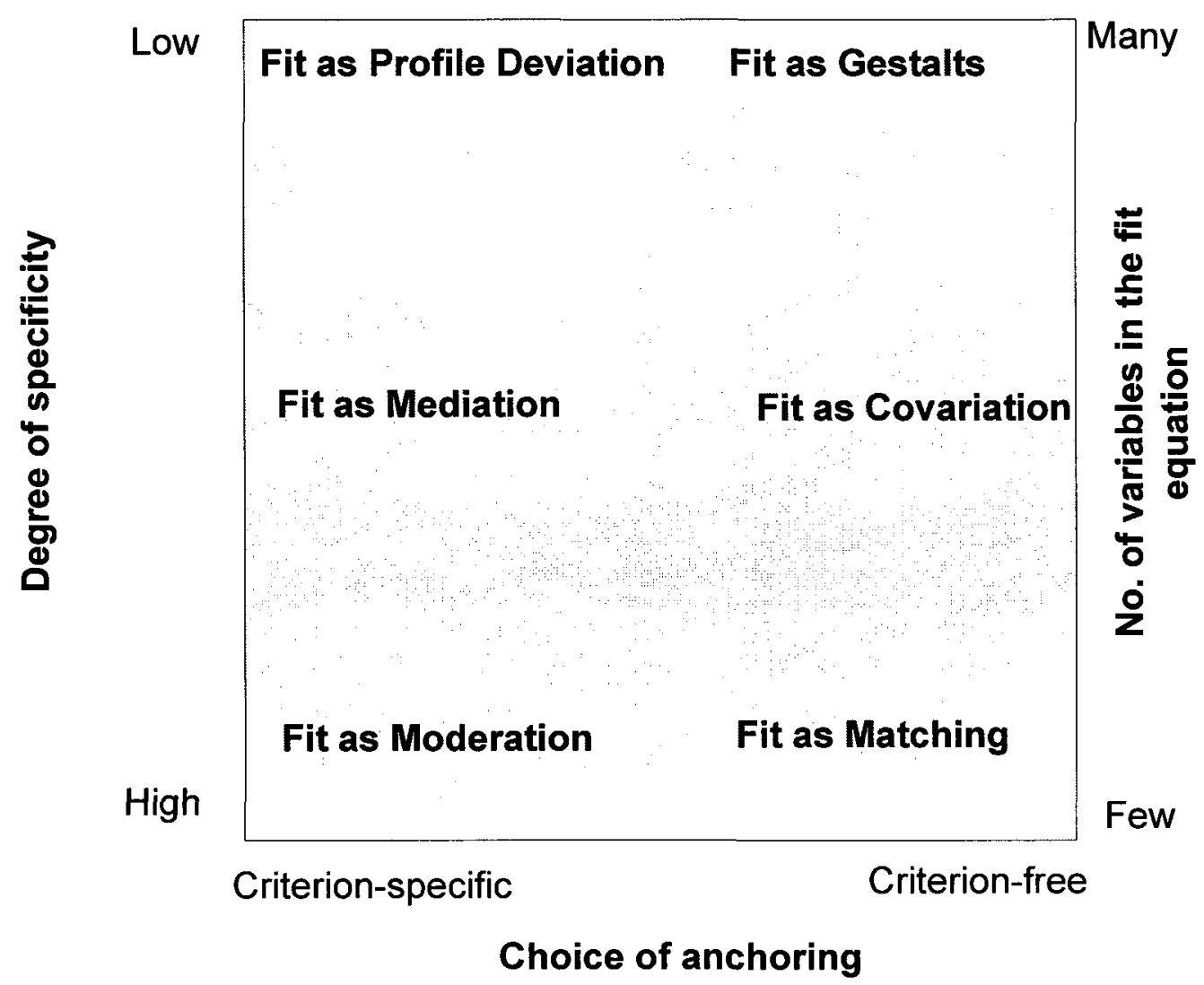

Figure 3-3 A classification scheme for fit measurement approaches (Venkataraman, 1989).

Venkataraman and Prescott (1990), in one of the related papers, further classified the six fit approaches into reductionist and holistic perspectives mainly in the context of strategyenvironment co-alignment. The reductionist conceptualization is based on the central assumption that the "co-alignment between two constructs can be best understood in terms of pair-wise coalignment among the individual dimensions that represent the two constructs" (Venkataraman and Prescott, 1990 p. 2) and moderation, mediation, and matching fall under this category. Under the holistic conceptualization, several variables are examined together to retain the total nature of the co-alignment (Venkataraman and Prescott, 1990) and profile deviation, covariation, and gestalt fall under this category. 
It is important for researchers studying fit to select the appropriate interpretation of the fit to a specific context. Research in the field of contingency approach to study fit criticizes the lack of consistency in defining the concept of fit and selecting the appropriate approach for testing the fit (Drazin and Van de Ven, 1985; Schoonhoven, 1981; Hoffman et al., 1992). Venkataraman (1989) argued that the same variables can be used under different approaches of fit depending on the theoretical considerations. A few studies in IS literature have used multiple perspectives of fit and compared them (Bergeron et al., 2001; Nidumolu, 1996; Nelson and Cooprider, 2001).

This study explicitly addresses the effects of social and technical capability on team performance, the criterion variable. We have used moderation, matching, and profile deviation approaches to measure fit. Two of the three approaches fall under the reductionist category (moderation and matching) and the third falls under the holistic category (profile deviation). Drazin and Van de Ven (1985) argued that the comparison of two approaches, such as interaction (moderation) and profile deviation, can be illuminating since the interaction approach fails to capture the effects of fit that are present at the holistic level. They further argued that the failure of one approach over the other in detecting fit has implications. For example, if the interaction approach does not detect fit and the system approach does, it can be concluded that fit does not occur at the individual level; rather it occurs at the level of deviation from an overall pattern of several variables (Van de Ven and Drazin, 1985). We are of the opinion that studying fit from multiple perspectives using multiple analytical techniques for the same model may provide more comprehensive results. 


\subsubsection{Fit as "Matching"}

The "matching" perspective of fit conceptualizes fit as a theoretically defined match between the two related variables (Venkataraman, 1989). A number of studies have applied this perspective of measuring fit over the years in management research in general (Alexander and Randolph, 1985; Keller, 1994; David et al. 1989) and IS development in particular (Lai, 1999; Nidumolu, 1996; Bergeron et al., 2001).

In the matching perspective of fit, a measure of fit is developed independently of any performance variable, though its effect on criterion variable (e.g., performance) may be examined (Venkataraman, 1989). Alexander and Randolph (1985) used this perspective to measure the impact of fit between technology and structure on the quality of care in nursing subunits. Similarly, Keller (1994) explored the fit between technology characteristics and information processing needs of R\&D sub-units and how it predicted project performance. David et al. (1989) used the three characteristics of technology as task predictability, task analyzability, and task interdependence; they studied their fit with structure characteristics of connectedness, vertical and horizontal differentiation, and ultimately how it impacted group performance. Lai (1999) used this perspective within the software development context to measure the impact of fit between case characteristics and task characteristics on a software developer's performance.

We used the matching perspective of fit to study the social and technical capabilities within a software development team. The basic argument is that a team's ability to exploit technical capabilities depends on its social capability. We conceptualized fit as a theoretically defined match between social and technical capability variables. 


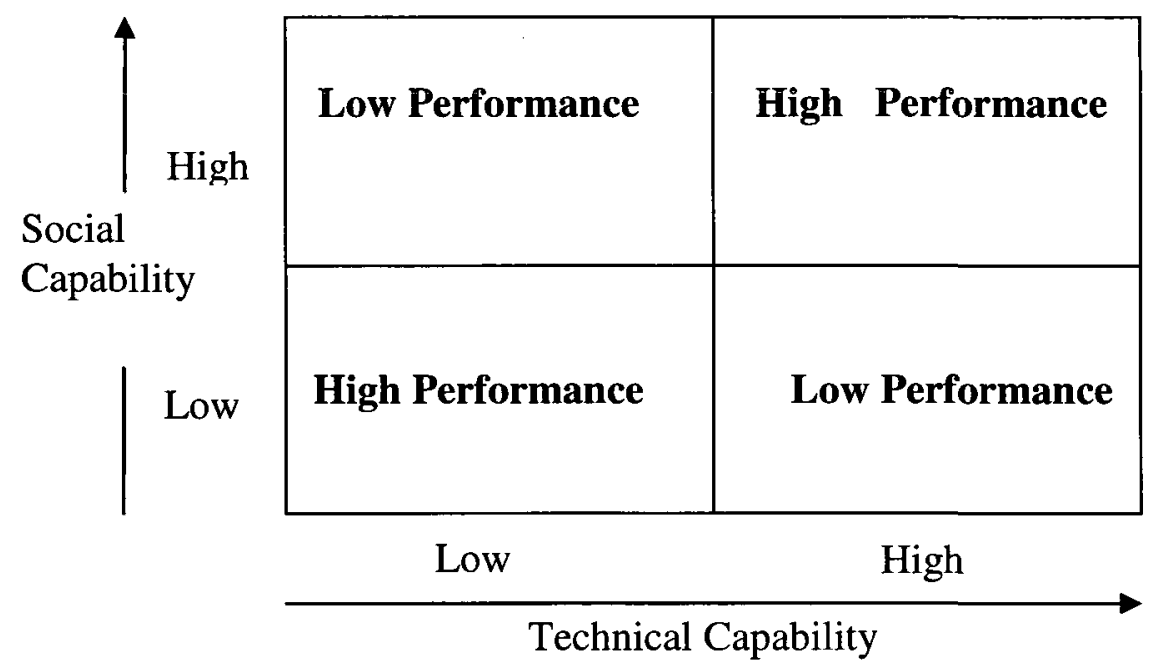

Figure 3-4 A schematic diagram of fit as matching

Figure 3.4 suggests that fit under the matching perspective is attained when the social and technical capability are as close as possible. Thus, according to the definition of fit under the matching perspective, high levels predict higher performance and low levels also predict higher performance. However, since matching approach is not a criterion specific approach this explanation may not be justifiable, i.e., the two variables may be low in value and close to each other which may not indicate higher performance. This can be considered as a drawback for measuring fit under this approach and researchers have to exercise caution in interpreting the results. Matching is a reductionistic approach and is more suitable for analyzing the pair-wise 
hypotheses among the individual dimensions of the overall constructs, thus restricting the overall character of the relationship (Drazin and Ven de Ven, 1985).

Venkataraman (1989) proposed three analytical techniques for testing the matching perspective: deviation score analysis, residual analysis, and analysis of variance. Each technique has its advantages and disadvantages. We have used deviation score analysis in our research. It is the most common technique used in research mainly for its intuitive appeal. One of the main advantages of this technique is that it is very simple and easy to apply. However, there are certain limitations associated with this technique. Venkataraman (1989) pointed to three main analytical issues associated with this technique: 1) potential unreliability of the fit measure (the difference score), 2) the possibility of the spurious association of the fit measure with an external variable, and 3) weak discriminant validity if the transformed variable cannot be differentiated from the individual variables.

A set of twelve elaborated and more specific contingency hypotheses were postulated to test which social capability variable must match with which technical capability variable to result in higher performance of the software development team. In other words, mismatch between the two capabilities may result in lower performance for the team.

Hypothesis 1Match: The fit between communication ability and production capability will be a significant predictor of performance. More the mismatch between communication and production capability less will be the performance.

Hypothesis 2Match: The fit between communication ability and control (performance) capability will be a significant predictor of performance. More the mismatch between communication and control (performance) capability less will be the performance.

Hypothesis 3Match: The fit between communication ability and control (standardization) capability will be a significant predictor of performance. More the mismatch between communication and control (standardization) capability less will be the performance. 
Hypothesis 4Match: The fit between communication ability and IT infrastructure capability will be a significant predictor of performance. More the mismatch between communication and IT infrastructure) capability less will be the performance.

Hypothesis 5Match: The fit between conflict resolution ability and production capability will be a significant predictor of performance. More the mismatch conflict resolution and production capability less will be the performance.

Hypothesis 6Match: The fit between conflict resolution ability and control (performance) capability will be a significant predictor of performance. More the mismatch between conflict resolution and control (performance) capability less will be the performance.

Hypothesis 7Match: The fit between conflict resolution ability and control (standardization) capability will be a significant predictor of performance. More the mismatch between conflict resolution and control (standardization) capability less will be the performance.

Hypothesis 8Match: The fit between conflict resolution ability and IT infrastructure capability will be a significant predictor of performance. More the mismatch between conflict resolution and IT infrastructure capability less will be the performance.

Hypothesis 9Match: The fit between supportiveness ability and production capability will be a significant predictor of performance. More the mismatch between supportiveness and production capability less will be the performance.

Hypothesis 10Match: The fit between supportiveness ability and control (performance) capability will be a significant predictor of performance. More the mismatch between supportiveness and control (performance) capability less will be the performance.

Hypothesis 11Match: The fit between supportiveness ability and control (standardization) capability will be a significant predictor of performance. More the mismatch between supportiveness and control (standardization) capability less will be the performance.

Hypothesis 12Match: The fit between supportiveness ability and IT infrastructure capability will be a significant predictor of performance. More the mismatch between supportiveness and IT infrastructural capability less will be the performance.

Hypotheses (1Match-12Match) suggest that individual dimensions of social capability communication, conflict resolution, and supportiveness - must accompany individual dimensions of technical capability - production, control, and IT infrastructure for effective performance. By analyzing these hypotheses separately, we propose to study the different 
directional matches among the dimensions of social and technical capability that could have been ignored by considering the overall constructs of social and technical capability.

\subsubsection{Fit as "Moderation"}

According to the moderation perspective, commonly called interaction, the fit between the predictor and the moderator is the primary determinant of the criterion/performance variable (Venkataraman, 1989). Moderator, as the name suggests, moderates the relationship between the predictor and the criterion variable. Schoonhoven (1981) pointed out that in contingency research when the relationship between two variables predicts the third variable, an interaction is found to exist between the first two variables. Basically, in simple terms, it is a criterion-specific bivariate perspective, where fit is conceptualized as the interaction between two variables. The advantage of this approach is that it captures the individual (social capability and technical capability, in our case) dimensions in detail and the disadvantage, as mentioned earlier, is the characteristic of the reductionist approach which restricts the overall character of the relationships (Drazin and Van de Ven, 1985).

A number of studies have used interaction approach to study the fit among variables and its impact on performance (e.g. Drazin and Van de Ven; 1989; Hoffman et al, 1992). Drazin and Van de Ven (1985) studied the interaction effect of organizational context and structure on performance. Similarly, Hoffman et al. (1992) studied the technology structure impact of performance. Within the IS field also studies have looked at examining interaction (Nidumolu, 1996; Bergeron et al., 2001; Kim and Umanath, 1993; Kim, 1988). Nidumolu (1996) looked at the interaction between coordination modes and requirements uncertainty on performance. Kim and Umanath (1993) and Kim (1988), in a more specific software development unit context, found that coordination mechanisms that improve performance depended on the nature of the 
task. Bergeron et al. (2001) looked at the relationship between the fit among various IT-related variables and performance from multiple perspectives including interaction. We found that the moderation perspective is studied more than other perspectives in the IS literature.

Researchers have to address a few analytical issues in moderation analysis for their results to be meaningful (Venkataraman, 1989). First the distinction between the form or strength of the moderation needs to be clarified. In our research, we focus on the form of moderation where we specify that the performance outcome is jointly specified by the interaction between the two variables. The second issue relates to multicollineraity, since in this approach the product or the interaction term will be highly correlated with the individual components of the product term. This problem can be solved by a simple transformation in case of interval scales, which we have done in our research. The third issue relates to the comparison of main and interaction effects. Moderation approach used is limited to assessing ratio levels of measurements when comparing main and interaction effects. Our research has used interval scale measures. Thus, we have analyzed only the impact of interaction effects (fit) on performance using moderation perspective.

In this study context, the interactive effect of the social capability of a team and technical capability of a team on team performance was measured (Figure 3.5). A set of twelve interaction hypotheses (1Moderation-12Moderation) were postulated to test which social capability variable interacts with which technical capability variable resulting in higher performance of the software development team. The various hypotheses test whether the interaction improves team performance. We used moderated structural equation modeling (SEM) to measure and test the impact of fit under this perspective. 


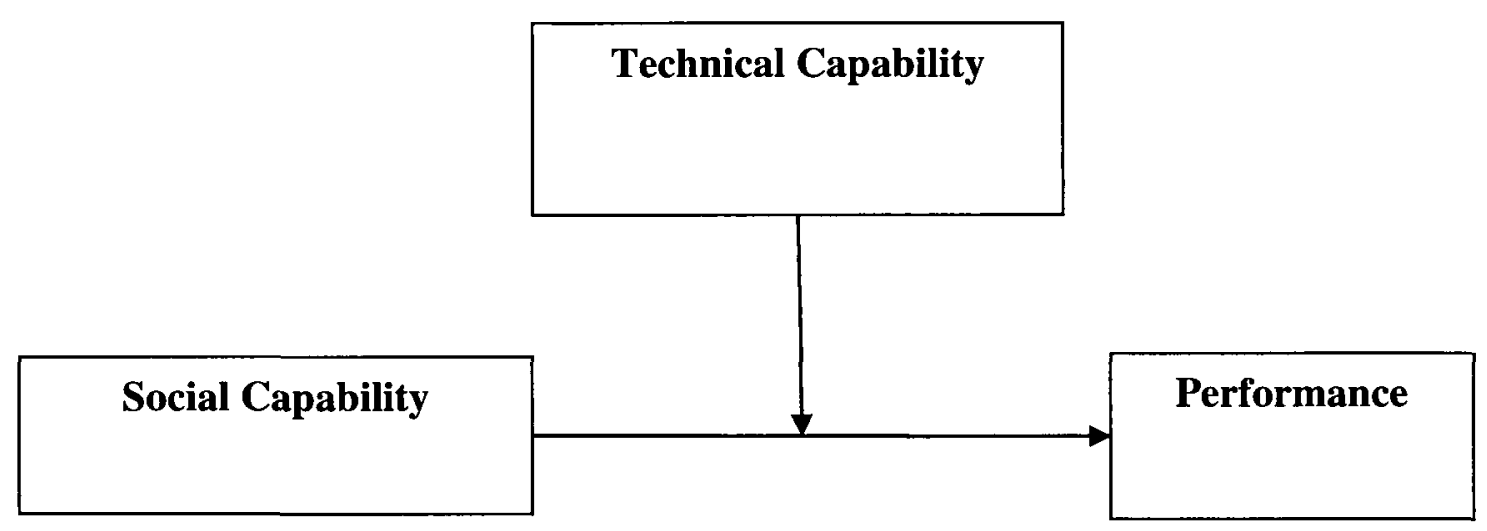

Figure 3-5 A schematic diagram of fit as moderation

The first set of hypotheses (1Moderation-4Moderation) test the interaction effect between communication and the technical capability variables on team performance. We hypothesize that when communication interacts with production, control and infrastructure capability, the team performance is improved.

Hypothesis 1Moderation: The interaction between communication and production capability of a software development team influences its performance (product and process).

Hypothesis 2Moderation: The interaction between communication and control (performance) capability of a software development team influences its performance (product and process).

Hypothesis 3Moderation: The interaction between communication and control (standardization) capability of a software development team influences its performance (product and process).

Hypothesis 4Moderation: The interaction between communication and IT infrastructure capability of a software development team influences its performance (product and process).

The second set of hypotheses (5Moderation-8Moderation) test the interaction effect between conflict resolution and technical capability variables on team performance. In this set of 
hypotheses, we hypothesize that when conflict resolution interacts with production, control and infrastructure capability, the team performance is improved.

Hypothesis 5Moderation: The interaction between conflict resolution and production capability of a software development team influences its performance (product and process).

Hypothesis 6Moderation: The interaction between conflict resolution and control (performance) capability of a software development team influences its performance (product and process).

Hypothesis 7Moderation: The interaction between conflict resolution and control (standardization) capability of a software development team influences its performance (product and process).

Hypothesis 8Moderation: The interaction between conflict resolution and IT infrastructure capability of a software development team influences its performance (product and process).

The third set of hypotheses (9Moderation-12Moderation) test the interaction effect between supportiveness and technical capability variables on team performance. We hypothesize that when supportiveness interacts with production, control and infrastructure capability, the team performance is improved.

Hypothesis 9Moderation: The interaction between supportiveness and production capability of a software development team influences its performance (product and process).

Hypothesis 10Moderation: The interaction between supportiveness and control (performance) capability of a software development team influences its performance (product and process).

Hypothesis 11Moderation: The interaction between supportiveness and control (standardization) capability of a software development team influences its performance (product and process).

Hypothesis 12Moderation: The interaction between supportiveness and IT infrastructure capability of a software development team influences its performance (product and process).

\subsubsection{Fit as "Profile Deviation"}

Profile deviation is a holistic and systems approach to measuring fit. It is a criterionspecific approach that presupposes an ideal multidimensional profile, and deviations from such a 
profile should have adverse impact on performance (Venkataraman, 1989). Basically, fit is measured as the degree of adherence to the ideal profile.

Barki et al. (2001) tested the model of software project risk management using the profile deviation approach and found that in order to increase the performance of the project, the risk management profile needs to vary according to the risk exposure of the project. Bergeron et al. (2001) also followed a similar approach within small enterprises and found that firms seeking to achieve higher performance must aim at reducing the gap between themselves and top performers in terms of IT management and strategic orientation. However, Nidumolu (1996) did not find much support for their research model when profile deviation was used as the fit measurement approach.

For this research, we consider social capability as a multi-dimensional profile construct and technical capability as a single construct ranging from low to high. The main analytical issue associated with this approach is the development of the ideal profile. Two methods have been suggested in the literature to develop the ideal profile: 1) from prior theory and 2) from the empirically available data. Most of the studies have developed an ideal profile based on the empirical data (Barki et al., 2001; Venkataraman and Prescott, 1990; Bergeron et al., 2001; Nidumolu, 1996). Ideal social capability profiles for software development teams for varying levels of technical capability have not been specified by prior theory. Empirical data was used to calculate an ideal profile for social capability in this research.

Formulation of hypotheses under this perspective followed the guidelines of Nidumolu (1996). A total of two hypotheses (1profile-2Profile) were formulated.

Hypothesis 1Profile: The greater the team's deviation from the empirically derived ideal profile of social capability dimensions, the lower the product performance. 
Hypothesis 2Profile: The greater the team's deviation from the empirically derived ideal profile of social capability dimensions, the lower the process performance.

The hypotheses indicate that deviation from an appropriate pattern would be negatively related to performance. When the team's deviation from the empirically derived ideal profile of social capability for high and low categories of technical capability is greater, the performance is lower.

In summary, this chapter presented the research model of the study and all constructs were described one after the other. The social capability construct, along with the dimensions of communication, conflict resolution, and supportiveness, was developed specifically for a software development team. Similarly, the technical capability construct, along with the dimensions of production, control, and infrastructure, was developed. A review of the major software development team performance studies over the last two decades showed the importance of adopting the two-dimensional view for studying team performance. Further, the organizational factors relevant for the study were outlined. Finally, three ways to conceptualize and measure fit along with the research hypotheses was presented. 


\section{Chapter 4 Research Methodology}

This chapter describes the steps taken to conduct the study. It is divided into three sections. Section 4.1 outlines the research design of the proposed study. Section 4.2 discusses the sampling and data collection details. Section 4.3 looks at questionnaire design details including measures for the constructs.

\subsection{Research Design}

A research design is a "master plan specifying the methods and procedures for collecting and analyzing the needed information" (Zikmund, 1994 p. 43). It is a blueprint for the collection, measurement, and analysis of data (Cooper and Schindler, 1998). The study involves an investigation into understanding the impact of social and technical capability and their fit on software development team performance. The study is formal in nature though it involves some level of exploration especially at the model development stage. Primary data was collected using self-administered survey method. An ex-post facto design was implemented, as the researchers had no control over the independent variables. The study is cross-sectional in nature and data collected represents the snapshot of one point in time.

\subsection{Sampling Strategy}

The focus of this study is to survey software development teams. Software development, an industry in itself, is also undertaken by organizations in other industries such as computer manufacturing, semiconductor manufacturing and telecommunication firms. We focused on 
information and manufacturing sectors based on the North American Industry Classification System (NAICS) classification scheme. We chose two industries to study software development team performance as it provides greater scope for generalizability of the study results.

Within the Information sector (primary NAICS code 51), publishing industries (NAICS 511) is an important sub-sector and is relevant for the study (Table 4.1). Software publishing is included here because software development is basically the creation of a copyrighted product and is equivalent to the creation process for other types of intellectual products. We collected data from the software publishing industry.

Table 4-1 List of Industries in publishing sub-sector (NAICS Code 511)

\begin{tabular}{|l|l|}
\hline NAICS Code & Industries \\
\hline 511110 & Newspaper, Periodical, Book, and Directory Publishers \\
\hline $\mathbf{5 1 1 2 1 0}$ & Software Publishers \\
\hline
\end{tabular}

Within the Manufacturing sector (NAICS code 33), computer and electronic product manufacturing sub-sector (NAICS code 334) is an important sub-sector (Table 4.2). Data was collected from semiconductor and other electronic component manufacturing industry (NAICS code 334410). 
Table 4-2 List of Industries in computer and electronic product manufacturing sub-sector

\begin{tabular}{|l|l|}
\hline NAICS Code & Industries \\
\hline 334110 & Computer and Peripheral Equipment Manufacturing \\
\hline 334210 & Communications Equipment Manufacturing \\
\hline 334310 & Audio and Video Equipment Manufacturing \\
\hline $\mathbf{3 3 4 4 1 0}$ & Semiconductor and Other Electronic Component Manufacturing \\
\hline 334510 & Navigational, Measuring, Electro-medical, and Control Equipments \\
& Manufacturing \\
\hline 334610 & Manufacturing and Reproducing Magnetic and Optical Media \\
\hline
\end{tabular}

The survey was undertaken for two samples of software development teams: one from firms within the software industry - i.e., software publishing firms - and the other from firms in the semiconductor and other electronic component manufacturing industry. Main product for software publishing firms is software and the presence of software development teams is the greatest in such firms. For semiconductor firms, main product may not be software; however, most of their products are software supported. These two resources provide a representative sample of the target population.

Scott's Online Directory of Scottsinfo.com was used as the starting point to gather information about the companies in the chosen sectors. The database provides basic information about the company along with contact information of executives. However, contact information related to software development managers and team leaders was not available. We randomly selected 1000 companies from the list of the companies obtained from Scott's Online Directory. Based on the company names we searched for the needed information on the internet. We 
specifically looked at online databases such as Spoke, ZoomInfo, and Linkedin to get the contact information including email addresses of software development professionals for the companies identified in the chosen sector. We had to expand our search to USA and India as the person who responded to the survey was residing in one of the three countries. This is due to the reason that many of the companies chosen from the database had their software development activities taking place in USA or India.

\subsubsection{Adequacy of sample size}

Calculation of an appropriate sample size depends on a number of factors unique to each survey and it is up to the researcher to make decisions related to those factors. The three most commonly cited are accuracy desired, confidence in the results, and the costs involved. For structural equation modeling (SEM), there is no accepted formula to calculate the sample size. Large sample sizes provide degree of confidence but do not provide a guideline about when sample size is large enough (Tanaka, 1987). Sample size smaller than 100 is not considered appropriate in SEM analysis (Boomsma, 1987). Acceptable sample size in SEM analysis is 100 and reasonably good estimates can be obtained when the sample size is close to 200 in $\mathrm{ML}$ estimation method (Boomsma, 1987; Gerbing and Anderson, 1985).

Three different analytical techniques were needed to analyze the data for the three different fit conceptualizations. For fit as 'Matching', deviation score was used and for fit as 'Moderation', SEM was used, and for the profile deviation conceptualization correlation was used. Since we used SEM as one of the analytical techniques, a sample size close to 200 should provide reasonably good estimates. We were able to collect data from 220 respondents. 


\subsubsection{Data collection and unit of analysis}

This section highlights data collection strategy that was used to test the hypotheses and validate the research model. The study addresses team related factors; attention must be given to the individual teams. Software development team is the appropriate unit of analysis. In choosing the software development teams, the following guidelines were used to ensure some similarity across the teams. First, we limited our research to teams that have worked together for at least four months. This is especially important for the social capability aspect within a team, as it takes time for the team members to get used to each other and support each other. Second, we looked at teams that had at least five team members. Third, only teams that were actively involved in developing a product, i.e., the output of the team was either a software product or a software module was considered. For example, teams that were only involved in planning and implementation tasks were not considered.

We used the key informant approach in the research. Key informants are the members of the team who can provide a wide-ranging sample of the views and perceptions of the entire team (Sawyer, 2001). The key informant in our study was the team leader, project leader/manager, project coordinator, or a senior software development professional. Although the key informant approach has been mostly used with qualitative approach to study team level issues, several researchers have also used this approach in collecting survey data on teams. This approach has been used widely in IS literature especially when data is to be collected from IS design teams (Henderson and Lee, 1992; Nidumolu, 1995; Sawyer, 2001). Confidentiality issues are important and the confidentiality measures were described in the cover letter (Appendix I). Approval from the Ethics Committee at Carleton University was received before sending out the survey. 
Data was collected using web-based self administered survey (Appendix II). Based on the nature of the task i.e. software development, email and web based survey is the most suitable data collection method. We used a survey service application provider (survey monkey) to host our survey. We purchased the secured subscription for hosting the survey on their website. The web site was secured with SSL that allowed data to be collected in a totally encrypted environment. Survey questions were uploaded online and a website address was created for the survey. We used an online cover letter which was hosted on the researcher's personal home page on the university website, which had the link to the survey.

\subsection{Questionnaire Design and Development}

The questionnaire included the measurement items for all the constructs and was divided into five sections. The first section was about project and team related information. The second section had questions about the team capabilities (social and technical). The third section was about team performance. The fourth section contained questions related to the organizational factors and finally, the last section requested the respondents to provide contact information and additional comments, if any.

\subsubsection{Measures}

To test the various hypotheses, the theoretical constructs of social capability, technical capability, and software development team performance must be measured, and the relationships among them be analyzed. Previously validated indicators with some modifications were used to measure the various dimensions of the three constructs: 1) social capability, 2) technical capability, and 3) software development team performance. All the items were measured using 
five point Likert scale. Fit is a pseudo measure and was calculated using various analytical techniques. Despite the use of previously validated measures, all constructs were retested for reliability and validity.

The social capability construct consisted of communication, conflict resolution, and supportiveness variables. All of these variables have been tested independently many times in management literature as well in the software development context. For communication, we adapted the measures provided by Hoegl and Gemeuenden (2001) and measured it with nine items. For conflict resolution ability, we adapted the scale given by Andres and Zmud (2001) and Miranda and Bostrom (1993-94) and measured it using nine items, with three items being reverse coded. For supportiveness, we adapted the measures given by Hoegl and Gemeunden (2001), Kirsch (1996), and Sawyer and Guinan (1998) and measured it with seven items. See Appendix III for details of the measurement items.

Similarly, for technical capability construct existing scales with some modifications were used for measuring production, control, and infrastructure capability. Measures for production capability were based on the work by Khatri et al. (2006) and Rouessava (2008) and consisted of five items. Measures of control capability were based on the work by Nidumolu and Subramani (2003) and Henderson and Cooprider (1990) and consisted of thirteen items. Measures of IT infrastructure capability were based on the work of Broadbent et al. (1999) and consisted of ten items. See Appendix III for measurement item details for each of the variables.

The performance of a software development team has been measured in many different ways (Sawyer and Guinan, 1998). Two arguments are prevalent in the literature with respect to measuring software development team performance. Researchers not only stress the importance of adopting a two-dimensional view of measuring performance - i.e., product and process view 
or the efficiency and effectiveness trade-off - but also stress combining the objective and subjective/perceptual measures of measuring team performance. Over the years, software development team performance has been measured using both the objective and subjective/perceptual measures (Kemerer, 1989). However, researchers have also emphasized substantial problems associated with the objective measures (Henderson and Lee, 1992). Objective measures (such as lines of code per person per month) not only suffer from unavailability and manipulation problems but also reflect the specific accounting practices of a firm and cannot control for the differences associated with different projects or specific situational constraints (Faraj and Sambamurthy, 2006). For this research we used perceptual/subjective process measures of team performance. Because our study involved teams from multiple organizations, the use of internal accounting systems data to measure performance was not considered an appropriate strategy. However, there could be a slight possibility of responses coming from multiple teams within one organization as we did not control for it.

The perception of success is dependent in part on the perspective of the evaluator (Hoegl and Gemuenden, 2001). Another variation seen in measuring performance is at the level of respondent, i.e., the person whose perception is being measured. The respondent can be a stakeholder within or outside the team, a key informant, or the user of the system. It is claimed in the literature that perceptual performance measures need to be asked from the stakeholders and not directly to the team members to avoid self-report bias (Sawyer, 2001). We argue that the team leader is also a stakeholder and he/she would be the best judge to answer the questions in this research survey.

The performance measures used in the study were adapted from Nidumolu $(1995,1996)$ who addressed the dichotomist view of performance: process performance and product 
performance. Nidumolu (1995) used the measure project performance in their model, which included both product and process performance and Nidumolu (1996) kept both the measures of performance separate in their analysis. Process performance reflects the quality of the development process (efficiency) and product performance reflects the performance of the finished product (effectiveness). These performance measures have been adopted by various other researchers (Wallace et al., 2004; Na et al., 2007; Liang et al., 2007) with success. We measured process performance using two items and we measured product performance using six items. We also measured team satisfaction using four measurement items. See Appendix III for details of the measurement items.

Organizational factors were measured using the well established existing scales. Centralization was measured using five items adopted from Hage and Aiken (1967) and Jawroski and Kohli (1993). Formalization was measured using four items given by Grover and Goslar (1993). Specialization was measured using one item based on the definitions of specialization given by Damanpour (1991) and James and Jones (1976). Incentives and rewards systems was measured using three items based on the Lurey and Raisinghani (2001) and Shaw and Scheier (1995) studies with one item being reverse coded.

Fit was measured in three different ways. Chapter 8 explains the various techniques used for each of the three perspectives of fit under investigation. We also used one direct measure of fit by asking the perception of the respondent about the presence of fit in their team.

\subsubsection{Pre-test}

Pre-tests are basically "trial runs with a group of respondents for the purpose of detecting problems in survey instructions or design" (Zikmund, 1994 p. 216). Pre-tests are normally conducted in the form of personal interviews that allow opportunity for feedback and follow up 
by probing. Based on the pre-test results, some changes may be undertaken in the survey instrument.

We conducted four pre-tests and the comments were incorporated in the questionnaire. Pre-test participants were mainly selected based on contacts of the researcher and included one team leader, two software development managers, and one senior software development professional. Overall the survey was received well but a few minor changes were suggested by the pre-test participants. We did not include data related to these four surveys in the final sample. Revised questionnaire was used for the full scale data collection process.

In summary, this chapter outlined the research methodology that was used to validate the model. We used web based survey to collect data from software development professionals and team leaders. The method proved to be time and cost effective. 


\section{Chapter 5 Data Preparation}

This chapter describes the various procedures undertaken to prepare the data for testing the hypotheses. Before testing the hypotheses, first important thing was to screen the data for data entry inaccuracy, missing data, outliers, and normality. These four things are discussed as part of the data screening section in this chapter. We also discuss some of the measures undertaken to reduce common method biases and non-response bias.

\subsection{Data Screening}

\subsubsection{Data clean up and missing values}

Data entry inaccuracy is not an issue in this research as the survey was conducted online and the researcher did not manually input the data into the spreadsheet. Subscription to the survey provider services allowed for automatic download of data from their web server into the excel spreadsheet. Once a certain number of responses were received (220) (June 2009) the researchers downloaded the entire data on to their computer for analysis and cancelled the subscription membership.

Reverse coding was needed in a few measurement items as they were negatively worded to make them usable for analysis. One of the construct involved not applicable in the measurement item scale and not applicable analysis was appropriately performed so that the data related to those items could be excluded from the analysis.

A drawback for collecting primary data using surveys is that the researcher has no control over how the respondent answers the survey such as whether the respondent is completing the 
survey or not. This results in missing values, reduced sample size and loss of data. There are a number of reasons why missing values occur in survey research. On some occasions missing data occurs as a survey design flaw where the respondent did not understand the question and therefore did not answer it. On other occasions the question did not turn out to be applicable and was left unanswered or in some other cases the respondent got bored and did not complete the survey.

Research suggests that a pattern of the missing data if there is any needs to be evaluated before the analysis can start. Missing data at random poses fewer problems in research as compared to missing data that is non-random (Rubin, 1976). In our research, we did not see any particular pattern in the missing data and thus we assumed that the data was missing at random. Literature suggests a number of ways to deal with the missing data. We had only small number of missing values making it high probability that the missing values were random. All the key variables of the study contained less than $5 \%$ of missing information. We chose to deal with the missing data by mean substitution procedure where the missing value for a particular item was substituted by the mean for that item.

\subsubsection{Outliers}

Outliers are data points in the data set that are very different from the rest of the data in the data set. Outliers are traditionally analyzed when conducting correlation and regression analysis. These statistical techniques can be quite sensitive to the presence of outliers in the data set. We checked for multivariate outliers in our study. Multivariate outliers can be calculated using the statistic called Mahalanobis Distance. It is the distance of particular scores from the center cluster of remaining cases (Stevens, 1996). 
The data set was mostly free from multivariate outliers except for two cases and we decided to keep them in the analysis. The reason being, we are doing a composite score which reduces the possibility of individual item outliers in the final analysis. As a precaution we did the analysis without the outliers and the results did not differ much. So we decided to keep all the data points in the final analysis.

\subsubsection{Normality}

Normality refers to the normal distribution of sample data. Among the several methods available in the literature to check for normality we decided to use Skewness and Kurtosis for checking normality. Skewness reflects the symmetry of the distribution. Perfect symmetric distribution signifies normality. A positively skewed distribution is reflected when the scores are clustered to the left, with the tail extending to the right. A negatively skewed distribution is reflected when the scores are clustered to the right, with the tail extending to the left. Skewness is said to be present when the skewness statistic values are outside the range of -2 to +2 (Stevens, 1996). No cases of excessive skewness was found in the data, however there is evidence of negative skewness which was within the recommended range (Table 5.1).

Kurtosis shows peaks in the distribution. A bell-shaped distribution shows normality. A peak in the distribution indicates positive kurtosis and a flat distribution indicates negative kurtosis (Stevens, 1996). For normal distribution the value of kurtosis should be 0. Excessive kurtosis occurs when the test values are outside the range of -7 to +7 . The test results indicate that there was no massive kurtosis for the variables in the dataset (Table 5.1). For individual measurement item statistics see Appendix IV. 
Table 5-1 Descriptive statistics of the independent and dependent variables

\begin{tabular}{|l|r|r|r|r|r|}
\hline Name & Mean & Std. Error & $\begin{array}{l}\text { Std. } \\
\text { Deviation }\end{array}$ & Skewness & Kurtosis \\
\hline $\begin{array}{l}\text { Communication } \\
\text { (com) }\end{array}$ & 3.7524 & 0.03524 & 0.48826 & -0.040 & 0.433 \\
\hline $\begin{array}{l}\text { Conflict } \\
\text { Resolution (cr) }\end{array}$ & 3.4527 & 0.04141 & 0.57373 & -0.472 & 1.584 \\
\hline $\begin{array}{l}\text { Supportiveness } \\
\text { (sup) }\end{array}$ & 3.9626 & 0.03825 & 0.52999 & -0.215 & 0.274 \\
\hline $\begin{array}{l}\text { Production } \\
\text { Capability (pc) }\end{array}$ & 3.9500 & 0.04262 & 0.59061 & -0.550 & 0.928 \\
\hline $\begin{array}{l}\text { Control (perf) } \\
\text { Capability (cop) }\end{array}$ & 3.7765 & 0.05053 & 0.70012 & -0.707 & 1.240 \\
\hline $\begin{array}{l}\text { Control (std) } \\
\text { Capability (cos) }\end{array}$ & 3.6132 & 0.05651 & 0.78296 & -0.509 & 0.534 \\
\hline $\begin{array}{l}\text { It infrastructure } \\
\text { capability (it) }\end{array}$ & 3.6670 & 0.04638 & 0.64264 & -0.059 & 0.243 \\
\hline $\begin{array}{l}\text { Product } \\
\text { Performance } \\
\text { (prod) }\end{array}$ & 3.8870 & 0.04083 & 0.56578 & -0.620 & 0.260 \\
\hline $\begin{array}{l}\text { Process } \\
\text { Performance } \\
\text { (proc) }\end{array}$ & 3.6893 & 0.05883 & 0.81524 & -0.535 & 0.238 \\
\hline Centralization & 2.3368 & 0.06143 & 0.8512 & 0.661 & 0.039 \\
\hline Formalization & 2.8737 & 0.06224 & 0.86243 & 0.010 & -0.205 \\
\hline Incentives & 3.5528 & 0.05541 & 0.76780 & -0.844 & 0.829 \\
\hline Specialization & 3.7224 & 0.05723 & 0.79295 & -0.482 & 0.096 \\
\hline
\end{tabular}




\subsection{Common Method Biases/Variances}

Common method variances are one of the main sources of measurement error (Podsakoff et al., 2003). These variances are caused as a result of the measurement method and not because of the construct of interest (Bagozzi and Yi, 1990). The variance causes biases that can have serious impact on research findings. Common source/respondent, item characteristics, item context, and measurement context are some of the sources of method biases in survey research. There are number of ways to reduce these biases but there is always a tradeoff between reducing the biases at the expense of time and cost.

Protecting the identity of the respondent i.e. keeping respondent anonymous helps in reducing the common source bias as the respondent is less likely to answer the questions based on social desirability, leniency, and consistency (Podsakoff et al., 2003). We strictly followed respondent anonymity in the data collection process. Counterbalancing the question order reduces biases related to item context. We changed the order of questions (predictor and criterion) in the middle of the data collection process to reduce biases associated with item contexts. Careful construction of the item at the design stage helps in removing ambiguity, vagueness and double barreled questions in the survey. Survey items were carefully designed and pre-tested before the final survey was rolled out. This helped in reducing biases associated with item characteristics. We had no control over the time and location of measurement as we used web-based survey to collect data. However, research suggests that use of face to face interviews tend to introduce more biases in the research as compared to computer based surveys (Richman et al., 1999).

Harman's single- factor test is the most widely known test for assessing common method biases when a single respondent is involved (Podsakoff et al, 2003; Sabherwal and Fernandez, 
2003). Confirmatory factor analysis (CFA) can be used when administering Harman's single factor test (Malhotra et al., 2006). In this method, all the measurement items are considered as the indicators of a single factor. The CFA test indices revealed that the fit of the single factor model was unsatisfactory (Chi-Square $=5758.99, \mathrm{df}=945, \mathrm{RMSEA}=0.163, \mathrm{CFI}=0.80$, and NNFI=0.79). Thus, the results indicated that common method bias was not a major source of variation in the measurement items in this research.

\subsection{Non Response Bias and Response Rate}

Non-response refers to "the many sources of failure to obtain observations on some elements selected and designated for the sample" (Kish, 1965 p. 532). The reasons could be nonavailability, unwillingness to respond, cannot respond, and do not exist. In our case we contacted potential respondents through email. In few cases we got an email message for not availability, not suitable to respond and in many cases the email just returned indicating that the person is no longer using the email address.

Commonly, non-response bias is viewed on a continuum, ranging from fast responders to slow responders. Non-response bias can be checked by comparing the characteristics of early respondents with the late respondents. Our data collection lasted for four months. We sent at least one reminder email and sometimes two reminder emails after the first month. We compared the characteristics of respondents who answered the survey in the first month to the ones who answered in last month. A non-significant independent sample t-test indicated no difference in the two groups.

After an initial pretest of the survey and the modifications, the survey was hosted on the website. We created our own database of software development team leaders/managers and 
senior software development professionals based on the information available from the various online databases and search engines. A randomly selected software development professionals/managers and team leaders from the database were sent an email explaining the purpose of the survey and providing the link to the website where the survey was hosted. A total of 1150 emails were send to the prospective respondents over a period of one month. 75 emails returned making the total survey send as 1075 . Follow up emails were sent to the appropriate persons over a period of three months to encourage them to respond. A total of 220 responses were received before we closed the data collection process.

Overall response rate was $220 /(1150-75)(20.5 \%)$. Out of the 220 responses, 28 were unusable. A total of 192 responses could be used for the analysis which gave a usable response rate of $192 / 1075(17.9 \%)$. We had to leave out 28 surveys from the final analysis as they did not fit the criteria that we had selected initially such as team size or the survey was incomplete.

In summary, this chapter outlined the data preparation procedures and tests that were used to make the data usable for research purposes. Missing values are a real possibility when researchers decide to collect primary data, which was discussed in the chapter. Tests were conducted to check for outliers and normality. This chapter also discussed how the common method biases were dealt with in the research. Response rate achieved in the study is close to the average response rate reported in IS research (Sivo et al., 2006), which is encouraging. 


\section{Chapter 6 Preliminary Data Analysis}

This chapter is divided into two sections. The first section is related to the descriptive statistics for the data collected for the research purposes. In the second section we give results of the preliminary analysis conducted on the data.

\subsection{Descriptive Statistics}

This section contains three sets of information. First, we describe the profile of the responding teams and second, we describe the projects that the respondents worked on. Finally, descriptive data related to the organizational factors are presented.

\subsubsection{Overview of the responding teams}

Our unit of analysis in the study was the software development team. Data related to the size of the team, the type of software developed, and the location of the team was collected. The respondents, mostly software development managers and team leaders were asked to provide details about the type of software product they were currently working on or had recently completed. We selected two types of industries in our dataset: software publishing firms, basically producing any kind of software as their product (multi-media, security, education etc.) and semiconductor and other electronic component manufacturing firms, as software development is one of their major activities. Approximately 25\% of the teams that responded to the survey were from the semiconductor and telecom industry and the rest $75 \%$ were from the software publishing industry (Figure 6.1). We collected data from two types of industries to increase the generalizability of the study results. 


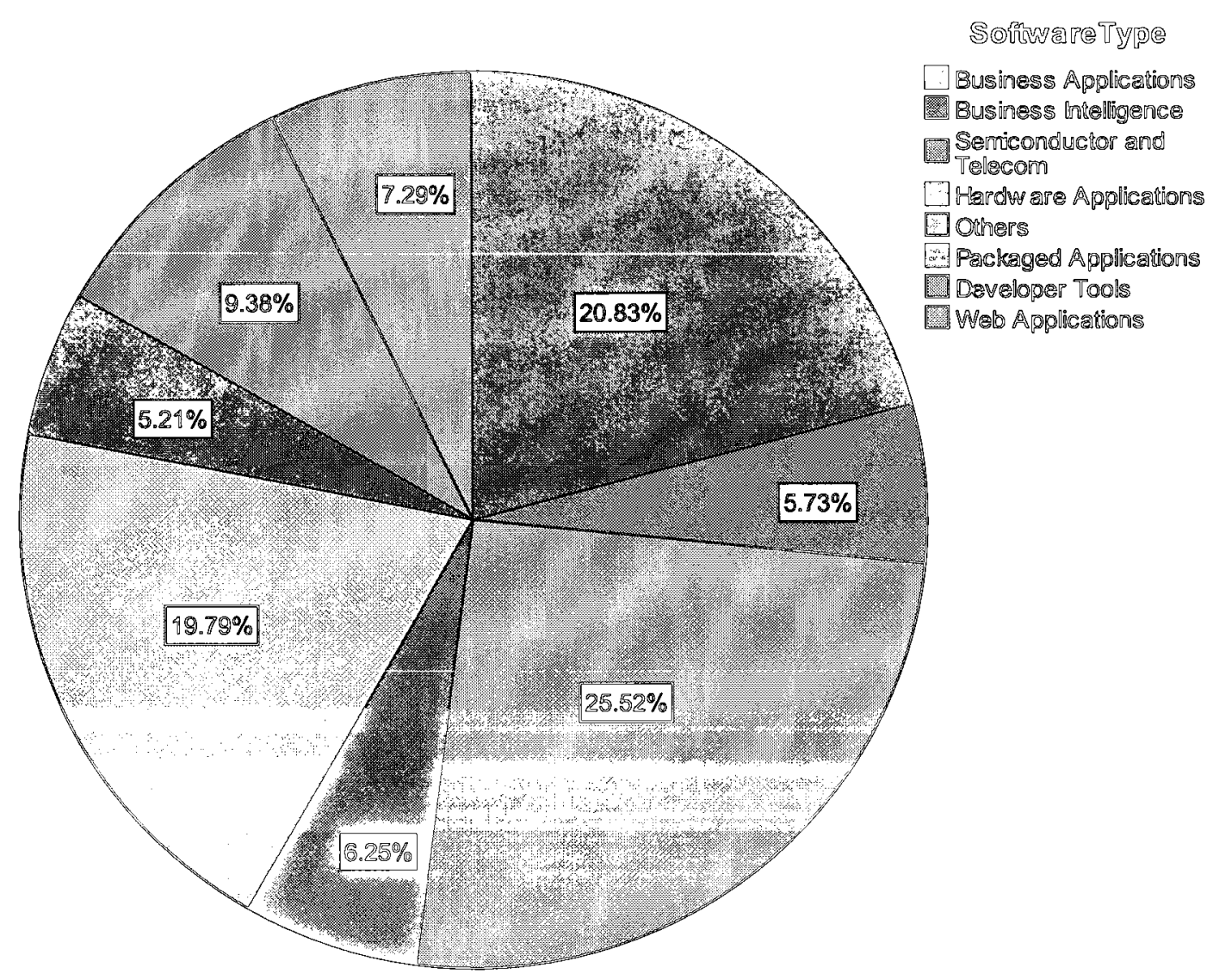

Finguree Ga1 Distributiom of the dataset by the type of sofitware developed

Data collected for the research came from three different coumtries and two different geographic locations: North America (Camada and USA) and Asia (India). Majority of the respondents were based in North America (70\%) as compared to $30 \%$ in India (Figure 6.2). This categorization is based on the location of the respondent. The person who responded to the survey was residing in one of the three countries. However, our dataset shows that the team 
members may mot be located in the same place. About $60 \%$ of teams surveyed were geographically dispersed as compared to $40 \%$ that were located in one place.

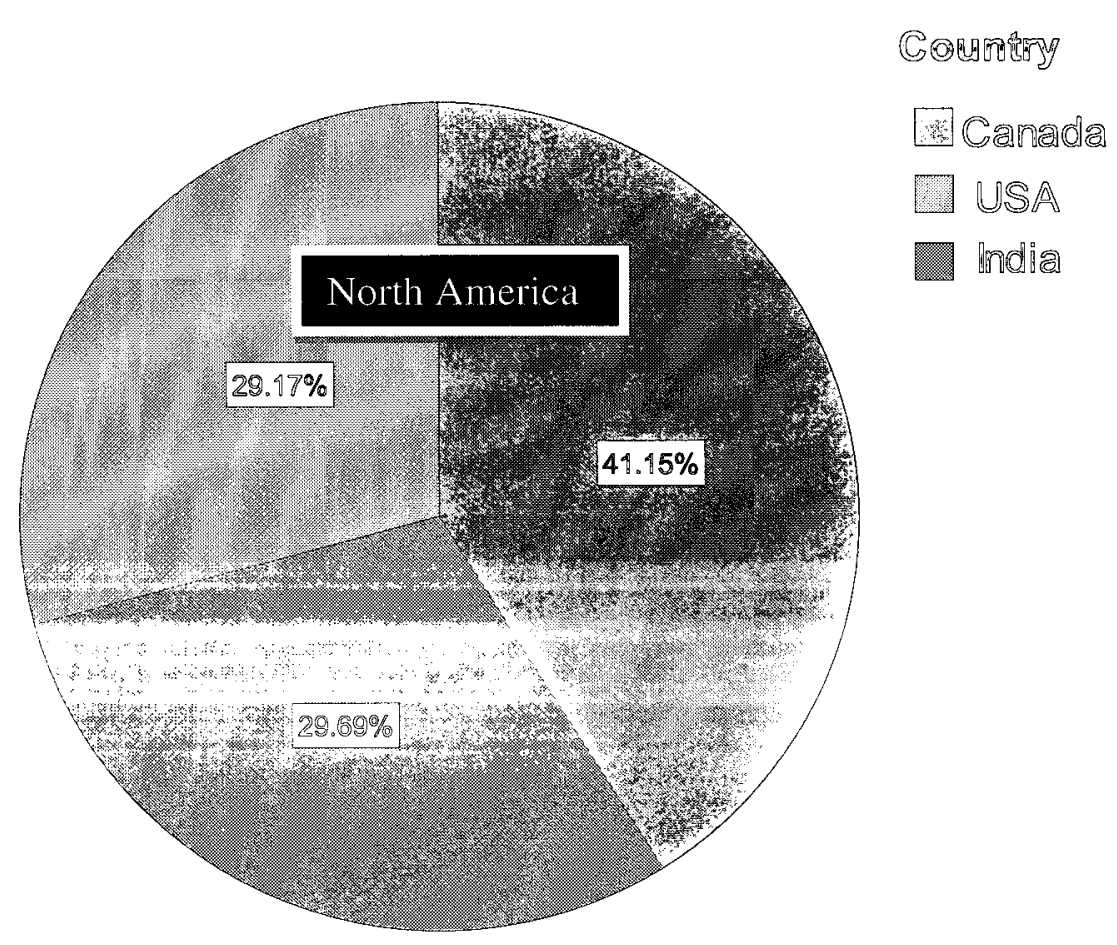

Figure 6.2 Distritbution or the dataset loy the location of the respomdent

Team size is comsidered an important variable in research studies. We asked the respondent to provide the number of team members in their team. We made two categories for team size: small and large. Teams that have 15 and more members are considered large and teams that have less than 15 members are considered small for the purpose of analysis. The upper limit of team size in our data set was 100 . This categorization is based on expert opinions and previous studies undertaken in the context of software development (Farai and Sproull, 
2000). Approximately 58\% (112 teams) of the responding teams were small and $42 \%$ ( 80 teams) of the responding teams were large (Figure 6.3).

\section{Team Size}

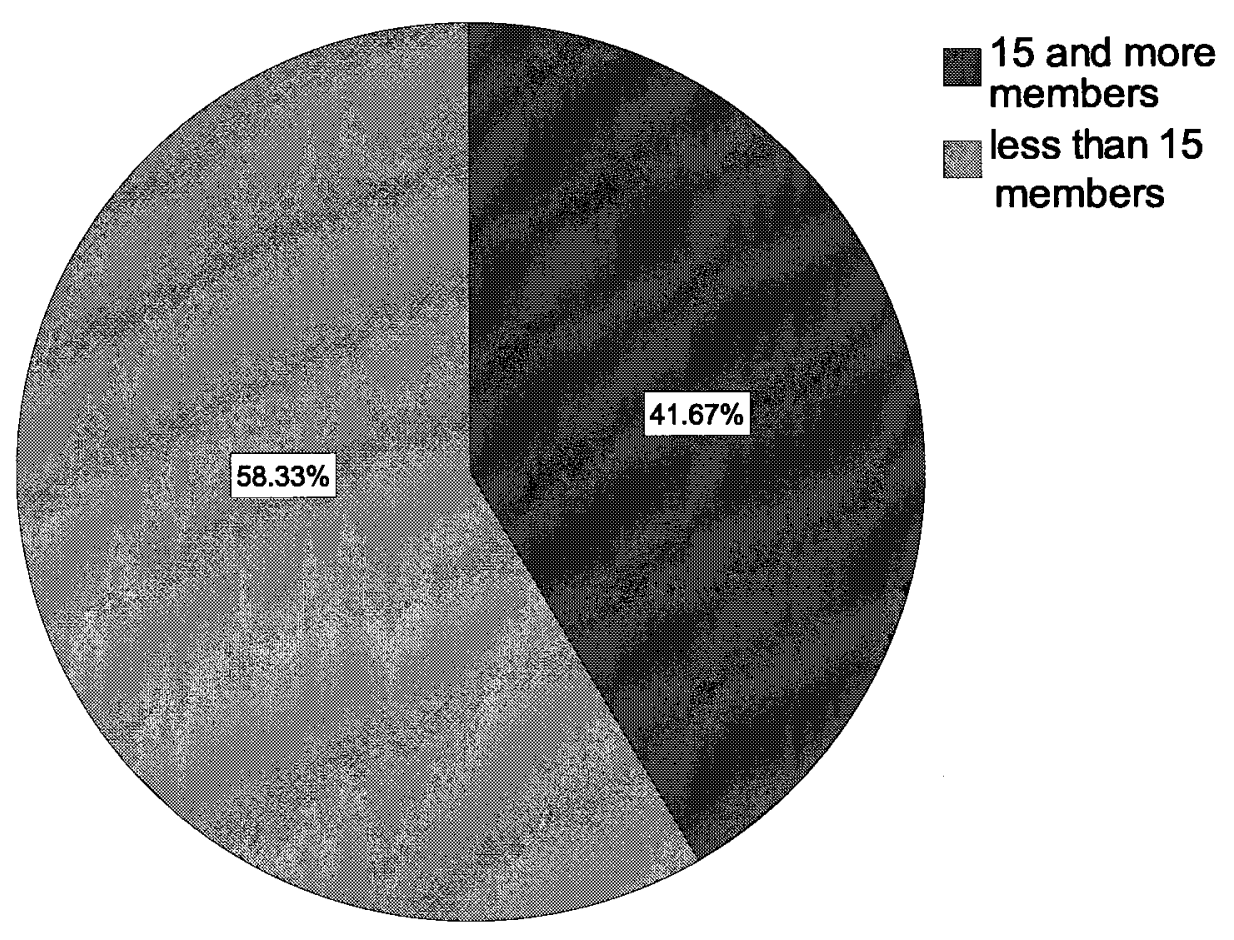

Figure 6-3 Distribution of the dataset by team size

\subsubsection{Software development projects}

Respondents were asked to pick a project they were currently working on or recently completed. Duration for most of the projects studied was 24 months or less (approximately 90\%) with a few exceptions. 
Two characteristics of projects that we looked in our sample were task complexity and task interdependence. Most of the projects were considered highly complex and highly interdependent by the respondents (Figure 6.4 and Figure 6.5)

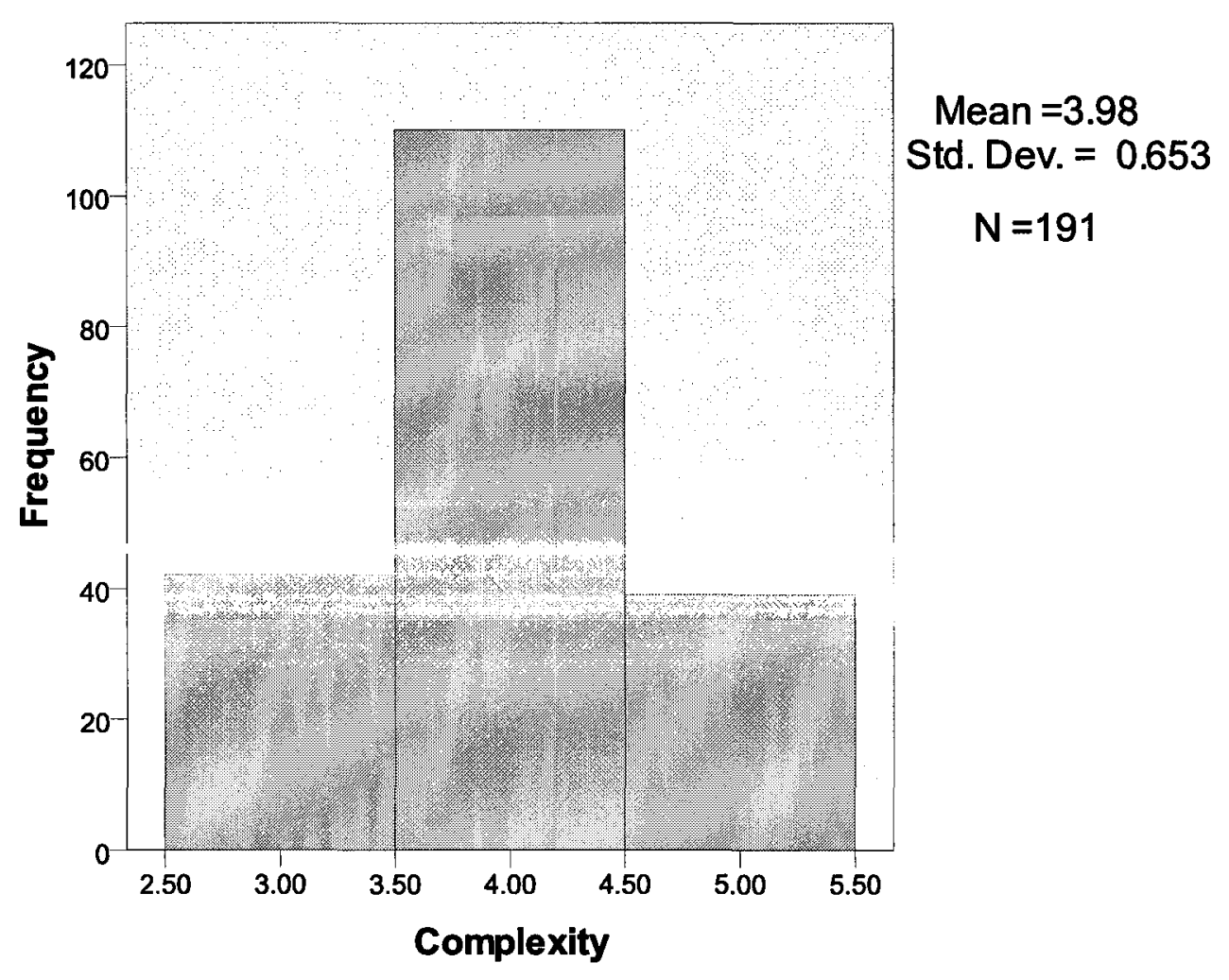

Figure 6-4 Histogram of task complexity

Task complexity histogram shows a near normal distribution and a mean of 3.98 which indicates that most of the projects surveyed were perceived highly complex by the respondents (on a scale of 1 to 5 ). 


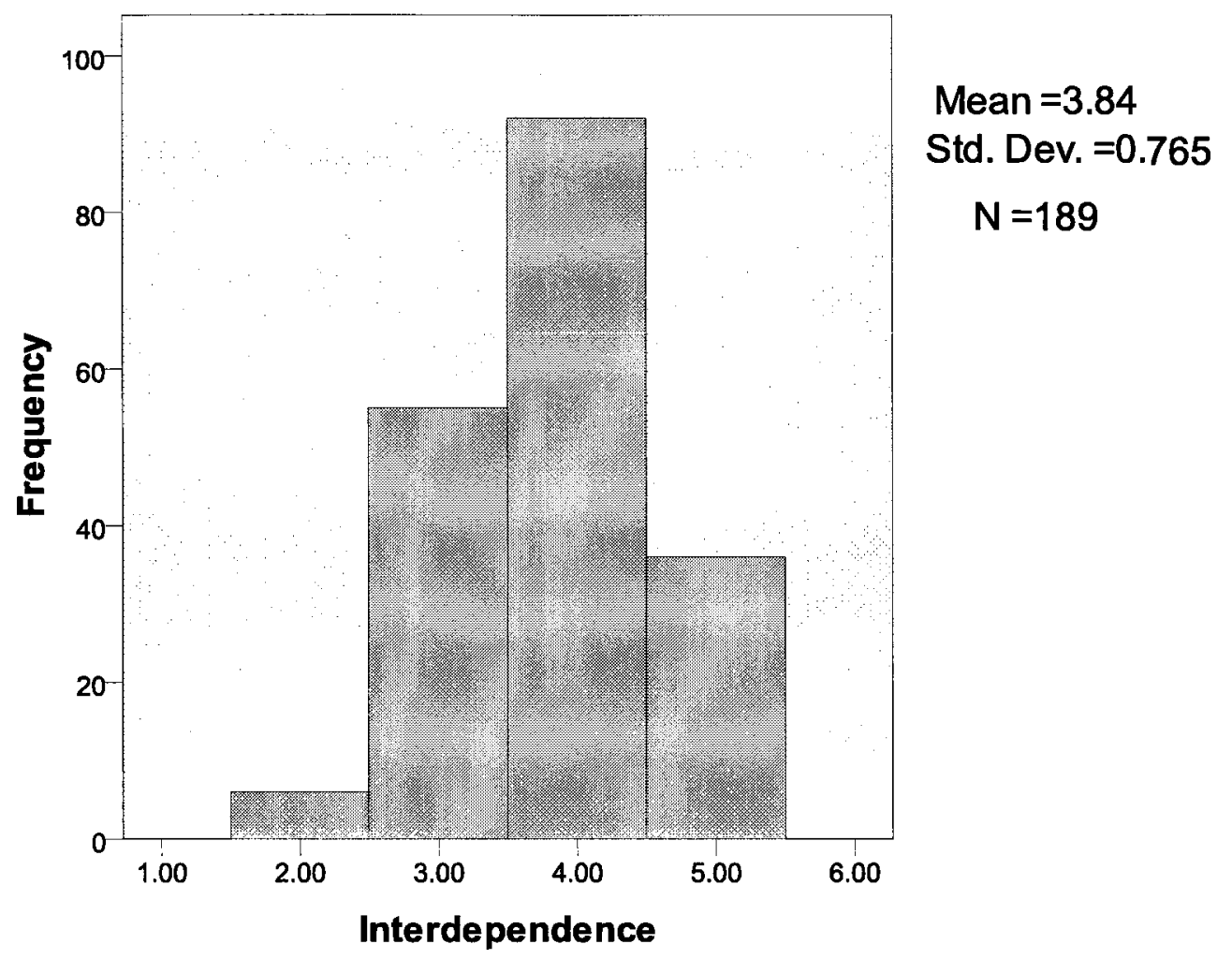

Figure 6-5 Histogram of task interdependence

Task interdependence histogram shows a near normal distribution and a mean of 3.84 indicates that most of the projects surveyed were perceived highly interdependent by the respondents (on a scale of 1 to 5 ).

\subsubsection{Organizational factors}

We looked at four organizational factors of centralization, formalization, incentives and reward systems, and specialization in our research. Since these factors are at the organizational level we considered them as moderating variables affecting the relationship between the fit and performance. 


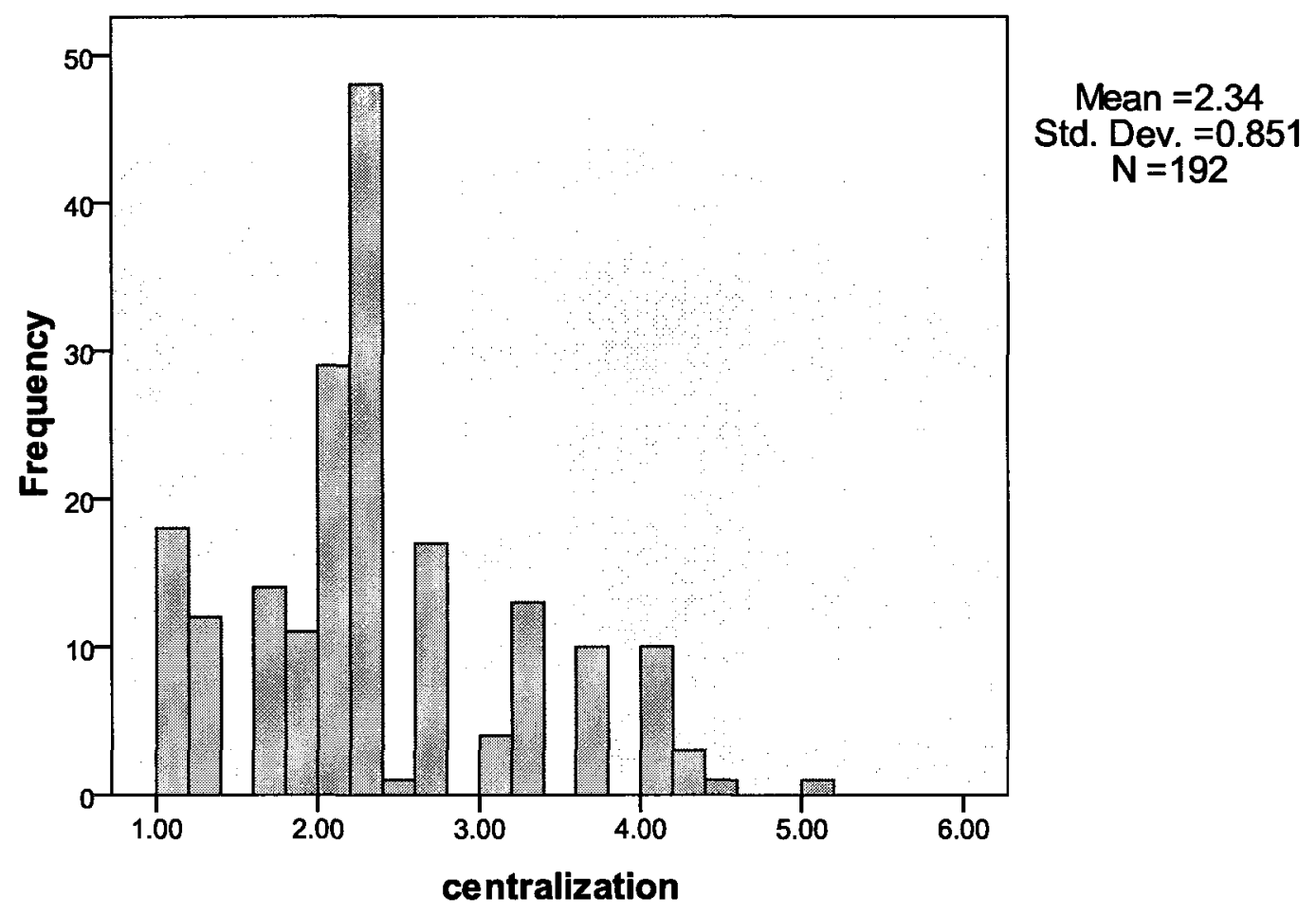

Figure 6-6 Histogram of centralization

Figure 6.6 shows the distribution of the dataset based on the level of centralization in the organization in which the team was operating, as perceived by the respondents (on a scale of 1 to $5)$. 


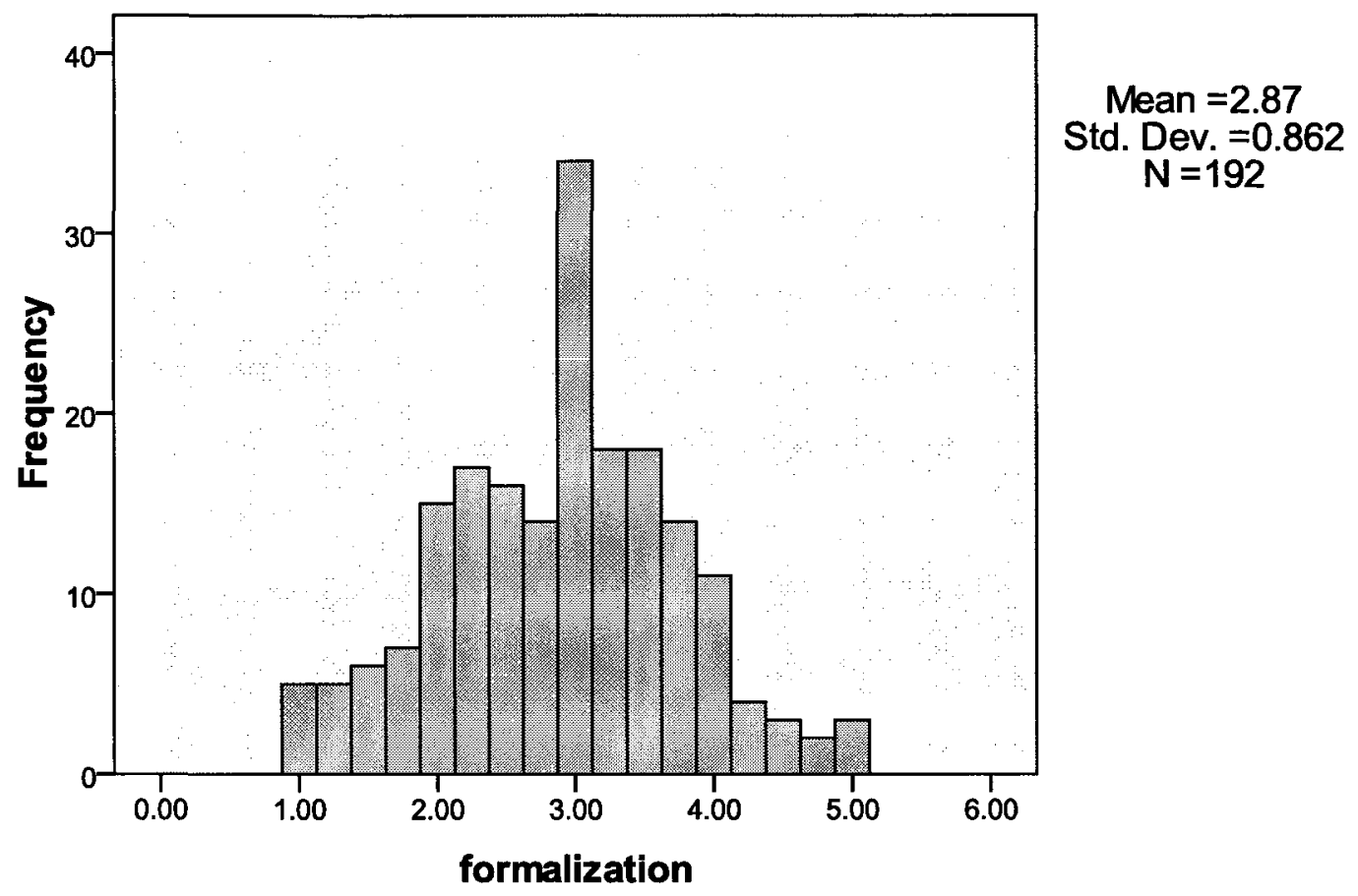

Figure 6-7 Histogram of formalization

Figure 6.7 shows the distribution of the dataset based on the level of formalization in the organization in which the team was operating, as perceived by the respondents (on a scale of 1 to 5). 


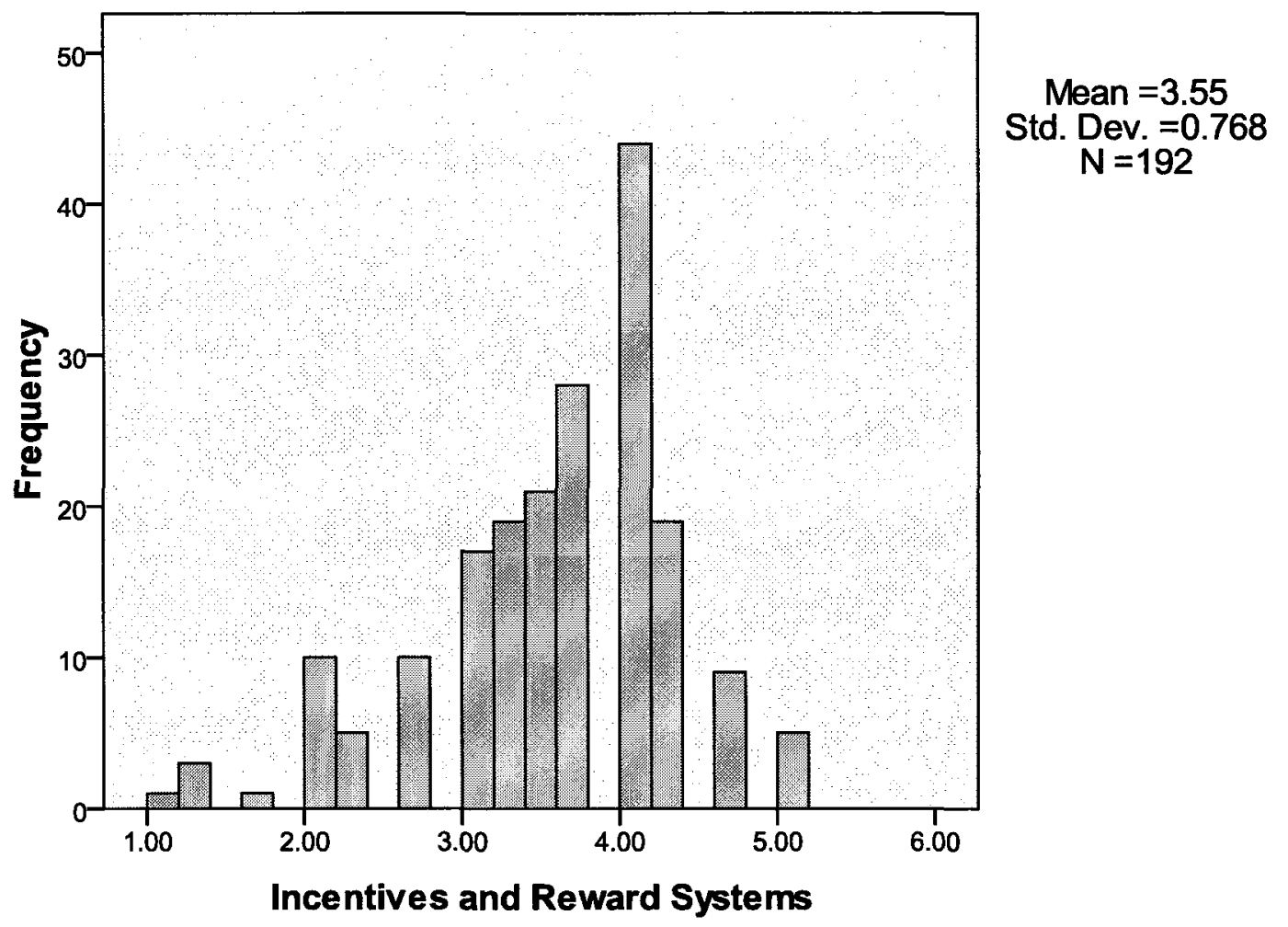

Figure 6-8 Histogram of incentives and reward systems

Figure 6.8 shows the distribution of the dataset based on the presence of incentives and reward systems in the organization in which the team was operating, as perceived by the respondents (on a scale of 1 to 5). 


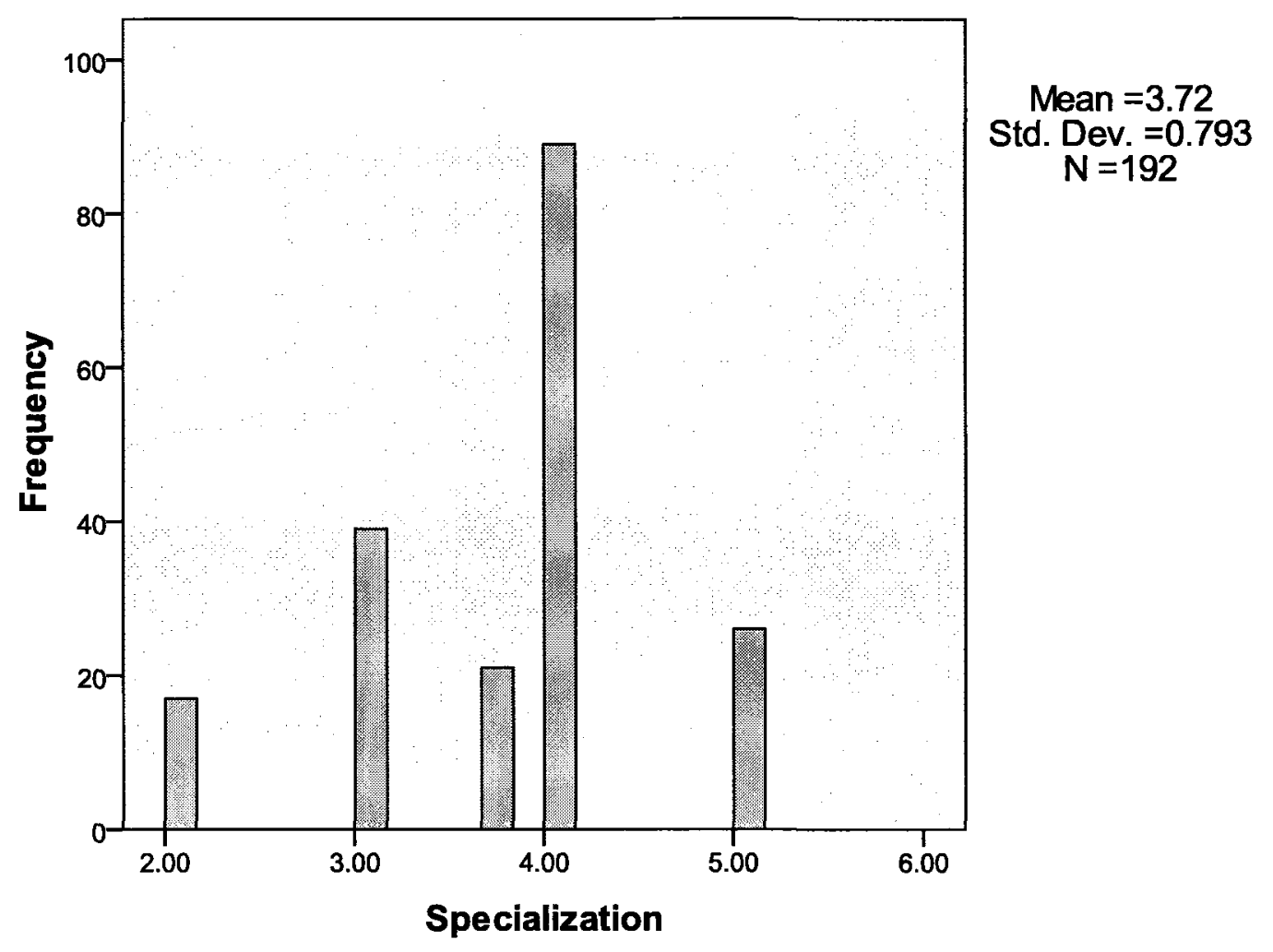

Figure 6-9 Histogram of specialization

Figure 6.9 shows the distribution of the dataset based on the level of specialization in the organization in which the team was operating, as perceived by the respondents (on a scale of 1 to $5)$.

\subsection{Preliminary Analysis}

The preliminary analysis section is further divided into two sub-sections. In the first subsection we assess the impact of perceived fit on performance. In the second sub-section results of independent sample t-tests are presented to check for capabilities (social and technical) differences across team size, geographic regions, and within virtual and co-located software development teams. 


\subsubsection{Impact of perceived fit on performance}

A direct question to assess the fit within the team was asked to the respondent. We wanted to see if the respondent perceived the presence of fit within the team. Correlation between the direct measure of fit and product and process performance was assessed to see if the perceived fit had an impact on performance. The results indicate that the perceived fit impacted both product performance and process performance.

Table 6-1 Correlations of perceived fit and performance

\begin{tabular}{|l|l|}
\hline Variable & Fit \\
\hline Fit & 1 \\
\hline Prod & $0.222^{* *}$ \\
\hline Proc & $0.168^{*}$ \\
\hline${ }^{*} \mathrm{p}<0.05$ & \\
$* * \mathrm{p}<0.01$ &
\end{tabular}

\subsubsection{Capabilities differences across team size, region, and between virtual and co-located teams}

An independent sample t-test was conducted to see if there was a difference in the capabilities across the regions. The t-test results revealed (Table 6.2) that there was no difference in social and technical capability across the two different regions i.e. North America (Canada and USA) and India. We interpret that there is no significant difference in capabilities across the two regions. Thus, region specific analysis was not conducted on the data set. 
Table 6-2 Independent samples t-test for capability differences across the two regions

\begin{tabular}{|c|c|c|c|c|c|c|c|c|c|c|c|c|}
\hline & \multicolumn{3}{|c|}{ Group Statistics } & \multicolumn{2}{|c|}{$\begin{array}{c}\text { Levene's } \\
\text { Test for } \\
\text { Equality } \\
\text { of } \\
\text { Variances }\end{array}$} & \multicolumn{7}{|c|}{ t-test for Equality of Means } \\
\hline \multirow{2}{*}{\begin{tabular}{|l} 
Capability \\
\end{tabular}} & \multirow[b]{2}{*}{ Region } & \multirow[b]{2}{*}{$\mathbf{N}$} & \multirow[b]{2}{*}{ Mean } & \multirow[b]{2}{*}{$\mathbf{F}$} & \multirow[b]{2}{*}{\begin{tabular}{|l|} 
Sig. \\
\end{tabular}} & \multirow[b]{2}{*}{$\mathbf{T}$} & \multirow[b]{2}{*}{ Df } & \multirow[b]{2}{*}{$\begin{array}{l}\text { Sig.(2- } \\
\text { tailed) }\end{array}$} & \multirow[b]{2}{*}{$\begin{array}{l}\text { Mean } \\
\text { Diff. }\end{array}$} & \multirow[b]{2}{*}{$\begin{array}{l}\text { Std. } \\
\text { Error } \\
\text { Diff. }\end{array}$} & \multicolumn{2}{|c|}{$\begin{array}{l}\text { 95\% Confidence } \\
\text { Interval } \\
\end{array}$} \\
\hline & & & & & & & & & & & Lower & Upper \\
\hline \multirow[t]{2}{*}{ sc } & India & 57 & 3.65 & \multirow[t]{2}{*}{.360} & \multirow[t]{2}{*}{.549} & \multirow[t]{2}{*}{1.391} & \multirow[t]{2}{*}{190} & \multirow[t]{2}{*}{.166} & \multirow[t]{2}{*}{0.096} & \multirow[t]{2}{*}{0.069} & \multirow[t]{2}{*}{-0.040} & \multirow[t]{2}{*}{0.232} \\
\hline & $\begin{array}{r}\text { North } \\
\text { America } \\
\end{array}$ & 135 & 3.75 & & & & & & & & & \\
\hline \multirow[t]{2}{*}{ to } & India & 57 & 3.80 & \multirow[t]{2}{*}{.449} & \multirow[t]{2}{*}{.504} & \multirow[t]{2}{*}{-.888} & \multirow[t]{2}{*}{190} & \multirow[t]{2}{*}{.376} & \multirow[t]{2}{*}{-0.073} & \multirow[t]{2}{*}{0.082} & \multirow[t]{2}{*}{-0.236} & \multirow[t]{2}{*}{0.0895} \\
\hline & $\begin{array}{r}\text { North } \\
\text { America }\end{array}$ & 135 & 3.73 & & & & & & & & & \\
\hline
\end{tabular}

We conducted an independent sample t-test to see if there was a difference in the capabilities across virtual teams (teams that had members located in more than one place) and co-located teams. The results of the t-test revealed (Table 6.3) that there was no difference in social and technical capability across the two teams, i.e. virtual teams and co-located teams. We interpret that there is no significant difference in capabilities across virtual and co-located teams. Thus, team location specific analysis was not conducted on the data set. 
Table 6-3 Independent sample test for capability differences across virtual and co-located teams

\begin{tabular}{|c|c|c|c|c|c|c|c|c|c|c|c|c|}
\hline & \multicolumn{3}{|c|}{ Group Statistics } & \multicolumn{2}{|c|}{$\begin{array}{c}\text { Levene's } \\
\text { Test for } \\
\text { Equality of } \\
\text { Variances }\end{array}$} & \multicolumn{7}{|c|}{ t-test for Equality of Means } \\
\hline \multirow[b]{2}{*}{ Capability } & \multirow[b]{2}{*}{$\begin{array}{l}\text { Virtual } \\
\text { Team }\end{array}$} & \multirow[b]{2}{*}{$\mathbf{N}$} & \multirow[b]{2}{*}{ Mean } & \multirow[b]{2}{*}{$\mathbf{F}$} & \multirow[b]{2}{*}{ Sig. } & \multirow[b]{2}{*}{$\mathbf{T}$} & \multirow[b]{2}{*}{ Df } & \multirow[b]{2}{*}{$\begin{array}{l}\text { Sig.(2- } \\
\text { tailed) }\end{array}$} & \multirow[b]{2}{*}{$\begin{array}{l}\text { Mean } \\
\text { Diff. }\end{array}$} & \multirow[b]{2}{*}{$\begin{array}{l}\text { Std. } \\
\text { Error } \\
\text { Diff. } \\
\end{array}$} & \multicolumn{2}{|c|}{$\begin{array}{l}95 \% \\
\text { Confidence } \\
\text { Interval }\end{array}$} \\
\hline & & & & & & & & & & & Lower & Upper \\
\hline \multirow[t]{2}{*}{ sc } & Yes & 117 & 3.69 & \multirow[t]{2}{*}{1.439} & \multirow[t]{2}{*}{0.232} & \multirow[t]{2}{*}{-1.07} & \multirow[t]{2}{*}{190} & \multirow[t]{2}{*}{0.285} & \multirow[t]{2}{*}{-0.069} & \multirow[t]{2}{*}{0.065} & \multirow[t]{2}{*}{-0.197} & \multirow[t]{2}{*}{0.058} \\
\hline & No & 75 & 3.76 & & & & & & & & & \\
\hline \multirow[t]{2}{*}{ tc } & Yes & 117 & 3.80 & \multirow[t]{2}{*}{0.482} & \multirow[t]{2}{*}{0.488} & \multirow[t]{2}{*}{1.738} & \multirow[t]{2}{*}{190} & \multirow[t]{2}{*}{0.084} & \multirow[t]{2}{*}{0.133} & \multirow[t]{2}{*}{0.077} & \multirow[t]{2}{*}{-0.018} & \multirow[t]{2}{*}{0.285} \\
\hline & No & 75 & 3.67 & & & & & & & & & \\
\hline
\end{tabular}

We conducted an independent sample t-test to see if there were differences in social and technical capabilities across large and small teams. Table 6.4 shows that there was a difference in social capability across team size and there was no difference across team size for technical capability. This makes us to believe that team size may act as a moderating variable in our research model. Social capability is related to how team members interact among themselves and team size may play a crucial role in how they interact within a team. Further analysis related to team size as a moderating variable is presented in Chapter 9. 
Table 6-4 Independent samples test for capability differences across team size

\begin{tabular}{|c|c|c|c|c|c|c|c|c|c|c|c|c|}
\hline \multirow[b]{3}{*}{ Capability } & \multirow{2}{*}{\multicolumn{3}{|c|}{ Group Statistics }} & \multicolumn{2}{|c|}{$\begin{array}{c}\text { Levene's } \\
\text { Test for } \\
\text { Equality of } \\
\text { Variances }\end{array}$} & \multicolumn{7}{|c|}{ t-test for Equality of Means } \\
\hline & & & & \multirow[b]{2}{*}{$\mathbf{F}$} & \multirow[b]{2}{*}{ Sig. } & \multirow[b]{2}{*}{$\mathbf{T}$} & \multirow[b]{2}{*}{ Df } & \multirow[b]{2}{*}{$\begin{array}{l}\text { Sig.(2- } \\
\text { tailed) }\end{array}$} & \multirow[b]{2}{*}{$\begin{array}{l}\text { Mean } \\
\text { Diff. }\end{array}$} & \multirow[b]{2}{*}{$\begin{array}{l}\text { Std. } \\
\text { Error } \\
\text { Diff. } \\
\end{array}$} & \multicolumn{2}{|c|}{$\begin{array}{l}95 \% \\
\text { Confidence } \\
\text { Interval }\end{array}$} \\
\hline & $\begin{array}{l}\text { Team } \\
\text { Size }\end{array}$ & $\mathbf{N}$ & Mean & & & & & & & & Lower & Upper \\
\hline \multirow[t]{2}{*}{ sc } & Large & 80 & 3.633 & \multirow[t]{2}{*}{0.014} & \multirow[t]{2}{*}{0.905} & \multirow[t]{2}{*}{-2.42} & \multirow[t]{2}{*}{190} & \multirow[t]{2}{*}{0.016} & \multirow[t]{2}{*}{-0.153} & \multirow[t]{2}{*}{0.063} & \multirow[t]{2}{*}{-0.278} & \multirow[t]{2}{*}{-0.028} \\
\hline & Small & 112 & 3.786 & & & & & & & & & \\
\hline \multirow[t]{2}{*}{ tc } & Large & 80 & 3.825 & \multirow[t]{2}{*}{1.816} & \multirow[t]{2}{*}{0.179} & \multirow[t]{2}{*}{1.644} & \multirow[t]{2}{*}{190} & \multirow[t]{2}{*}{0.102} & \multirow[t]{2}{*}{0.125} & \multirow[t]{2}{*}{0.076} & \multirow[t]{2}{*}{-0.025} & \multirow[t]{2}{*}{0.275} \\
\hline & Small & 112 & 3.670 & & & & & & & & & \\
\hline
\end{tabular}

In summary, this chapter provided the details about how the data can be described in terms of team size, software type, project duration, task interdependence, and task complexity. It also provided some insights into the presence of organizational factors such as centralization, formalization, and specialization in the data set. T-test results indicated that other than team size none of the other factors such as team location and geographic dispersion played a role in capability differences across the data set. 


\section{Chapter 7 Analysis using Structural Equation Modeling}

In this chapter we introduce the technique of structural equation modeling (SEM). The steps in validating a measure, which is the starting point in SEM analysis, are discussed along with the results. Finally, structural model without the fit term is tested.

\subsection{Introduction about SEM}

SEM is a second generation multivariate analysis technique. It allows the researcher to test the relationships among multiple predictor (independent) variables and criterion (dependent) variables. This helps in advancing our understanding of the complex relationships that exists among the constructs of interest. SEM models consist of structural models and confirmatory factor models. Analysis involves developing measurement models to define latent variables, commonly called, confirmatory factor analysis (CFA) and then establishing relationships or structural paths among the latent variables (independent and dependent). Measurement models relate constructs to their measures and structural model relates constructs to each other. "Proper specification of the measurement model is needed before meaning can be assigned to the analysis of the structural model" (Anderson and Gerbing, 1982, pg. 453). This is the reason for first running the measurement model and then running the structural model in SEM analysis. Early development of this technique is credited to Karl Jöreskog (1973) who developed LISREL, one of the software packages that is used to test the models using SEM techniques.

Use of this technique in management research and IS research in particular, has increased over the last decade with number of researchers using SEM techniques to test their models (e.g., Sabherwal and Fernandez, 2003; Agarwal and Karahanna, 2000; Chin et al., 1997). This 
technique provides greater flexibility as compared to other analytical techniques such as multiple regression and factor analysis in playing with theory and data (Anderson and Gerbing, 1988; Ping, 2004). In SEM the unobserved/latent variables are constructed from the observed/measured variables. SEM techniques take measurement error in account in statistically analyzing data. It allows the researcher to estimate the coefficients within the research/structural model while controlling for the measurement error (Kline, 2005).

We have used SEM to test our research model. LISREL software, version 8.72 was used as the software tool to assist in the model testing process.

\subsection{Measurement Model Assessment}

Validation of measures is the first step in SEM before any data can be analyzed. We followed the guidelines given by Ping (2004) for measure validation. As pointed by Ping (2004), the steps in validating a measure include first establishing its uni-dimensionality using CFA, then testing the reliability, and validity (Figure 7.1). In this section, we first assess the unidimensionality by performing CFA for all our latent variables. We do eight first order CFA for our independent and dependent variables, and we do two second order CFA for social and technical capability constructs. Then, we assess reliability and validity of the various measures. 


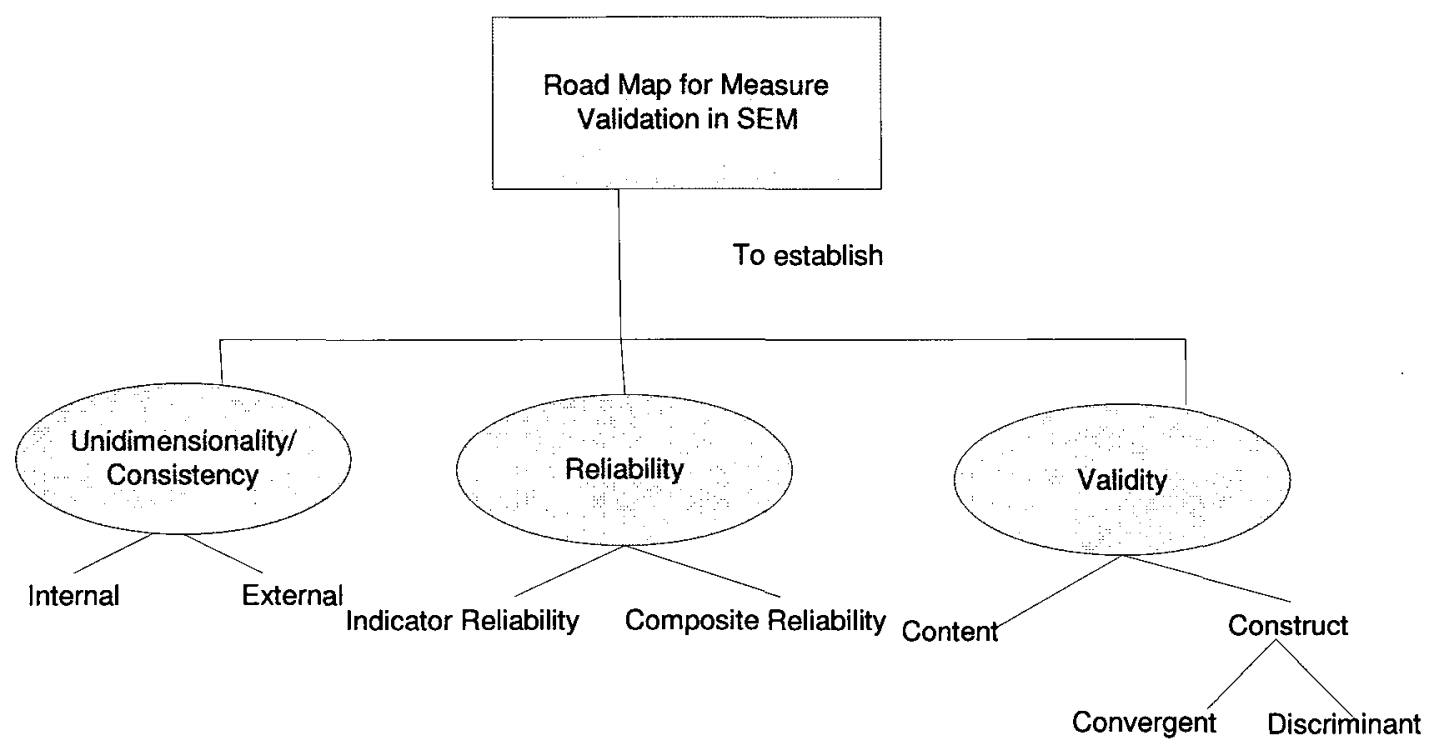

Figure 7-1 Road map for measure validation in SEM

\subsubsection{Assessing uni-dimensionality: First order CFA}

Achieving uni-dimensionality is crucial in theory testing and development and a must for assessing reliability (Anderseon and Gerbing, 1988). Internal and external consistency needs to be established for a construct to be uni-dimensional in nature (Anderson and Gerbing, 1988). CFA assumes internal and external consistency when generating parameter estimates and thus a model fit under CFA can be considered sufficient enough for the underlying construct to be unidimensional (Bollen, 1989).

The underlying construct of interest can be either a first order factor or a second order factor. We did CFA to assess uni-dimensionality of the various constructs. Primary rationale for CFA is to statistically test whether the sample data fits the model. For an acceptable model fit, root mean square error of approximation (RMSEA) values less than 0.08 , normed fit index (NFI), non-normed fit index (NNFI) and comparative fit index (CFI), all model fit indices, 
greater than 0.9 are desirable (Baldwin, 1989). In our model analysis we chose maximum likelihood estimation (MLE) chi-square estimation method.

\section{Communication}

Communication (com) was conceptualized as a uni-dimensional construct, measured using nine items (com1 - com9, see Appendix III for details). The initial measurement model for communication which included all the nine items showed a poor fit to the data (ChiSquare $=94.38, \mathrm{df}=27$, and $\mathrm{RMSEA}=0.114)$.

Further analysis of the modification indices and correlation among the errors, and standardized indicator loadings resulted in removing three indicator variables from the model (com2, com4, com9). com 4 and com 9 had loadings less than 0.4 and com 2 had highly correlated errors with other indicators. The modified model of communication is shown in Figure 7.2. The model shows standardized indicator loadings and measurement errors. The modified model fit indices are Chi-Square=13.52, $\mathrm{df}=9, \mathrm{RMSEA}=0.051, \mathrm{NNFI}=0.99$, and $\mathrm{CFI}=0.99$ ). 


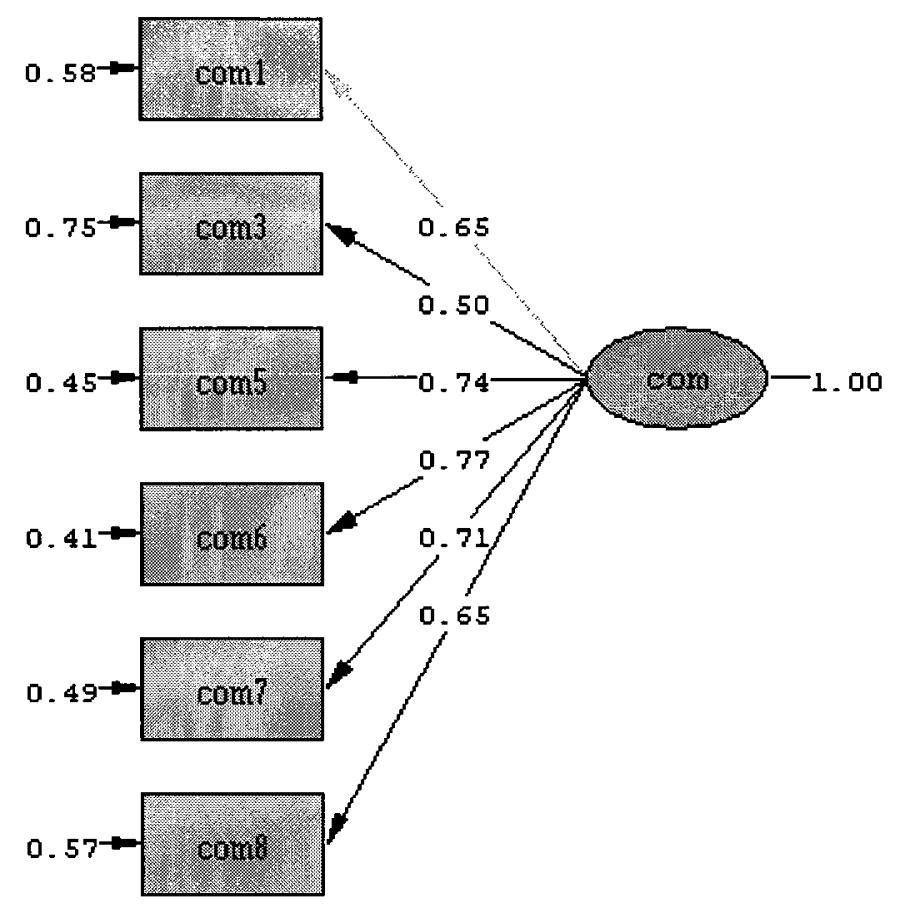

Figure 7-2 Measurement model of communication (com)

\section{Conflict Resolution}

Conflict resolution (cr) was conceptualized as a uni-dimensional construct measured using nine items ( $\mathrm{cr} 1-\mathrm{cr} 9$, see Appendix III for details). The initial measurement model for conflict resolution which included all the nine items showed poor fit to the data (ChiSquare $=111.31, \mathrm{df}=27$, and RMSEA $=0.128$ ).

Further analysis of the modification indices and correlation among the errors, and standardized indicator loadings resulted in removing three indicator variables from the model (cr6, cr8, cr9). cr9 had loading less than 0.4 and cr6 and cr8 had highly correlated errors with other indicators. The modified model of conflict resolution is shown in Figure 7.3. The model 
shows standardized indicator loadings and measurement errors. The modified model fit indices are Chi-Square $=23.72, \mathrm{df}=9, \mathrm{RMSEA}=0.093, \mathrm{NNFI}=0.95$, and $\mathrm{CFI}=0.97$.

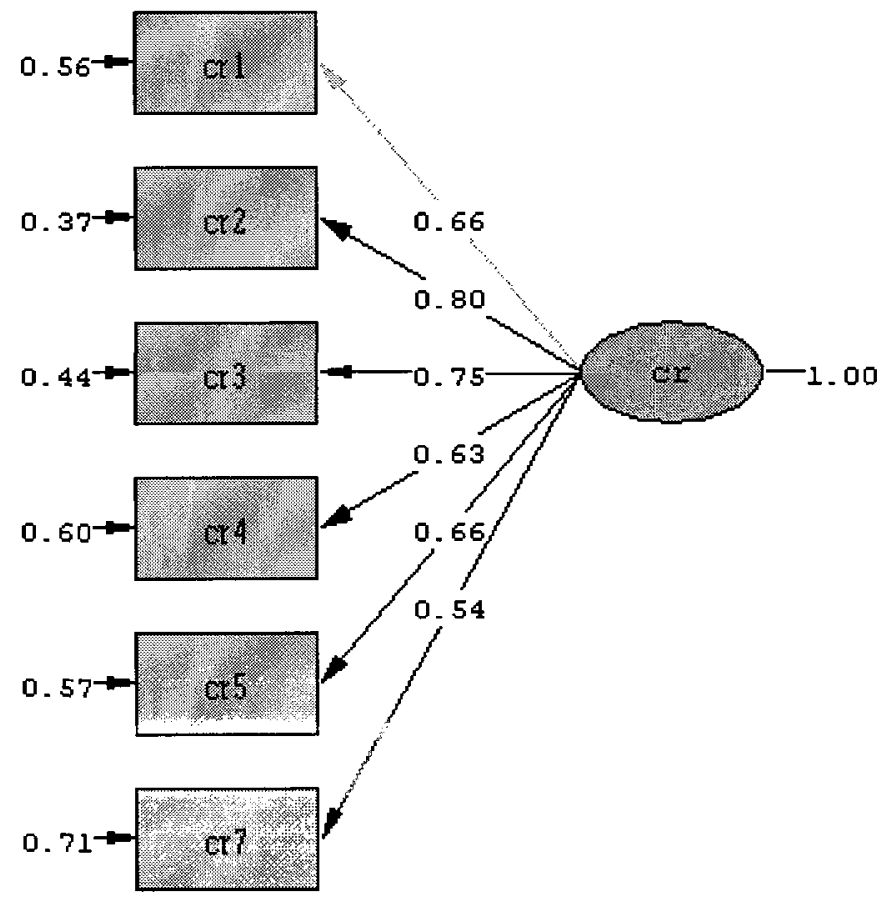

Figure 7-3 Measurement model of conflict resolution (cr)

\section{Supportiveness}

Supportiveness (sup) was conceptualized as a uni-dimensional construct measured using seven items (sup1 - sup7, see Appendix III for details). The initial measurement model for supportiveness which included all the seven items showed poor fit to the data (ChiSquare $=81.62, \mathrm{df}=14$, and $\mathrm{RMSEA}=0.159$ ).

Further analysis of the modification indices and correlation among the errors resulted in removing one indicator variable from the model (sup1). sup1 had highly correlated errors with 
other indicators. The modified model of supportiveness that fits the data is shown in Figure 7.4. The modified model shows standardized indicator loadings and measurement errors. The model fit indices are Chi Square $=19.58, \mathrm{df}=8, \mathrm{RMSEA}=0.087, \mathrm{NNFI}=0.97$, and $\mathrm{CFI}=0.98$.

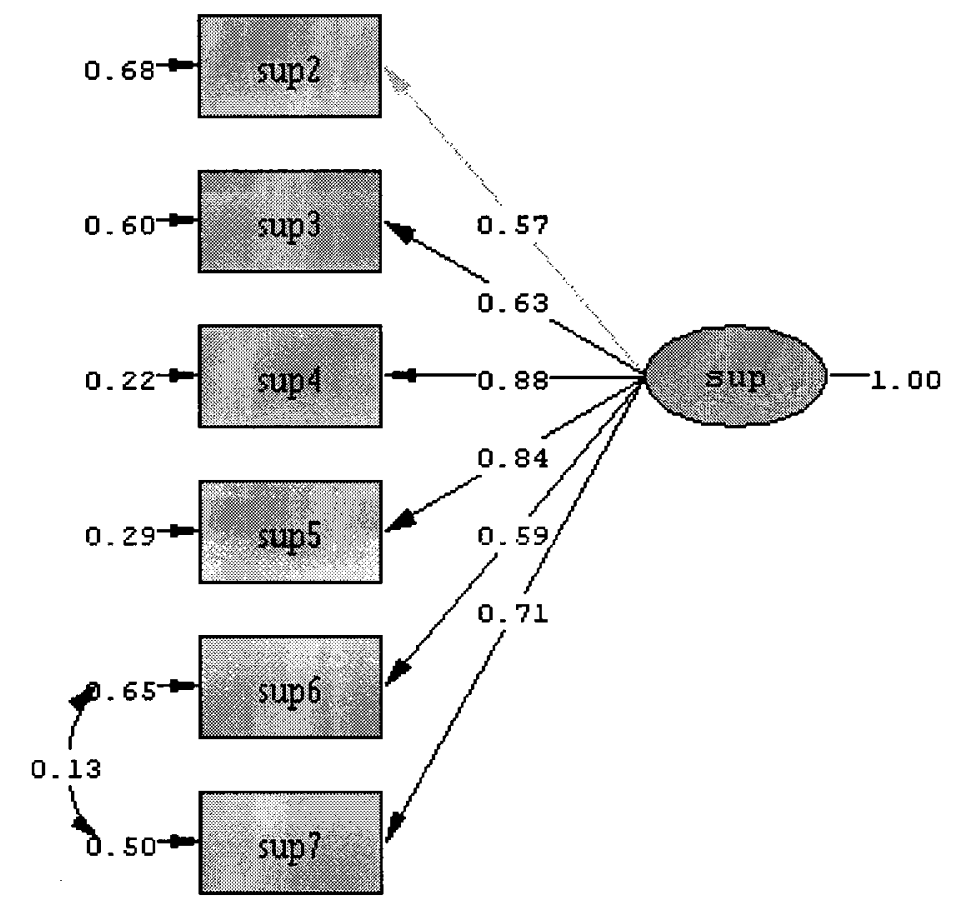

Figure 7-4 Measurement model of supportiveness (sup)

\section{Production Capability}

Production capability (pc) was conceptualized as a uni-dimensional construct, measured using five items (pc1 - pc5, see Appendix III for details). The initial measurement model for production capability which included all the five items showed poor fit to the data (ChiSquare $=55.97, \mathrm{df}=5$, and RMSEA $=0.231$ ). 
Further analysis of the modification indices and correlation among the measurement errors resulted in removing one indicator variable from the model (pc2). pc2 had highly correlated errors with other indicators. The modified model of production capability that fits the data is shown in Figure 7.5. The model shows standardized indicator loadings and measurement errors. The modified model fit indices are Chi-Square $=3.10, \mathrm{df}=2, \mathrm{RMSEA}=0.054, \mathrm{NNFI}=0.99$, and $\mathrm{CFI}=1.00$.

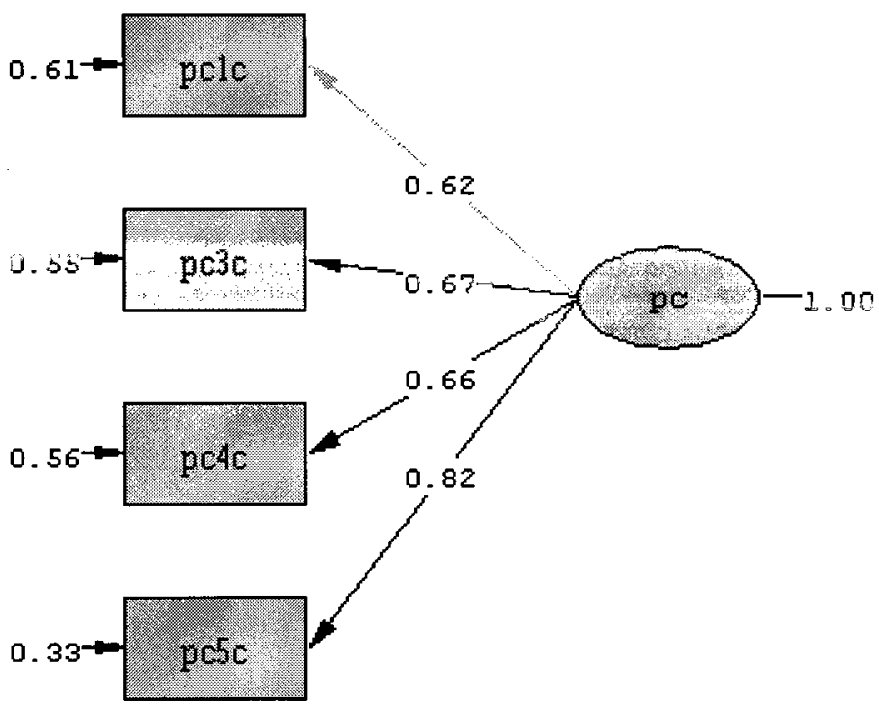

Figure 7-5 Measurement model of production capability (pc)

\section{Control Capability}

Control capability has two dimensions: control by performance and control by standardization. We tested these two dimensions/latent constructs separately. Control 
(performance) capability (cop) was conceptualized as a uni-dimensional construct, measured using five items (cop1 - cop5, see Appendix III for details). The initial measurement model for control (performance) capability which included all the five items showed poor fit to the data (Chi-Square $=47.38, \mathrm{df}=5$, and RMSEA=0.211).

Further analysis of the modification indices and correlation among the errors resulted in removing one indicator variable from the model (cop4). The measurement item cop4 had highly correlated errors with other indicators. The modified model of control (performance) capability that fits the data is shown in Figure 7.6. The model shows standardized indicator loadings and measurement errors. The modified model fit indices are Chi-Square $=3.74, \mathrm{df}=2, \mathrm{RMSEA}=0.067$, $\mathrm{NNFI}=0.98$, and $\mathrm{CFI}=0.99$.

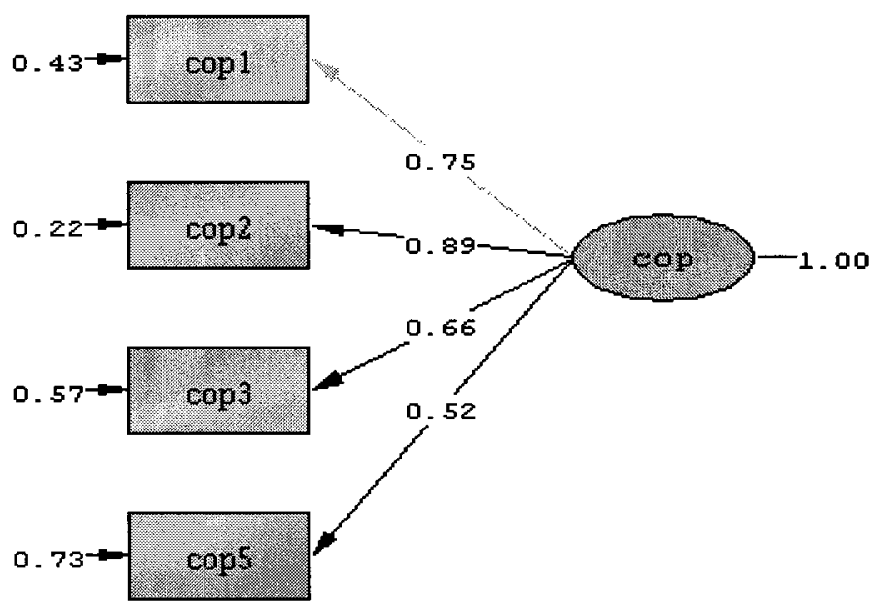

Figure 7-6 Measurement model of control (performance) capability (cop) 
Control (standardization) capability (cos) was conceptualized as a uni-dimensional construct, measured using eight items $(\cos 1-\cos 8$, see Appendix III for details). The initial measurement model for control (standardization) capability which included all the eight items showed poor fit to the data (Chi-Square=122.23, $\mathrm{df}=20$, and $\mathrm{RMSEA}=0.163$ ).

Further analysis of the modification indices and correlation among the errors resulted in removing two indicator variables from the model $(\cos 2$ and $\cos 6) \cdot \cos 2$ and $\cos 6$ had highly correlated errors with other indicators. The modified model of control (standardization) capability that fits the data is shown in Figure 7.7. The model shows standardized indicator loadings and measurement errors. The modified model fit indices are Chi-Square $=17.38, \mathrm{df}=9$, RMSEA $=0.070, \mathrm{NNFI}=0.99, \mathrm{CFI}=0.99$.

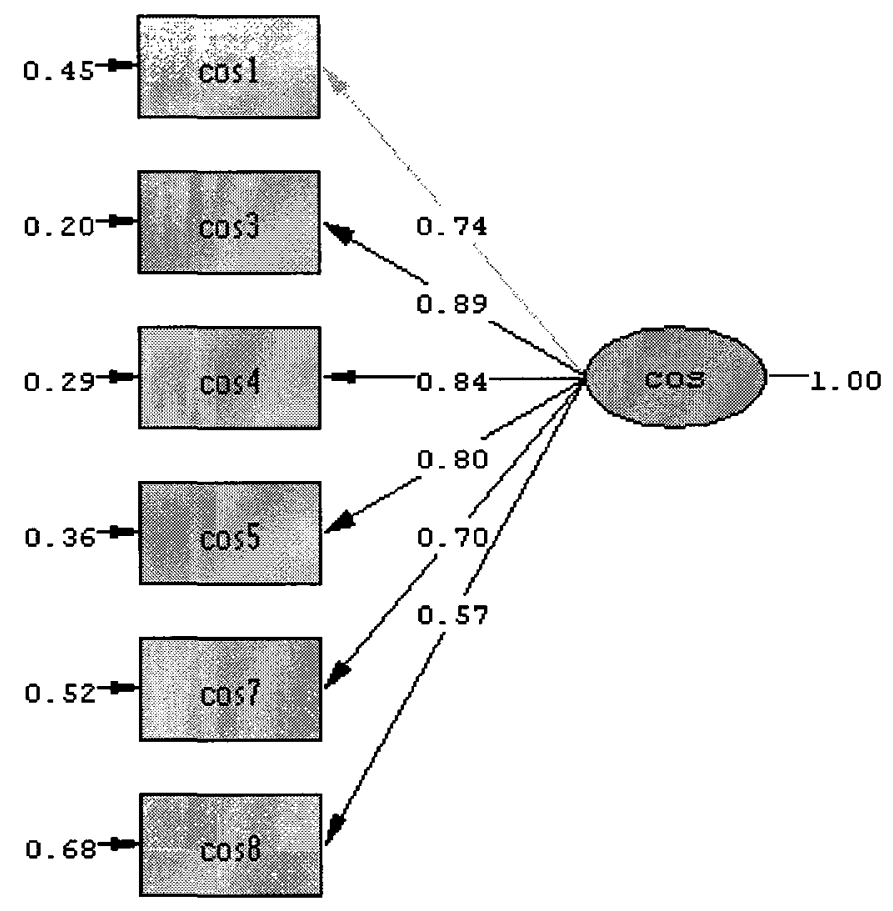

Figure 7-7 Measurement model of control (standardization) capability (cos) 


\section{$\underline{\text { IT Infrastructure Capability }}$}

IT infrastructure capability (it) was conceptualized as a uni-dimensional construct, measured using ten items (it1 - it10, see Appendix III for details). The initial measurement model for IT infrastructure capability which included all the ten items showed poor fit to the data (Chi Square=158.89, df=35, and RMSEA=0.136).

Further analysis of the modification indices and correlation among the errors resulted in removing four indicator variables from the model (it7, it8, it9, and it 10). The measurement items it9 and it10 had standardized loadings less than 0.40 . The measurement items it7 and it8 had highly correlated errors with other indicators. The modified model of IT infrastructure capability that fits the data is shown in Figure 7.8. The model shows standardized indicator loadings and measurement errors. The modified model fit indices are Chi-Square $=20.12, \mathrm{df}=9$, RMSEA $=0.080, \mathrm{NNFI}=0.97$, and $\mathrm{CFI}=0.98$. 


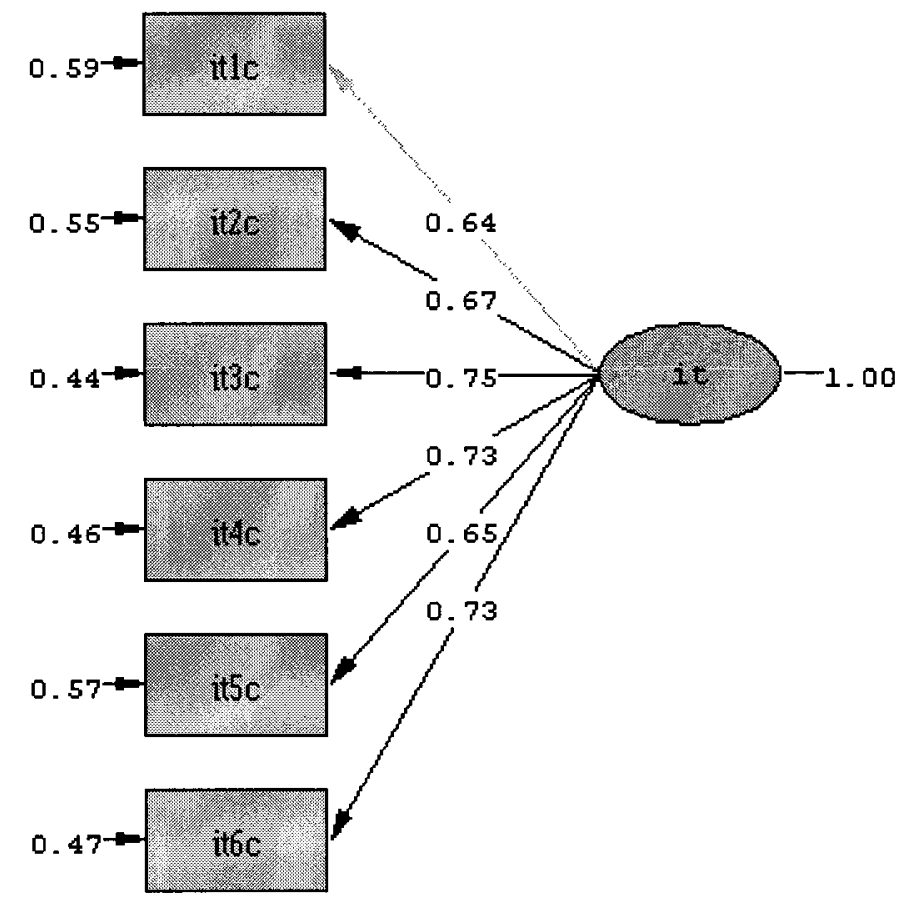

Figure 7-8 Measurement model of IT infrastructure capability (it)

\section{Software Development Team Performance}

Software development team performance was conceptualized as a two-dimensional construct consisting of the following two dimensions: product performance and process performance. We treated both these dimensions as separate constructs and tested them separately in the model. Product performance (prod) was conceptualized as a uni-dimensional construct, measured using six items (prod1 - prod6, see Appendix III for details). The initial measurement model for product performance which included all the six items showed poor fit to the data (Chi-Square $=28.84, \mathrm{df}=9$, and RMSEA=0.107).

Further analysis of the modification indices and correlation among the errors and standardized loadings for the indicators resulted in removing one indicator variable from the 
model (prod5). The measurement item prod5 had standardized loading less than 0.40 . The modified model of product performance that fits the data is shown in Figure 7.9. The model shows standardized indicator loadings and measurement errors. The modified model fit indices are Chi-Square=11.33, $\mathrm{df}=5, \mathrm{RMSEA}=0.081, \mathrm{NNFI}=0.97$, and $\mathrm{CFI}=0.98$.

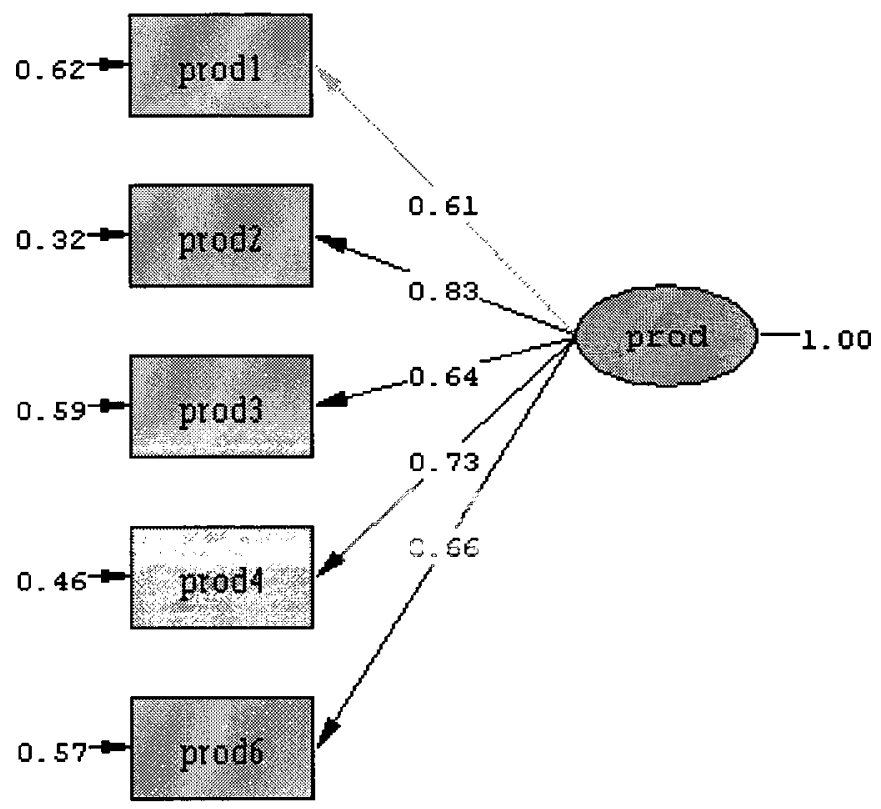

Figure 7-9 Measurement model of product performance (prod)

Process performance (proc) was measured using two items (proc1 and proc2, see Appendix III for details). Measurement model for process performance could not be estimated as it was under-identified. 
Table 7-1 Summary of modified measurement models

\begin{tabular}{|l|l|l|l|l|l|}
\hline Construct Name & Chi $^{2}$ & df & $\begin{array}{c}\text { P } \\
\text { value }\end{array}$ & RMSEA & \multicolumn{1}{|c|}{ Fit indices } \\
\hline Communication (com) & 13.529 & 9 & $\begin{array}{l}0.1404 \\
3\end{array}$ & 0.051 & $\begin{array}{l}\text { NFI=0.98, } \\
\text { NNFI=0.99, CFI=0.99 }\end{array}$ \\
\hline Conflict Resolution (cr) & 23.729 & 9 & $\begin{array}{l}0.0047 \\
7\end{array}$ & 0.093 & $\begin{array}{l}\text { NFI=0.96, } \\
\text { NNFI=0.95, CFI=0.97 }\end{array}$ \\
\hline Supportiveness (sup) & 19.58 & 8 & $\begin{array}{l}0.0120 \\
3\end{array}$ & 0.087 & $\begin{array}{l}\text { NFI=0.97, } \\
\text { NNFI=0.97, CFI=0.98 }\end{array}$ \\
\hline Production Capability (pc) & 3.10 & 2 & $\begin{array}{l}0.2123 \\
7\end{array}$ & 0.054 & $\begin{array}{l}\text { NFI =0.99 } \\
\text { NNFI=0.99, CFI=1.00 }\end{array}$ \\
\hline $\begin{array}{l}\text { Control (performance) } \\
\text { Capability (cop) }\end{array}$ & 3.74 & 2 & $\begin{array}{l}0.1542 \\
8\end{array}$ & 0.067 & $\begin{array}{l}\text { NFI=0.99, } \\
\text { NNFI=0.98, CFI=0.99 }\end{array}$ \\
\hline $\begin{array}{l}\text { Control (Standardization) } \\
\text { Capability (cos) }\end{array}$ & 17.38 & 9 & $\begin{array}{l}0.0431 \\
4\end{array}$ & 0.070 & $\begin{array}{l}\text { NFI=0.98, } \\
\text { NNFI=0.99, CFI=0.99 }\end{array}$ \\
\hline $\begin{array}{l}\text { IT Infrastructure Capability } \\
\text { (it) }\end{array}$ & 20.12 & 9 & $\begin{array}{l}0.0172 \\
1\end{array}$ & 0.080 & $\begin{array}{l}\text { NFI=0.97, } \\
\text { NNFI=0.97, CFI=0.98 }\end{array}$ \\
\hline Product Performance (prod) & 11.33 & 5 & $\begin{array}{l}0.0451 \\
7\end{array}$ & 0.081 & $\begin{array}{l}\text { NFI=0.97, } \\
\text { NNFI=0.97, CFI=0.98 }\end{array}$ \\
\hline
\end{tabular}

\subsubsection{Assessing uni-dimensionality: Second order CFA}

Several types of constructs exist in social sciences including the first order constructs (the ones discussed in the previous section) and the higher order constructs such as the second order constructs which are less popular in research. Unlike first order constructs where the indicators of the latent variable are the measured items, indicators for second order constructs are the first order latent constructs. Second order constructs basically have first order constructs as their indicators. Inappropriate use of SEM in IS research is a concern cited by many researchers (e.g., Chin, 1998). Researchers have argued that use of second order factor models may provide answers to the problems associated with inappropriate use of first order structure in research studies (Xi and Lee, 2005; Koufteros et al., 2009). 
SEM allows the researcher to combine several related constructs into a higher level of abstraction. There are both statistical and conceptual reasons to combine first order constructs in to higher second order constructs. Researchers have argued that the first order constructs that are highly correlated and make conceptual sense can be considered as reflective indicators for a second order construct (Koufteros et al., 2009). When such first order constructs are entered in the model impacting some dependent variable chances are they all may not show significance and may even show an opposite sign (for path coefficient). The second order construct comes as a rescue but at the same time retains the idiosyncratic nature of the first order constructs. The second order construct becomes the independent variable in the research model. In the study, we tested the second order factor structure for social and technical capability constructs.

\section{Social Capability}

Social capability (sc) was conceptualized as a multi-dimensional/second order construct that characterizes the extent to which the team members communicate, resolve conflicts and are supportive of each other. The three dimensions of social capability derived from the literature are communication, conflict resolution, and supportiveness, which are the first order constructs with measurable indicators. Most researchers agree that these constructs are different. But at the same time we would expect them to be highly correlated. Team members who are highly supportive of each other are able to communicate better and resolve conflicts amicably. Thus, it makes conceptual and statistical sense to combine the three dimensions of communication, conflict resolution, and supportiveness into a second order construct. SEM was used to test and confirm whether these three dimensions were part of the social capability construct using a second order CFA. We used the "total disaggregated second order factor model" as used by Koufteros et al. 
(2009) and coined by Bagozzi and Heatherton (1994). Under this conceptualization, every single measured variable is considered as a reflective indicator for the first order construct and each and every first order construct is considered as a reflective indicator for the second order construct. Based on the methodology given by of Doll et al. (1995), Stewart and Segars (2002) and Koufteros et al. (2009) for testing the second order factor structure; we developed four alternative models for social capability (Table 7.2). Based on the various fit indices conclusions were derived.

Table 7-2 Alternative models for social capability

\begin{tabular}{|l|l|l|l|l|}
\hline $\begin{array}{l}\text { Goodness of fit Statistics } \\
\text { for alternative models } \\
\text { (acceptable values) }\end{array}$ & Model 1 & Model 2 & Model 3 & Model 4 \\
\hline Chi square & 696.22 & 366.82 & 229.17 & 243.93 \\
\hline Chi-square/df (<2) & 5.15 & 3.08 & 1.97 & 1.85 \\
\hline NFI (> 0.9) & 0.87 & 0.90 & 0.94 & 0.94 \\
\hline NNFI (>0.9) & 0.88 & 0.91 & 0.96 & 0.96 \\
\hline CFI (>0.9) & 0.90 & 0.93 & 0.97 & 0.97 \\
\hline RMSEA (<0.08) & 0.148 & 0.104 & 0.071 & 0.067 \\
\hline $\begin{array}{l}\text { Standardized RMR (close } \\
\text { to 0.08) }\end{array}$ & 0.094 & 0.26 & 0.072 & 0.070 \\
\hline
\end{tabular}

The first model (Model 1) was run with the 18 measured items (communication, conflict resolution, and supportiveness) as the reflective indicators of one latent variable of social capability (Appendix VI). The chi-square/df was $>2$ and the other model fit indices indicated a poor fit to the data (Table 7.2). This can be explained by the fact that combining various items from different domains into one first order construct is conceptually and methodologically inappropriate. 
The second model (Model 2) was run with three uncorrelated first order latent constructs of communication, conflict resolution, and supportiveness (see Appendix VI). The chi-square/df was $>2$ and RMSEA and SRMR values indicated a poor model fit to the data (Table 7.2). The poor fit of the model can be explained by the presence of high correlation among the first order latent constructs. This model specification would be a good alternative when the latent first order factors are uncorrelated.

The third model (Model 3) is similar to the Model 2, except that the first order factors or the three latent variables were free to correlate (see Appendix VI). The model fit indices indicated an acceptable fit with chi-square/df $<2$, RMSEA and SRMR $<0.08$, and NFI $>0.90$ (Table 7.2). This model has discriminant validity issues since the factors are highly correlated. When structural model is run with the first order factors that are highly correlated desired results may not be achieved (Koufteros et al., 2009).

Model 4 represents the second order factor model with the three latent variables of communication, conflict resolution, and supportiveness being the first order factors for the second order factor of social capability (Figure 7.10). A second order factor model is not a better fit than a first order factor model (Doll et al., 1994). However, it can be a good alternative in the light of multi-collinearity and discriminant validity issues. The results of a second-order CFA model of social capability showed that all goodness-of-fit indices were above acceptable standards $\quad$ (chi-square $=243.92, \quad \mathrm{df}=132, \quad \mathrm{CFI}=0.97, \quad \mathrm{NNFI}=0.96, \quad \mathrm{RMSEA}=0.067, \quad$ and SRMR=0.07). We can conclude that overall fit of the second order CFA model is satisfactory. We used Model 4 in our structural model for testing the impact of social capability on team performance. 


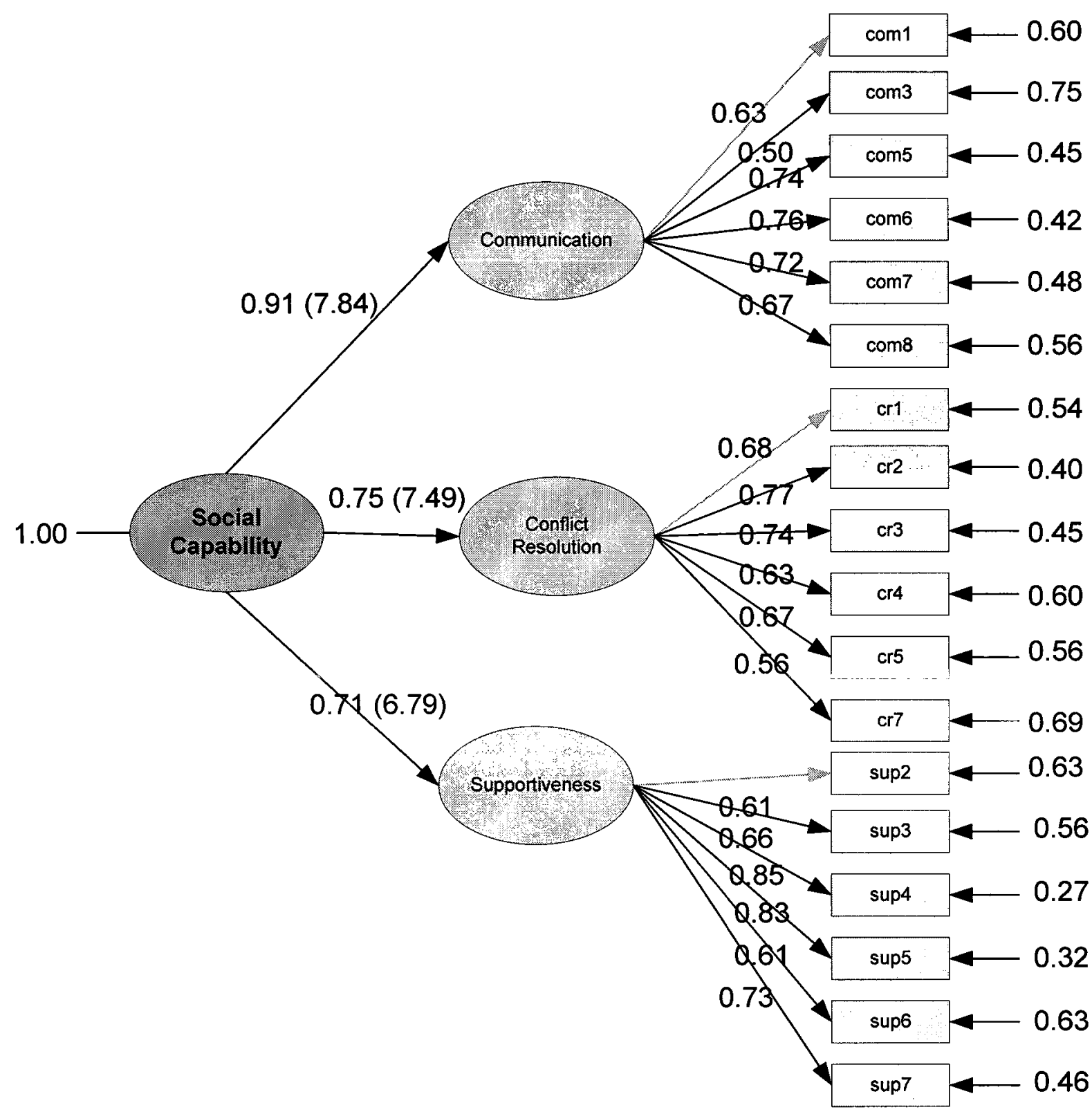

Figure 7-10 Measurement model of social capability (sc)

The justification of a second order factor model can be assessed by calculating the Target (T) coefficient (Marsh and Hocevar, 1985). It is the ratio of the chi-square of the first order model to the chi-square of the higher-order model. 
$\mathrm{T}=\chi^{2}$ (first-order model) $/ \chi 2$ (higher-order model)

Basically, $T$ coefficient signifies the percent of variation in the first-order factors that can be explained by the second-order construct (Doll et al., 1995). This coefficient has an upper limit of 1.0 and a higher number shows the validity of the second order model justifying that the relationship among the first order factors is sufficiently captured by the higher (second) order construct (Stewart and Segars, 2002). The T coefficient between Model 3 and Model 4 was 0.94, which is very high. This means that the second-order factor model of social capability accounts for $94 \%$ for the variance among the three first-order factors.

Lewis et al. (2005) suggested that all the paths between the construct and the underlying factors in the higher order model should have significant $t$-values to provide further supporting evidence of a viable higher order model (say second order factor model). Figure 7.10 shows that the standardized values for the estimates are all significant at the 0.01 level $(t>2.58)$. The standardized loadings (lambdas) of the first-order factors (ranging from 0.5 to 0.85 ) also reach significant levels, which suggest reasonable convergent validity (Jöreskog \& Sörbom, 2001). As shown in Figure 7.10, all the first-order factors load very well onto the second-order factor of social capability (ranging from 0.71 to 0.91 ). The values of the three path coefficients linking social capability to its three dimensions confirm the hypothesized structure of social capability as a second order construct.

\section{Technical Capability}

Technical capability (tc) was conceptualized as a multi-dimensional/second order construct that characterizes the extent to which the team possess production and control capabilities and has the IT infrastructure support to operate smoothly. The four dimensions of technical capability derived from the literature are production capability, control (performance 
and standardization) capability, and IT infrastructure capability, which are the first order constructs with measurable indicators. Most researchers agree that these constructs are different. But at the same time we would expect them to be highly correlated. Thus, it makes conceptual and statistical sense to combine them into a second order construct impacting performance.

SEM was used to test whether the dimensions of production, control, and IT infrastructure capability are part of the technical capability construct using a second order CFA. Similar to the arguments provided in the previous section of social capability, technical capability can be modeled and conceptualized as a second order factor. Every single measured variable is considered as a reflective indicator for the first order construct and each and every first order construct is considered as a reflective indicator for the second order construct. We developed four alternative models for technical capability (Table 7.3). Based on the various fit indices conclusions were derived.

Table 7-3 Alternative models for technical capability

\begin{tabular}{|l|l|l|l|l|}
\hline $\begin{array}{l}\text { Goodness of fit Statistics } \\
\text { for alternative models } \\
\text { (acceptable values) }\end{array}$ & Model 1 & Model 2 & Model 3 & Model 4 \\
\hline Chi-square & 1036.49 & 500.88 & 306.26 & 307.54 \\
\hline Chi-square/df (<2) & 6.1 & 2.94 & 1.87 & 1.85 \\
\hline NFI (>0.9) & 0.81 & 0.89 & 0.93 & 0.92 \\
\hline NNFI (>0.9) & 0.83 & 0.91 & 0.96 & 0.96 \\
\hline CFI (>0.9) & 0.85 & 0.92 & 0.96 & 0.96 \\
\hline RMSEA (<0.08) & 0.163 & 0.101 & 0.067 & 0.067 \\
\hline $\begin{array}{l}\text { Standardized RMR } \\
\text { (close to 0.08) }\end{array}$ & 0.12 & 0.23 & 0.067 & 0.067 \\
\hline
\end{tabular}


The first model (Model 1) was run with the 20 measured items as the reflective indicators of one latent variable of technical capability (See Appendix VII). The chi-square/ df $>2$ and the other model fit indices indicated a poor fit to the data (Table 7.3). This can be explained by the fact that combining various items from different domains into one first order construct is conceptually and methodologically inappropriate.

The second model (Model 2) was run with four uncorrelated first order latent constructs of production, control (performance), control (standardization) and IT infrastructure (see Appendix VII). The chi-square/df was $>2$, and RMSEA and SRMR values indicated a poor model fit to the data (Table 7.3). The poor fit of the model can be explained by the presence of high correlation among the first order latent constructs. This model specification would be a good alternative when the latent first order factors are uncorrelated.

The third model (Model 3) is similar to the Model 2, except that the first order factors or the four latent variables were free to correlate (see Appendix VII). The model fit indices indicated an acceptable fit with chi-square/df $<2$ and RMSEA and SRMR $<0.08$ and NFI is $>$ 0.90 (Table 7.3). This model has discriminant validity issues since the factors are highly correlated. When structural model is run with the first order factors that are highly correlated desired results may not be achieved (Koufteros et al., 2009).

Model 4 represents the second order factor model with the four latent variables of production, control (performance), control (standardization) and IT infrastructure as the first order factors for the second order factor of technical capability. Researchers have indicated that a second order factor model can never be a better fit than a first order factor model (Doll $e t a l$, 1994). However, it can be a good alternative in the light of multi-collinearity and discriminant validity issues. The results of a second-order CFA model of technical capability shows that all 
goodness-of-fit indices were above acceptable standards (chi-square $=307.54, \mathrm{df}=166, \mathrm{CFI}=0.96$, $\mathrm{NNFI}=0.96, \mathrm{RMSEA}=0.067$, and SRMR $=0.07$ ). We can conclude that overall fit of the second order CFA model is satisfactory. We used Model 4 in our structural model for testing the impact of technical capability on team performance.

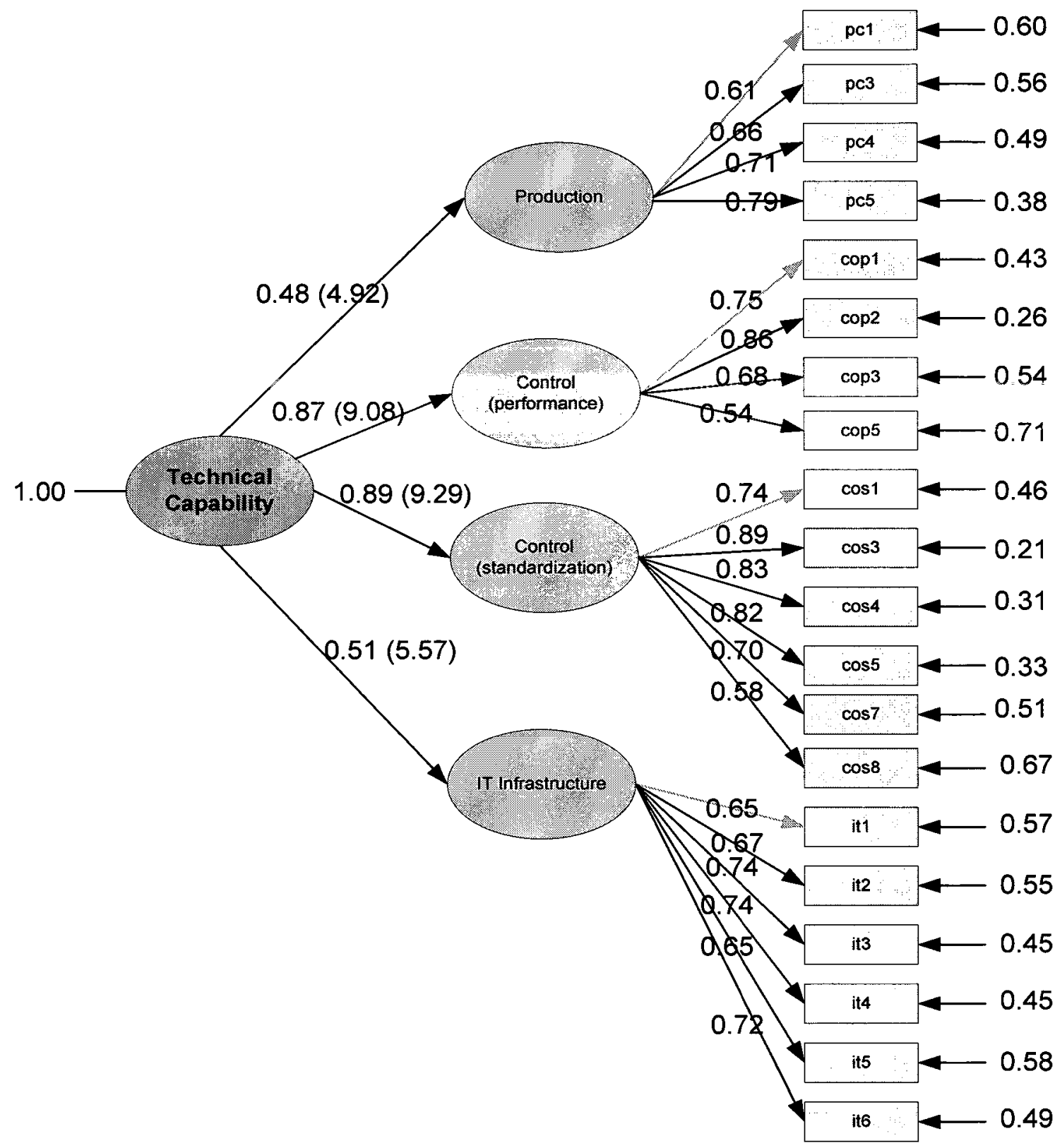

Figure 7-11 Measurement model of technical capability (tc) 
The T coefficient between Model 3 and Model 4 is 0.99 , which is very high. This means that the second-order factor model of technical capability accounts for $99 \%$ for the variance among the four first-order factors. Figure 7.11 shows the standardized values for the estimates. The standardized loadings (lambdas) of the first-order factors (ranging from 0.48 to 0.89 ) also reach significant levels, which suggest reasonable convergent validity (Jöreskog \& Sörbom, 2001). The values of the four path coefficients linking technical capability to its four dimensions confirm the hypothesized structure of technical capability as a second order construct. As shown in Figure 7.11, the path coefficients for the first order constructs (ranging from 0.48 to 0.89 ) are not as high as are in the social capability construct. However, the $\mathrm{T}$ coefficient value is high, suggesting the confirmation of the second order factor structure for technical capability.

\subsubsection{Reliability}

Reliability refers to the extent the construct is stable and is concerned with "the estimates of the degree to which the measurement is free from random or unstable error" (Cooper and Schindler, 1998 p. 171). Cronbach alpha is the most widely used reliability coefficient in management research but recently researchers have raised issues on the use of the cronbach alpha coefficient (Ping, 2003). The coefficient assumes that its items are perfectly correlated with the underlying construct which is an unreasonable assumption to make in practice, which

gives an under-estimated alpha value (Bollen, 1989). For this reason, researchers do not recommend using alpha as the reliability coefficient in SEM. Use of composite reliability is more common in studies that are analyzing data using SEM techniques. Composite reliability includes both the measurement error and the standardized loadings for each item in its calculation which reduces the chances of under-estimation of reliability (Wang et al., 2006). A composite 
reliability of 0.70 or more for the construct is considered acceptable for a scale to be considered reliable (Fornell and Larcker, 1981). We used the formula of composite reliability given by Fornell and Larcker (1981).

In equation (2), $\rho_{\eta}$ indicates composite reliability, $\lambda_{\mathrm{y}}$ is standardized loading, and $\operatorname{Var}\left(\varepsilon_{\mathrm{y}}\right)$ is the variance due to the measurement error. Composite reliability values for all the first order latent variables in the research were above 0.70 (Table 7.4).

$$
\rho_{\eta}=\frac{\left(\sum_{i=1}^{\rho} \lambda_{y i}\right)^{2}}{\left(\sum_{i=1}^{\rho} \lambda_{y i}\right)^{2}+\left(\sum_{i=1}^{\rho} \operatorname{Var}\left(\varepsilon_{i}\right)\right)}
$$


Table 7-4 Reliability statistics of first order constructs

\begin{tabular}{|c|c|c|}
\hline Indicator & $\begin{array}{l}\text { Path } \\
\text { Coefficient }(\lambda)\end{array}$ & $\begin{array}{l}\text { Error } \\
\text { Variance }(\varepsilon)\end{array}$ \\
\hline com1 & 0.65 & 0.58 \\
\hline com3 & 0.5 & 0.75 \\
\hline com5 & 0.74 & 0.45 \\
\hline com6 & 0.77 & 0.41 \\
\hline $\operatorname{com} 7$ & 0.71 & 0.49 \\
\hline com8 & 0.65 & 0.57 \\
\hline \multicolumn{3}{|c|}{$\begin{array}{l}\text { Composite Reliability for communication= } \\
0.832\end{array}$} \\
\hline cr1 & 0.66 & 0.56 \\
\hline cr2 & 0.8 & 0.37 \\
\hline cr3 & 0.75 & 0.44 \\
\hline $\mathrm{cr} 4$ & 0.63 & 0.6 \\
\hline cr5 & 0.66 & 0.56 \\
\hline cr7 & 0.54 & 0.71 \\
\hline \multicolumn{3}{|c|}{$\begin{array}{l}\text { Composite Reliability for conflict resolution = } \\
\mathbf{0 . 8 3 4}\end{array}$} \\
\hline $\operatorname{sup2}$ & 0.57 & 0.68 \\
\hline sup3 & 0.63 & 0.6 \\
\hline sup4 & 0.88 & 0.22 \\
\hline sup5 & 0.84 & 0.29 \\
\hline sup6 & 0.59 & 0.65 \\
\hline $\sup 7$ & 0.71 & 0.5 \\
\hline \multicolumn{3}{|c|}{$\begin{array}{l}\text { Composite Reliability for supportiveness = } \\
0.86\end{array}$} \\
\hline pc1 & 0.62 & 0.61 \\
\hline $\mathrm{pc} 3$ & 0.67 & 0.55 \\
\hline pc4 & 0.66 & 0.56 \\
\hline pc5 & 0.82 & 0.33 \\
\hline \multicolumn{3}{|c|}{ Composite Reliability for production $=0.79$} \\
\hline
\end{tabular}




\begin{tabular}{|c|c|c|}
\hline Indicator & $\begin{array}{l}\text { Path } \\
\text { Coefficient }\end{array}$ & $\begin{array}{l}\text { Error } \\
\text { Variance }\end{array}$ \\
\hline cop1 & 0.75 & 0.43 \\
\hline cop2 & 0.89 & 0.22 \\
\hline cop3 & 0.66 & 0.57 \\
\hline cop5 & 0.52 & 0.73 \\
\hline \multicolumn{3}{|c|}{$\begin{array}{l}\text { Composite Reliability for control } \\
\text { (performance) }=\mathbf{0 . 8 0}\end{array}$} \\
\hline $\cos 1$ & 0.74 & 0.45 \\
\hline $\cos 3$ & 0.89 & 0.2 \\
\hline $\cos 4$ & 0.84 & 0.29 \\
\hline $\cos 5$ & 0.8 & $\overline{0.36}$ \\
\hline $\cos 7$ & 0.7 & 0.52 \\
\hline $\cos 8$ & 0.57 & 0.68 \\
\hline \multicolumn{3}{|c|}{$\begin{array}{l}\text { Composite Reliability for control } \\
\text { (standardization) }=\mathbf{0 . 8 9}\end{array}$} \\
\hline it1 & 0.64 & 0.59 \\
\hline it2 & 0.67 & 0.55 \\
\hline it3 & 0.75 & 0.44 \\
\hline it 4 & 0.73 & 0.46 \\
\hline it5 & 0.65 & 0.57 \\
\hline it6 & 0.73 & 0.47 \\
\hline \multicolumn{3}{|c|}{$\begin{array}{l}\text { Composite Reliability for IT infrastructure = } \\
\mathbf{0 . 8 5}\end{array}$} \\
\hline prod1 & 0.61 & 0.62 \\
\hline prod2 & 0.83 & 0.32 \\
\hline prod3 & 0.64 & 0.59 \\
\hline prod4 & 0.73 & 0.46 \\
\hline prod6 & 0.66 & 0.57 \\
\hline \multicolumn{3}{|c|}{$\begin{array}{l}\text { Composite Reliability for product performance } \\
=0.82\end{array}$} \\
\hline
\end{tabular}

Similarly, we calculated composite reliability for the two second order constructs. Both the values were above 0.70 (Table 7.5). 
Table 7-5 Reliability statistics of second order constructs

\begin{tabular}{|l|l|l|}
\hline Indicator & $\begin{array}{l}\text { Path } \\
\text { Coefficient }(\lambda)\end{array}$ & $\begin{array}{l}\text { Error } \\
\text { Variance ( }(\boldsymbol{)})\end{array}$ \\
\hline Communication & 0.91 & 0.17 \\
\hline $\begin{array}{l}\text { Conflict } \\
\text { resolution }\end{array}$ & 0.75 & 0.44 \\
\hline Supportiveness & 0.71 & 0.49 \\
\hline $\begin{array}{l}\text { Composite reliability of social capability (sc) }= \\
\mathbf{0 . 8 4}\end{array}$ & 0.48 & 0.77 \\
\hline $\begin{array}{l}\text { Production } \\
\text { capability }\end{array}$ & 0.87 & 0.24 \\
\hline $\begin{array}{l}\text { Control } \\
\text { (performance) }\end{array}$ & 0.89 & 0.20 \\
\hline $\begin{array}{l}\text { Control } \\
\text { (standardization) }\end{array}$ & 0.51 & 0.74 \\
\hline IT infrastructure & 0.51 \\
\hline $\begin{array}{l}\text { Composite reliability of technical capability (tc) } \\
=\mathbf{0 . 8 0}\end{array}$ & \\
\hline
\end{tabular}

\subsubsection{Validity}

Validity refers to how well a measure reflects its unobservable construct (Ping, 2004). Testing validity is important because we have measured our theoretical constructs and their relationships indirectly through observed variables. Two types of validity commonly considered important in research studies are content/face validity and construct validity. Content validity for a measure comes from the literature indicating a general agreement in the literature about the items that are measuring the construct i.e. how well the items match their conceptual definition (Nunnally, 1979; Ping, 2004). An exhaustive literature review was conducted and expert opinion was gathered by pre-testing the various scales. Modification, if necessary was done to ensure content validity for all the measures.

Construct validity ensures that the scale is measuring what it is supposed to measure (Davis, 2005). Researchers measure construct validity through convergent and discriminant 
validity. Convergent validity is said to be present when the different measurement tools are in agreement i.e. essentially measuring the same concept (Davis, 2005). Reporting reliability measure as a substitute for convergent validity is a common way in research studies (Ping, 2004). Fornell and Larcker (1981) proposed the use of average variance extracted (AVE), which is the percentage error variance in a measure, to assess convergent validity.

$$
\rho_{\mathrm{vc}(\eta)}=\frac{\left(\sum_{i=1}^{\rho} \lambda^{2}{ }_{y i}\right)}{\left(\sum_{i=1}^{\rho} \lambda^{2}{ }_{y i}\right)+\left(\sum_{i=1}^{\rho} \operatorname{Var}\left(\varepsilon_{i}\right)\right)}
$$

In equation (3), $\rho_{\mathrm{vc}(\mathfrak{\eta})}$ is the AVE for the construct. Together, an adequate convergent validity is attainted when composite reliability is 0.8 or higher and AVE is 0.5 or higher (Ping, 2004). AVE values for the variables were reasonably close to the desired value of 0.50 and AVE values for social and technical capability were well above the limit (Table 7.6).

Table 7-6 Average variance extracted (AVE)

\begin{tabular}{|l|l|}
\hline Construct & AVE \\
\hline Communication & 0.46 \\
\hline Conflict resolution & 0.46 \\
\hline Supportiveness & 0.51 \\
\hline Social capability & 0.63 \\
\hline Production capability & 0.49 \\
\hline Control (performance) capability & 0.51 \\
\hline Control (standardization) capability & 0.58 \\
\hline IT infrastructure capability & 0.49 \\
\hline Technical capability & 0.51 \\
\hline Product performance & 0.49 \\
\hline
\end{tabular}


Discriminant validity, opposite of convergent validity, refers to the extent a construct in a research model differs from other constructs in the same model (Churchill, 1979). A low correlation with other measures is commonly used as a substitute for discriminant validity (Ping, 2004). Fornell and Larcker (1981) suggested that the shared variance between any two constructs should be less than the variance extracted by each one of the individual construct. One of the ways to show discriminant validity is to check if the AVE of each construct is greater than the construct correlation between any two constructs (Yang et al., 2008). We assess discriminant validity using this approach (Table 7.7). Discriminant validity is not exhibited in the case of social capability dimensions i.e. between communication, conflict resolution, and supportiveness. This can be attributed to the fact that they are part of the higher order construct of social capability. Sometimes discriminant validity is not supported when the first order constructs/latent variables are highly correlated (Koufteros et al., 2009). This is one of the reasons for us to explore the second order factor structure for social capability. However, discriminant validity is exhibited among the dimensions of social capability and technical capability. Results of discriminant validity are not as clear cut within the technical capability dimensions and more research may be needed to establish a clear structure for technical capability.

In summary, all the constructs and their dimensions in the study, after re-specification, achieved moderate to high level of construct validity. 
Table 7-7 Correlation matrix and average variance extracted (on the diagonal)

\begin{tabular}{|l|l|l|l|l|l|l|l|}
\hline & Com & cr & Sup & Pc & Cop & cos & It \\
\hline Com & $\mathbf{. 4 6}$ & & & & & & \\
\hline Cr & 0.67 &. $\mathbf{4 6}$ & & & & & \\
\hline Sup & 0.65 & 0.53 & .51 & & & & \\
\hline Pc & 0.41 & 0.40 & 0.42 &. $\mathbf{4 9}$ & & & \\
\hline Cop & 0.34 & 0.30 & 0.40 & 0.43 & .51 & & \\
\hline Cos & 0.17 & 0.17 & 0.32 & 0.40 & 0.75 & $\mathbf{. 5 8}$ & \\
\hline It & 0.05 & 0.14 & 0.17 & 0.22 & 0.42 & 0.46 &. $\mathbf{4 9}$ \\
\hline
\end{tabular}

\subsection{Structural Model Assessment of Capabilities on Team Performance}

Once the measurement models were established, structural model was run to statistically test the relationships among the independent and dependent variables. The structural model of the impact of social and technical capability on product and process performance was created by substituting the second order factor measurement model for social and technical capability. Product performance construct was also included in its revised form. LISREL treats the first order latent variables: communication, conflict resolution, supportiveness, production, control (standardization and performance) and IT infrastructure, which are the reflective indicators of the second order constructs of social capability and technical capability as endogenous variables. The dependent variables (product and process performance) are also endogenous variables. One variable can either be an independent variable or a dependent variable but it can't be both at the same time in SEM analysis.

The model was estimated using MLE method and the standardized path coefficients are presented in Figure 7.12. The model fit indices provided an adequate overall fit to the data (Table 7.8). The dotted line in the model indicates non-significant relationship $(\alpha=0.05)$. 


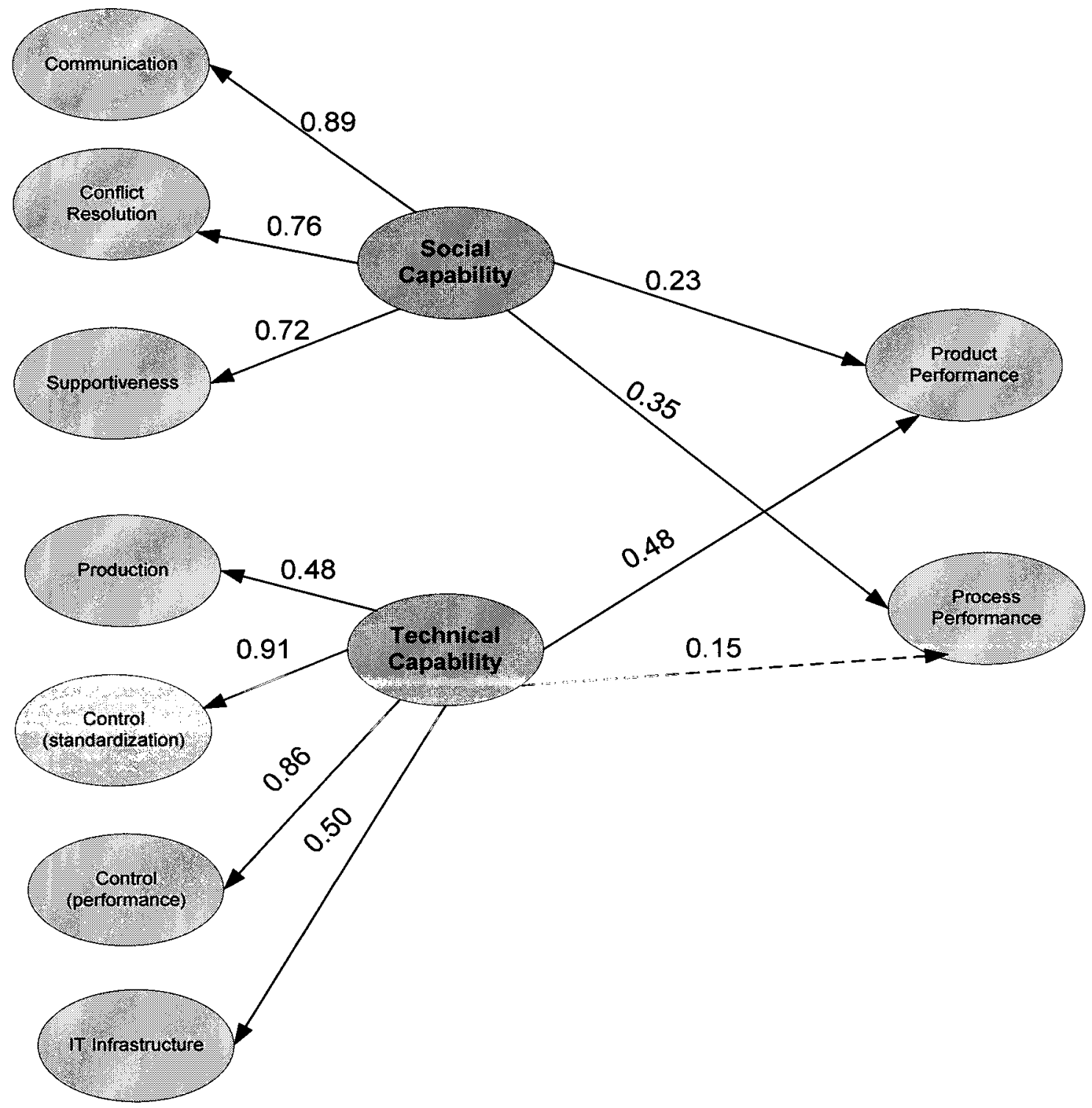

Figure 7-12 Structural model of social and technical capability and performance

Hypothesis 1: Social capability positively influences software development team performance (product and process).

A statistically significant standardized path coefficients from social capability to product and process performance provided support for our hypothesis. The results show that there is a 
significant effect $(0.23)$ between social capability and product performance and significant effect (0.35) between social capability and process performance. Social capability positively influenced product and process performance.

Hypothesis 2: Technical capability positively influences software development team performance (product and process).

A statistically significant standardized path coefficient from technical capability to product performance provided support for our hypothesis (Table 7.8). However, the path coefficient from technical capability to process performance was not found to be significant. The results show that there is a significant effect $(0.48)$ between technical capability and product performance and a non-significant effect $(0.15)$ between technical capability and process performance. The hypothesis was partially supported as technical capability positively influenced product performance but not process performance.

\section{Table 7-8 Models fit indices}

\begin{tabular}{|c|c|c|c|}
\hline $\begin{array}{l}\text { Latent } \\
\text { Variable }\end{array}$ & \begin{tabular}{|l|} 
Product \\
Performance
\end{tabular} & Process Performance & \\
\hline & $\begin{array}{l}\text { Standardized } \\
\text { Coefficients (t- } \\
\text { value) }\end{array}$ & $\begin{array}{l}\text { Standardized } \\
\text { Coefficients (t-values) }\end{array}$ & Model Values \\
\hline $\begin{array}{l}\text { Social } \\
\text { capability }\end{array}$ & $0.23^{*}(2.72)$ & $0.35 *(4.51)$ & \multirow{2}{*}{$\begin{array}{l}\text { Chi-Square }=1343.52, \mathrm{df}=934 \text {, } \\
\text { RMSEA }=0.048, \mathrm{NNFI}=0.95 \text {, } \\
\text { and } C F I=0.95\end{array}$} \\
\hline $\begin{array}{l}\text { Technical } \\
\text { capability }\end{array}$ & $0.48 *(5.11)$ & $0.15(1.95)$ & \\
\hline
\end{tabular}

${ }^{*} \mathrm{p}<0.05$

In summary, this chapter provided details about how measurement models were constructed for the latent variables. Both first order and second order CFA was conducted and results showed that social capability and technical capability can be considered as second order 
constructs. It was also learned that social capability and technical capability positively influenced product performance and only social capability influenced process performance. 


\section{Chapter 8 Measurement of Fit}

The focus of this chapter is to measure fit using the three approaches of moderation, matching, and profile deviation. We used two reductionist approaches (moderation and matching) and one systems approach (profile deviation) to test our hypotheses. We argue that a comparison of the results of the reductionist and systems approaches to measuring fit will be informative. Reductionist approaches assume that a pair-wise analysis of social and technical capability dimensions on performance is possible. These approaches may not be able to detect effects of the overall fit that is present at the holistic or the system level (Van de Ven and Drazin, 1985; Venkataraman, 1989). We used moderation and matching approaches to test the effects of individual/pair-wise fit on performance and the profile deviation approach for testing the effects of the overall fit on performance.

This chapter is divided into three sections. The first section is based on moderation approach to fit measurement. An overview of how moderation is dealt with in SEM is also provided to give readers an idea about the complexity involved in the analysis associated with using the interaction terms in SEM. The second section is based on matching approach to fit measurement and finally, the third section is about the profile deviation approach to fit measurement.

\subsection{Moderation/Interaction}

According to the moderation perspective, commonly called interaction, the fit between the predictor and the moderator is the primary determinant of the criterion variable (Venkataraman, 1989). In simple terms, it is a criterion-specific bivariate perspective, where fit 
is conceptualized as the interaction between two variables. The advantage of this approach is that it captures the individual dimensions (social and technical capability dimensions) in detail. We used moderated SEM (MSEM) technique (Kenny and Judd, 1984; Hayduk, 1988; Ping, 1995) to calculate fit and eventually test its impact on performance.

Researchers over the years have struggled to use non-linear and interaction terms in the modeling process in SEM (Kline and Dunn, 2000). Using interaction terms in SEM is not as simple as using interaction terms in regression (Kenny and Judd, 1984). In regression a simple product of the two interaction terms is calculated and entered in the model. However, in SEM there is a detailed procedure to be followed which will be discussed in the following sub-section. One of the key assumptions of maximum likelihood estimation (MLE) test in SEM is the distribution of multivariate normality in the model. However, when a product term is included in the model this assumption of multivariate normality is violated (Kenny and Judd, 1984). If the interaction term is a product term just multiplying the raw scores of the two variables makes the interaction variable highly correlated with the other two variables. Also the resulting covariance matrix (phi matrix) is singular and is not a positive definite and when the model is run it does not converge (Kline and Dunn, 2000). Researchers have suggested the use of mean centered variables as a solution to avoiding the collinearity problems (Jöreskog and Yang, 1996). In MSEM centering of observed variables prior to calculating the product terms for the latent variables minimizes the relationships between the indicators of the product/interaction term and the indicators of the latent variables. No empirical work suggests that centering is harmful within the MLE method in SEM (Cortina and Dunlap, 2001). We did mean centering for all the latent variables in our research. 
Kenny and Judd (1984) were the first researchers to introduce interaction in SEM. Their method is considered mathematically challenging and too cumbersome if the number of observed variables for the latent variables is large. Much of the difficulty created by the Kenny and Judd (1984) and Hayduk (1988) procedures for MSEM is because of the fact that all possible cross products of the indicators of the latent variables are used as indicators of the latent product variable. As an alternative some authors have suggested single indicators of the latent product variable (Ping, 1995, Jöreskog and Yang, 1996) and some have suggested a reduced number of indicators for the latent product variable (Jaccard and Wan, 1995).

Single indicator product analysis technique proposed by Ping (1995) is used to study the interaction effects in our research model ${ }^{5}$. This technique is mathematically less challenging and can be conducted using LISREL. The next few paragraphs explain the process of calculating the interaction term in a generic sense. The same process was applied to calculate the interaction term when testing all the pair-wise hypotheses.

\subsubsection{Procedure}

Let us consider a model that has four latent variables, with three exogenous variables, $\mathrm{X}$, $\mathrm{Z}$, and $\mathrm{X}^{*} \mathrm{Z}$ (the product of $\mathrm{X}$ and $\mathrm{Z}$ ), and one endogenous variable, $\mathrm{Y}$. It is likely that $\mathrm{X}$ and $\mathrm{Z}$ will covary with one another and with their product. $\mathrm{X}$ has four indicators (X1 to X4) and Z has 3 indicators ( $\mathrm{Z} 1$ to $\mathrm{Z} 3$ ) and $\mathrm{X} * \mathrm{Z}$, which is the interaction term, has one indicator $[(\mathrm{X} 1+\mathrm{X} 2+\mathrm{X} 3$ $\left.+\mathrm{X} 4)^{*}(\mathrm{Z} 1+\mathrm{Z} 2+\mathrm{Z} 3)\right]$

We followed the two step procedure given by Ping (1995) to calculate the effect of the interaction term on the dependent variable. The two step procedure can be coded in SIMPLIS

\footnotetext{
${ }^{5}$ See Cortina and Dunlap, 2001; Li et al., 1998 for details on the various techniques used in MSEM.
} 
(See Appendix $\mathrm{V}$ for SIMPLIS Code for the two step procedure). In the first step the measurement model was run to calculate the starting values for the lambda $(\lambda)$ and theta $(\theta)$ for the interaction term. $\lambda$ is the loading for the path from the latent variable (interaction term) to its indicator. $\theta$ is the error variance for the interaction term. Anderson and Gerbing (1988) pointed that the fixing of certain parameters in the MSEM model is perfectly justified based on the values from the measurement model when the latent variables are uni-dimensional. Unstandardized path coefficients were used in the analysis for calculating the starting values of $\lambda$ and $\theta$. The reason for preferring unstandardized path coefficients has to do with the fact that the variance of the latent product (interaction) term is a function of the variances of the latent main effect variables and their covariance (Cortina and Dunlap, 2001). As such this variance is bound to be different from the variances of the latent main effect variables. The variance of the interaction term in the standardized LISREL solution is always 1 and therefore incorrect. Only the unstandardized value is correct. In the second step, full model with the interaction term along with the starting values for $(\lambda)$ and $(\theta)$ was run.

We tested all the hypotheses one by one for all the interaction terms using this procedure. First, all the hypotheses related to communication and the technical capability dimensions are analyzed. Second, hypotheses related to conflict resolution and the technical capability dimensions are analyzed followed by hypotheses related to supportiveness and the technical capability dimensions. Excel spread sheet which was used to calculate the starting values for all the interaction terms is attached in Appendix $\mathrm{V}^{6}$.

\footnotetext{
${ }^{6}$ The spreadsheet template was downloaded from http://www.wright.edu/ robert.ping/
} 


\subsubsection{Impact of fit between communication and technical capability variables on performance}

We tested the interaction/fit effect of communication with the technical capability variables of production capability, control (performance and standardization) capability, and IT infrastructure capability on product and process performance in this section. We substituted the value of communication for social capability in the original model (Figure 3.5). We used the procedure given by Ping (1995), as described in the previous section, and tested all the four hypotheses. The starting values for all the four interaction terms $\left(\mathrm{com}^{*} \mathrm{pc}, \mathrm{com}^{*} \mathrm{cop}, \mathrm{com}^{*} \mathrm{cos}\right.$, and com*it) are given in Table 8.1.

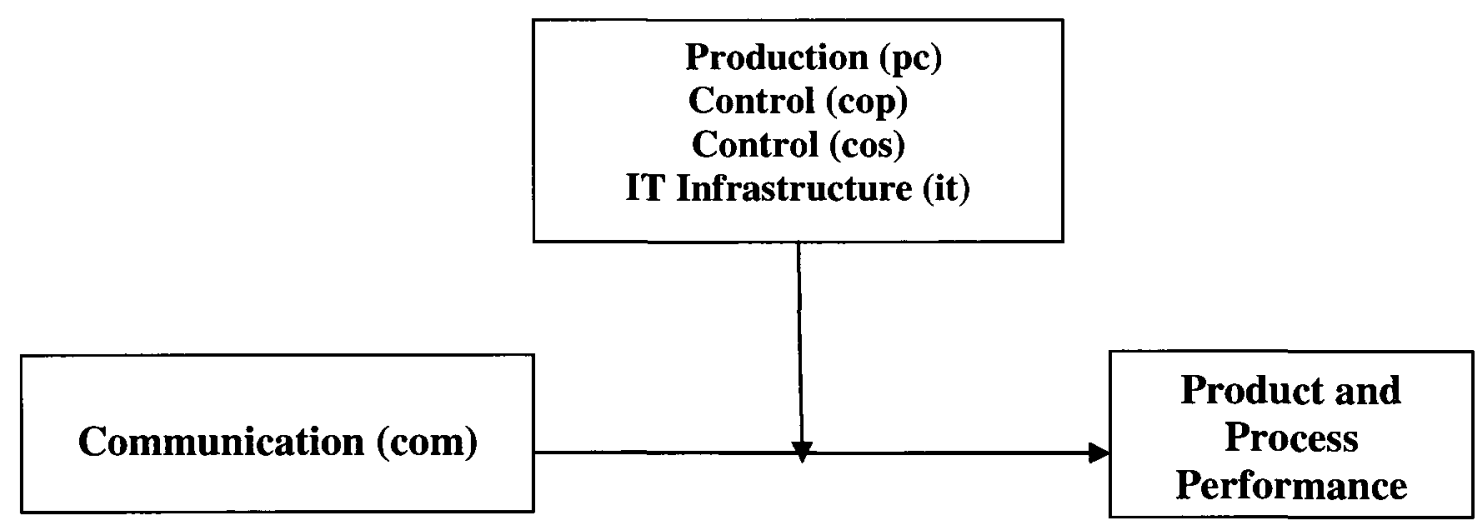

Figure 8-1 Schematic diagram of communication and technical capability dimensions under the moderation approach 
Table 8-1 Interaction term starting values and reliability

\begin{tabular}{|l|l|l|l|}
\hline $\begin{array}{l}\text { Latent Product } \\
\text { Variable }\end{array}$ & Lambda $(\lambda)$ & Theta $(\boldsymbol{\theta})$ & Reliability \\
\hline com* ${ }^{*} \mathrm{cc}$ & 1.26485 & .04195 & .70343 \\
\hline $\operatorname{com}^{*} \operatorname{cop}$ & 1.07767 & .05258 & 0.70041 \\
\hline $\operatorname{com}^{*} \cos$ & 1.00640 & 0.05136 & 0.75066 \\
\hline $\operatorname{com}^{*} \mathrm{it}$ & 1.12030 & 0.04953 & 0.71143 \\
\hline
\end{tabular}

Hypothesis 1Moderation: The interaction between communication and production capability of a software development team influences its performance (product and process).

The structural model of the impact of communication and production capability fit was tested by using communication dimension for social capability and production capability dimension for technical capability. Both constructs were included in the analysis in their revised measurement forms as discussed in section 7.2.1. The model was estimated using MLE method. The model fit indices provided an adequate overall fit to the data (Chi-Square $=185.75, \mathrm{df}=130$, RMSEA $=0.047, \mathrm{NNFI}=0.95$, and $\mathrm{CFI}=0.96$ ).

A statistically significant coefficient for the multiplicative interaction term (com*pc) would support the fit as "interaction" interpretation. The results (Table 8.2) show that there was a significant effect $(0.24)$ between fit and product performance. However, the interaction term was not significant $(0.12)$ for process performance. The hypothesis was partially supported, i.e., communication did make greater contribution to product performance at higher levels of production capability but has no impact on process performance at higher levels of production 
capability. The fit between communication and production capability positively impacted product and product performance.

Table 8-2 Model fit indices for communication and technical capability dimensions

\begin{tabular}{|l|l|l|l|l|l|l|}
\hline $\begin{array}{c}\text { Latent } \\
\text { Variable }\end{array}$ & $\begin{array}{c}|c| \\
\text { Product } \\
\text { Performance }\end{array}$ & \multicolumn{1}{c|}{$\begin{array}{c}\text { Process } \\
\text { Performance }\end{array}$} & \multicolumn{3}{c|}{ Model Fit Indices } \\
\hline & Std. Coefficients & Std. Coefficients & Chi-sqr(df) & RMSEA & NNFI & CFI \\
\hline com* $\mathrm{pc}$ & $0.24^{* *}$ & 0.12 & $185.75(130)$ & 0.047 & 0.95 & 0.96 \\
\hline com*cop & 0.08 & 0.06 & $233.67(130)$ & 0.065 & 0.94 & 0.95 \\
\hline $\operatorname{com}^{*} \cos$ & 0.01 & 0.04 & $248.81(165)$ & 0.052 & 0.96 & 0.96 \\
\hline $\operatorname{com}^{*} \mathrm{it}$ & $0.26^{* *}$ & $0.19 * *$ & $233.57(165)$ & 0.047 & 0.95 & 0.96 \\
\hline$* * \mathrm{p}<0.05$ & & & & & &
\end{tabular}

Hypothesis 2Moderation: The interaction between communication and control (performance) capability of a software development team influences its performance (product and process).

The structural model of the impact of communication and control (performance) capability fit was tested by using communication dimension for social capability and control (performance) capability dimension for technical capability. Both constructs were included in the analysis in their revised measurement forms as discussed in 7.2.1. The model was estimated using MLE method. The model fit indices provided an adequate overall fit to the data (ChiSquare $=233.67, \mathrm{df}=130, \mathrm{RMSEA}=0.065, \mathrm{NNFI}=0.94$, and $\mathrm{CFI}=0.95$ ).

A statistically significant coefficient for the multiplicative interaction term (com*cop) would support the fit as "interaction" interpretation. The results (Table 8.2) show that the interaction term was not significant for product and process performance. The hypothesis was not supported. Communication did not make greater contribution to product performance and 
process performance at higher levels of control (performance) capability. Fit between communication and control (performance) showed no impact on team performance.

Hypothesis 3Moderation: The interaction between communication and control (standardization) capability of a software development team influences its performance (product and process).

The structural model of the impact of communication and control (standardization) capability fit was tested by using communication dimension for social capability and control (standardization) capability dimension for technical capability. Both constructs were included in the analysis in their revised measurement forms as discussed in 7.2.1. The model was estimated using MLE method. The model fit indices provided an adequate overall fit to the data (ChiSquare $=248.81, \mathrm{df}=165, \mathrm{RMSEA}=0.052, \mathrm{NNFI}=0.96$, and $\mathrm{CFI}=0.96$ )

A statistically significant coefficient for the multiplicative interaction term $(\mathrm{com} * \cos )$ would support the fit as "interaction" interpretation. The results (Table 8.2) show that the interaction term was not significant for product and process performance. The hypothesis was not supported. Communication did not make greater contribution to product performance and process performance at higher levels of control (standardization) capability. Fit between communication and control (standardization) showed no impact on team performance.

Hypothesis 4Moderation: The interaction between communication and IT infrastructure capability of a software development team influences its performance (product and process).

The structural model of the impact of communication and IT infrastructure capability fit was tested by using communication dimension for social capability and IT infrastructure capability dimension for technical capability. Both constructs were included in the analysis in 
their revised measurement forms as discussed in 7.2.1. The model was estimated using MLE method. The model fit indices provided an adequate overall fit to the data (Chi-Square=233.57, $\mathrm{df}=165, \mathrm{RMSEA}=0.047, \mathrm{NNFI}=0.95$, and $\mathrm{CFI}=0.96$ ).

A statistically significant coefficient for the multiplicative interaction term (com*it) would support the fit as "interaction" interpretation. The results (Table 8.2) show that there is a significant effect (0.26) between fit and product performance and a significant effect $(0.19)$ between fit and process performance. The hypothesis was supported, i.e., communication did make greater contribution to product and process performance at higher levels of IT infrastructure capability. Fit between communication and IT infrastructure capability positively impacted team performance.

\subsubsection{Impact of fit between conflict resolution and technical capability variables on performance}

We tested the interaction/fit effect of conflict resolution with the technical capability dimensions of production capability, control (performance and standardization) capability, and IT infrastructure capability on product and process performance in this section. We substituted conflict resolution for social capability in the Figure 3.5. The staring values for all the four interaction terms (cr*pc, cr*cop, cr*cos, and cr*it) are given in Table 8.3. 


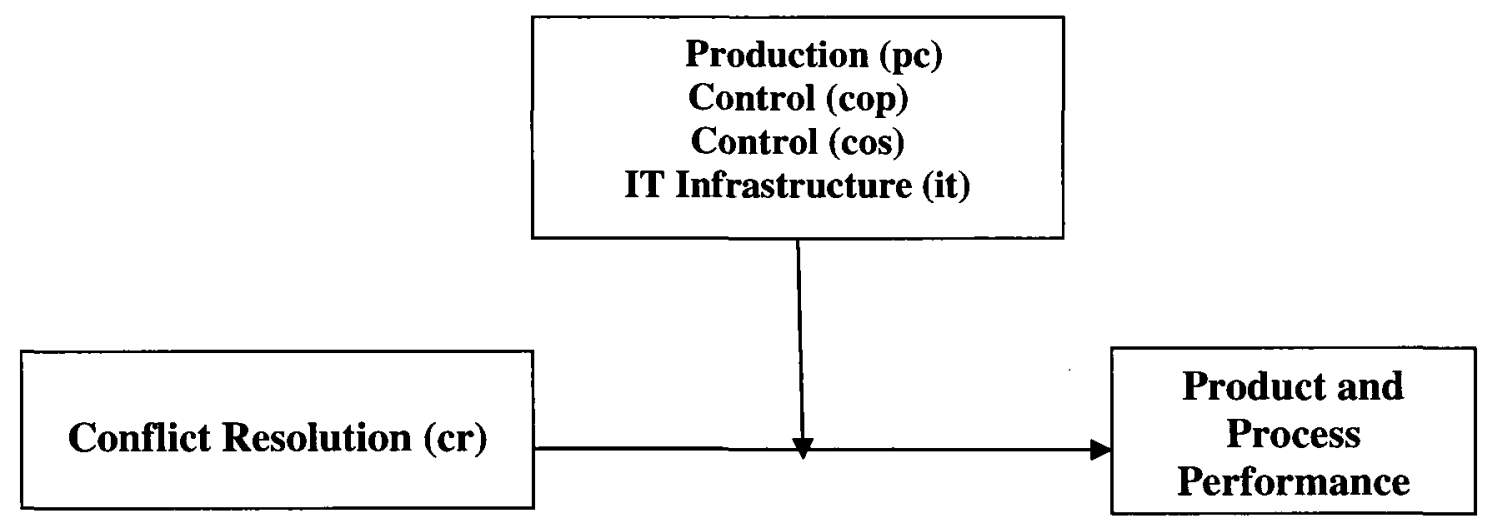

Figure 8-2 Schematic diagram of conflict resolution and technical capability dimensions under the moderation approach

Table 8-3 Interaction term starting values and reliability

\begin{tabular}{|l|l|l|l|}
\hline $\begin{array}{l}\text { Latent Product } \\
\text { Variable }\end{array}$ & Lambda $(\lambda)$ & Theta $(\boldsymbol{\theta})$ & Reliability \\
\hline $\mathrm{cr} * \mathrm{pc}$ & 1.39087 & 0.05018 & 0.70554 \\
\hline $\mathrm{cr} * \mathrm{cop}$ & 1.19280 & 0.06175 & 0.69163 \\
\hline $\mathrm{cr} * \cos$ & 1.11000 & 0.06050 & 0.74997 \\
\hline $\mathrm{cr}^{*} \mathrm{it}$ & 1.23009 & 0.05831 & 0.71092 \\
\hline
\end{tabular}

Hypothesis 5Moderation: The interaction between conflict resolution and production capability of a software development team influences its performance (product and process).

The structural model of the impact of conflict resolution and production capability fit was tested by using conflict resolution dimension for social capability and production capability dimension for technical capability. Both constructs were included in the analysis in their revised measurement forms as discussed in section 7.2.1. The model was estimated using MLE method. The model fit indices provided an adequate overall fit to the data (Chi-Square $=234.88, \mathrm{df}=130$, RMSEA $=0.065, \mathrm{NNFI}=0.94$, and $\mathrm{CFI}=0.95)$. 
A statistically significant coefficient for the multiplicative interaction term (cr*pc) would support the fit as "interaction" interpretation. The results (Table 8.4) show that there was a significant effect $(0.20)$ between fit and product performance. However, the interaction term was not significant $(0.11)$ for process performance. The hypothesis was partially supported, i.e., conflict resolution did make greater contribution to product performance at higher levels of production capability but had no impact on process performance at higher levels of production capability. Fit between conflict resolution and production capability positively impacted product performance.

Table 8-4 Model fit indices for conflict resolution and technical capability dimensions

\begin{tabular}{|l|l|l|l|l|l|l|}
\hline $\begin{array}{c}\text { Latent } \\
\text { Variable }\end{array}$ & \multicolumn{1}{|c|}{$\begin{array}{c}\text { Product } \\
\text { Performance }\end{array}$} & $\begin{array}{l}\text { Process } \\
\text { Performance }\end{array}$ & \multicolumn{4}{|c|}{ Model Fit Indices } \\
\hline & $\begin{array}{l}\text { Std. } \\
\text { Coefficients }\end{array}$ & $\begin{array}{l}\text { Std. } \\
\text { Coefficients }\end{array}$ & Chi-sqr (df) & RMSEA & NNFI & CFI \\
\hline cr*pc & $0.20^{* *}$ & 0.11 & $234.88(130)$ & 0.065 & 0.94 & 0.95 \\
\hline $\mathrm{cr}^{*} \mathrm{cop}$ & 0.07 & 0.01 & $204.03(130)$ & 0.055 & 0.96 & 0.96 \\
\hline $\mathrm{cr}^{*} \cos$ & -0.02 & 0.09 & $225.00(165)$ & 0.044 & 0.97 & 0.98 \\
\hline $\mathrm{cr}^{*}$ it & $0.16^{* *}$ & $0.23^{*}$ & $228.17(165)$ & 0.045 & 0.96 & 0.97 \\
\hline
\end{tabular}

** $p<0.05$

Hypothesis 6Moderation: The interaction between conflict resolution and control (performance) capability of a software development team influences its performance (product and process).

The structural model of the impact of conflict resolution and control (performance) capability fit was tested by using conflict resolution dimension for social capability and control (performance) capability dimension for technical capability. Both constructs were included in the analysis in their revised measurement forms as discussed in 7.2.1. The model was estimated 
using MLE method. The model fit indices provided an adequate overall fit to the data (ChiSquare=204.03, $\mathrm{df}=130, \mathrm{RMSEA}=0.055, \mathrm{NNFI}=0.96$, and $\mathrm{CFI}=0.96$ ).

A statistically significant coefficient for the multiplicative interaction term (cr*cop) would support the fit as "interaction" interpretation. The results (Table 8.4) show that the interaction term was not significant for product and process performance. The hypothesis was not supported. Conflict resolution did not make greater contribution to product performance and process performance at higher levels of control (performance) capability. Fit between conflict resolution and control (performance) showed no impact on team performance.

Hypothesis 7Moderation: The interaction between conflict resolution and control (standardization) capability of a software development team influences its performance (product and process).

The structural model of the impact of conflict resolution and control (standardization) capability fit was tested by using conflict resolution dimension for social capability and control (standardization) capability dimension for technical capability. Both constructs were included in the analysis in their revised measurement forms as discussed in 7.2.1. The model was estimated using MLE method. The model fit indices provided an adequate overall fit to the data (ChiSquare $=225.00, \mathrm{df}=165, \mathrm{RMSEA}=0.044, \mathrm{NNFI}=0.97$, and $\mathrm{CFI}=0.98$ ).

A statistically significant coefficient for the multiplicative interaction term (cr*cos) would support the fit as "interaction" interpretation. The results (Table 8.4) show that the interaction term was not significant for product and process performance. The hypothesis was not supported. Conflict resolution did not make greater contribution to product performance and process performance at higher levels of control (standardization) capability. Fit between conflict resolution and control (standardization) showed no impact on team performance. 
Hypothesis 8Moderation: The interaction between conflict resolution and IT infrastructure capability of a software development team influences its performance (product and process).

The structural model of the impact of conflict resolution and IT infrastructure capability fit was tested by using conflict resolution dimension for social capability and IT infrastructure capability dimension for technical capability. Both constructs were included in the analysis in their revised measurement forms as discussed in 7.2.1. The model was estimated using MLE method. The model fit indices provided an adequate overall fit to the data (Chi-Square $=228.17$, $\mathrm{df}=165, \mathrm{RMSEA}=0.045$, NNFI $=0.96$, and $\mathrm{CFI}=0.97$ ).

A statistically significant coefficient for the multiplicative interaction term (cr*it) would support the fit as "interaction" interpretation. The results (Table 8.4) show that there is a significant effect $(0.16)$ between fit and product performance and a significant effect $(0.23)$ between fit and process performance. The hypothesis was supported, i.e., conflict resolution did make greater contribution to product and process performance at higher levels of IT infrastructure capability. Fit between conflict resolution and IT infrastructure capability positively impacted team performance.

\subsubsection{Impact of fit between supportiveness and technical capability variables on performance}

We test the interaction/fit effect of supportiveness with the technical capability variables of production capability, control (performance and standardization) capability, and IT infrastructure capability on product and process performance in this section. We substituted supportiveness for social capability in the Figure 3.5. The staring values for all the four interaction terms (sup*pc, sup*cop, sup*cos, and sup*it) are given in Table 8.5. 


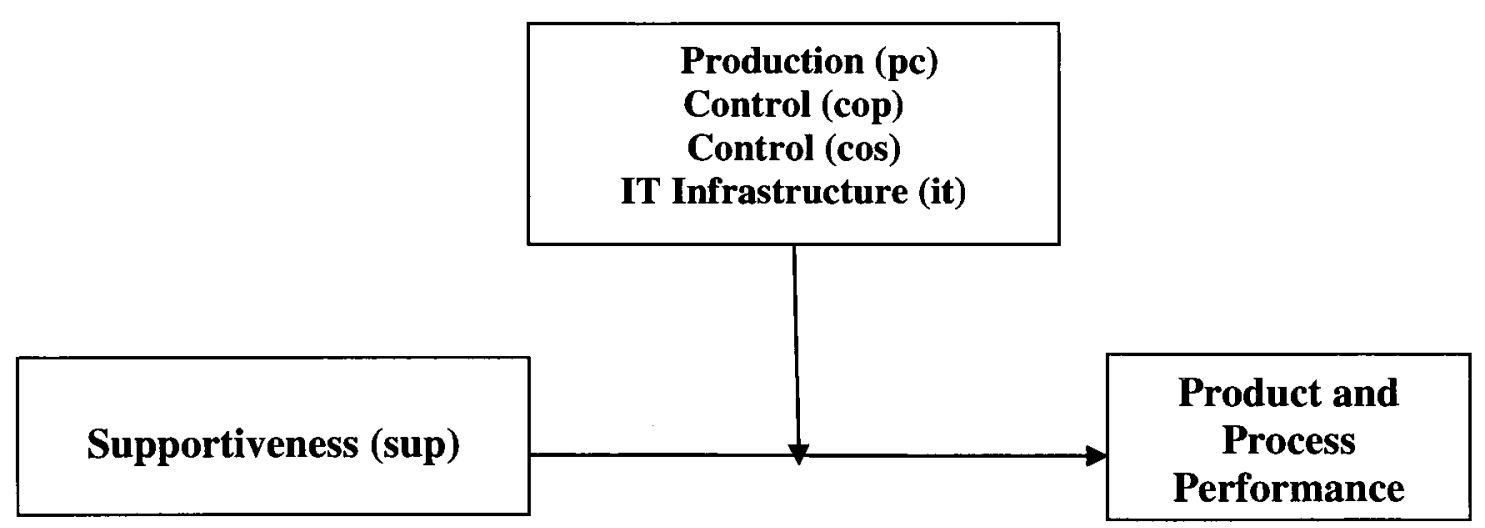

Figure 8-3 Schematic diagram of supportiveness and technical capability dimensions under the moderation approach

Table 8-5 Interaction term starting values and reliability

\begin{tabular}{|l|l|l|l|}
\hline $\begin{array}{l}\text { Latent Product } \\
\text { Variable }\end{array}$ & Lambda $(\boldsymbol{\lambda})$ & Theta $(\boldsymbol{\theta})$ & Reliability \\
\hline sup*pc & 1.83330 & 0.03831 & 0.73647 \\
\hline sup*cop & 1.57290 & 0.04594 & 0.73892 \\
\hline sup*cos & 1.46520 & 0.04358 & 0.79536 \\
\hline sup*it & 1.62129 & 0.04282 & 0.74094 \\
\hline
\end{tabular}

Hypothesis 9Moderation: The interaction between supportiveness and production capability of a software development team influences its performance (product and process).

The structural model of the impact of supportiveness and production capability fit was tested by using supportiveness dimension for social capability and production capability dimension for technical capability. Both constructs were included in the analysis in their revised measurement forms as discussed in 7.2.1. The model was estimated using MLE method. The model fit indices provided an adequate overall fit to the data (Chi-Square $=208.13, \mathrm{df}=130$, RMSEA $=0.056, \mathrm{NNFI}=0.94$, and $\mathrm{CFI}=0.95$ ). 
A statistically significant coefficient for the multiplicative interaction term (sup*pc) would support the fit as "interaction" interpretation. The results (Table 8.6) show that there is a significant effect $(0.19)$ between fit and product performance and a significant effect $(0.21)$ between fit and process performance. The hypothesis was supported, i.e., supportiveness did make greater contribution to product and process performance at higher levels of production capability. Fit between supportiveness and production capability positively impacted team performance.

Table 8-6 Model fit indices for supportiveness and technical capability dimensions

\begin{tabular}{|l|l|l|l|l|l|l|}
\hline $\begin{array}{c}\text { Latent } \\
\text { Variable }\end{array}$ & $\begin{array}{c}\text { Product } \\
\text { Performance }\end{array}$ & $\begin{array}{c}\text { Process } \\
\text { Performance }\end{array}$ & \multicolumn{3}{|c|}{ Model Fit Indices } \\
\hline & $\begin{array}{l}\text { Std. } \\
\text { Coefficients }\end{array}$ & $\begin{array}{l}\text { Std. } \\
\text { Coefficients }\end{array}$ & Chi-sqr (df) & RMSEA & NNFI & CFI \\
\hline sup*pc & $0.19^{* *}$ & $0.21^{* *}$ & $208.13(130)$ & 0.056 & 0.94 & 0.95 \\
\hline sup*cop & -0.02 & 0.06 & $227.46(130)$ & 0.062 & 0.95 & 0.95 \\
\hline sup*cos & -0.04 & 0.03 & $244.78(165)$ & 0.050 & 0.96 & 0.97 \\
\hline sup*it & $0.16^{* *}$ & $0.21^{* *}$ & $243.15(165)$ & 0.050 & 0.95 & 0.96 \\
\hline
\end{tabular}

** $\mathrm{p}<0.05$

Hypothesis 10Moderation: The interaction between supportiveness and control (performance) capability of a software development team influences its performance (product and process).

The structural model of the impact of supportiveness and control (performance) capability fit was tested by using supportiveness dimension for social capability and control (performance) capability dimension for technical capability. Both constructs were included in the analysis in their revised measurement forms as discussed in 7.2.1. The model was estimated 
using MLE method. The model fit indices provided an adequate overall fit to the data (ChiSquare $=227.46, \mathrm{df}=130, \mathrm{RMSEA}=0.062, \mathrm{NNFI}=0.95$, and $\mathrm{CFI}=0.95$ ).

A statistically significant coefficient for the multiplicative interaction term (sup*cop) would support the fit as "interaction" interpretation. The results (Table 8.6) show that the interaction term was not significant for product and process performance. The hypothesis was not supported. Supportiveness did not make greater contribution to product performance and process performance at higher levels of control (performance) capability. Fit between supportiveness and control (performance) showed no impact on team performance.

Hypothesis 11Moderation: The interaction between supportiveness and control (standardization) capability of a software development team influences its performance (product and process).

The structural model of the impact of supportiveness and control (standardization) capability fit was tested by using supportiveness dimension for social capability and control (standardization) capability dimension for technical capability. Both constructs were included in the analysis in their revised measurement forms as discussed in 7.2.1. The model was estimated using MLE method. The model fit indices provided an adequate overall fit to the data (ChiSquare $=244.78, \mathrm{df}=165, \mathrm{RMSEA}=0.050, \mathrm{NNFI}=0.96$, and $\mathrm{CFI}=0.97)$.

A statistically significant coefficient for the multiplicative interaction term (sup*cos) would support the fit as "interaction" interpretation. The results (Table 8.6) show that the interaction term was not significant for product and process performance. The hypothesis was not supported. Supportiveness did not make greater contribution to product performance and 
process performance at higher levels of control (standardization) capability. Fit between supportiveness and control (standardization) showed no impact on team performance.

Hypothesis 12Moderation: The interaction between supportiveness and IT infrastructure capability of a software development team influences its performance (product and process).

The structural model of the impact of supportiveness and IT infrastructure capability fit was tested by using supportiveness dimension for social capability and IT infrastructure capability dimension for technical capability. Both constructs were included in the analysis in their revised measurement forms as discussed in 7.2.1. The model was estimated using MLE method. The model fit indices provided an adequate overall fit to the data (Chi-Square $=243.15$, $\mathrm{df}=165, \mathrm{RMSEA}=0.050, \mathrm{NNFI}=0.95$, and $\mathrm{CFI}=0.96$ ).

A statistically significant coefficient for the multiplicative interaction term (sup*it) would support the fit as "interaction" interpretation. The results (Table 8.6) show that there is a significant effect $(0.16)$ between fit and product performance and a significant effect $(0.21)$ between fit and process performance. The hypothesis was supported, i.e., supportiveness did make greater contribution to product and process performance at higher levels of IT infrastructure capability. Fit between supportiveness and IT infrastructure capability positively impacted team performance.

This section presented the results for hypotheses related to all the individual (pair-wise) fit terms using moderation approach. Results show that control dimension did not have any performance implications in the fit analysis. Pair-wise fit variables other than where control dimension was involved had positive performance implications. There was partial support for 
some hypotheses where fit impacted only product performance and full support for the other hypotheses where fit impacted both product and process performance.

\subsection{Matching}

Fit as matching was conceptualized as a theoretically defined match between the two variables in question. In this approach, unlike moderation approach, calculation of fit is free from the criterion variable. However, in the matching approach the impact of fit on the criterion variable can be eventually studied. In this research, we study the impact of fit variables on product and process performance, our dependent variables. A number of techniques have been suggested in the literature to analyze fit using the matching approach such as deviation score, analysis of variance (ANOVA), and residual analysis (Venkataraman, 1989). We used deviation score to calculate fit and ultimately analyze its impact on performance. The other approach of ANOVA using hierarchical regression did not work in this case as we did not know the order of putting the variables in the regression analysis.

\subsubsection{Procedure}

Deviation score analysis is one of the common techniques used in assessing fit when considered under the matching perspective. Many authors have successfully used the deviation score approach in their analysis for measuring fit and ultimately its impact on the criterion variable (Bergeron et al., 2001; Alexander \& Randolph, 1985; Chakravarthy, 1987).

The technique is based on the premise that the absolute difference between the standardized scores of the two variables indicates a lack of fit (Venkataraman, 1989). The fit under this perspective is the absolute difference between the values of the social and technical 
capability variables/dimensions $($ i.e. Fit $=$ Isocial capability dimension - technical capability dimensionl). The dimensions were measured on a five-point Likert scale. The measure assumes that for each value of a social capability dimension there is a best value of a technical capability dimension to yield the highest performance.

The match between social capability dimensions (communication, conflict resolution, and supportiveness) and technical capability dimensions (production, control, and IT infrastructure) can be analyzed using difference scores between two variables with or without the reference to the criterion variable of product and process performance. Under this approach, the closer the fit of the two matching variables, the greater is the performance of the software development team. For example, if communication and production capability values are close to each other, fit will be higher within the team. Thus, a zero absolute difference would be a perfect fit. In other words, the fit score is the difference or the mismatch score, signifying an inverse relationship with the criterion variable. Under this approach, the fit variable has a negative impact on performance i.e. higher the fit score lower the performance of the team or lower the fit score, higher the performance.

We calculated 12 pair-wise fit variables as the squared difference between the social capability dimensions (communication, conflict resolution, and supportiveness) and the technical capability dimensions (production, control, and IT infrastructure) respectively. These fit terms were correlated with performance (product and process) after controlling for the linear and quadratic effects of their two components, which was the partial correlation. Partial correlation is the relationship between the two variables, when we control for other variables (could be more than one). In our case, we controlled for the linear and quadratic effects of the individual terms that we used to calculate fit. For example, when we calculated fit between communication (com) 
and production capability ( $\mathrm{pc}$ ), we took the square of the difference between com and pc variables to calculate fit which is (com-pc) ${ }^{2}$. To get a partial correlation between the fit term and the performance term (product or process) we controlled for the linear terms of com and pc and the quadratic terms of $\mathrm{com}^{2}$ and $\mathrm{pc}^{2}$. Similarly, we calculated all the fit terms and the partial correlations among the fit terms and the product and process performance variables (See Tables 8.7 and Table 8.8). 
Table 8-7 Correlations of fit variables with product performance

\begin{tabular}{|l|l|l|}
\hline $\begin{array}{c}\text { Correlation of fit } \\
\text { variables with product } \\
\text { performance }\end{array}$ & \multicolumn{1}{|c|}{ Zero Order } & \multicolumn{1}{|c|}{ Partial $^{\mathrm{a}}$} \\
\hline (com-pc) $^{2}$ & $-0.242^{*}$ & $-0.254^{* *}$ \\
\hline (com-cop) $^{2}$ & $-0.171^{*}$ & -0.096 \\
\hline (com-cos) $^{2}$ & $-0.154^{*}$ & -0.033 \\
\hline (com-it) $^{2}$ & $-0.152^{*}$ & $-0.242^{*}$ \\
\hline (cr-pc) $^{2}$ & -0.084 & $-0.168^{*}$ \\
\hline (cr-cop) $^{2}$ & -0.071 & -0.083 \\
\hline (cr-cos) $^{2}$ & -0.038 & -0.032 \\
\hline (cr-it) $^{2}$ & -0.026 & $-0.124^{* * *}$ \\
\hline (sup-pc) $^{2}$ & $-0.238^{* *}$ & $-0.216^{*}$ \\
\hline (sup-cop) $^{2}$ & -0.100 & 0.024 \\
\hline (sup-cos) $^{2}$ & -0.103 & 0.026 \\
\hline (sup-it) $^{2}$ & -0.078 & $-0.178^{*}$ \\
\hline (sc-tc) $^{2}$ & -0.116 & -0.087 \\
\hline
\end{tabular}

${ }^{a}$ Controlling for linear and quadratic effects of the fit variables original components.

${ }^{*} \mathrm{p}<0.05$

${ }^{* *} \mathrm{p}<0.001$

$\mathrm{p}<0.10$ 
Table 8-8 Correlations of fit variables with process performance

\begin{tabular}{|l|l|l|}
\hline $\begin{array}{c}\text { Correlation of fit } \\
\text { variables with process } \\
\text { performance }\end{array}$ & \multicolumn{1}{|c|}{ Zero Order } & \multicolumn{1}{|c|}{ Partial $^{\mathrm{a}}$} \\
\hline (com-pc) $^{2}$ & $-0.150^{*}$ & $-0.127^{* *}$ \\
\hline (com-cop) $^{2}$ & -0.044 & -0.002 \\
\hline (com-cos) $^{2}$ & -0.007 & 0.016 \\
\hline (com-it) $^{2}$ & -0.057 & -0.097 \\
\hline (cr-pc) $^{2}$ & -0.030 & -0.042 \\
\hline (cr-cop) $^{2}$ & 0.067 & 0.064 \\
\hline (cr-cos) $^{2}$ & -0.016 & 0.007 \\
\hline (cr-it) $^{2}$ & -0.164 & $-0.179^{*}$ \\
\hline (sup-pc) $^{2}$ & $-0.136^{* *}$ & $-0.153^{*}$ \\
\hline (sup-cop) $^{2}$ & -0.036 & 0.020 \\
\hline (sup-cos) $^{2}$ & 0.025 & 0.015 \\
\hline (sup-it) $^{2}$ & -0.020 & -0.119 \\
\hline (sc-tc) $^{2}$ & -0.043 & -0.052 \\
\hline
\end{tabular}

${ }^{a}$ Controlling for linear and quadratic effects of the fit variables original components. ${ }_{* *}^{*} \mathrm{p}<0.05$ $\mathrm{p}<0.10$

We present the analysis associated with our individual fit hypotheses one by one in the following sub-sections (8.2.2 to 8.2.4).

\subsubsection{Impact of fit between communication and technical capability variables on team performance (product and process)}

In this section we test the four hypotheses of fit involving communication and the four technical capability variables of production, control (performance and standardization), and IT infrastructure under the matching approach. 
Hypothesis 1Match: The fit between communication ability and production capability will be a significant predictor of performance. The more the mismatch between communication and production capability less will be the performance.

The hypothesis was supported for both product and process performance as evidenced by the partial correlation of $-0.254(\mathrm{p}<0.01)$ between the fit variable of $(\mathrm{com}-\mathrm{pc})^{2}$ and product performance and the partial correlation of $-0.127(\mathrm{p}<0.1)$ between the fit variable of $(\mathrm{com}-\mathrm{pc})^{2}$ and process performance (Table 8.7 and 8.8 ). The sign of the partial correlation between the fit variable and product and process performance was negative suggesting that higher the mismatch between the two components lower the performance. The relationship between the communication and production capability fit and product and process performance was statistically significant. These results confirmed the need to closely monitor communication needs with the production capability needs or in other words we can interpret that the team members need to be skilled enough in formal and informal communication for the product and process performance of the team to increase.

Hypothesis 2Match: The fit between communication ability and control (performance) capability will be a significant predictor of performance. The more the mismatch between communication and control (performance) capability less will be the performance.

The hypothesis was not supported for both product and process performance as evidenced by the partial correlation of -0.096 between the fit variable of (com-cop) ${ }^{2}$ and product performance and the partial correlation of -0.002 between the fit variable of (com-cop) $)^{2}$ and process performance (Table 8.7 and 8.8). The sign of the partial correlation between the fit variable and product and process performance was negative suggesting that higher the mismatch between the two components lower the performance. However, the relationships between communication and control (performance) capability fit and product and process performance were not statistically significant. 
Hypothesis 3Match: The fit between communication ability and control (standardization) capability will be a significant predictor of performance. The more the mismatch between communication and control (standardization) capability less will be the performance.

The hypothesis was not supported for both product and process performance as evidenced by the partial correlation of -0.033 between the fit variable of (com-cos) ${ }^{2}$ and product performance and the partial correlation of 0.016 between the fit variable of (com-cos) $)^{2}$ and process performance (Table 8.7 and 8.8 ). The sign of the partial correlation was negative between the fit variable and product performance suggesting that higher the mismatch between the two components lower the product performance. However, the relationship between communication and control (standardization) capability fit was not statistically significant. On the other hand, the fit between the two components did not have any impact on process performance.

Hypothesis 4Match: The fit between communication ability and IT infrastructure capability will be a significant predictor of performance. The more the mismatch between communication and IT infrastructure) capability less will be the performance.

The hypothesis was partially supported i.e., we saw statistical support for product performance but not for process performance as evidenced by the partial correlation of -0.242 $(\mathrm{p}<0.05)$ between the fit variable of $(\mathrm{com}-\mathrm{it})^{2}$ and product performance and the partial correlation of -0.097 between the fit variable of (com-it) $)^{2}$ and process performance (Table 8.7 and 8.8 ). The sign of the partial correlation was negative between the fit and product performance suggesting that higher the mismatch between the two components lower the product performance. The relationship between communication and IT infrastructure capability fit and product performance was statistically significant. On the other hand, the partial correlation between the fit variable and process performance, though negative, was not statistically significant. This confirms the 
need to closely monitor communication needs with the infrastructural capability available within the organization. In other words, we suggest that organizations should focus on incorporating formal and informal communication needs within the IT infrastructure design and strategy for the product and process performance to increase.

\subsubsection{Impact of fit between conflict resolution and technical capability variables on performance (product and process)}

In this section we present the four hypotheses of fit involving conflict resolution and the four technical capability variables of production, control (performance and standardization), and IT infrastructure.

Hypothesis 5Match: The fit between conflict resolution ability and production capability will be a significant predictor of performance. The more the mismatch conflict resolution and production capability less will be the performance.

The hypothesis was supported for product performance but not for process performance as evidenced by the partial correlation of $-0.168(\mathrm{p}<0.05)$ between the fit variable of $(\mathrm{cr}-\mathrm{pc})^{2}$ and product performance and the partial correlation of -0.042 between the fit variable of (cr-pc) ${ }^{2}$ and process performance (Table 8.7 and 8.8 ). The sign of the partial correlation was negative between the fit variable and product performance suggesting that higher the mismatch between the two components lower the product performance. The relationship between conflict resolution and production capability fit and product performance was statistically significant. On the other hand, the partial correlation between the fit variable and process performance though negative was not statistically significant. This confirms the need for the organizations to focus on building the skills needed for resolving conflicts or hiring the right personnel with the required skills for the performance to increase. 
Hypothesis 6Match: The fit between conflict resolution ability and control (performance) capability will be a significant predictor of performance. The more the mismatch between conflict resolution and control (performance) capability less will be the performance.

The hypothesis was not supported for both product and process performance as evidenced by the partial correlation of -0.083 between the fit variable of (cr-cop) $)^{2}$ and product performance and the partial correlation of -0.064 between the fit variable of (cr-cop) ${ }^{2}$ and process performance (Table 8.7 and 8.8). The sign of the partial correlation was negative suggesting that higher the mismatch between the two components lower the performance. However, the relationships between conflict resolution and control (performance) capability fit and product and process performance were not statistically significant.

Hypothesis 7Match: The fit between conflict resolution ability and control (standardization) capability will be a significant predictor of performance. The more the mismatch between conflict resolution and control (standardization) capability less will be the performance.

The hypothesis was not supported for both product and process performance as evidenced by the partial correlation of -0.032 between the fit variable of $(\mathrm{cr}-\mathrm{cos})^{2}$ and product performance and the partial correlation of 0.007 between the fit variable of $(\mathrm{cr}-\mathrm{cos})^{2}$ and process performance (Table 8.7 and 8.8 ). The sign of the partial correlation was negative between the fit variable and product performance suggesting that higher the mismatch between the two components lower the product performance but the relationship was not found to be statistically significant. On the other hand, the fit between the two components did not show any impact on process performance of the team.

Hypothesis 8Match: The fit between conflict resolution ability and IT infrastructure capability will be a significant predictor of performance. The more the mismatch between conflict resolution and IT infrastructure capability less will be the performance. 
The hypothesis was supported for both product and process performance as evidenced by the partial correlation of $-0.124(\mathrm{p}<0.1)$ between the fit variable of $(\mathrm{cr}-\mathrm{it})^{2}$ and product performance and the partial correlation of $-0.179(\mathrm{p}<0.05)$ between the fit variable of $(\mathrm{cr}-\mathrm{it})^{2}$ and process performance (Table 8.7 and 8.8 ). The sign of the partial correlation was negative between the fit variable and product and process performance suggesting that higher the mismatch between the two components lower the product and process performance. The results show that organizations should focus on a sound IT infrastructure which will aid in resolving conflicts and ultimately improving the product and process performance of the team. Team related conflict resolution requirements need to be kept in mind when dealing with IT infrastructure.

\subsubsection{Impact of fit between supportiveness and technical capability variables on performance (product and process)}

In this section we present the four hypotheses of fit involving supportiveness and the four technical capability dimensions of production, control (performance and standardization), and IT infrastructure.

Hypothesis 9Match: The fit between supportiveness ability and production capability will be a significant predictor of performance. The more the mismatch between supportiveness and production capability less will be the performance.

The hypothesis was supported for both product and process performance as evidenced by the partial correlation of $-0.216(\mathrm{p}<0.05)$ between the fit variable of (sup-pc) ${ }^{2}$ and product performance and the partial correlation of $-0.153(\mathrm{p}<0.05)$ between the fit variable of (sup-pc $)^{2}$ and process performance (Table 8.7 and 8.8 ). The sign of the partial correlation between the fit variable and product and process performance was negative suggesting that higher the mismatch 
between the two components lower the performance. The relationships between supportiveness and production capability fit and product and process performance were statistically significant. This result shows that there is a need within the organizations to pay attention to the skills needed for keeping the team members supportive of each other for a team to succeed.

Hypothesis 10Match: The fit between supportiveness ability and control (performance) capability will be a significant predictor of performance. The more the mismatch between supportiveness and control (performance) capability less will be the performance.

The hypothesis was not supported for both product and process performance as evidenced by the partial correlation of 0.024 between the fit variable of (sup-cop) $)^{2}$ and product performance and the partial correlation of 0.020 between the fit variable of (sup-cop) ${ }^{2}$ and process performance (Table 8.7 and 8.8 ). The fit between the two components, did not have any impact on product and process performance of the team.

Hypothesis 11Match: The fit between supportiveness ability and control (standardization) capability will be a significant predictor of performance. The more the mismatch between supportiveness and control (standardization) capability less will be the performance.

The hypothesis was not supported for both product and process performance as evidenced by the partial correlation of 0.026 between the fit variable of (sup-cos) $)^{2}$ and product performance and the partial correlation of 0.015 between the fit variable of (sup-cos) $)^{2}$ and process performance (Table 8.7 and 8.8). The partial correlation results indicated that the fit between supportiveness and control (standardization) capability did not have any impact on product and process performance of the team.

Hypothesis 12Match: The fit between supportiveness ability and IT infrastructure capability will be a significant predictor of performance. The more the mismatch between supportiveness and IT infrastructural capability less will be the performance. 
The hypothesis was supported for product performance but not for process performance as evidenced by the partial correlation of $-0.178(\mathrm{p}<0.05)$ between the fit variable of (sup-it) ${ }^{2}$ and product performance and the partial correlation of -0.119 between the fit variable of (sup-it) ${ }^{2}$ and process performance (Table 8.7 and 8.8 ). The sign of the partial correlation was negative between the fit variable and product performance suggesting that higher the mismatch between the two components lower the product performance. The relationship between supportiveness and IT infrastructure capability fit and product performance was shown to be statistically significant. On the other hand, the partial correlation between the fit and process performance though negative was not statistically significant. The results provide an initial support to the argument that organizations need to focus on how the IT infrastructure can help to build supportiveness among the team members, which could ultimately improve performance of the team.

In this section we presented the results of measuring fit from matching perspective and analyzed the impact of fit on product and process performance. We found some support at the individual level of fit analyses. We found that control; a technical capability dimension did not play any role in fit analyses. However, there was partial and full support present for other fit dimensions.

\subsection{Profile Deviation}

Profile deviation approach to measuring fit conceptualizes fit as the degree of adherence to a specified ideal profile or pattern on a series of underlying dimensions. It is a systems approach to measuring fit. This holistic or the systems approach provides a broader 
conceptualization for measuring fit among the variables of interest. It maintains the holistic view by retaining the complex inter-linkages among the variables (Venkataraman and Prescott, 1990).

This holistic approach to measuring fit is different than the other two reductionist approaches to measuring fit. It is a criterion specific approach similar to the moderation perspective. However, it differs from the moderation in terms of the degree of specificity. Unlike, the moderation approach, degree of specificity is low in the profile deviation approach. It is more suited to test the hypotheses at the macro level. We tested the individual or the pair-wise fit hypotheses using the two approaches of moderation and matching in the previous two sections. We have used profile deviation approach to test the overall fit hypothesis.

We adapted Venkataraman's (1989) definition of fit as profile deviation to the context of software development team. The basic premise of this approach is that an ideal profile exists and any deviation from this ideal profile results in lower performance. To be more specific for our research question, an ideal pattern of social capability profile was specified for a particular level of technical capability, and a software team's degree of adherence to such a multidimensional profile was hypothesized to positively impact performance. Conversely, a deviation from this profile implied a low degree of fit resulting in negative impact on performance.

\subsubsection{Hypothesis testing}

Fit in the profile deviation approach was defined as the extent to which a team's social capability profile matched its technical capability. One of the objectives of the present study was

to test the hypothesis that fit influenced software development team performance. The closer a team's social capability profile was to the empirically derived ideal profile, the higher its performance, both in terms of product and process performance. The two hypotheses we tested by this approach are: 
Hypothesis 1Profile: The greater the team's deviation from the empirically derived ideal profile of social capability dimensions, lower the product performance.

Hypothesis 2Profile: The greater the team's deviation from the empirically derived ideal profile of social capability dimensions, lower the process performance.

A negative and significant correlation of the distance/deviation score with the performance would provide support for the profile deviation approach and the above hypotheses. We followed the procedures given by Drazin and Van de Ven (1985) and further applied by Nidumolu (1996) and Barki et al. (2001) within the software development project context. Based on the procedure described in the next section, we derived an ideal profile for social capability, calculated the Euclidean distance and finally tested the correlation between the distance and the product and process performance.

\subsubsection{Procedure}

Profile deviation approach is similar to the deviation score approach used in the matching analysis. The major difference between the two techniques is in the way deviation is measured. In deviation score analysis, deviation is measured from a single linear equation, while in profile deviation approach deviation is measured as a distance from an ideal profile. The procedure for testing the hypotheses involved five steps. The first step involved dividing the data set into two groups; second step involved identifying the high performing teams in both groups; the third step involved calculating the ideal profiles; in the fourth step distance score was calculated, and finally the fifth step involved correlating the distance score with the performance dimension. Details of these five steps are presented one by one in this section. We describe the steps for 
analyzing the impact of fit on product performance. Same steps were carried out for analyzing the impact of fit on process performance.

\section{Step 1}

We classified the teams (the number of cases) into five quintiles based on their scores on technical capability. The first and second quintiles were assumed to represent teams with low technical capability and the fourth and fifth quintiles represented teams with high technical capability. We dropped the cases which fell in the third quintile from subsequent analysis in order to clearly distinguish between high and low technical capability groups.

\section{Step 2}

High performing teams belonging to both technical capability groups (low and high) were picked. A high performing team was the one whose product performance score was half a standard deviation above the mean for the product performance score in the entire sample. Based on the mean and standard deviation numbers, teams with high product performance had a mean score above 4.16 .

\section{Step 3}

Ideal profiles were calculated for both the technical capability groups by taking the mean values for the social capability dimensions of communication (com), conflict resolution (cr), and supportiveness (sup) for the corresponding high performing teams (Table 8.9). 
Table 8-9 Mean values for social capability dimensions

\begin{tabular}{|l|l|l|l|}
\hline & \multicolumn{3}{|l|}{ Product Performance } \\
\hline \multirow{2}{*}{$\begin{array}{l}\text { Low Technical } \\
\text { Capability }\end{array}$} & \multicolumn{3}{|l|}{ No. of high performing teams = 15 } \\
\cline { 2 - 4 } & Com & Cr & sup \\
\cline { 2 - 4 } & 3.92 & 3.49 & 3.80 \\
\hline \multirow{2}{*}{$\begin{array}{l}\text { High Technical } \\
\text { Capability }\end{array}$} & No. of high performing teams $=40$ \\
\cline { 2 - 4 } & Com & Cr & Sup \\
\cline { 2 - 4 } & 4.05 & 3.64 & 4.32 \\
\hline
\end{tabular}

\section{Step 4}

We computed the deviation score for the team/case by taking the Euclidean distance from its three dimensions of the social capability profile to the three dimensions of the corresponding ideal profile/team for that group. Deviation scores were calculated for teams that were not high performing according to our criterion i.e. the hold out or the remaining sample was used. The Euclidean distance measure formula given by Drazin and Van de Ven (1985) was used.

$$
D I S T=\sqrt{\sum(X i s-X j s)^{2}}
$$

Where, $\mathrm{X}_{\mathrm{is}}$ is the score of the ideal team on the $\mathrm{s}^{\text {th }}$ social capability profile dimension and $\mathrm{X}_{\mathrm{js}}$ is the score of the $\mathrm{j}^{\text {th }}$ team on the $\mathrm{s}^{\text {th }}$ social capability profile dimension. For example, team j's distance score, with product performance was calculated as follows:

Dist $t_{\mathrm{j}}=\operatorname{SQRT}\left[\left(3.92-\mathrm{com}_{\mathrm{j}}\right)^{2}+\left(3.49-\mathrm{cr}_{\mathrm{j}}\right)^{2}+\left(3.80-\mathrm{sup}_{\mathrm{j}}\right)^{2}\right]$

if the team ${ }_{\mathrm{j}}$ is under the low technical capability group, and $\operatorname{Dist}_{\mathrm{j}}=\operatorname{SQRT}\left[\left(4.05-\mathrm{com}_{\mathrm{j}}\right)^{2}+\left(3.64-\mathrm{cr}_{\mathrm{j}}\right)^{2}+\left(4.32-\mathrm{sup}_{\mathrm{j}}\right)^{2}\right]$ 
if the team ${ }_{j}$ is under the high technical capability group.

\section{Step 5}

Based on the distance scores calculated in step 4, correlation between the distance score of the team with the product performance score of the team was calculated. Fit or we say misfit was demonstrated when the distance score was negatively related to product performance. If the correlation is significant and negative, we say that fit has an impact on performance.

The correlation between the distance score and product performance $\left(-0.204^{*}\right)$ was negative and significant $(\alpha=0.05)$ indicating that the deviation from an ideal social capability profile was negatively related to product performance. Hypothesis 1 was supported under the profile deviation approach for measuring fit. In other words, we inferred that the closer a team's social capability profile was to an empirically derived ideal profile, the higher its product performance.

All the above steps were repeated for measuring the impact of fit on process performance (Table 8.10). The correlation between the distance score and process performance $\left(-0.184^{*}\right)$ was negative and significant $(\alpha=0.05)$ indicating that the deviation from an ideal social capability profile was negatively related to process performance. Hypothesis 2 was supported under the profile deviation approach for measuring fit. In other words, we inferred that the closer a team's social capability profile was to an empirically derived ideal profile, the higher its process performance. 
Table 8-10 Mean values for social capability dimensions

\begin{tabular}{|l|l|l|l|}
\hline & \multicolumn{3}{|l|}{ Process Performance } \\
\hline \multirow{4}{*}{$\begin{array}{l}\text { Low Technical } \\
\text { Capability }\end{array}$} & \multicolumn{3}{|l|}{ No. of high performing teams = 8 } \\
\cline { 2 - 4 } & com & cr & Sup \\
\cline { 2 - 4 } & 3.74 & 3.31 & 3.64 \\
\hline \multirow{3}{*}{$\begin{array}{l}\text { High Technical } \\
\text { Capability }\end{array}$} & \multicolumn{3}{|l}{ No. of high performing teams $=19$} \\
\cline { 2 - 4 } & com & cr & Sup \\
\cline { 2 - 4 } & 4.20 & 3.73 & 4.36 \\
\hline
\end{tabular}

Besides measuring the team performance with two dimensions of product and process we also measured team satisfaction. When we looked at the correlation between team satisfaction and product $(0.353, \alpha=0.05)$ and process $(0.298, \alpha=0.05)$ performance dimensions we found that they were significantly correlated. Thus, we did not use satisfaction in our analysis for testing at the individual level hypotheses. However, just to confirm we used the profiled deviation approach to study the impact of fit on team satisfaction. The third row in Table 8.11 shows the correlation between team satisfaction and the distance score. We did the same analysis with the satisfaction variable and constructed the ideal social capability profile and calculated the distance score according to the procedure described previously. Since it is not the main focus of our research we provide the details in Appendix VIII. 
Table 8-11 Correlations between performance measures and profile distance scores

\begin{tabular}{|l|l|}
\hline Performance Measure & \multicolumn{1}{|c|}{$\begin{array}{c}\text { Correlation with Respective Profile } \\
\text { Distance Score }\end{array}$} \\
\hline Product & $-0.204^{*}$ \\
\hline Process & $-0.184^{*}$ \\
\hline Satisfaction & $-0.532^{* *}$ \\
\hline $\begin{array}{l}* \mathrm{p}<0.05 \\
* * \mathrm{p}<0.01\end{array}$
\end{tabular}

We found that as expected, fit between the social and technical capability impacted team satisfaction. In other words we inferred that the closer a team's social capability profile was to an empirically derived ideal profile, the higher its satisfaction.

In this section we presented the results of measuring fit using the profile deviation approach and analyzing the impact of fit on product and process performance. We found support for our hypotheses. Support at the holistic level/macro level also confirmed the basic premise of the profile deviation perspective of low specificity in the approach as outlined by Venkataraman (1989).

In summary, this chapter presented the analysis associated with the three fit measurement approaches. The results confirm that moderation and matching measurement approaches are more suited for micro level fit analysis and profile deviation approach is more suited for macro level fit analysis. 


\section{Chapter 9 Impact of Moderating Variables}

This chapter reports the results of the preliminary analysis of the effect of organizational factors and team size on the relationships hypothesized in the proposed research model. For the selected organizational factors of centralization, formalization, incentives and reward systems, and specialization the following analysis was conducted. The dataset was divided into two groups based on the particular organizational factor score (low or high). We also tested the impact of team size on fit and performance relationship. The proposed model was tested using the profile deviation approach for both the groups separately for all the five variables. We only tested the overall fit hypotheses using the profile deviation approach. As previously stated, profile deviation approach is more suited to test relationships at the holistic level. The procedure followed is the same as described in section 8.3.2. We did not specifically formulate and test hypotheses for the moderating variables in this research. The analysis in this chapter is more at the exploratory level where we see the influence of these moderating variables on the relationship between fit and performance. More research is needed to substantiate the claims presented in this chapter, which is the work for future research.

\subsection{Centralization}

We expected centralization, which is an organizational factor to influence the relationship between fit and performance. We collected data from the respondents about the level of centralization in an organization under which the software development team was operating from the respondents. Based on the average score of centralization (Mean Centralization $=2.34$ ), dataset was divided into two groups. Teams whose respondents gave scores greater than 2.34 fell 
under the high centralization group (98 teams) and teams whose respondents gave scores less than or equal to 2.34 fell under the low centralization group (94 teams). We analyzed the impact of fit on performance in both the groups separately.

We adapted Venkataraman's (1989) definition of fit as profile deviation to the context of software development team for our research, which implied that if an ideal pattern of social capability profile was specified for a particular level of technical capability, a software team's degree of adherence to such a multidimensional profile will be positively related to performance Conversely, deviation from this profile would imply a low degree of fit resulting in a negative effect on performance. The basic premise of this approach is that an ideal profile exists and any deviation from this ideal profile results in lower performance. Lack of fit or mismatch was measured as the distance score of a team from its ideal profile. A high performing team was the one whose performance (product and process) score was half a standard deviation above the mean for the performance score (product and process) in the entire sample.

Table 9-1 More centralization group

\begin{tabular}{|l|l|l|l|l|l|l|}
\hline \multirow{2}{*}{$\begin{array}{l}\text { 94 Cases } \\
\text { 92.34 }\end{array}$} & \multicolumn{2}{|l|}{ Product Performance } & \multicolumn{2}{l|}{ Process Performance } \\
\hline \multirow{2}{*}{$\begin{array}{l}\text { Low Technical } \\
\text { Capability }\end{array}$} & \multicolumn{2}{|l|}{ No. of high performing teams = 4 } & \multicolumn{2}{l|}{ No. of high performing teams = 4 } \\
\cline { 2 - 7 } & Com & cr & sup & Com & cr & sup \\
\cline { 2 - 7 } & 3.53 & 3.28 & 3.36 & 3.59 & 3.03 & 3.46 \\
\hline \multirow{2}{*}{$\begin{array}{l}\text { High Technical } \\
\text { Capability }\end{array}$} & No. of high performing teams = 16 & \multicolumn{2}{l|}{ No. of high performing teams = 8 } \\
\cline { 2 - 8 } & Com & cr & sup & Com & cr & sup \\
\cline { 2 - 8 } & 3.91 & 3.6 & 4.24 & 4.08 & 3.70 & 4.36 \\
\hline
\end{tabular}

First, social capability ideal profile was calculated for the four groups in the more centralized group (Table 9.1). Distance score was computed for both the low technical capability 
and high technical capability groups (both product and process performance). We found that correlation coefficient between the distance score and product performance was -0.282 * $(\alpha=0.05)$, which was significant. Similarly, correlation coefficient between the distance score and process performance was $-0.222 *(\alpha=0.10)$, which was also significant.

Table 9-2 Less centralization group

\begin{tabular}{|l|l|l|l|l|l|l|}
\hline \multirow{2}{*}{\begin{tabular}{l} 
98an Cases $<=\mathbf{2 . 3 4}$ \\
\multirow{2}{*}{$\begin{array}{l}\text { Low Technical } \\
\text { Capability }\end{array}$}
\end{tabular}} & \multicolumn{2}{|l|}{ Product Performance } & \multicolumn{2}{l|}{ Process Performance } \\
\cline { 2 - 7 } & Com & Cr & sup & com & cr & sup \\
\cline { 2 - 7 } & 4.13 & 3.66 & 4.07 & 4.13 & 3.53 & 4.18 \\
\hline \multirow{2}{*}{$\begin{array}{l}\text { High Technical } \\
\text { Capability }\end{array}$} & No. of high performing teams = 19 & \multicolumn{2}{l|}{ No. of high performing teams = 10 } \\
\cline { 2 - 7 } & Com & Cr & sup & com & cr & sup \\
\cline { 2 - 7 } & 4.21 & 3.79 & 4.48 & 4.24 & 3.66 & 4.46 \\
\hline
\end{tabular}

Second, social capability ideal profile was calculated for the four groups in the less centralized group (Table 9.2). Distance score was computed for both the low technical capability and high technical capability groups (both product and process performance). We found that correlation coefficient between the distance score and product performance was -0.044 , which was not significant. Similarly, correlation coefficient between the distance score and process performance is 0.084 , which was also not significant.

The results show that centralization played a role when studying the impact of fit on performance. More centralized groups showed positive impact of fit on product and process performance. On the other hand, in the less centralized group fit did not impact product and process performance. 


\subsection{Formalization}

We expected formalization, which is an organizational factor to influence the relationship between fit and product and process performance of the software development team. From our respondents, besides collecting data directly related to the functioning of the team, we also collected data about the degree of formalization in an organization under which the software development team was operating. Based on the average score of formalization (Mean Formalization $=2.87$ ), we divided the dataset into two groups. Teams whose respondents gave scores greater than 2.87 fell under the more formalized group (107 teams) and teams whose respondents gave scores less than or equal to 2.87 fell under the less formalized group (85 teams). A high performing team was the one whose performance (product and process) score was half a standard deviation above the mean for the performance score (product and process) in the entire sample.

Table 9-3 More formalized group

\begin{tabular}{|c|c|c|c|c|c|c|}
\hline $\begin{array}{l}\text { Mean }>2.87 \\
107 \text { Cases }\end{array}$ & \multicolumn{3}{|c|}{ Product Performance } & \multicolumn{3}{|c|}{ Process Performance } \\
\hline \multirow{3}{*}{$\begin{array}{l}\text { Low Technical } \\
\text { Capability }\end{array}$} & \multicolumn{3}{|c|}{ No. of high performing teams 10} & \multicolumn{3}{|c|}{ No. of high performing teams $=8$} \\
\hline & Com & $\mathbf{C r}$ & sup & com & cr & sup \\
\hline & 3.93 & 3.63 & 3.84 & 3.8 & 3.41 & 3.79 \\
\hline \multirow{3}{*}{$\begin{array}{l}\text { High Technical } \\
\text { Capability }\end{array}$} & \multicolumn{3}{|c|}{ No. of high performing teams $=22$} & \multicolumn{3}{|c|}{ No. of high performing teams $=12$} \\
\hline & Com & $\mathbf{C r}$ & sup & com & cr & sup \\
\hline & 4.03 & 3.69 & 4.38 & 4.15 & 3.7 & 4.40 \\
\hline
\end{tabular}

First, social capability ideal profile was calculated for the four groups in the more formalized group (Table 9.3). Distance score was computed for both the low technical capability 
and high technical capability groups (both product and process performance). We found that correlation coefficient between the distance score and product performance was $-0.298^{*}$ ( $\alpha=0.05$ ), which was significant. Similarly, correlation coefficient between the distance score and process performance was $-0.294 *(\alpha=0.05)$, which was also significant.

Table 9-4 Less formalized group

\begin{tabular}{|c|c|c|c|c|c|c|}
\hline $\begin{array}{l}\text { Mean }<=2.87 \\
85 \text { Cases }\end{array}$ & \multicolumn{3}{|c|}{ Product Performance } & \multicolumn{3}{|c|}{ Process Performance } \\
\hline \multirow{3}{*}{$\begin{array}{l}\text { Low Technical } \\
\text { Capability }\end{array}$} & \multicolumn{3}{|c|}{ No. of high performing teams $=4$} & \multicolumn{3}{|c|}{ No. of high performing teams $=1$} \\
\hline & Com & $\mathbf{C r}$ & sup & Com & cr & Sup \\
\hline & 4.13 & 3.91 & 4.11 & 4 & 3.75 & 4 \\
\hline \multirow{3}{*}{$\begin{array}{l}\text { High Technical } \\
\text { Capability }\end{array}$} & \multicolumn{3}{|c|}{ No. of high performing teams $=17$} & \multicolumn{3}{|c|}{ No. of high performing teams $=11$} \\
\hline & Com & $\mathbf{C r}$ & sup & Com & cr & Sup \\
\hline & 4.15 & 3.70 & 4.27 & 4.20 & 3.70 & 4.40 \\
\hline
\end{tabular}

Second, social capability ideal profile was calculated for the four groups in the less formalized group (Table 9.4). Distance score was computed for both the low technical capability and high technical capability groups (both product and process performance). We found that correlation coefficient between the distance score and product performance was -0.217 , which was not significant. Similarly, correlation coefficient between the distance score and process performance was 0.022 , which was also not significant.

The results show that formalization played a role when studying the impact of fit on performance. More formalized groups showed the positive impact of fit on product and process performance. On the other hand, in the less formalized group fit did not impact product and process performance. 


\subsection{Incentives and reward systems}

We expected incentives and reward systems, which is an organizational factor to influence the relationship between fit and performance. Data was collected from the respondents about how they perceived the presence of incentives and reward systems in their organization, under which their software development team was operating. Based on the average score of incentives and reward systems $($ Mean $=3.6)$, we divided the dataset into two groups. Teams whose respondents gave scores greater than and equal to 3.6 fell under the more incentives and reward systems group (105 teams) and teams whose respondents gave scores less than 3.6 fell under the less incentives and reward systems group (87 teams). A high performing team was the one whose performance (product and process) score was half a standard deviation above the mean for the performance score (product and process) in the entire sample.

Table 9-5 More incentives and rewards group

\begin{tabular}{|l|l|l|l|l|l|l|}
\hline \multirow{2}{*}{$\begin{array}{l}\text { Mean }>=3.6 \\
\text { 105 Cases }\end{array}$} & \multicolumn{4}{l|}{ Product Performance } & \multicolumn{2}{l|}{ Process Performance } \\
\hline \multirow{2}{*}{$\begin{array}{l}\text { Low Technical } \\
\text { Capability }\end{array}$} & \multicolumn{2}{|l|}{ No. of high performing teams 7 } & \multicolumn{2}{l|}{ No. of high performing teams = 9 } \\
\cline { 2 - 7 } & Com & Cr & Sup & com & cr & sup \\
\cline { 2 - 7 } & 4.07 & 3.55 & 4.08 & 3.88 & 3.44 & 4.05 \\
\hline \multirow{2}{*}{$\begin{array}{l}\text { High Technical } \\
\text { Capability }\end{array}$} & No. of high performing teams = 20 & \multicolumn{2}{l|}{ No. of high performing teams = 12 } \\
\cline { 2 - 7 } & Com & Cr & Sup & com & cr & sup \\
\cline { 2 - 7 } & 4.17 & 3.82 & 4.44 & 4.16 & 3.79 & 4.43 \\
\hline
\end{tabular}

First, social capability ideal profile was calculated for the four groups in the more incentives and rewards group (Table 9.5). Distance score was computed for both the low 
technical capability and high technical capability groups (both product and process performance). We found that correlation coefficient between the distance score and product performance was $-0.300 *(\alpha=0.05)$, which was significant. Correlation coefficient between the distance score and process performance was -0.076 , which was not significant.

Table 9-6 Less incentives and rewards group

\begin{tabular}{|c|c|c|c|c|c|c|}
\hline $\begin{array}{l}\text { Mean }<3.6 \\
87 \text { Cases }\end{array}$ & \multicolumn{3}{|c|}{ Product Performance } & \multicolumn{3}{|c|}{ Process Performance } \\
\hline \multirow{3}{*}{$\begin{array}{l}\text { Low Technical } \\
\text { Capability }\end{array}$} & \multicolumn{3}{|c|}{ No. of high performing teams 5} & \multicolumn{3}{|c|}{ No. of high performing teams $=16$} \\
\hline & Com & $\mathbf{C r}$ & Sup & com & $\mathbf{C r}$ & Sup \\
\hline & 3.9 & 3.48 & 3.71 & 3.8 & 3.36 & 3.68 \\
\hline \multirow{3}{*}{$\begin{array}{l}\text { High Technical } \\
\text { Capability }\end{array}$} & \multicolumn{3}{|c|}{ No. of high performing teams $=14$} & \multicolumn{3}{|c|}{ No. of high performing teams $=16$} \\
\hline & Com & $\mathrm{Cr}$ & Sup & com & $\mathrm{Cr}$ & Sup \\
\hline & 4 & 3.5 & 4.15 & 4.04 & 3.55 & 4.03 \\
\hline
\end{tabular}

Second, social capability ideal profile was calculated for the four groups in the less incentives and rewards group (Table 9.6). Distance score was computed for both the low technical capability and high technical capability groups (both product and process performance). We found that correlation coefficient between the distance score and product performance was -0.057 , which was not significant. Similarly, correlation coefficient between the distance score and process performance was -0.131 , which was also not significant.

We found partial support for our arguments that incentives and reward systems played a moderating role in the relationship between fit and product and process performance. The results show that fit impacted product performance when more incentives and rewards were given in an organization but did not have any impact on process performance in the more rewards group. Fit 
had no impact on product and process performance in the low incentives and reward group. Thus, it can be inferred that fit will have a positive impact on product performance of the team when the organization is able to provide more incentives and rewards to the team.

\subsection{Specialization}

We expected specialization, which is an organizational factor to influence the relationship between fit and performance. Data was collected from the respondents about how they perceived the presence of specialization in their organization, under which their software development team was operating. Based on the average score of specialization (Mean $=3.72)$, we divided the dataset into two groups. Teams whose respondents gave scores greater than 3.72 fell under the greater specialization group (115 teams) and teams whose respondents gave scores less than or equal to 3.72 fell under the less specialization group ( 77 teams). A high performing team was the one whose performance (product and process) score was half a standard deviation above the mean for the performance score (product and process) in the entire sample.

Table 9-7 Greater specialization group

\begin{tabular}{|c|c|c|c|c|c|c|}
\hline $\begin{array}{l}\text { Mean }>3.72 \\
115 \text { Cases }\end{array}$ & \multicolumn{3}{|c|}{ Product Performance } & \multicolumn{3}{|c|}{ Process Performance } \\
\hline \multirow{3}{*}{$\begin{array}{l}\text { Low Technical } \\
\text { Capability }\end{array}$} & \multicolumn{3}{|c|}{ No. of high performing teams $=5$} & \multicolumn{3}{|c|}{ No. of high performing teams $=4$} \\
\hline & Com & $\mathbf{C r}$ & Sup & com & $\mathrm{Cr}$ & sup \\
\hline & 3.83 & 3.5 & 3.89 & 3.94 & 3.41 & 3.93 \\
\hline \multirow{3}{*}{$\begin{array}{l}\text { High Technical } \\
\text { Capability }\end{array}$} & \multicolumn{3}{|c|}{ No. of high performing teams $=22$} & \multicolumn{3}{|c|}{ No. of high performing teams $=12$} \\
\hline & Com & $\mathbf{C r}$ & Sup & com & $\mathrm{Cr}$ & sup \\
\hline & 3.88 & 3.52 & 4.27 & 4.08 & 3.57 & 4.32 \\
\hline
\end{tabular}


First, social capability ideal profile was calculated for the four groups in the greater specialization group (Table 9.7). Distance score was computed for both the low technical capability and high technical capability groups (both product and process performance). We found that correlation coefficient between the distance score and product performance was $-0.372^{* *}(\alpha=0.01)$. Similarly, correlation coefficient between the distance score and process performance was -0.132 , which was not significant.

Table 9-8 Less specialization group

\begin{tabular}{|c|c|c|c|c|c|c|}
\hline $\begin{array}{l}\text { Mean }<=3.72 \\
77 \text { Cases }\end{array}$ & \multicolumn{3}{|c|}{ Product Performance } & \multicolumn{3}{|c|}{ Process Performance } \\
\hline \multirow{3}{*}{$\begin{array}{l}\text { Low Technical } \\
\text { Capability }\end{array}$} & \multicolumn{3}{|c|}{ No. of high performing teams $=3$} & \multicolumn{3}{|c|}{ No. of high performing teams $=4$} \\
\hline & Com & $\mathbf{C r}$ & Sup & com & cr & Sup \\
\hline & 4.08 & 3.33 & 4.19 & 3.87 & 3.25 & 3.93 \\
\hline \multirow{3}{*}{$\begin{array}{l}\text { High Technical } \\
\text { Capability }\end{array}$} & \multicolumn{3}{|c|}{ No. of high performing teams $=12$} & \multicolumn{3}{|c|}{ No. of high performing teams $=\varepsilon$} \\
\hline & Com & $\mathbf{C r}$ & Sup & com & cr & Sup \\
\hline & 4.34 & 3.84 & 4.5 & 4.16 & 3.67 & 4.36 \\
\hline
\end{tabular}

Second, social capability ideal profile was calculated for the four groups in the less specialization group (Table 9.8). Distance score was computed for both the low technical capability and high technical capability groups (both product and process performance). We found that correlation coefficient between the distance score and product performance was -0.233 , which was not significant. Similarly, correlation coefficient between the distance score and process performance was -0.033 , which was also not significant. 
We found partial support for our arguments that specialization played a moderating role in the relationship between fit and product and process performance. The results show that fit impacted product performance when the organization had greater specialization but did not have any impact on process performance in the greater specialization group. Fit had no impact on product and process performance in the less specialization group. Thus, it can be inferred that fit will have a positive impact on product performance of the team when the organization has greater specialization.

\subsection{Team Size}

We expected team size to influence the relationship between fit and performance. Data was collected from the respondents about the number of members in a team. Based on the number of team members, we divided the dataset into two groups. Teams with team members more than and equal to 15 fell under the large team size group (80 teams) and teams with team members less than 15 fell under the small team size group (112 teams).

Table 9.9 Large team size

\begin{tabular}{|c|c|c|c|c|c|c|}
\hline $\begin{array}{l}\text { Size }>=15 \\
80 \text { Cases }\end{array}$ & \multicolumn{3}{|c|}{ Product Performance } & \multicolumn{3}{|c|}{ Process Performance } \\
\hline \multirow{3}{*}{$\begin{array}{l}\text { Low Technical } \\
\text { Capability }\end{array}$} & \multicolumn{3}{|c|}{ No. of high performing teams $=4$} & \multicolumn{3}{|c|}{ No. of high performing teams $=6$} \\
\hline & Com & $\mathbf{C r}$ & Sup & Com & cr & Sup \\
\hline & 3.81 & 3.53 & 3.79 & 3.87 & 3.44 & 3.88 \\
\hline \multirow{3}{*}{$\begin{array}{l}\text { High Technical } \\
\text { Capability }\end{array}$} & \multicolumn{3}{|c|}{ No. of high performing teams $=17$} & \multicolumn{3}{|c|}{ No. of high performing teams $=7$} \\
\hline & Com & $\mathbf{C r}$ & Sup & Com & cr & Sup \\
\hline & 3.82 & 3.64 & \begin{tabular}{|l}
4.34 \\
\end{tabular} & 3.97 & 3.34 & 4.33 \\
\hline
\end{tabular}


In the large team size group, a high performing team was the one whose performance (product and process) score was half a standard deviation above the mean for the performance score (product and process) in the entire sample. Social capability ideal profile was calculated for the four groups in the large team size group (Table 9.9). Distance score was computed for both the low technical capability and high technical capability groups (both product and process performance). We found that correlation coefficient between the distance score and product performance was -0.085 , which was not significant. Similarly, correlation coefficient between the distance score and process performance was 0.022 , which was also not significant.

Table 9-10 Small team size

\begin{tabular}{|c|c|c|c|c|c|c|}
\hline $\begin{array}{l}\text { Size }<=15 \\
112 \text { Cases }\end{array}$ & \multicolumn{3}{|c|}{ Product Performance } & \multicolumn{3}{|c|}{ Process Performance } \\
\hline \multirow{3}{*}{$\begin{array}{l}\text { Low Technical } \\
\text { Capability }\end{array}$} & \multicolumn{3}{|c|}{ No. of high performing teams $=4$} & \multicolumn{3}{|c|}{ No. of high performing teams $=4$} \\
\hline & Com & $\mathbf{C r}$ & Sup & com & cr & sup \\
\hline & 3.61 & 3.22 & 3.71 & 3.56 & 3.16 & 3.68 \\
\hline \multirow{3}{*}{$\begin{array}{l}\text { High Technical } \\
\text { Capability }\end{array}$} & \multicolumn{3}{|c|}{ No. of high performing teams $=21$} & \multicolumn{3}{|c|}{ No. of high performing teams $=13$} \\
\hline & Com & $\mathbf{C r}$ & Sup & com & cr & sup \\
\hline & 3.99 & 3.70 & 4.38 & 4.09 & 3.88 & 4.44 \\
\hline
\end{tabular}

In the small team size group, a high performing team was the one whose performance (product and process) score was half a standard deviation above the mean for the performance score (product and process) in the entire sample. Social capability ideal profile was calculated for the four groups in the small team size group (Table 9.10). Distance score was computed for both the low technical capability and high technical capability groups (both product and process performance). We found that correlation coefficient between the distance score and product 
performance was $-0.287^{*}(\alpha=0.05)$, which was significant. Similarly, correlation coefficient between the distance score and process performance was -0.046 , which was not significant.

We found support for our arguments that team size played a moderating role in the relationship between fit and product and process performance. The results show that fit impacted product performance when the team size was small but did not have any impact on process performance in the small team size group. Fit had no impact on product and process performance in the large team size group. Thus, it can be inferred that fit will have a positive impact on product performance of the team when the size is small.

In summary, in this chapter we presented the results of the role played by the moderating variables in the relationship between fit and performance. We chose to study fit at the overall level using the profile deviation approach. We found that centralization, formalization, incentives and rewards, specialization, and team size act as moderators in the relationship. In particular fit impacted product performance when centralization was more, formalization was more, more incentives and reward systems were given, greater specialization was present, and the team size was small. Fit impacted process performance when more centralization and formalization was present in the organization. 


\section{Chapter 10 Findings and Discussion}

This chapter reviews the results presented in the previous two chapters and analyzes them from the perspective of the goals of the research. The research was carried out with four broad research objectives in mind.

1. To develop the constructs of social and technical capabilities within the software development team context.

2. To study the impact of social and technical capabilities on the performance of the team.

3. To measure the fit (pair-wise fit and overall fit) and assess its impact on software development team performance.

4. To compare the three approaches for measuring fit.

Five research questions were formulated to achieve these research objectives and goals.

1. What are the dimensions of social capability of a software development team?

2. What are the dimensions of technical capability of a software development team?

3. What are the contributions of social and technical capabilities on software development team performance?

4. Does the fit between social and technical capabilities impact software development team performance?

5. Is one fit measurement approach better than the other in explaining the impact of fit on team performance?

Theoretical framework was developed based on the socio-technical systems (STS) theory, resource based view (RBV) theory, contingency theory, and the relevant IS literature. Different hypotheses were constructed to investigate the research questions. The research was 
successful in providing answers to the research questions and a significant and original contribution is made to the literature. Many interesting findings emerged from the research which will be discussed in the following sections. Qualitative responses from the respondents are presented to strengthen the arguments related to the relationships among the variables of interest.

First, the construct of social capability is discussed, followed by the construct of technical capability. Further, how these two constructs affect team performance is presented. Measurement of fit using the three approaches along with its impact on performance (both product and process) is discussed. Finally, the three fit measurement approaches are compared and contrasted.

\subsection{Social Capability: A Second Order Construct}

First objective of the research was to conceptualize and measure the construct of social capability. No previous research was available in the software development context where social capability as a construct was defined. We relied on the previous IS literature to identify the dimensions of social capability. Social capability was defined and conceptualized as a three dimensional construct where each dimension reflected a social process that takes place within a software development team. The three dimensions were communication, conflict resolution, and supportiveness. We found support for our arguments in the comments provided by the respondents and the results of the second order CFA.

We present some of the comments to show the importance of communication, conflict resolution, and supportiveness as seen by the software development managers or team leaders. These comments reassured the validity of the approach we have used to conceptualize the construct of social capability. 
“....Our team has a culture of open communication with daily standup meetings. Issues arising out of the meetings are quickly escalated for resolution.... "

“....We work in a very open office concept. Nobody has a private office ... even the president. Communication is quick and decision making is quick."

In words of the manager of a development project who supported the presence of various stakeholders in a team including a customer representative, despite increase in conflicts.

“.... Being a manager of a project related to development, all members of the team were having sound experience and had quite a good exposure to business processes. Team included members from customer too.

“.....This also led to conflicts but conflict resolution resulted in a very powerful ... software customized to customer's specific business requirements...."

One of the respondents, a team leader of a geographically dispersed team stated that

"Conflicts among the team members is the major factor that hinders the team performance. Cultural issues and geographical separation often raises the eyebrows of many members. It is often the case even with the senior members of the team, once the team meets together and gets to know each other; everything seems to get faded away. Team member starts relaying and trusting each other."

Importance of supportiveness and team building cannot be understated especially when the team comprise of people from both functional and technical domains. This sentiment was clearly reflected in the comments written by a number of managers.

"The team consists of separate individuals from all walks of life..........The technical team is combined along with the functional team and we work together for the completion of the project. The project can only be completed with all kinds of co-operation from each member of the team."

A project manager of a large software development project commented that

“....Keeping the team was a challenge, however most (members) were cross trained to do other positions (so people could be sick or go on vacation) and we developed an excellent team relationship. My staff meetings were more social then informational and we had plenty of team building events even when people had to pay their own way." 
Another project leader commented on the importance of team bonding and the sense of ownership.

"I think team bonding is essential to a good team. Most developers are not good at social events, so management should strive to encourage these types of bonding activities"

In words of a frustrated manager for a software development project on importance of team building and team spirit:

"Team spirit plays a major role in software development. If your team is jelled up well then you always have high productive results in all your projects. Today, I feel that if you have excellent team players in your team then you can deliver best solutions to client but its very tough to make all the team members happy and what ifeel this is one of the toughest task for manager to make everybody happy."

The second order CFA conducted for social capability offered some interesting findings. Specifically, this study provided insights into the relative value attached to each of the social capability dimensions by the software development professionals. The factor loadings of "social capability" relative to each first-order construct indicated the relative importance of each dimension. The results showed that each dimension had a very high factor loading. Among the three dimensions, communication (factor loading $=0.91$ ) had the highest loading followed by conflict resolution (factor loading $=0.75$ ) and supportiveness (factor loading $=0.71$ ). Thus it can be interpreted that, in the perception of software development professionals, these three dimensions make a significant contribution to the social capability of a software development team.

Second order factor modeling is able to show the contribution of each dimension to a higher level construct separately as compared to bundling together to get a composite score (Koufteros et al., 2009). The contribution of the thesis is not limited to proposing the 
conceptualization of social capability. The study provided a measurement model for conceptualizing social capability as a second order construct. The second order model generated had high reliability and validity which can be used in further research.

\subsection{Technical Capability: A Second Order Construct}

Second part of the first objective was to conceptualize and measure the construct of technical capability. No previous research was available in the software development context where technical capability as a construct was defined. We relied on the previous IS literature to identify the dimensions of technical capability. Technical capability was defined and conceptualized as a four dimensional construct where each dimension reflected a technical aspect. The dimensions were production capability, control (performance and standardization) capability, and IT infrastructure capability. We found support for our arguments in the comments provided by the respondents and the results of the second order CFA.

We present some of the comments to show the importance of production, control, and IT infrastructure capabilities as seen by software development managers and team leaders. These comments reassured the validity of the approach we have used to conceptualize the construct of technical capability.

Importance of standardization can be judged from the comment of one of the respondent who argued that despite having a strong technical team they lacked standardization which resulted in lot of disagreements. However, the disagreements were resolved with mutual discussions.

".....there is a lot of disagreement regarding the best way to do things since there is no standardization......" 
One of the respondents raised the concern about the lack of technical skills of the team members which he felt was related to the lack of education and training provided to the employees. In this digital age of changing technological and software solutions it is very important for the software development professionals to keep themselves updated.

“.... Software team members sometimes lacked fundamental software knowledge/understanding, and this interfered with communication between team members and with the writing of quality code. The company did not provide educational opportunities which might have alleviated this problem....."

Another respondent emphasized the benefits of sharing technical knowledge among the team members. In his words:

"In our team the technical knowledge is shared within members to train each other and bring them upto speed, this helps the team performance and creates a good environment for team members."

However, just providing training is not enough if you did not hire the right person in the first place. Recruitment and selection of the team members was a crucial concern as can be inferred from the comments of a few of the respondents.

"In general the team is built to ensure they have technical abilities and that they will build a team that can work together."

“....Finally, it boils down to hiring made by the group. If hiring is done carefully so that persons with good attitude and who are technically competent selected, there is a good chance that team gels well socially and technically."

Frustration was evident in the comment of one of the project manager whose company (senior management) was not willing to listen to the advice of his team for providing them with the right development tools needed to build the software.

"....The company was unwilling to listen to the sound advice of the software team, and acquire development tools and schedule product development in a manner that reflected that advice. The 
company preferred to cut corners at all stages of product development, to save money in development, and this led over a period of more than a decade to the gradual development of unmaintainable legacy software...."

The second order CFA conducted for technical capability offered some interesting findings. Specifically, this study provided insights into the relative value attached to each of the technical capability dimensions by the software development professionals. The factor loadings of "technical capability" relative to each first-order construct indicated the relative importance of each dimension. The results showed that dimensions of control (performance and standardization) had high factor loadings as compared to the other two dimensions. Among the four dimensions, control (standardization) (factor loading $=0.89$ ) and control (performance) (factor loading $=0.87)$ had higher loadings followed by IT infrastructure (factor loading $=0.51$ ) and production (factor loading $=0.48$ ). The values indicated that the factor loadings were close to 0.5 and above but they were not as high as in the social capability construct. The contribution of the thesis is not limited to proposing the conceptualization of technical capability. It also provided a measurement model for conceptualizing technical capability as a second order construct. The second order model for technical capability had high reliability and convergent validity. However, low factor loadings on two dimensions and some issues with discriminant validity have to be treated with caution and more work may be needed to build the construct.

\subsection{Relationship between Social and Technical Capability and Team Performance}

Second objective of this research was to investigate the relationship between social capability and team performance and technical capability and team performance. Positive impact of the various dimensions of social capability and technical capability on team performance is 
widely accepted in the literature (e.g. Kraut and Steeler, 1995; Hoegl and Guemendeum, 2001; Sawyer, 2001; Crowston et al., 2005; Henderson and Lee, 1992). The importance of social capability and technical capability for the team was also evident from the comments of the practitioners (our respondents).

- “....The team social and technical capabilities does impact a lot. It is most of the time very difficult to keep all associates motivated within the team and at the same time groom them on expected work and new technology...."

- "Social and technical capabilities will increase the confidence on the team which has more capabilities than other teams."

- "Social and technical capabilities within my team are part of continuous learning process. After the end of each project, best practices and lesson learnt by the team are gathered, published and followed in the next project as guidelines"

We found a number of studies devoted to the role played by the dimensions of social capability and technical capability. However, none of them addressed the issue of social capability and technical capability within the software development team context in a comprehensive way as it was done in this research. This research made significant contribution to the IS literature in better understanding the relationships between social capability and technical capability and team performance. It applied the proposed conceptualization of social capability and technical capability as a second order construct in analyzing the impact of the two on team performance. Performance was considered as a two dimensional construct comprising of product and process performance and the research looked at the impact of social and technical capability across the two dimensions of performance.

We used Model 4 (second order factor model) for both social and technical capability (Table 7.2 and Table 7.3) as the best measurement model for the social and technical capability constructs in testing the structural model with dependent variables of product and process 
performance. Results of the structural model confirmed our research hypotheses that social capability positively impact product and process performance. Path coefficients for social capability indicate that it impacted process performance $(0.35)$ more than product performance (0.23) (Table 7.8). This could be attributed to the fact that communication, conflict resolution, and supportiveness exert greater impact on the process of building the software than on the attributes related to the software product itself.

Technical capability showed positive and significant impact on product performance (0.48) but did not show a significant impact on process performance (0.15) (Table 7.8). This could be attributed to the fact that technical capability plays a greater role when it comes to developing a reliable and easy to maintain software as compared to developing the software on time and within budget. We can explain this result by looking at the conceptualization of the technical capability construct which tells us that skills, control standards and infrastructure are important when it comes to developing a reliable and easy to upgrade and maintainable software. At the same time these dimensions may not be as significant for developing the product on time and within budget.

\subsection{The Measurement of Fit}

One of the key contributions made by the study is the measurement of fit using three different but related approaches. Both the matching and moderation approaches are the reductionistic approaches for measuring fit (Venkataraman \& Prescott, 1990). These approaches are based on the assumption that the fit between the two constructs (social and technical capability) can be tested in terms of the pair-wise fit among the individual dimensions (such as communication and production capability) that represent the two constructs. Venkataraman's 
(1989) classification is based on two main criteria of specificity and anchoring, i.e., the degree of specificity in describing the relationship between the fit components and whether the fit is anchored with a criterion or a dependent variable. Matching and moderation approaches are high on specificity with moderation being criterion specific and matching being criterion free (Venkataraman, 1989). We also used profile deviation approach, which is the holistic/systems approach to fit measurement. Profile deviation approach is low on specificity and is a criterion specific approach. We used two reductionistic approaches and one holistic approach for measuring fit and studying its impact on product and process performance. Importance of fit within software development teams can be understood from the words of some of our respondents.

- "Our team has a good mix of propeller heads and process wonks. We celebrate the creative friction, and usually happy to come to work and interact".

- "Our team works as a very tightly knit.... So we meet every day for 30 min and discuss plan of action, stay in loop. This helps not only to improve social skills but technical skills as well."

- "The team has the technical ability for the project. The real strength of the team is the combination of the core technical skills and the ability to work well with the rest of the team."

The following sub-sections present the findings associated with the impact of fit variables (pair-wise and overall) on product and process performance.

\subsubsection{Fit between communication and technical capability variables}

Communication and production capability fit showed a positive impact on product and process performance. The results indicated that communication skills (both formal and informal) 
need to be carefully looked at the time of recruitment in the hiring and selection process. This can also be explained in the words of one of the software development manager.

"We pretty much don't hire people unless they are not only technically saavy, but also able to communicate well in both spoken and written forms. For example, we have a monthly staff meeting. The first half is typical business matters and updates. The second hour is a technical talk given by one or more of our developers, so we highly value communication, information sharing, and honest discussion and feedback."

Communication and IT infrastructure fit also showed positive impact on product and process performance. Communication should be made part of the IT infrastructure, i.e., organizations should carefully look at communication needs when taking IT infrastructure decisions. Communication and control fit showed no impact on product and process performance suggesting that communication had no impact on performance at varying levels of control. This can be explained by the argument that presence of control standards and control criteria for performance are neutral to the communication needs within a software development team.

\subsubsection{Fit between conflict resolution and technical capability variables}

Conflict resolution and production capability fit showed a positive impact on product performance. Conflicts are inevitable within a software development team. However, results show that conflicts can be resolved easily when the team members possess necessarily skills to do their jobs, ultimately resulting in improved product performance. We did not see any significant results with process performance. In words of one of the team leaders,

"....The team has the technical ability for the project. The real strength of the team is the combination of the core technical skills and the ability to work well with the rest of the team and in timely resolution of conflicts..."

Fit between conflict resolution and IT infrastructure impacted both process and product performance. Significant results suggest that organizations should carefully look at what can be done to build conflict resolution capability when taking IT infrastructure decisions. Conflict 
resolution and control fit showed no impact on product and process performance. This result was similar to the communication and control fit result.

\subsubsection{Fit between supportiveness and technical capability variables}

Fit between supportiveness and production capability fit showed a positive impact on product and process performance. The results suggest that organizations should pay close attention in hiring the people with a positive attitude and avoid hiring people with me too attitude. This sentiment was also reflected in the words of one of the software development manager

“....With long experience comes the rigidity of behaviour. In most instances, the teams are skewed one way or other due to experienced people. Though each individual is exceptional, as a team their contribution does not add up."

Supportiveness and IT infrastructure showed a positive impact on product and process performance. A sound IT infrastructure will aid the team members in supporting each other and ultimately in improving product and process performance. Supportiveness and control fit did not impact product and process performance. This was similar to the communication and control fit and conflict resolution and control fit result.

\subsubsection{Overall fit}

In the previous three sub-sections, we looked at the impact of various pair-wise fit variables on product and process performance. In this section we discuss the impact of overall fit on product and process performance. Based on the analysis using the profile deviation approach for measuring fit, we found that overall fit impacted both product and process performance. A direct question was also asked to the respondents about their perception of whether fit was present in their team. The results showed that presence of perceived fit positively impacted 
product and process performance. The results obtained by studying the impact of perceived fit and the fit calculated using profile deviation approach on performance were similar. Similar findings ensured the validity of our results and our hypothesized relationships. The sentiments were also reflected in the words of one of the software development manager:

"The team members were exceptionally talented and high performers, yet to bring together and deliver the project was a big challenge. The focus and energy was to gel them together. Often budget and time was another constraint to fit into the project schedule."

\subsection{Comparing the Three Fit Measurement Approaches}

Our final research objective was to compare the results of the three approaches for measuring fit and see for differences or similarities in the results. A comparison of the results of the reductionist and systems approaches to measuring fit was informative. The reductionist approaches (moderation and matching) assume that a pair-wise analysis of social and technical capability dimensions on performance is possible. These approaches may not be able to detect effects of fit that are present at the holistic or the system level (Van de Ven and Drazin, 1985; Venkataraman, 1989). Thus, we used the profile deviation approach to study the effects of fit present at the holistic level.

As can be seen from the discussion in the previous section both moderation and matching approaches provided similar results with a few exceptions. The aggregate findings of this study are shown in Table 10.1. The key observations from the table are presented below.

- First, matching and moderation approach gave similar results when studying the impact of fit variables on product performance. 
- Second, fit between control capability and other social capability variables (communication, conflict resolution, and supportiveness) did not appear to predict or explain product and process performance in both the moderation and matching approaches to fit measurement.

- Third, the moderation and matching approaches got the same results for the impact of fit between conflict resolution and technical capability variables (production, control, and IT infrastructure) on product and process performance.

- Fourth, communication and production capability fit measured under the moderation approach provided slightly different results for process performance, i.e., we saw the positive impact of the fit on product performance in both the approaches but did not see the impact of fit on process performance in the moderation perspective.

- Fifth, communication and IT infrastructure capability fit measured under the matching approach provided slightly different results for process performance, i.e., we saw the positive impact of the fit on product performance in both the approaches but did not see the impact of fit on process performance in the matching perspective.

- Sixth, moderation and matching approaches got the same results for the impact of fit between supportiveness and technical capability variables (production, control, and IT infrastructure) and performance except in one case. For supportiveness and infrastructure fit matching approach provided slightly different results when for process performance, i.e., we saw the positive impact of fit on product performance in both the approaches but did not see the impact of fit on process performance in the matching perspective.

- Finally, the profile deviation approach confirmed the positive impact of overall fit in improving product and process performance of a software development team. 
Table 10-1 Aggregate findings linking fit with product and process performance

\begin{tabular}{|l|l|l|l|l|}
\hline \multicolumn{1}{|c|}{ Fit Approach } & \multicolumn{2}{c|}{ Moderation } & \multicolumn{2}{c|}{ Matching } \\
\hline Variable & Product & Process & Product & Process \\
\hline com and pc & Yes & No & Yes & Yes \\
\hline com and cop & No & No & No & No \\
\hline com and cos & No & No & No & No \\
\hline com and it & Yes & Yes & Yes & No \\
\hline cr and pc & Yes & No & Yes & No \\
\hline cr and cop & No & No & No & No \\
\hline cr and cos & No & No & No & No \\
\hline cr and it & Yes & Yes & Yes & Yes \\
\hline sup and pc & Yes & Yes & Yes & Yes \\
\hline sup and cop & No & No & No & No \\
\hline sup and cos & No & No & No & No \\
\hline sup and it & Yes & Yes & Yes & No \\
\hline Fit Approach & & \multicolumn{2}{|c|}{ Profile Deviation } \\
\hline Variable & Product & Process & \\
\hline sc and tc & Yes & Yes \\
\hline
\end{tabular}

Similar results were obtained in most of the cases in testing the various bi-variate fit hypotheses using moderation and matching fit measurement approaches. Significant results were obtained when profile deviation was used. Results obtained in our research provide support for the classification scheme given by Venkataraman (1989) in the strategy literature. This also suggests that the application of the classification scheme for fit measurement is universal in nature and can be applied in domains other than strategy. 
In summary, overall pattern of the various results show that the pair-wise fit variables other than where control dimension was involved seemed to have positive performance implications. Being one of the first empirical investigations to study the fit of social and technical capability dimensions within the team, the results of this study are encouraging. Overall fit which was measured using the profile deviation approach was also found to significantly impact product and process performance. 


\section{Chapter 11 Conclusion}

We chose to study software development teams as our backdrop for understanding the impact of social and technical capabilities and their fit on team performance. The latest software development methodologies such as agile and scrum require a more collaborative and dynamic environment for teams to work. Short iterations and continuous integration mean results and feedback are shared continuously and system configurations change often. To achieve the needed flexibility, teams need to be in sync with the capabilities they possess and the capabilities need to be in sync with each other. Thus, we explored this concept of sync in this research, which is more commonly termed as fit in the academic world.

This chapter wraps up the thesis by providing a conclusion to the study. We first, discuss the theoretical and practical contributions made by the study. Second, the chapter outlines some of the limitations of the study, and finally, recommendations for future research are presented.

\subsection{Theoretical and Practical Contributions}

This is the first study of its kind to include the concept of fit in empirical research at the software development team level in a comprehensive and systematic way. We found a gap in the IS literature in studying the software development projects as an organized/whole system. We accepted this as a challenge and studied software development as a whole, including the technical and social sub-systems. The research highlighted the socio-technical nature of software development and the importance of studying social and technical capability and their fit on software development team performance. The results have also supported the arguments given 
by RBV theorists on the importance of focusing on capabilities within a firm. In this research, we have been able to successfully explain the importance of studying capabilities at the software development team level. The study made some novel contributions to the IS literature by understanding the impact of social and technical capabilities and their fit on team performance.

From a theoretical perspective, the primary contribution of this work is to provide an intellectually coherent view of software development. Software development is a socio-technical process that embraces both social and technical capability dimensions that are needed to facilitate team performance. While the constructs of the study were not the only ones impacting team performance, the authors argue that software development failures are equally related to social and technical reasons and the framework presented in the study is of considerable relevance to both academicians and practitioners. The second major contribution of the research is in the unpacking/break down of the social and technical capability constructs within the software development context which enhanced our understanding of the nature and dimensionality of those construct. We found support for the second order factor structure for social and technical capability constructs within our dataset. Modeling a set of constructs as an aggregate measure leads to different results than modeling a set of constructs as reflective indicators for a higher order construct (Law, Wong, \& Mobley, 1998; Bollen and Lennox, 1991). The second-order factor structure acknowledges the multi-dimensional nature of the social and technical capability constructs and is able to retain all the possible sources of variance at the same time.

The third major contribution of the study is related to the measurement of fit in multiple ways, which has not been specifically measured in the literature in a software development team context. From a methodological standpoint, the study results are able to provide 
recommendations on the conceptualization of fit most appropriate for a software development team. We used two reductionistic approaches and one systems approach for fit measurement. We found that the reductionistic approaches are more suited to study the fit at the micro level of analysis and the systems approach is more suited to study fit at the macro level of analysis. The results establish that Venkataraman's (1989) fit conceptualization classification scheme can be successfully applied in domains other than strategy research.

Practitioners can benefit by the results of the study. The study provides a way of assessing the capabilities of a software development team. Practitioners may be able to diagnose and correct the misfit present in the individual teams. The research provides benefits to the practitioners in directing their efforts in enhancing those capabilities that can contribute more towards team performance. They may be able to divert their precious resources in such a way that the capabilities are strengthened and the fit is increased. It can be concluded from the results of the study that fit between social capability dimensions and control capability did not show any performance implications. Results show that diverting resources away from building control capability and focusing more on hiring the right kind of people to work in the team for enhancing production capability can have positive performance implications for the team.

\subsection{Limitations of the Study}

One of the limitations of the study is associated with the data collection method. Our study only collected data from one source (team leader/manager) and single respondent bias cannot be ruled out in the study. Triangulation, i.e., collecting similar data from other team members can avoid the single respondent bias. However, there are costs and time constraints associated with triangulation approach and sample size may be reduced as well. A thorough 
literature review from various related domains was conducted to ensure that the construct definitions for social and technical capability were complete. However, social and technical capability constructs are complex and this research may not have captured every aspect of those constructs. Our study only focused on the capabilities internal to the team. A team operates in a larger environment within the organization as well as external to the organization. External factors may also play a role in the way capabilities impact team performance, e.g., if there is a shortage of skilled labor. Our study did not include other constructs that could significantly impact software development team performance.

The three different fit approaches have their own limitations too. In the moderation approach the existence of fit cannot be separated from the effects of fit. The meaning of fit is tied with the criterion variable (performance) and may not be generalizable to other performance measures (Venkataraman, 1989). The second limitation is associated with the difficulty in attaching theoretical meaning to the individual interaction terms. This approach fails to capture the overall interaction and its impact on performance. Matching approach is a criterion free approach and caution has to be exercised in interpreting the results of the matching approach when the fit is low. The deviation score analysis technique may not be able to justify the impact of fit on performance when the fit is low.

The profile deviation approach specifies the dimensions that are appropriate for a particular environment/situation and Venkataraman (1989) argued that can only be derived theoretically. However, research shows that most studies derive them empirically using a calibration sample of high performance in the given sample, limiting the potential of the profile deviation approach. The profile of high performance cases in the calibration sample may be less than ideal which results in underestimation of the negative impact of performance from misfits 
(Klaas et al., 2006). Burton et al. (2006) argued that deviations from the ideal profile can be calculated in a number of ways and more research is needed in deciding on the theoretical answers and implementing them in more complex statistical models.

Due to the inherent limitations associated with each of the fit measurement approaches researchers have to exercise caution in interpreting results and if possible should use multiple ways to measure fit (Venkataraman, 1989).

Finally, the study adopted a cross-sectional research design which captured the static nature of fit. Researchers have debated if fit should be treated as an outcome or a dynamic process (Avison et al., 2004). Software development is not a static process and the various social and technical elements are constantly changing. Lyytinen et al. (1998) argued that this change results in incongruence between the social and technical components that needs to be addressed by the software development team to avoid failure or underperformance. Sabherwal et al. (2001) argued that even if the fit is achieved organizations and teams may fail to recognize the need to adjust their fit with the changes happening around them and may become too complacent.

Despite the limitations, the study contributes to the current body of knowledge related to fit and team performance.

\subsection{Recommendations for Future Research}

A of number of future directions could be undertaken to provide better understanding of the relationships investigated in the study and to increase the generalizability of the results. The socio-technical fit and the performance impact discussed were for the traditional software development teams. However, the framework could be applied to other domains as well. For example, applying the same model in open source software development teams may provide 
some further insights into the relationship between fit and performance. Open source software development is different from the traditional way of developing the software. In future research, it could be seen if the results remain the same in the context of open source.

The research model presented in the study could be expanded to include determinants or the influencing factors for social and technical capability. With validated social and technical capability constructs, additional research could be carried out in linking the antecedents for these two constructs with the consequences. A similar study could also be carried out at the firm level. The framework could be extended to include other sub-systems external to the team, such as the environmental sub-system. The role of moderating variables in studying the pair-wise fit hypotheses could be a work for future research.

Based on the results of the study fit is found to impact team satisfaction. For future research, team satisfaction can be built into the research model as an intervening variable between fit and team performance. Another interesting extension of the model can be made by focusing on the level of maturity of the software development processes. Based on the SEICMM framework, a moderating variable related to the CMM maturity level may be introduced in the model which may help in improving the model fit.

As mentioned in the limitations section, fit is not a static entity. Studying the dynamic process of fit may aid in providing further insights into the fit research. We suggest that future researchers adopt a longitudinal view to deal with the dynamic processes that occur in achieving fit. 


\section{References}

Abramovitz, M. (1986). "Catching Up, Forging Ahead, and Falling Behind", Journal of Economic History 46(2): 385-406.

Acha, V. (2000). "The Role of Technological Capabilities in Determining Performance: The Case of the Upstream Petroleum Industry", DRUID Winter Conference on Industrial Dynamics, Hilerod.

Afuah, A. (2002). "Mapping Technological Capabilities into Product Markets and Competitive Advantage: The Case of Cholesterol Drugs", Strategic Management Journal 23(2): 171-179.

Agarwal, R. and E. Karahanna (2000). "Time flies when you're having fun: Cognitive absorption and beliefs about information technology usage", MIS Quarterly 24(4): 665-694.

Aladwani, A. M., A. Rai and A. Ramaprasad (2000). "Formal Participation and Performance of the System Development Group: The Role of Group Heterogeneity and Group-Based Rewards", The Database for Advances in Information Systems 31(4): 25-40.

Alexander, J. W. and W. A. Randolph (1985). "The Fit Between Technology and Structure as a Predictor of Performance in Nursing Subunits", Academy of Management Journal 28(4): 844859.

Amit, R. and P. J. H. Schoemaker (1993). "Strategic Assets and Organizational Rent", $\underline{\text { Strategic }}$ Management Journal 14(1): 33-46.

Anderson, J. C., and D. W. Gerbing (1982). "Some Methods for Respecifying Measurement Models to Obtain Unidimensional Construct Measurement", Journal of Marketing Research 19(4): 453-460.

Anderson, J. C., and D. W. Gerbing (1988). "Structural Equation Modelling in Practice: A Review and Recommended Two Step Appraoch", Psychological Bulletin 103(3): 411-423.

Andres, H. P. and R. W. Zmud (2001). "A Contingency Approach to Software Project Coordination", Journal of Management Information Systems 18(3): 41-70.

Avison, D., J. Jones, P. Powell, and D. Wilson (2004). "Using and Validating the Strategic Alignment Model,” Journal of Strategic Information Systems 13( 3): 223-246.

Aw and Batra (1998). "Technological Capability and Firm Efficiency in Taiwan (China)", The World Bank Economic Review 12(1): 59-79.

Bagozzi, R.P. and T. F. Heatherton (1994). "A General Approach to Representing Multifaceted Personality Constructs: Application to State Self-Esteem", Structural Equation Modelling 1 (1): 
$35-67$.

Bagozzi R. P. and Y. Yi (1990). "Assessing Method Variance in Multitrait-Multimethod Matrices: The Case of Self-Reported Affect and Perceptions at Work", Journal of Applied Psychology 75(5): 547-560.

Baldwin B. (1989). "A Primer in the Use and Interpretation of Structural Equation Models", Measurement and Evaluation in Counseling and Development 22(2): 100-112.

Banker, R. D., G. B. Davis and S. A. Slaughter (1998). "Software Development Practices, Software Complexity, and Software Maintenance Performance: A Field Study", Management Science 44(4): 433-450.

Barki, H., S. Rivard and J. Talbot (1993). "Toward an Assessment of Software Development Risk", Journal of Management Information Systems 10(2): 203-225.

Barki, H. and J. Hartwick (1994). "User Participation, Conflict, and Conflict Resolution: The Mediating Roles of Influence", Information Systems Research 5(4): 422-438.

Barki, H., S. Rivard and J. Talbot (2001). "An Integrative Contingency Model of Software Project Risk Management", Journal of Management Information Systems 17(4): 37-69.

Barney, J. (1991). "Firm Resources and Sustained Competitive Advantage", Journal of Management 17(1): 99-120.

Bell, M. and K. Pavitt (1993 1995). "Technological Accumulation and Industrial Growth: Contrasts Between Developed and Developing Countries", Industrial and Corporate Change 2(2): 157-210.

Benbasat, I. and I. Vessey (1980). "Programmer and Analyst Time/Cost Estimation", MIS Quarterly 4(2): 31-43.

Bergeron, F., L. Raymond and S. Rivard (2001). "Fit in Strategic Information Technology Management Research: An Empirical Comparison of Perspectives", OMEGA International Journal of Management Science 29(2): 125-142.

Berryman, K., J. Jones, J. Mohiuddin and M. R. Rangaswami (2007). State of the Software Industry 2007, McKinsey \& Company Inc. and Sand Hill Group: 20.

Bettenhausen, K. L. and J. K. Murnigham (1991). "The Development of an Intragroup Norm and the Effects of Interpersonal and Structural Challenges", Administrative Science Quarterly 36(1): 20-35.

Bharadwaj, A. S. (2000). "A Resource-Based Perspective on Information Technology Capability and Firm Performance: An Empirical Investigation”, MIS Quarterly 24(1): 169-196. 
Boehm, B. and R. Ross (1989). "Theory -W Software Project Management: Principles and Examples", IEEE Transactions on Software Engineering 15(7): 902-916.

Bollen, K. A. (1989). Structural Equations with Latent Variables New York, John Wiley \& Sons.

Boomsma, (1987). "The Robustness of Maximum Likelihood Estimation in Structural Equation Models", In Cuttance, P. and E. Russell (Eds.) Structural Modeling by Example: Applications in Educational, Sociological, and Behavioural Research. Cambridge University Press, 160-188.

Bostrom, R. P. and S. Heinen (1977). "MIS Problems and Failures: A Socio-Technical Perspective. Part I: The Causes", MIS Quarterly 1(3): 17-32.

Brancheau, J. C., B. D. Janz and J. C. Wetherbe (1996). "Key Issues in Information Systems Management: 1994-95 SIM Delphi Results", MIS Quarterly 20(2): 225-242.

Broadbent, M., P. Weill, T. O'Brien and B. N. Neo (1996). "Firm Context and Patterns of IT Infrastructure Capability", Proceedings of the $17^{\text {th }}$ International Conference on Information Systems, Cleveland, U.S.A.

Broadbent, M., P. Weill and D. St. Clair (1999). "The Implications of Information Technology Infrastructure for Business Process Redesign", MIS Quarterly 23(2): 159-182.

Brusoni, S. (2005). "The Limits to Specialization: Problem Solving and Coordination in 'Modular Networks"', Organization Studies 26 (12):1885-1907.

Burton, R. M., B. Eriksen, D. D. Hakonsson, and C. Snow (2006). Organization Design: The Evolving State of the Art. New York, Springer.

Byrd, T. A. and D. E. Turner (2000). "Measuring the Flexibility of Information Technology Infrastructure: Exploratory Analysis of a Construct", Journal of Management Information Systems 17(1): 167-208.

Caramel, E. and S. Sawyer (1998). "Packaged Software Development Teams: What makes them Different?", Information Technology and People 11(1): 7-19.

Carayannis, E. G. and J. W. Alexander (2002). "Is Technological learning a Firm Core Competence, When, How and Why? A Longitudinal, multi-industry Study of Firm Technological Learning and Market Performance", Technovation 22(10): 625-643.

Carter, N. M. and T. L. Keon. (1989). "Specialization as a Multidimensional Construct", Journal of Management Studies 26 (1): 11-28.

Cataldo, M., Wagstrom, J. D. Herbsleb and K. Carley (2006). Identification of Coordination Requirements: Implications for the Design of Collaboration and Awareness Tools, Computer Supported Cooperative Work, Banff, Alberta, Canada, ACM. 
Chakravarthy, B. S. (1987). "On Tailoring a Strategic Planning System to its Context: Some Empirical Evidence", Strategic Management Journal 8(6): 517-534.

Charette, R. N. (2005). "Why Software Fails", IEEE Spectrum 42(9): 42-49.

Cheney, P. H. and L. N. R. (1980). "Information Systems Skills Requirements: A Survey”, $\underline{\text { MIS }}$ Quarterly 4(1): $35-43$.

Cherns, A. (1976). "The Principles of Sociotechnical Design", Human Relations 29(8): 783-792.

Cherns, A. (1987). "Principles of Sociotechnical Design Revisited", 153-162.

Child, J. (1972). "Organization Structure and Strategies of Control: A Replication of the Aston Study", Administrative Science Quarterly 17 (2): 163-177.

Child, J. (2001). "Trust: The Fundamental Bond in Global Collaboration", Organizational Dynamics 29(4): 274-288.

Chin, W. W. (1998). "Issues and Opinion on Structural Equation Modeling", Management Information Systems Quarterly 22(1): 7-16.

Chin, W. W., A. Gopal, and W. D. Salisbury (1997). "Advancing the theory of adaptive structuration: The development of a scale to measure faithfulness of appropriation", Information Systems Research 8(4): 342-367.

Chung, W. Y. and P. J. Guinan (1994). Effects of Participative management on the Performance of Software Development Teams. SIGCPR, Alexandria, Virginia, U.S.A., ACM.

Churchill, J. G. A. (1979). "A Paradigm for Developing Better Measures of Marketing Constructs", Journal of Marketing Research 16(1): 64-73.

Cibbora, C. and O. Hanseth (1998). "Toward a Contingency View of Infrastructure an Knowledge: An Exploratory Study", Proceedings of the $19^{\text {th }}$ International Conference on Information Systems, Helsinki, Finland.

Clegg, C. W., P. E. Waterson and C. M. Axtell (1997). "Software Development: Some Critical Reviews", Behavior and Information Technology 16(6): 359-362.

Clegg, C. W. (2000). "Sociotechnical Principles for System Design", Applied Ergonomics 31(5): 463-477.

Coakes, E., D. Willis and R. Lloyd-Jones, Eds. (2000). The New SocioTech: Graffiti on the Long Wall. Computer Supported Cooperative Work. London, Springer-Verlag.

Cooper, D. R. and P. S. Schindler (1998). Business Research Methods. New York, McGraw-Hill 
International Editions.

Cooprider, J. G. and J. C. Henderson (1990). "Technology-Process Fit: Perspectives on Achieving Prototyping Effectiveness." Journal of Management Information Systems 7(3): 67-87.

Cortina, J. M., G. Chen, and W. P. Dunlap (2001). "Testing Interaction Effects in LISREL: Examination and Illustration of Available Procedures," Organizational Research Methods 4(4): 324-360.

Crowston, K., K. Wei, Q. Li, U. Y. Eseryel and J. Howison (2005). "Coordination of Free/Libre Open Source Software Development," Proceedings of the 26th International Conference on Information Systems, Las Vegas, U.S.A.

Cummings, T. G. (1978). "Self-Regulating Work Groups: A Socio-Technical Synthesis." The Academy of Management Review 3(3): 625-634.

Curtis, B., H. Krasner and N. Iscoe (1988). "A Field Study of the Software Design Process for Large Systems." Communications of the ACM 31(11): 1268-1287.

Damanpour, F. (1991). "Organizational Innovation: A Meta-Analysis of Effects of Determinants and Moderators." Academy of Management Journal 34(3): 555-590.

David, F. R., W. A. Randolph and J. A. Pearce II (1989). "Linking Technology and Structure to Enhance Group Performance." Journal of Applied Psychology 74(2): 233-241.

Davis, D (2005). Business research for decision making. Canada, Thomson Brooks/Cole.

Davis, G. B., A. S. Lee, K. R. Nickles, S. Chatterjee, R. Hartung and W. Youlan (1992). "Diagnosis of an Information System Failure." Information and Management 23(5): 293-318.

DeBrabander, B. and A. Edstrom (1977). "Successful Information System Development Projects." Management Science 24(2): 191-199.

Deephouse, c., T. Mukhopadhyay, D. r. Goldenson and M. I. Kellner (1996). "Software Processes and Project Performance." Journal of Management Information Systems 12(3): 187205.

Deutsch, M. (2003). "Cooperation and Conflict: A Personal Perspective on the History of the Social Psychological Study of Conflict Resolution," In West, M. A., D. J. Tjosvold, and K. G. Smith (Eds.) International Handbook of Organizational Teamwork and Cooperative Working. John Wiley and Sons.

Di Tuillo, D. and B. Bahli (2006). "The Impact of Software Process Maturity and Software Development Risk on the Performance of Software Development Projects," Proceedings of the Twenty-Seventh International Conference on Information Systems. Milwaukee, U.S. 
Doherty, N. F. and M. King (1998). "The Importance of Organizational Issues in Systems Development." Information Technology and People 11(2): 104-123.

Doll,W. J., W. Xia and G. Torkzadeh (1994). "A Confirmatory Factor Analysis of the End-User Computing Satisfaction Instrument,” MIS Quarterly, 18(4): 453-461.

Doll, W. J., T.S. Raghunathan, J. S. Lim, and Y. P. Gupta (1995). "Research Report-A Confirmatory Factor Analysis of the User Information Satisfaction Instrument," Information Systems Research, 6(2): 177-188.

Dollinger, M. J. (1995). Entrepreneurship: Strategies and Resources. Boston, MA, Irwin.

Dosi, G., R. R. Nelson, S. G. Winter, eds. (2000). The Nature and Dynamics of Organizational Capabilities. Oxford University Press, Oxford, UK.

Dougherty, D. (1992). "Interpretive Barriers to Successful Product Innovation in Large Firms." Organization Science 3(2): 179-202.

Drazin, R. and A. H. Van de Ven (1985). "Alternative Forms of Fit in Contingency Theory." Administrative Science Quarterly 30(4): 514-539.

Duncan, N. B. (1995). "Capturing Flexibility of Information Technology Infrastructure: A Study of Resource Characteristics and their Measure." Journal of Management Information System 12(2): $37-57$.

Dutta, S., O. Narasimhan and S. Rajiv (1999). "Success in High-Technology Markets: Is Marketing Capability Critical.” Marketing Science 18(4): 547-568.

Dyusters, G. and J. Hagedoorn (2000). "Core Competencies and Company Performance in the Worldwide Computer Industry." Journal of High Technology Management Research 11(1): 7591.

Eisenhardt, K. M. (1985). "Control: Organizational and Economic Approaches." Management Science 31(2): 134-150.

Emery, F. (1982). "New Perspectove on the World of Work: Sociotechnical Foundations for a New Social Order." Human Relations 35(12): 1095-1122.

Ethiraj, S. K., P. Kale, M. S. Krishnan and J. V. Singh (2005). "Where Do Capabilities Come from and How Do they Matter? A Study in the Software Services Industry, " Strategic Management Journal 26(1): 25-45.

Fagerberg, J. (1994). "Technology and International Differences in Growth Rates." Journal of Economic Literature 32(3): 1147-1175.

Faraj, S. and L. Sproull (2000). "Coordinating Expertise in Software Development Teams." 
Management Science 46(12): 1554-1568.

Faraj, S. and V. Sambamurthy (2006). "Leadership of Information Systems Development Projects." IEEE Transactions on Engineering Management 53(2): 238-249.

Fichman, R. G. and C. Kemerer (2001). "Incentive Compatibility and Systematic Software Reuse." The Journal of Systems and Software 57(1): 45-60.

Figueiredo, P. N. (2001). Technological Learning and Competitive Performance. Cheltenham, U.K., Edward Elgar.

Follett, M. (1973). "Constructive Conflict," In Fox E. and L. Urwick. (Eds.) Dynamic Administration: The Collected Papers of Mary Parker Follett. London, Pitman.

Fornell, C. and D. F. Larcker (1981). "Evaluating Structural Equation Models with Unobservable Variables and Measurement Error," Journal of marketing research 18(1): 39-50.

Galbraith, J. R. (1977). Organization Design. Reading: MA, Addison-Wesley.

Gerbing, D. W. and J. C. Anderson (1985). "The Effects of Sampling Error and Model Characteristics on Parameter Estimation for Maximum Likelihood Confirmatory Factor Analysis," Multivariate Behavioral Research 20(3): 255-271.

Gladstein, D. L. (1984). "Groups in Context: A Model of Task Group Effectiveness." Administrative Science Quarterly 29(4): 499-517.

Gobeli, D. H., H. F. Koenig and I. Bechinger (1989). "Managing Conflicts in Software Development Teams: A Multilevel Analysis." Journal of Product Innovation Management 15(5): 423-435.

Goodhue, D. L. and R. L. Thompson (1995). "Task-Technology Fit And Individual Performance." MIS Quarterly 19(2): 213-236.

Gosain, S., D. P. Darcy, A. Gopal and Y. Lichtenstein (2003). "Organizational Control Systems and Software Quality: A Cross-National Study," Proceedings of the Twenty-Fourth International Conference on Information Systems, Seattle, Washington, U.S.A.

Grant, R. M. (1991). "The Resource-Based Theory of Competitive Advantage: Implications for Strategy Formulation." California Management Review 33(3): 114-135.

Grant, R. M. (1996). "Prospering in Dynamically-Competitive Environments: Organizational Capability as Knowledge Integration." Organization Science 7(4): 375-387.

Green, S. and T. Taber (1980). "The Effects of Three Social Decision Schemes in Decision Group Performance." Organizational Behavior and Human Performance 25(1): 97-106. 
Grover, V. and M.D. Goslar (1993). "The Initiation, Adoption, and Implementation of Telecommunications Technologies in U.S. Organizations," Journal of Management Information Systems 10(1): 141-163.

Gruhn, V. (1992). Software Processes and Social Processes. Fifth International Workshop on Computer-Aided Software Engineering, Montreal, Quebec, Canada.

Guinan, P. J., J. G. Cooprider and S. Sawyer (1997). "The effective use of automated application development tools.” IBM Systems Journal 36(1): 124-139.

Guinan, P. J., J. G. Cooprider and S. Faraj (1998). "Enabling Software Development Team Performance During Requirements Definition: A Behavioral Versus Technical Approach." Information Systems Research 9(2): 101-125.

Haas, M. R. (2006). "Knowledge Gathering, Team Capabilities, and Project Performance in Challenging Work Environments." Management Science 52(8): 11701184.

Hackman, J. R. (1987). "The Design of Work Teams," In Lorsch J. W. (Eds.) Handbook of Organizational Behavior. Englewood Cliffs, NJ, Prentice-Hall, 315-342.

Hage, J. and A. Michael (1967). "Relationship of Centralization to Other Structural Properties." Administrative Science Quarterly 12(1): 72-92.

Hardgrave, B. C., R. L. Wilson and K. Eastman (1999). "Toward a Contingency Model for Selecting an Information System Prototyping Strategy." Journal of Management Information Systems 16(2): 113-136.

Hayduk, L. A. (1988). Structural Equation Modeling with LISREL: Essentials and Advances. Baltimore, Johns Hopkins University Press, 405 pages.

He, J., B. S. Butler and W. R. King (2007). "Team Cognition: Development and Evolution in Software Project Teams." Journal of Management Information Systems 24(2): 261-292.

Henderson, J. C. and J. G. Cooprider (1990). "Dimensions of I/S Planning and Design Aids: A Functional Model of CASE Technology.” Information Systems Research 1(3): 227-254.

Henderson, J. C. and S. Lee (1992). "Managing I/S Design Teams: A Control Theories Perspective." Management Science 38(6): 757-777.

Henderson, R. and I. Cockburn (1994). "Measuring Competence? Exploring Firm Effects in Pharmaceutical Research.” Strategic Management Journal 15(S1): 63-84.

Herbsleb, J. D. and D. Moitra (2001). "Guest Editors' Introduction: Global Software Development." IEEE Software 18(2): 16-20.

Herbsleb, J. D. and A. Mockus (2003). "An Empirical Study of Speed and Communication in 
Globally Distributed Software Development." IEEE Transactions on Software Engineering 29(6): 481-494.

Hirschheim, R., H. K. Klein and M. Newman (1991). "Information Systems Development as Social Action: Theoretical Perspective and Practice." OMEGA International Journal of Management Science 19(6): 587-608.

Hirschheim, R., H. K. Klein and K. Lyytinen (1996). "Exploring the Intellectual Structures of Information Systems Development: A Social Action Theoretic Analysis." Accounting, Management, and Information Technology 6(1/2): 1-64.

Hoegl, M. and H. G. Gemuenden (2001). "Teamwork Quality and the Success of Innovative Projects: A Theoretical Concept and Empirical Evidence." Organization Science 12(4): 435-449.

Hoffman, J. J., J. B. Cullen, N. M. Carter and C. F. Hofacker (1992). "Alternative Methods for Measuring Organization Fit: Technology, Structure, and Performance." Journal of Management Studies 18(1): 45-57.

Hoopes, D. G. and S. Postrel (1999). "Shared Knowledge, "Glitches," and Product Development Performance.” Strategic Management Journal 20(9): 837-865.

Hoopes, D. G., T. L. Madsen and G. Walker (2003). "Guest Editors' Introduction to the Special Issue: Why is There a Resource-Based View? Toward a Theory of Competitive Heterogeneity." Strategic Management Journal 24(10): 889-902.

Hseih, M.-H. and K.-H. Tsai (2007). "Technological Capability, Social Capital and the Launch Strategy for Innovative Products." Industrial Marketing Management 36(4): 493-502.

Humphery, W. S. (1988). "Characterizing the Software Process: A Maturity Framework." IEEE Software 5(2): 73-79.

Huselid, M. A., S. E. Jackson and R. S. Schuler (1997). "Technical and Strategic Human Resource Management Effectiveness as Determinants of Firm Performance." Academy of Management Journal 40(1): 171-188.

Iivari, J. and R. Hirschheim (1996). "Analyzing information systems development: a comparison and analysis of eight IS development approaches." Information Systems 21(7): 551-575.

Isobe, T., S. Makino, D. B. Montgomery and L. K. Chian (2007). "Technological Capabilities and Firm Performance: The Case of Small Manufacturing Firms in Japan," Working paper, Stanford, CA, Stanford Graduate School of Business: 29.

Ivari, J. (1992). "The Organizational Fit of Information Systems." Journal of Information Systems 2(1): 3-29.

Jaccard, J.and C. K. Wan (1995). "Measurement Error in the Analysis of Interaction Effects 
between Continuous Predictors Using Multiple Regression: Multiple Indicator and Structural Equation Modeling," Psychological Bulletin 117(2): 348-357.

Jawroski, B. J. and A. K. Kohli (1993). "Market Orientation: Antecedents and Consequences." Journal of Marketing 57(3): 53-70.

Jiang, J. J., G. Klein and T. L. Means (2000). "Project Risk Impact on Software Development Team Performance." Project Management Journal 31(4): 19-26.

Jiang, J. J. and G. Klein (2000). "Software Development Risks to Project Effectiveness." The Journal of Systems and Software 52(1): 3-10.

Jiang, J. J., G. Klein and R. A. Pick (2003). "The Impact of IS Department Organizational Environments upon Project Team Performances." Information and Management 40(3): 213-220.

Jones, M. C. and A. W. Harrison (1996). "IS Project Team Performance: An Empirical Assessment." Information and Management 31(2): 57-65.

Jöreskog, K. G. (1973). "A General Method for Estimating a Linear Structural Equation System," In Goldberger, A. S. and O. S. Duncan (Eds.) Structural Equation Models in the Social Sciences. New York Academic press, 85-112.

Jöreskog, K. C. and D. Sörbom (2001). LISREL 8 User's Reference Guide. Chicago, Scientific Software International.

Jöreskog, K. G. and F. Yang (1996). "Non-linear Structural Equation Models: The Kenny-Judd Model with Interaction Effects," In Marcoulides, G. A. and R. E. Schumacker (Eds.) Advanced Structural Equation Modeling: Issues and Techniques Mahwah, NJ, Lawrence Erlbaum Associates, 57-88.

Joyce, W., J. J. W. Slocum and M. A. Von Glinow (1982). "Person-Situation Interaction: Competing Models of Fit." Journal of Occupational Behaviour 3(4): 265-280.

Kaiser, K. M. and R. P. Bostrom (1982). "Personality Characteristics of MIS Project Teams: An Empirical Study and Action-Research Design." MIS Quarterly 6(4): 43-60.

Kang, H.-R., H.-D. Yang and C. Rowley (2006). "Factors in Team Effectiveness: Cognitive and Demographic Similarities of Software Development Team Members." Human Relations 59(12): 1681-1710.

Katz, J. M. (1985). "Domestic Technological Innovations and Dynamic Competitive Advantages: Further Reflections on a Comparative Case-Study Program," In Rosenberg, N. and C. Firschtak, International Technology Transfer: Concepts, Measures and Comparisons. New York, Praeger.

Keen, P. G. W. (1991). Shaping the Future: Business Design Through Information Technology. 
Boston, MA, Harvard Business School Press.

Keen, P. G. W. (1997). The Process Edge: Creating Value where it Counts. Boston, MA, Harvard Business School Press.

Keil, M., A. Rai, J. E. C. Mann and G. P. Zhang (2003). "Why Software Projects Escalate: The Importance of Project Management Constructs." IEEE Transactions on Engineering Management 50(3): 251-261.

Keller, R. T. (1994). "Technology-Information Processing Fit and the Performance of R\&D Project Groups: A Test of Contingency Theory." The Academy of Management Journal 37(1): 167-179.

Kemerer, C. (1989). "An agenda for Research in the Managerial Evaluation of Computer-aided Software Engineering (CASE) Tool Impacts," Proceedings of the 22nd Annual Hawaii International Conference on System Sciences, Hawaii.

Kenny, D. A. and C. M. Judd (1984). "Estimating the Nonlinear and Interactive Effects of Latent Variables," Psychological Bulletin 96(1): 201-210.

Khatri, V., I. Vessey, V. Ramesh, P. Clay and S.-J. Park (2006). "Understanding Conceptual Schemas: Exploring the Role of Application and IS Domain Knowledge." Information Systems Research 17(1): 81-99.

Kim, K. K. (1988). "Organizational Coordination and Performance in Hospital Accounting Information Systems: An Empirical Investigation." The Accounting Review 63(3): 472-489.

Kim, K. K. and N. S. Umanath (1993). "Structure and perceived Effectiveness of Software Development Subunits: A Task Contingency Analysis." Journal of Management Information Systems 9(3): 157-181.

Kirsch, L. J. (1996). "The Management of Complex Tasks in Organizations: Controlling the Systems Development Process." Organization Science 7(1): 1-21.

Kirsch, L. J. (1997). "Portfolios of Control Modes and IS Project Management." Information Systems Research 8(3): 215-239.

Kish, L. (1965). Survey Sampling. New York, John Wiley and Sons.

Klaas, P., J. Lauridsen, and D. Hakonsson (2006). "New developments in contingency fit theory," In Burton, R. M., B. Eriksen, D. D. Hakonsson, and C. Snow (Eds.) Organization Design: The Evolving State of the Art. New York, Springer, 143-164.

Kline, R. B. (2005). Principles and Practice of Structural Equation Modelling, New York, The Guilford Press. 
Kline, T. J. and B. Dunn (2000). "Analysis of Interaction Terms in Structural Equation Models: A Non-Technical Demonstration using the Deviation Score Approach," Canadian Journal of Behavioural Science 32(2): 127-132.

Kogut, B. and U. Zander (1992). "Knowledge of the Firm, Combinative Capabilities, and the Replication of Technology." Organization Science 3(3): 383-397.

Koufteros, X., S. Babbar, and M. Kaighobadi (2009). “A Paradigm for Examining Second-Order Factor Models Employing Structural Equation Modeling," International Journal of Production Economics 120(2): 633-652.

Kraut, R. E. and L. A. Streeler (1995). "Coordination in Software Development." Communications of the ACM 38(3): 69-81.

Kristof, A. L. (1996). "Person-organization Fit: An Integrative review of its Conceptualizations, Measurement, and Implications." Personnel Psychology 49(1): 1-49.

Kulkarni, U. R., S. Ravindran and R. Freeze (2006-07). "A Knowledge Management Success Model: Theoretical Development and Empirical Validation." Journal of Management Information Systems 23(3): 309-347.

Lado, A. and M. Wilson (1994). "Huma Resource Systems and Sustained Competitive Advantage: A Competency-Based Perspective." The Academy of Management Review 19(4): 699-727.

Lai, V. S. (1999). "A Contingency Examination of CASE-task Fit on Software Developer's Performance." European Journal of Information Systems 8(1): 27-39.

Lakhanpal, B. (1993). "Understanding the Factors Influencing the Performance of Software Development Groups: An Exploratory Group-level Analysis." Information and Software Technology 35(8): 468-473.

Lall, S. (1992). "Technological Capabilities and Industrialisation." World Development 20(2): 165-186.

Land, F. (2000). "Evaluation in a Socio-Technical Context," In Basskerville, R., J. Stage, and J. I. DeGross (Eds.) Organizational and Social Perspectives on Information Technology. Boston, Kluwer Academic Publishers, 115-126.

Law, K. S., C. S. Wong, and W. H. Mobley (1998). "Toward a taxonomy of multidimensional constructs", The Academy of Management Review 23(4): 741-755.

Lawrence, P. R. and J. W. Lorsch (1967). Organization and Environment. Cambridge, MA, Harvard University Press.

Lee, D. M. S., E. M. Trauth and D. Farwell (1995). "Critical Skills and Knowledge 
Requirements of IS Professionals: A Joint Academic/Industry Investigation.” MIS Quarterly 19(3): 313-340.

Lee, C., K. Lee and J. M. Pennings (2001). "Internal Capabilities, external Networks, and Performance: A Study on Technology Based Ventures." Strategic Management Journal 22(6-7): 615-640.

Lee, G. and W. Xia (2005). "The Ability of Information Systems Development Project Teams to Respond to Business and Technology Changes: A Study of Flexibility Measures." European Journal of Information Systems 14(1): 75-92.

Leonard-Barton, D. (1992). "Core Capabilities, Core Rigidities: Paradox in Managing New Product Development," Strategic Management Journal 13(S1): 111-125.

Lewis, B. R., G. F. Templeton and T. A. Byrd (2005). "A Methodology for Construct Development in MIS Research," European Journal of Information Systems 14(4): 388-400.

Lewis, K. (2004). "Knowledge and Performance in Knowledge-worker Teams: A Longitudinal Study of Transactive Memory Systems." Management Science 50(11): 1519-1533.

Liang, T.-P., C.-C. Liu, L. Tse-Min and L. Binshan (2007). "Effect of Team Diversity on Software Project Performance." Industrial Management \& Data Systems 107(5): 636-653.

Lurey, J. S. and M. H. Raisinghani (2001). "An Empirical Study of Best Practices in Virtual Teams," Information and Management 38(8): 523-544.

Lyytinen, K., L. Mathiassen and J. Rooponen (1998). "Attention Shaping and Software Risk-A Categorical Analysis of Four Classical Risk Management Approaches." Information Systems Research 9(3): 233-255.

Mahoney, J. T. and J. R. Pandian (1992). "The Resource-Based View Within the Conversation of Strategic Management." Strategic Management Journal 13(5): 363-380.

Makadok, R. (2001). "Towards a Synthesis of Resource-Based and Dynamic Capability Views of Rent Creation." Strategic Management Journal 22(5): 387-402.

Malerba, F. and S. Torrisi (1992). "Internal Capabilities and External Networks in Innovative Activities. Evidence from the Software Industry." Economics of Innovation and New Technology 2: 49-71.

Mandal, A. and S. G. Deshmukh (1994). "Vendor Selection Using Interpretive Structural Modelling (ISM)." International Journal of Operations and Production Management 14(6): 52-59.

March, J. G. and H. A. Simon (1958). Organizations, John Wiley \& Sons. 
Marchand, D. A., W. J. Kettinger and J. D. Rollins (2000). "Information Orientation: People, Technology and the Bottom line." Sloan Management Review 41(4): 69-80.

Markus, L. (2001). "Toward a Theory of Knowledge Reuse: Types of Knowledge Reuse Situations and Factors in Reuse Success." Journal of Management Information Systems 18(1): 57-93.

Marsh, H. W. and D. Hocevar (1985). "Application of confirmatory factor analysis to the study of self-concept: First-and higher-order factor models and their invariance across groups", Psychological Bulletin 97(3): 562-582.

McEvily and Chakravarthy (2002). "The Persistence of Knowledge-based Advantage: An Empirical Test for Product Performance and Technological Knowledge." Strategic Management Journal 23(4): 285-305.

McGrath, J. E. (1984). Groups: Interaction and Performance. Englewood Cliffs,NJ, PrenticeHall.

Mckay, D. T. and D. W. Brockway (1989). Building I/T Infrastructure for the 1990s. Stage by Stage, Nolan Norton and Company: 1-11.

Mintzberg, H. (1979). The Structuring of Organizations: A Synthesis of the Research. Englewood Cliffs, N.J, Prentice Hall.

Miranda, S. M. and R. P. Bostrom (1993-94). "The Impact of Group Support Systems on Group Conflict and Conflict Management." Journal of Management Information Systems 10(3): 63-95.

Mithas, S., N. Ramasubbu and V. Sambamurthy. (2008). "Information Management Capability and Firm Performance: An Empirical Analysis." Retrieved July 4th, 2008, from http://papers.ssrn.com/sol3/papers.cfm?abstract_id=1003316.

Morosini, P. (2004). "Competing on Social Capabilities," In Chowdhury S. (Eds.) Next Generation Business Handbook: New Strategies from tomorrow's thought Leaders John Wiley and Sons, 248-271.

Mumford, E. (1995). Effective Systems Design and Requirements Analysis: the ETHICS Method. London, Macmillan.

Mumford, E. (2000). "A Socio-Technical Approach to Systems Design." $\underline{\text { Requirements }}$ Engineering 5(2): 125-133.

Mumford, E. (2003). Redesigning Human Systems. Hershey, IRM Press.

Na, K.-S., J. T. Simpson, L. Xiaotong, T. Singh and K.-Y. Kim (2007). "Software Development Risk and Project Performance Measurement: Evidence in Korea." The Journal of Systems and Software 80(4): 596-605. 
Nelson, R. and S. Winter (1982). An Evolutionary Theory of Economic Change. Cambridge, MA, Belknap Press.

Nelson, R. R. (1991). "Educational Needs as Perceived by IS and End-User Personnel: A Survey of Knowledge and Skill Requirements." MIS Quarterly 15(4): 503-525.

Nelson, K. M. and J. G. Cooprider (1996). "The Contribution of Shared Knowledge to IS Group Performance.” MIS Quarterly 20(4): 409-432.

Nelson, K. M. and J. G. Cooprider (2001). "The Relationship of Software System Flexibility to Software System and Team Performance," 22nd International Conference on Information Systems, New Orleans, Louisiana, USA.

Nidumolu, S. (1995). "The Effect of Coordination and Uncertainty on Software Project Performance: Residual Performance Risk as an Intervening Variable." Information Systems Research 6(3): 191-219.

Nidumolu, S. R. (1996). "A Comparison of the Structural Contingency and Risk-Based Perspectives on Coordination in Software-Development Projects." Journal of Management Information Systems 13(2): 77-113.

Nidumolu, S. R. and M. R. Subramani (2003). "The Matrix of Control: Combining Process and Structure Approaches to Managing Software Development." Journal of Management Information Systems 20(3): 159-196.

Nunnally, J. C. and I. H. Bernstein (1994). Psychometric Theory. New York, McGraw-Hill.

Orlikowski, W. J. (1991). "Integrated Information Environment or Matrix of Control? The Contradictory Implications of Information Technology." Accounting, Management and Information Technologies 1(1): 9-42.

Ouchi, W. G. (1977). "The Relationship Between Organizational Structure and Control." Administrative Science Quarterly 22(1): 95-113.

Ouchi, W. G. (1979). "A Conceptual Framework for the Design of Organizational Control Mechanisms.” Management Science 25(9): 833-848.

Ouchi, W. G. (1980). "Markets, Bureaucracies, and Clans." Administrative Science Quarterly 25(1): 129-141.

Passmore, W., C. Francis and J. Haldeman (1982). "Sociotechnical Systems: A North American Reflection on Empirical Studies of the Seventies." Human Relations 35(12): 1179-1204.

Patnayakuni, R., C. P. Ruppel and A. Rai (2006). "Managing the Complementarity of Knowledge Integration and Process Formalization for Systems Development Performance." 
Journal of the Association for Information Systems 7(8): 545-567.

Paul, S., I. M. Samarah, P. Seetharaman and P. P. Mykytyn Jr. (2004-05). "An Empirical Investigation of Collaborative Conflict Management Style in Group Support System-Based Global Virtual Teams.” Journal of Management Information Systems 21(3): 185-222.

Penrose, E. T. (1959). The Theory of the Growth of the Firm. New York, John Wiley.

Perez, R. G., H. J. Wen, and P. Mahatanankoon. (2004). "Systems Development Project Team Management: A Resource-Based View." Human Systems Management 23(3): 169-177.

Ping Jr, R. A. (1995). "A Parsimonious Estimating Technique for Interaction and Quadratic Latent Variables," Journal of Marketing Research 32(3): 336-347.

Ping Jr., R. A. (2003). "Antecedents of Satisfaction in a Marketing Channel," Journal of Retailing, 79(4): 237-248.

Ping Jr., R. A. (2004). “On Assuring Valid Measures for Theoretical Models using Survey Data. Journal of Business Research 57(2): 125-141.

Pinto, M. B. and J. K. Pinto (1990). "Project Team Communication and Cross-Functional Cooperation in New Program Development." Journal of Product Innovation Management 7(3): 200-212.

Podsakoff, P.M., S. B. MacKenzie, and J. Lee (2003). "Common Method Biases in Behavioral Research: A Critical Review of the Literature and Recommended Remedies," Journal of Applied Psychology 88(5): 879-903.

Posner, B. Z., J. M. Kouzes and W. H. Schmidt (1985). "Shared Values Make a Difference: An Empirical Test of Corporate Culture." Human Resource Management 24(3): 293-309.

Prahalad, C. K. and G. Hamel (1990). "The Core Competence of the Corporation." Harvard Business Review 68(3): 79-91.

Pugh, D. S., Hickson, D. J., Hinings, C. R. and C. Turner. (1968). "Dimensions of Organizational Structure," Administrative Science Quarterly 13 (1): 65-105.

Rahim, M. A. (1985). "A Strategy for Managing Conflict in Complex Organizations." Human Relations 38(1): 81-89.

Rahim, M. A. (2002). "Toward a Theory of Managing Organizational Conflict." International Journal of Conflict Management 13(3): 206-235.

Rai, A. and H. Al-Hindi (2000). "The Effects of Development Process Modeling and Task Uncertainty on Development Quality Performance." Information and Management 37(6): 335346. 
Ramanathan, K. (2007). "The Role of Information and Communication Technology (ICT) in Enhancing Technological Capabilities," United Nations Economic and Social Commission for Asia and the Pacific- Asian and Pacific Centre for Transfer of Technology (UNESCAP-APCTT), New Delhi, India.

Ravichandran, T. and A. Rai (2000). "Quality Management in Systems Development: An Organizational System Perspective.” MIS Quarterly 24(3): 381-415.

Ravichandran, T. and C. Lertwongsatien (2005). "Effect of Information Systems Resources and Capabilities on Firm Performance: A Resource-Based Perspective." Journal of Management Information Systems 21(4): 237-276.

Raymond, L., G. Pare and F. Bergeron (1994). "Matching Information Technology and Organizational Structure: An Empirical Study with Implications for Performance." European Journal of Information Systems 4(1): 3-16.

Reed, F. M. and K. Walsh (2002). "Enhancing Technological Capability Through Supplier Development: A Study of the U.K. Aerospace Industry." IEEE Transactions on Engineering Management 49(3): 231-242.

Richman, W. L., S. Kiesler, S. Weisband, and F. Drasgow (1999). "A Meta-Analytic Study of Social Desirability Distortion in Computer-Administered Questionnaires, Traditional Questionnaires, and Interviews," Journal of Applied Psychology, 84(5): 754-775.

Robey, D. (1984). "Conflict Models for Implementation Research", in R.L. Schultz \& M.J. Ginzberg (eds.), Management Science Implementation JAI Press, 89-105.

Robey, D. and D. L. Farrow (1982). "User Involvement in Information System Development: A Conflict Model and Empirical Test.” Management Science 28(1): 73-85.

Robey, D., D. L. Farrow and C. R. Franz (1989). "Group Process and Conflict in System Development." Management Science 35(10): 1172-1191.

Robey, D., L. A. Smith and L. R. Vijayasarathy (1993). "Perceptions of Conflict and Success in Information Systems Development Projects." Journal of Management Information Systems 10(1): 123-139.

Robey, D. (1994). "Modeling Interpersonal Processes During System Development: Further Thoughts and Suggestions.” Information Systems Research 5(4): 439-449.

Robey, D. and M. Newman (1996). "Sequential Patterns in Information Systems Development: An Application of a Social Process Model." ACM Transactions on Information Systems 14(1): 30-63.

Robey, D., D. Turk and R. W. Welke (2001). "Traditional, Iterative, and Component-Based 
Development: A Social Analysis of Software Development Paradigms." Information Technology and Management 2(1): 53-70.

Robins, J. and M. F. Wiersema (1995). "A Resource-Based Approach to the Multibusiness Firm: Empirical Analysis of Portfolio Interrelationships and Corporate Financial Performance." Strategic Management Journal 16(4): 277-299.

Rogers, E.M. (1983). The Diffusion of Innovations. New York, The Free Press.

Rousseva, R. (2008). "Identifying Technological Capabilities with Different Degrees of Coherence: The Challenge to achieve High Technological Sophistication in Latecomer Software Companies" Technological Forecasting and Social Change 75(7): 1007-1031.

Rubin, D. B. (1976). “Inference and Missing Data,” Biometrika 63(3): 581-592.

Sabherwal, R. Hirschheim, and T. Goles (2001). "The Dynamics of Alignment: Insights from a Punctuated Equilibrium Model,” Organizational Science, 12(2): 179-197.

Sabherwal, R. and I. B. Fernandez (2003). "An empirical study of the effect of knowledge management processes at individual, group, and organizational levels", Decision Sciences 34(2): 225-260.

Sambamurthy, V. and M. S. Poole (1992). "The Effects of Variations in Capabilities of GDSS Designs on Management of Cognitive Conflict in Groups." Information Systems Research 3(3): 224-251.

Sambamurthy, V. and L. J. Kirsch (2000). "An Integrative Framework of the Information Systems Development Processes.” Decision Sciences 31(2): 391-411.

Sarin, S. and V. Mahajan (2001). "The Effect of Reward Structures on the Performance of CrossFunctional Product Development Teams." Journal of Marketing 65(2): 35-53.

Sawyer, S. and P. J. Guinan (1998). "Software Development: Processes and Performance." $\underline{\text { BBM }}$ Systems Journal 37(4): 552-569.

Sawyer, S. (2000). A Social Analysis of Software Development Teams: Three Models and their Differences. Americas Conference on Information Systems, Long Beach, California.

Sawyer, S. (2001). "Effects of intra-group Conflict on Packaged Software Development Team Performance." Information Systems Journal 11(2): 155-178.

Sawyer, S. (2004). "Software Development Teams: Three Archetypes and their Differences." Communications of the ACM 17(12): 92-97.

Scacchi, W. (2005). Socio-Technical Interaction Networks in Free/Open Source Software Development Processes. Software Process Modelling. S. T. Acuna and N. Juristo. New York, 
Springer Science + Business Media Inc.: 1-27.

Schoenecker, T. and L. Swanson (2002). "Indicators of Firm Technological Capability: Validity and Performance Implications." IEEE Transactions on Engineering Management 49(1): 36-44.

Schoonhoven, C. B. (1981). "Problems with Contingency Theory: Testing Assumptions Hidden within the Language of Contingency Theory." Administrative Science Quarterly 26(3): 349-377.

Scott, W. R. (1998). Organizations: Rational, Natural and Open Systems. Upper Saddle River: NJ, Prentice Hall.

Shani, A. B., R. M. Grant, R. Krishnan and E. Thompson (1992). "Advanced Manufacturing Systems and Organizational Choice: Sociotechnical System Approach." California Management Review 34(4): 91.

Shaw, D. G. and C. E. Schneier (1995). "Team Measurement and Rewards: How Some Companies Are Getting It Right.” Human Resource Planning 18(3): 34-49.

Shrednick, H. R., R. J. Shutt and M. Weiss (1992). "Empowerment: Key to IS World-Class Quality." MIS Quarterly 16(4): 491-505.

Sillars, A. L. (1982). Attributions and Communication: Are people "naïve scientists" or just naïve? Social Cognition and Communication. M. E. Roloff and C. R. Berger. Newbury Park, CA, Sage: 73-106.

Simmel, G. (1955). Conflict and the Web of Group Affiliations. New York, The Free Press.

Sivo, S. A., C. Saunders, Q. Chang, and J. J. Jiang (2006). "How Low Should You Go? Low Response Rates and the Validity of Inference in IS Questionnaire Research," Journal of the Association for Information Systems 7(6): 351-414.

Smith, P. G. and E. L. Blanck (2002). "From Experience: Leading Dispersed Teams." Journal of Product Innovation Management 19(4): 294-304.

Stevens, J. (1996). Applied Multivariate Statistics for the Social Sciences. Hillsdale: NJ, Lawrence Erblaum Associates.

Stewart, K. A. and A.H. Segars (2002). "An Empirical Examination of the Concern for Information Privacy Instrument,” Information Systems Research 13(1): 36-49.

Swanson, E. B. and C. M. Beath (1990). "Departmentalization in Software Development and Maintenance." Communications of the ACM 33 (6): 658-667.

Szilagyi, A. J. and M. Wallace (1980). Organizational Behavior and Performance. Santa Monica: CA, Goodyear. 
Tanaka, J. S. (1987). ““How Big is Big Enough?”: Sample Size and Goodness of Fit in Structural Equation Models with Latent Variables," Child Development 58(1): 134-146.

Teece, D. and G. Pisano (1994). "The Dynamic Capabilities of Firms: An Introduction." Industrial and Corporate Change 3(3): 537-556.

Teece, D. J., R. Rumelt, G. Dosi and S. Winter (1994). "Understanding Corporate Coherence : Theory and Evidence." Journal of Economic Behavior and Organization 23(1): 1-30.

Teece, D., G. Pisano and A. Shuen (1997). "Dynamic Capabilities and Strategic Management." Teece, D., G. Pisano and A. Shuen (1997). "Dynamic Capabilities and Strategic Management." Strategic Management Journal 18(7): 509-533.

Thompson, J. D. (1967). Organization in Action. Chicago, Illinois, McGraw Hill.

Thompson, L. (2003). Making the Team: A Guide for Managers. Upper Saddle River, NJ, Prentice Hall.

Tiwana, A. and M. Keil (2006). "Functionality Risk in Information Systems Development: An Empirical Investigation." IEEE Transactions on Engineering Management 53(3): 412-425.

Tjosvold, D. (1984). “Cooperation Theory and Organizations." Human Relations 37(9): 743-767.

Torrisi, S. (1998). Industrial Organisation and Innovation. An International Study of the Software Industry. Cheltenham, U.K., Edward Elgar.

Trice, H. M. and J. M. Beyer (1993). The Cultures of Work Organizations. Englewood Cliffs, NJ, Prentice Hall.

Tsai, K.-H. (2004). “The Impact of Technological Capability on Firm Performance in Taiwan's Electronics Industry.” Journal of High Technology Management Research 15(2): 183-195.

Tschang, T. (2001). The Basic Characteristics of Skills and Organizational Capabilities in the Indian Software Industry. Tokyo, Asian Development Bank Institute: 30.

Valetto, G., M. Helander, K. Ehrlich, S. Chulani, M. Wegman and C. Williams (2007). Using Software Repositories to Investigate Socio-technical Congruence in Development Projects. Fourth International Workshop on Mining Software Repositories, IEEE Computer Society.

Van de Ven, A. H., A. L. Delbecq and J. R. Koenig (1976). "Determinants of Coordination Modes within Organizations." American Sociological Review 41(2): 322-338.

Venkatraman, N. (1989). "The Concept of Fit in Strategy Research: Toward Verbal and Statistical Correspondence.” Academy of Management Review 14(1): 423.

Venkatraman, N. and J. E. Prescott (1990). “Environment - Strategy Co-alignment: An Empirical 
Test of its Performance." Strategic Management Journal 11(1): 1-23.

Venkatraman, N. (1991). IT-induced Business Reconfiguration. Corporation of the 1990s. S. M. S. Morton. New York, Oxford University Press: 122-158.

Verona, G. (1999). "A Resource-Based View of Product Development." Academy of Management Review 24(1): 132-142.

Vitalari, N. (1985). "Knowledge as a Basis for Expertise in Systems Analysis: An Empirical Study." MIS Quarterly 9(3): 221-241.

Wageman, R. and G. Baker (1997). "Incentives and Cooperation: The Joint Effects of Task and Reward Interdependence on Group Performance." Journal of Organizational Behavior 18(2) 139158.

Wallace, L. and M. Keil (2004). "How Software Project Risk Affects Project Performance: An Investigation of the Dimensions of Risk and an Exploratory Model." Decision Sciences 35(2): 289-321.

Walz (1993). "Inside a Software Design Team: Knowledge Acquisition, Sharing, an Integration." Communications of the ACM 36(10): 63-77.

Wang, C. L., P. K. Ahmed, and M. Rafiq (2008). "Knowledge management orientation: construct development and empirical validation", European Journal of Information Systems 17(3): 219-235.

Weill, P. and M. H. Olson (1989). "An Assessment of the Contingency Theory of Management Information Systems." Journal of Management Information Systems 6(1): 59-85.

Weill, P. and M. Vitale (2002). "What IT Infrastructure Capabilities are Needed to Implement Ebusiness Models." MIS Quarterly Executive 1(1): 17-34.

Wenger, E. C. and W. M. Snyder (2000). "Communities of Practice: The Organizational Frontier Harvard Business Review, Jan-Feb 2000, pp. 139-145." Harvard Business Review 78(1): 139145 .

Wernerfelt, B. (1984). "A Resource-Based View of the Firm." Strategic Management Journal 5(2): 171-180.

Westphal, L. E., L. Kim and C. J. Dahlman (1985). "Reflections on the Republic of Korea's Acquisition of Technological Capability," In Rosenberg, N. and C. Firschtak (Eds.) International Technology Transfer: Concepts, Measures and Comparisons. New York, Praeger.

White, K. B. (1984). "MIS Project Teams: An Investigation of Cognitive Style Implications." MIS Quarterly 8(2): 95-101. 
Xia, W. and W. R. King (2002). "Determinants of Organizational IT Infrastructure Capabilities: An Empirical Study,” Working Paper, MIS Research Center, University of Minnesota.

Xia, W.and G. Lee (2005). "Complexity of Information Systems Development Projects: Conceptualization and Measurement Development," Journal of Management Information Systems 22(1): 45-83.

Yang, H. D., H. R. Kang, and R. M. Mason (2008). "An exploratory study on meta skills in software development teams: Antecedent cooperation skills and personality for shared mental models", European Journal of Information Systems 17(1): 47-61.

Yourdan, E. (1989). Managing the Structured Techniques, Prentice Hall.

Zachary, G. P. (1998). "Armed Truce: Software in an Age of Teams.” Information Technology and People 11(1): 62-65.

Zahra, S. A. and A. P. Nielson (2002). "Sources of Capabilities, Integration and Technology Commercialization." Strategic Management Journal 23(5): 377 - 398.

Zahra, S. A., D. O. Neubaum and B. Larraneta (2007). "Knowledge Sharing and Technological Capabilities: The Moderating Role of Family Involvement." Journal of Business Research 60(10): 1070-1079.

Zikmund, W. G. (1994). Business Research Methods, Dryden Press.

Zmud, R. W. (1980). "Management of Large Software Development Efforts." MIS Quarterly 4(1): 45-55.

Zmud, R. W. (1982). "Diffusion of Modern Software Practices: Influence of Centralization and Formalization." Management Science 28(12): 1421-1431.

Zmud, R. W. (1983). "The Effectiveness of External Information Channels in Facilitating Innovation Within Software Development Groups." MIS Quarterly 7(2): 43-58. 


\section{Appendix I Letter of Invitation to Participate in the Study}

\section{Survey of Software Development Team Capabilities and their Impact on Team Performance}

\section{Purpose:}

This survey is a part of PhD thesis study of Manjari Maheshwari, student of the Sprott School of Business at Carleton University- Ottawa, Canada. The study looks at social and technical capabilities within software development teams and their impact on team performance.

\section{Who can fill:}

Software development team leader/manager, project leader/manager or any other software professional in the team who has an idea about the overall functioning of the team.

\section{Survey Procedures:}

The survey consists of six sections and takes approximately 15 minutes to fill. I would greatly appreciate if you can complete the survey and submit it on line. Since the validity of the results depend on obtaining a high response rate, your participation is crucial to the success of this study.

\section{Anticipated Benefits:}

\section{Click here to take the survey}

Team performance is a critical issue for software development firms and software professionals are always looking for ways to improve the performance. This study covers both the social and technical sides of the software development activity and the results will improve our understanding of how these capabilities influence team performance. If you are interested in receiving the study results, please provide us with your contact information in the last section of the survey.

\section{Confidentiality and Anonymity Measures:}

Please be assured that your responses will be held in the strictest confidence and analyzed anonymously in statistical form only. This study has been reviewed and approved by Ethics 
Committee of Carleton University. Your submission of survey indicates your consent to participate in this study. The survey is secured with SSL that allows data transmitted to be encrypted for security. The survey is hosted by a professional survey application service provider (surveymonkey). The responding computer IP address will not be stored in the survey results to assure anonymity. Study results will only use aggregate data from all responses and no identifying information will be used.

\section{Researcher(s) Contact Information:}

If you have any questions about this study, you can contact me or my thesis supervisor Prof. Uma Kumar.

$\begin{array}{ll}\text { Manjari Maheshwari } & \text { Uma Kumar } \\ \text { Ph.D. Student } & \text { Professor of Technology and Innovation } \\ & \text { Management } \\ \text { Sprott School of Business } & \text { Sprott School of Business } \\ \text { mmnagory@connect.carleton.ca } & \text { Uma kumar@carleton.ca }\end{array}$

I hope that you will be able to participate in this study. Please click on the link below to access the survey.

\section{Click here to take the survey}

Sincerely, Manjari Maheshwari 


\section{Appendix II Questionnaire}

\section{Section I: Team/Project Information}

Q 1. Please select and describe one of the software project that you may be currently working or have recently completed.

\begin{tabular}{|l|l|}
\hline General Information & Information \\
\hline $\begin{array}{l}\text { How many project/ team members are } \\
\text { involved in the project/team }\end{array}$ & \\
\hline Project duration (in months): & \\
\hline $\begin{array}{l}\text { Type of Product (e.g. banking, } \\
\text { communication, multimedia etc.) }\end{array}$ & \\
\hline Is your team geographically dispersed? & \\
\hline
\end{tabular}

Q 2. Please rate the level of task complexity and task interdependence within the above mentioned project on a five point scale with $1=$ Very Low, $3=$ Medium, and $5=$ Very High.

\begin{tabular}{|l|c|c|c|c|c|}
\hline Project Variables & $\begin{array}{c}\text { Very } \\
\text { Low }\end{array}$ & Low & Medium & High & $\begin{array}{c}\text { Very } \\
\text { High }\end{array}$ \\
\hline $\begin{array}{l}\text { Level of task complexity } \\
\text { Level of task } \\
\text { interdependence }\end{array}$ & 1 & 2 & 3 & 4 & 5 \\
\hline
\end{tabular}




\section{Section II: Team Capabilities}

Q 3. Please rate your level of agreement for the following items related to communication within your team on a five point scale, with $1=$ definitely disagree, $3=$ neither disagree nor agree, and $5=$ definitely agree.

\begin{tabular}{|c|c|c|c|c|c|}
\hline $\begin{array}{l}\text { Social Capability } \\
\text { Communication }\end{array}$ & \begin{tabular}{|r|} 
Definitely \\
Disagree \\
\end{tabular} & Disagree & $\begin{array}{c}\text { Neither } \\
\text { Disagree Nor } \\
\text { Agree }\end{array}$ & Agree & $\begin{array}{r}\text { Definitely } \\
\text { Agree } \\
\end{array}$ \\
\hline $\begin{array}{l}\text { 1. Team members } \\
\text { communicate frequently } \\
\text { with each other }\end{array}$ & 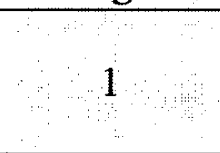 & 2 & 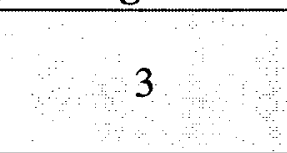 & 4 & 5 \\
\hline $\begin{array}{l}\text { 2. Team members often } \\
\text { communicate informally } \\
\text { with each other }\end{array}$ & 1 & 2 & 3 & 4 & 5 \\
\hline $\begin{array}{l}\text { 3. Team members } \\
\text { communicate mostly } \\
\text { directly and personally } \\
\text { with each other }\end{array}$ & 1 & 2 & 3 & 4 & 5 \\
\hline $\begin{array}{l}\text { 4. Team members mostly } \\
\text { communicate through } \\
\text { moderators within the } \\
\text { team }\end{array}$ & 1 & 2 & 3 & 4 & 5 \\
\hline $\begin{array}{l}\text { 5. Team members share } \\
\text { project related } \\
\text { information openly }\end{array}$ & 1 & 2 & 3 & 4 & 5 \\
\hline $\begin{array}{l}\text { 6. Team members receive } \\
\text { information from other } \\
\text { team members in a timely } \\
\text { manner }\end{array}$ & 1 & 2 & 3 & 4 & 5 \\
\hline $\begin{array}{l}\text { 7. Team members receive } \\
\text { information from other } \\
\text { team members in a } \\
\text { precise manner }\end{array}$ & 1 & 2 & 3 & 4 & 5 \\
\hline $\begin{array}{l}\text { 8. Team members find the } \\
\text { information they receive } \\
\text { from other team members } \\
\text { useful }\end{array}$ & 1 & 2 & 3 & 4 & 5 \\
\hline $\begin{array}{l}\text { 9. Most of the time team } \\
\text { meetings are unplanned } \\
\text { and done on ad-hoc basis, } \\
\text { as and when required }\end{array}$ & 1 & 2 & 3 & 4 & 5 \\
\hline
\end{tabular}


Q 4. Please rate your level of agreement for the following items related to conflict resolution within your team on a five point scale, with $1=$ definitely disagree, $3=$ neither disagree nor agree, and $5=$ definitely agree.

\begin{tabular}{|l|c|c|c|c|c|}
\hline $\begin{array}{l}\text { Social Capability } \\
\text { Conflict Resolution }\end{array}$ & Definitely & Disagree & $\begin{array}{c}\text { Neither } \\
\text { Disagree Nor } \\
\text { Agree }\end{array}$ & Agree & Definitely \\
\hline $\begin{array}{l}\text { 1. Team members resolve } \\
\text { differences in a timely } \\
\text { fashion }\end{array}$ & 1 & 2 & 3 & 4 & 5 \\
\hline $\begin{array}{l}\text { 2. Team members find } \\
\text { ways to minimize mutual } \\
\text { disagreements among } \\
\text { them }\end{array}$ & 1 & 2 & 3 & 4 & 5 \\
\hline $\begin{array}{l}\text { 3. Team members attempt } \\
\text { to examine the } \\
\text { viewpoints of everyone }\end{array}$ & 1 & 2 & 3 & 4 & 5 \\
\hline $\begin{array}{l}\text { 4. During conflicts team } \\
\text { members attempt to get } \\
\text { all issues and concerns } \\
\text { out in the open }\end{array}$ & 1 & 2 & 3 & 4 & 5 \\
\hline $\begin{array}{l}\text { 5. Conflicts are generally } \\
\text { resolved to the } \\
\text { satisfaction of all the } \\
\text { members involved }\end{array}$ & 1 & 2 & 3 & 4 & 5 \\
\hline $\begin{array}{l}\text { 6. Team members ignore } \\
\text { others who express a } \\
\text { different point of view }\end{array}$ & 1 & 2 & 3 & 4 & 5 \\
\hline $\begin{array}{l}\text { 7. Team members do not } \\
\text { acknowledge and } \\
\text { confront conflict openly }\end{array}$ & 1 & 2 & 3 & 4 & 5 \\
\hline $\begin{array}{l}\text { 8. Some team members } \\
\text { dominate others during } \\
\text { disagreements }\end{array}$ & 1 & 2 & 3 & 5 \\
\hline $\begin{array}{l}\text { 9. Project manager or } \\
\text { team leader often } \\
\text { organizes sessions which } \\
\text { helps in resolving the } \\
\text { conflicts among the team }\end{array}$ & 1 & & 3 & 5 \\
\hline
\end{tabular}


Q 5. Please rate your level of agreement for the following characteristics of supportiveness within your team on a five point scale, with $1=$ definitely disagree, $3=$ neither disagree nor agree, and $5=$ definitely agree.

\begin{tabular}{|c|c|c|c|c|c|}
\hline $\begin{array}{l}\text { Social Capability } \\
\text { Supportiveness }\end{array}$ & $\begin{array}{l}\text { Definitely } \\
\text { Disagree }\end{array}$ & Disagree & $\begin{array}{c}\text { Neither } \\
\text { Disagree Nor } \\
\text { Agree }\end{array}$ & Agree & $\begin{array}{c}\text { Definitely } \\
\text { Agree }\end{array}$ \\
\hline $\begin{array}{l}\text { 1. Team members help } \\
\text { and support each other } \\
\text { as best as they can }\end{array}$ & 1 & 2 & 3 & 4 & 5 \\
\hline $\begin{array}{l}\text { 2. Team members } \\
\text { discuss and develop } \\
\text { suggestions and } \\
\text { contributions }\end{array}$ & 1 & 2 & 3 & 4 & 5 \\
\hline $\begin{array}{l}\text { 3. Team members } \\
\text { respect suggestions } \\
\text { and contributions of } \\
\text { other team members }\end{array}$ & 1 & 2 & 3 & 4 & 5 \\
\hline $\begin{array}{l}\text { 4. } 4 \text { Team members are } \\
\text { proud to be part of the } \\
\text { team }\end{array}$ & 1 & 2 & 3 & 4 & 5 \\
\hline $\begin{array}{l}\text { 5. 5. Team members are } \\
\text { loyal to the team }\end{array}$ & 1 & 2 & 3 & 4 & 5 \\
\hline $\begin{array}{l}\text { 6. 6. Team members get } \\
\text { the recognition as } \\
\text { needed }\end{array}$ & 1 & 2 & 3 & 4 & 5 \\
\hline $\begin{array}{l}\text { 7. Team members get } \\
\text { a sense of } \\
\text { belongingness when } \\
\text { working for the team }\end{array}$ & 1 & 2 & 3 & 4 & 5 \\
\hline
\end{tabular}


Q 6. Please rate your level of agreement with the following items of your team's production capability on a five point scale, with $1=$ definitely disagree, $3=$ neither disagree nor agree, and $5=$ definitely agree.

\begin{tabular}{|l|c|c|c|c|c|}
\hline Technical Capability & Definitely & Disagree & $\begin{array}{c}\text { Neither } \\
\text { Disagree Nor } \\
\text { Agree }\end{array}$ & Agree & Definitely \\
\hline $\begin{array}{l}\text { 1. Team has sufficient } \\
\text { technical skills-sets } \\
\text { needed to perform the job }\end{array}$ & 1 & 2 & 3 & 4 & 5 \\
\hline $\begin{array}{l}\text { 2. Team has the } \\
\text { capability to understand } \\
\text { the business environment } \\
\text { it supports }\end{array}$ & 1 & 2 & 3 & 4 & 5 \\
\hline $\begin{array}{l}\text { 3. Team has the } \\
\text { capability to interpret } \\
\text { business problems and } \\
\text { develop appropriate } \\
\text { technical solutions }\end{array}$ & 1 & 2 & 3 & 4 & 5 \\
\hline $\begin{array}{l}\text { 4. Team has the } \\
\text { capability in software } \\
\text { quality assurance }\end{array}$ & 1 & 2 & 3 & 4 & 5 \\
\hline $\begin{array}{l}\text { 5. Team has the } \\
\text { capability to innovate }\end{array}$ & 1 & 2 & 3 & 4 & 5 \\
\hline
\end{tabular}

Q 7. a) Please rate to what extent your organization has defined control criterion for performance for your software development team for the following five items on a five point scale, with $1=$ not at all and $5=$ to a great extent.

\begin{tabular}{|l|c|c|c|c|c|}
\hline $\begin{array}{l}\text { Technical Capability } \\
\text { Control (Performance) }\end{array}$ & $\begin{array}{c}\text { Not At } \\
\text { All }\end{array}$ & Little & Somewhat & Much & $\begin{array}{c}\text { To a } \\
\text { Great } \\
\text { Extent }\end{array}$ \\
\hline 1. Software Functionality & 1 & 2 & 3 & 4 & 5 \\
\hline 2. Software Quality & 1 & 2 & 3 & 4 & 5 \\
\hline 3. Productivity & 1 & 2 & 3 & 4 & 5 \\
\hline 4. Budgets & 1 & 2 & 3 & 4 & 5 \\
\hline 5. Schedules & 1 & 2 & 3 & 4 & 5 \\
\hline
\end{tabular}


b) Please rate to what extent your organization has defined control standards for your software development team for the following five items on a five point scale, with 1 $=$ not at all and $5=$ to a great extent.

\begin{tabular}{|l|c|c|c|c|c|}
\hline $\begin{array}{l}\text { Technical Capability } \\
\text { Control } \\
\text { (Standardization) }\end{array}$ & $\begin{array}{c}\text { Not At } \\
\text { All }\end{array}$ & Little & Somewhat & Much & $\begin{array}{c}\text { To a } \\
\text { Great } \\
\text { Extent }\end{array}$ \\
\hline $\begin{array}{l}\text { 1. Standardized methods } \\
\text { for project management }\end{array}$ & 1 & 2 & 3 & 4 & 5 \\
\hline $\begin{array}{l}\text { 2. Standardized methods } \\
\text { for analysis }\end{array}$ & 1 & 2 & 3 & 4 & 5 \\
\hline $\begin{array}{l}\text { 3. Standardized methods } \\
\text { for design }\end{array}$ & 1 & 2 & 3 & 4 & 5 \\
\hline $\begin{array}{l}\text { 4. Standardized methods } \\
\text { for coding }\end{array}$ & 1 & 2 & 3 & 4 & 5 \\
\hline $\begin{array}{l}\text { 5. Standardized methods } \\
\text { for testing }\end{array}$ & 1 & 2 & 3 & 4 & 5 \\
\hline $\begin{array}{l}\text { 6. Standardized methods } \\
\text { for maintenance and } \\
\text { updates }\end{array}$ & 1 & 2 & 3 & 4 & 5 \\
\hline $\begin{array}{l}\text { 7. Standardized methods } \\
\text { for documentation }\end{array}$ & 1 & 2 & 3 & 4 & 5 \\
\hline $\begin{array}{l}\text { 8. Standardized methods } \\
\text { for change control }\end{array}$ & 1 & 2 & 3 & 4 & 5 \\
\hline
\end{tabular}

Q 8. For each item identified below, please indicate how satisfied or dissatisfied are you with the following characteristics of your firm's IT infrastructure on a five point scale, with 1 = very dissatisfied, $3=$ neither dissatisfied nor satisfied, and $5=$ very satisfied.

\begin{tabular}{|l|c|c|c|c|c|}
\hline $\begin{array}{l}\text { Technical } \\
\text { Capability }\end{array}$ & $\begin{array}{c}\text { Very } \\
\text { Dissatisfied }\end{array}$ & Dissatisfied & $\begin{array}{c}\text { Neither } \\
\text { Dissatisfied } \\
\text { Nor Satisfied }\end{array}$ & Satisfied & $\begin{array}{c}\text { Very } \\
\text { Satisfied }\end{array}$ \\
\hline $\begin{array}{l}\text { 1. A common systems } \\
\text { development } \\
\text { environment }\end{array}$ & 1 & 2 & 3 & 4 & 5 \\
\hline $\begin{array}{l}\text { 2. Technology } \\
\text { education services } \\
\text { (e.g. training) }\end{array}$ & 1 & 2 & 3 & 4 & 5 \\
\hline $\begin{array}{l}\text { 3. Multimedia } \\
\text { operations and } \\
\text { development (e.g. } \\
\text { video conferencing) }\end{array}$ & 1 & 2 & 3 & 4 & 5 \\
\hline
\end{tabular}




\begin{tabular}{|l|l|l|l|l|r|}
\hline $\begin{array}{l}\text { 4. Data management } \\
\text { standards }\end{array}$ & 1 & 2 & 3 & 4 & 5 \\
\hline $\begin{array}{l}\text { 5. Communication } \\
\text { network services }\end{array}$ & 1 & 2 & 3 & 4 & 5 \\
\hline $\begin{array}{l}\text { 6. Security, disaster } \\
\text { planning, and business } \\
\text { recovery services }\end{array}$ & 1 & 2 & 3 & 4 & 5 \\
\hline $\begin{array}{l}\text { 7. Technology advice } \\
\text { and support services }\end{array}$ & 1 & 2 & 3 & 4 & 5 \\
\hline $\begin{array}{l}\text { 8. Identifying and } \\
\text { testing new } \\
\text { technologies for } \\
\text { business purposes }\end{array}$ & 1 & 2 & 3 & 4 & 5 \\
\hline $\begin{array}{l}\text { 9. Development of } \\
\text { business applications } \\
\text { on request }\end{array}$ & 1 & 2 & 3 & 4 & 5 \\
\hline $\begin{array}{l}\text { 10. Software } \\
\text { development tools } \\
\text { such as debugging and } \\
\text { performance analysis }\end{array}$ & 1 & 2 & 3 & & 5 \\
\hline
\end{tabular}

\section{Section III: Team Performance}

Q 9. Please rate your level of agreement for software product related performance measures on a five point scale, with $1=$ definitely disagree, $3=$ neither disagree nor agree, and $5=$ definitely agree.

\begin{tabular}{|l|c|c|c|c|c|}
\hline Product Measures & Definitely & Disagree & $\begin{array}{c}\text { Neither } \\
\text { Disagree Nor } \\
\text { Agree }\end{array}$ & Agree & $\begin{array}{c}\text { Definitely } \\
\text { Agree }\end{array}$ \\
\hline $\begin{array}{l}\text { 1. Software developed is } \\
\text { reliable }\end{array}$ & 1 & 2 & 3 & 4 & 5 \\
\hline $\begin{array}{l}\text { 2. Software developed is } \\
\text { easy to maintain }\end{array}$ & 1 & 2 & 3 & 4 & 5 \\
\hline $\begin{array}{l}\text { 3. Software developed is } \\
\text { easy to upgrade }\end{array}$ & 1 & 2 & 3 & 4 & 5 \\
\hline $\begin{array}{l}\text { 4. User perceive that the } \\
\text { software meets their } \\
\text { functional requirements }\end{array}$ & 1 & 2 & 3 & 4 & 5 \\
\hline $\begin{array}{l}\text { 5. Software meets user } \\
\text { expectations with respect } \\
\text { to response time }\end{array}$ & 1 & 2 & 3 & 4 & 5 \\
\hline $\begin{array}{l}\text { 6. The overall quality of } \\
\text { the developed software is } \\
\text { high }\end{array}$ & 1 & 2 & 3 & 4 & 5 \\
\hline
\end{tabular}


Q 10. Please rate your level of agreement for software development process related performance measures on a five point scale with $1=$ definitely disagree, $3=$ neither disagree nor agree, and $5=$ definitely agree.

\begin{tabular}{|l|c|c|c|c|c|}
\hline Process Measures & $\begin{array}{c}\text { Definitely } \\
\text { Disagree }\end{array}$ & Disagree & $\begin{array}{c}\text { Neither } \\
\text { Disagree Nor } \\
\text { Agree }\end{array}$ & Agree & $\begin{array}{c}\text { Definitely } \\
\text { Agree }\end{array}$ \\
\hline $\begin{array}{l}\text { 1. Software developed is } \\
\text { within schedule }\end{array}$ & 1 & 2 & 3 & 4 & 5 \\
\hline $\begin{array}{l}\text { 2. Software developed is } \\
\text { within budget }\end{array}$ & 1 & 2 & 3 & 4 & 5 \\
\hline
\end{tabular}

Q 11. For each item identified below, please rate your satisfaction on a five point scale, with $1=$ not at all and $5=$ to a great extent.

\begin{tabular}{|l|c|c|c|c|c|}
\hline Team Satisfaction & $\begin{array}{c}\text { Not At } \\
\text { All }\end{array}$ & Little & Somewhat & Much & $\begin{array}{c}\text { To a } \\
\text { Great } \\
\text { Extent }\end{array}$ \\
\hline $\begin{array}{l}\text { 1. Satisfied with the } \\
\text { effort of the team } \\
\text { members }\end{array}$ & 1 & 2 & 3 & 4 & 5 \\
\hline $\begin{array}{l}\text { 2. Satisfied with the } \\
\text { quality of team members } \\
\text { interaction }\end{array}$ & 1 & 2 & 3 & 4 & 5 \\
\hline $\begin{array}{l}\text { 3. Satisfied with the } \\
\text { relationships that team } \\
\text { members share }\end{array}$ & 1 & 2 & 3 & 4 & 5 \\
\hline $\begin{array}{l}\text { 4. Satisfied with the } \\
\text { individual learning and } \\
\text { well being of team } \\
\text { members }\end{array}$ & 1 & 2 & 3 & 4 & 5 \\
\hline
\end{tabular}

Q 12. For each item identified below, please rate on a five point scale, with $1=$ not at all and $5=$ to a great extent.

\begin{tabular}{|l|c|c|c|c|c|}
\hline Overall Fit & $\begin{array}{c}\text { Not At } \\
\text { All }\end{array}$ & Little & Somewhat & Much & $\begin{array}{c}\text { Toa } \\
\text { Great } \\
\text { Extent }\end{array}$ \\
\hline $\begin{array}{l}\text { Do you think that social } \\
\text { and technical capabilities } \\
\text { within your team } \\
\text { complement each other }\end{array}$ & 1 & 2 & 3 & 4 & 5 \\
\hline
\end{tabular}




\section{Section IV: Organizational Factors}

Q 13. Please rate your level of agreement for the following characteristics related to formalization within your organization on a five point scale, with $1=$ definitely disagree, $3=$ neither disagree nor agree, and $5=$ definitely agree.

\begin{tabular}{|l|c|c|c|c|c|}
\hline $\begin{array}{l}\text { Organizational } \\
\text { Factor }\end{array}$ & Definitely & Disagree & $\begin{array}{c}\text { Neither } \\
\text { Disagree Nor } \\
\text { Agree }\end{array}$ & Agree & Definitely \\
\hline $\begin{array}{l}\text { 1. Whatever situation } \\
\text { arises, we have } \\
\text { procedures to follow in } \\
\text { dealing with it. }\end{array}$ & 1 & 2 & 3 & 4 & 5 \\
\hline $\begin{array}{l}\text { 2. Rules and procedures } \\
\text { are usually provided in } \\
\text { written form. }\end{array}$ & 1 & 2 & 3 & 4 & 5 \\
\hline $\begin{array}{l}\text { 3. The employees here } \\
\text { are constantly checked } \\
\text { for rule violations. }\end{array}$ & 1 & 2 & 3 & 4 & 5 \\
\hline $\begin{array}{l}\text { 4. Strong penalties are } \\
\text { given for violating } \\
\text { procedures. }\end{array}$ & 1 & 2 & 3 & 4 & 5 \\
\hline
\end{tabular}

Q 14. Please rate your level of agreement for the following characteristics related to centralization within your organization on a five point scale, with $1=$ definitely disagree, $3=$ neither disagree nor agree, and $5=$ definitely agree.

\begin{tabular}{|l|c|c|c|c|c|}
\hline $\begin{array}{l}\text { Organizational } \\
\text { Factor }\end{array}$ & Definitely & Disagree & $\begin{array}{c}\text { Neither } \\
\text { Disagree Nor } \\
\text { Agree }\end{array}$ & Agree & Definitely \\
\hline $\begin{array}{l}\text { 1. There can be little } \\
\text { action taken here until a } \\
\text { supervisor approves a } \\
\text { decision }\end{array}$ & 1 & 2 & 3 & 4 & 5 \\
\hline $\begin{array}{l}\text { 2. A person who wants to } \\
\text { make his own decisions } \\
\text { would be quickly } \\
\text { discouraged here }\end{array}$ & 1 & 2 & 3 & 4 & 5 \\
\hline $\begin{array}{l}\text { 3. Even small matters } \\
\text { have to be referred to }\end{array}$ & 1 & 2 & 3 & 4 & 5 \\
\hline
\end{tabular}




\begin{tabular}{|l|c|c|c|c|c|}
\hline $\begin{array}{l}\text { someone higher up for a } \\
\text { final answer }\end{array}$ & & 2 & 3 & 4 & 5 \\
\hline $\begin{array}{l}\text { 4. I have to ask my boss } \\
\text { before I do almost } \\
\text { anything }\end{array}$ & 1 & 2 & 3 & 4 & 5 \\
\hline $\begin{array}{l}\text { 5. Any decision I make } \\
\text { has to have my boss's } \\
\text { approval }\end{array}$ & 1 & & & & \\
\hline
\end{tabular}

Q 15. Please rate your level of agreement for the following characteristics related to incentives and reward systems within your organization on a five point scale, with $1=$ definitely disagree, $3=$ neither disagree nor agree, and $5=$ definitely agree.

\begin{tabular}{|c|c|c|c|c|c|}
\hline $\begin{array}{l}\text { Organizational } \\
\text { Factor } \\
\text { Incentives and Reward } \\
\text { Systems }\end{array}$ & $\begin{array}{l}\text { Definitely } \\
\text { Disagree }\end{array}$ & Disagree & $\begin{array}{c}\text { Neither } \\
\text { Disagree Nor } \\
\text { Agree }\end{array}$ & Agree & $\begin{array}{c}\text { Definitely } \\
\text { Agree }\end{array}$ \\
\hline $\begin{array}{l}\text { 1. Excellent team } \\
\text { performance pays off in } \\
\text { the organization }\end{array}$ & 1 & 2 & 3 & 4 & 5 \\
\hline $\begin{array}{l}\text { 2. Even teams that do an } \\
\text { especially good job are } \\
\text { not recognized or } \\
\text { rewarded by the } \\
\text { organization }\end{array}$ & 1 & 2 & 3 & 4 & 5 \\
\hline $\begin{array}{l}\text { 3. This organization } \\
\text { recognizes and reinforces } \\
\text { teams that perform well }\end{array}$ & 1 & 2 & 3 & 4 & 5 \\
\hline
\end{tabular}

Q 16. Please rate your level of agreement for the following characteristics related to specialization within your organization on a five point scale, with $1=$ definitely disagree, $3=$ neither disagree nor agree, and $5=$ definitely agree.

\begin{tabular}{|l|c|c|c|c|c|}
\hline $\begin{array}{l}\text { Organizational } \\
\text { Factor }\end{array}$ & Definitely & Disagree & $\begin{array}{c}\text { Neither } \\
\text { Disagree Nor } \\
\text { Agree }\end{array}$ & Agree & $\begin{array}{c}\text { Definitely } \\
\text { Agree }\end{array}$ \\
\hline $\begin{array}{l}\text { 1. In this organization } \\
\text { activities are subdivided } \\
\text { into separate jobs }\end{array}$ & 1 & 2 & 3 & 4 & 5 \\
\hline
\end{tabular}


Please make additional comments, if any, regarding the social and technical capabilities within your team. Your comments will be combined with others and the content will be recorded anonymously.

\section{Section V \\ Contact Information}

In case you would like to receive the summary results of the study, please provide the contact information below:

\begin{tabular}{|l|l|}
\hline Your Designation: & \\
\hline Name: & \\
\hline Email: & \\
\hline Country: & \\
\hline
\end{tabular}

Your contribution is highly appreciated. Thank you for completing this questionnaire 


\section{Appendix III Measurement Items}

\begin{tabular}{|c|c|c|}
\hline Variable & Measurement Items (Code) & References \\
\hline Communication & $\begin{array}{l}\text { 1. Team members communicate frequently with each other } \\
\text { (com1). } \\
\text { 2. Team members often communicate informally with each } \\
\text { other (com2). } \\
\text { 3. Team members communicate mostly directly and personally } \\
\text { with each other (com3). } \\
\text { 4. Team members mostly communicate through moderators } \\
\text { within the team (com4). } \\
\text { 5. Team members share project related information openly } \\
\text { (com5). } \\
\text { 6. Team members receive information from other team } \\
\text { members in a timely manner (com6). } \\
\text { 7. Team members receive information from other team } \\
\text { members in a precise manner (com7). } \\
\text { 8. Team members find the information they receive from other } \\
\text { team members useful (com8). } \\
\text { 9. Most of the time team meetings are unplanned and done on } \\
\text { ad-hoc basis, as and when required (com9). }\end{array}$ & $\begin{array}{l}\text { Hoegl and } \\
\text { Gemuenden } \\
\text { (2001) }\end{array}$ \\
\hline $\begin{array}{l}\text { Conflict } \\
\text { Resolution }\end{array}$ & $\begin{array}{l}\text { 1. Team members resolve differences in a timely fashion (cr1). } \\
\text { 2. Team members find ways to minimize mutual disagreements } \\
\text { among them (cr2). } \\
\text { 3. Team members attempt to examine the viewpoints of } \\
\text { everyone (cr3). } \\
\text { 4. During conflicts team members attempt to get all issues and } \\
\text { concerns out in the open (cr4). } \\
\text { 5. Conflicts are generally resolved to the satisfaction of all the } \\
\text { members involved (cr5). } \\
\text { 6. Team members ignore others who express a different point }\end{array}$ & $\begin{array}{l}\text { Andres and } \\
\text { Zmud } \\
\text { (2002); } \\
\text { Miranda and } \\
\text { Bostrom } \\
\text { (1993-1994) }\end{array}$ \\
\hline
\end{tabular}




\begin{tabular}{|c|c|c|}
\hline & $\begin{array}{l}\text { of view (cr6). } \\
\text { 7. Team members do not acknowledge and confront conflict } \\
\text { openly (cr7). } \\
\text { 8. Some team members dominate others during disagreements } \\
\text { (cr8). }{ }^{\mathbf{R}} \\
\text { 9. Project manager or team leader often organizes sessions } \\
\text { which helps in resolving the conflicts among the team (cr9). }\end{array}$ & \\
\hline Supportiveness & $\begin{array}{l}\text { 1. Team members help and support each other as best as they } \\
\text { can (sup1). } \\
\text { 2. Team members discuss and develop suggestions and } \\
\text { contributions (sup2). } \\
\text { 3. Team members respect suggestions and contributions of } \\
\text { other team members (sup3). } \\
\text { 4. Team members are proud to be part of the team (sup4). } \\
\text { 5. Team members are loyal to the team (sup5). } \\
\text { 6. Team members get the recognition as needed (sup6). } \\
\text { 7. Team members get a sense of belongingness when working } \\
\text { for the team (sup7). }\end{array}$ & $\begin{array}{l}\text { Sawyer and } \\
\text { Guinan } \\
\text { (1998); } \\
\text { Hoegl and } \\
\text { Gemuenden } \\
\text { (2001); } \\
\text { Kirsch } \\
(1996)\end{array}$ \\
\hline $\begin{array}{l}\text { Production } \\
\text { Capability }\end{array}$ & $\begin{array}{l}\text { 1. Team has sufficient technical skills-sets needed to perform } \\
\text { the job ( } \mathrm{pc} 1 \text { ). } \\
\text { 2. Team has the capability to understand the business } \\
\text { environment it supports (pc2). } \\
\text { 3. Team has the capability to interpret business problems and } \\
\text { develop appropriate technical solutions (pc3). } \\
\text { 4. Team has the capability in software quality assurance (pc4). } \\
\text { 5. Team has the capability to innovate (pc5). }\end{array}$ & $\begin{array}{l}\text { Byrd and } \\
\text { Turner } \\
(2000) ; \\
\text { Torrisi } \\
(1998) ; \\
\text { Rouessava } \\
(2006)\end{array}$ \\
\hline $\begin{array}{l}\text { Control } \\
\text { Capability }\end{array}$ & $\begin{array}{l}\text { Performance } \\
\text { 1. Software Functionality (cop1). } \\
\text { 2. Software Quality (cop2). }\end{array}$ & $\begin{array}{l}\text { Nidumolu } \\
\text { and } \\
\text { Subramani } \\
(2003) ; \\
\text { Henderson } \\
\text { and } \\
\text { Cooprider }\end{array}$ \\
\hline
\end{tabular}




\begin{tabular}{|c|c|c|}
\hline & $\begin{array}{l}\text { 3. Productivity (cop3). } \\
\text { 4. Budgets (cop4). } \\
\text { 5. Schedules (cop5). } \\
\text { Standardization } \\
\text { 1. Standardized methods for project management (cos1). } \\
\text { 2. Standardized methods for analysis (cos2). } \\
\text { 3. Standardized methods for design (cos3). } \\
\text { 4. Standardized methods for coding (cos4). } \\
\text { 5. Standardized methods for testing (cos5). } \\
\text { 6. Standardized methods for maintenance and updates (cos6). } \\
\text { 7. Standardized methods for documentation (cos7). } \\
\text { 8. Standardized methods for change control (cos8). }\end{array}$ & $(1990)$ \\
\hline $\begin{array}{l}\text { IT } \\
\text { Infrastructural } \\
\text { capability }\end{array}$ & $\begin{array}{l}\text { 1. A common systems development environment (it1). } \\
\text { 3. Technology education services (e.g. training) (it2). } \\
\text { 4. Data management standards (it4). } \\
\text { 5. Communication network services (it5). } \\
\text { 6. Security, disaster planning, and business recovery services } \\
\text { (it6). } \\
\text { 7. Technology advice and support services (it7). } \\
\text { 8. Identifying and testing new technologies for business } \\
\text { purposes (it8). } \\
\text { 9. Development of business applications on request (it9). } \\
\text { 10. Software development tools such as debugging and } \\
\text { performance analysis tools (it10). }\end{array}$ & $\begin{array}{l}\text { Broadbent } e t \\
\text { al.(1999) }\end{array}$ \\
\hline
\end{tabular}




\begin{tabular}{|c|c|c|}
\hline $\begin{array}{l}\text { Product } \\
\text { Performance }\end{array}$ & $\begin{array}{l}\text { 1. Software developed is reliable (prod1). } \\
\text { 2. Software developed is easy to maintain (prod2). } \\
\text { 3. Software developed is easy to upgrade (prod3). } \\
\text { 4. User perceive that the software meets their functional } \\
\text { requirements (prod4). } \\
\text { 5. Software meets user expectations with respect to response } \\
\text { time (prod5). } \\
\text { 6. The overall quality of the developed software is high } \\
\text { (prod6). }\end{array}$ & $\begin{array}{l}\text { Nidumolu } \\
\text { (1995); } \\
\text { Nidumolu } \\
\text { (1996); } \\
\text { Wallace } \text { et } \\
\text { al. (2004); } \\
\text { Na } \text { et al. } \\
\text { (2007), } \\
\text { Liang } \text { et al. } \\
\text { (2007) }\end{array}$ \\
\hline $\begin{array}{l}\text { Process } \\
\text { Performance }\end{array}$ & $\begin{array}{l}\text { 1. Software developed is within schedule (proc1). } \\
\text { 2. Software developed is within budget (proc2). }\end{array}$ & \\
\hline $\begin{array}{l}\text { Team } \\
\text { satisfaction }\end{array}$ & $\begin{array}{l}\text { 1. Satisfied with the effort of the team members (satis1). } \\
\text { 2. Satisfied with the quality of team member's interaction } \\
\text { (satis2). } \\
\text { 3. Satisfied with the relationships that the team members share } \\
\text { (satis3). } \\
\text { 4. Satisfied with the individual learning and well being of team } \\
\text { members (satis4). }\end{array}$ & $\begin{array}{l}\text { Hoegl and } \\
\text { Gemuenden } \\
\text { (2001) }\end{array}$ \\
\hline Centralization & $\begin{array}{l}\text { 1. There can be little action taken here until a supervisor } \\
\text { approves a decision (cent1). } \\
\text { 2. A person who wants to make his own decisions would be } \\
\text { quickly discouraged here (cent2). } \\
\text { 3. Even small matters have to be referred to someone higher up } \\
\text { for a final answer (cent3). } \\
\text { 4. I have to ask my boss before I do almost anything (cent4). } \\
\text { 5. Any decision I make has to have my boss's approval (cent5). }\end{array}$ & $\begin{array}{l}\text { Hage and } \\
\text { Aiken, } \\
\text { 1967; } \\
\text { Jawroski } \\
\text { and Kohli } \\
\text { (1993) }\end{array}$ \\
\hline Formalization & $\begin{array}{l}\text { 1. Whatever situation arises, we have procedures to follow in } \\
\text { dealing with it (form1). } \\
\text { 2. Rules and procedures are usually provided in written form }\end{array}$ & $\begin{array}{l}\text { Grover and } \\
\text { Goslar } \\
(1993) \text {; } \\
\text { Jiang } \text { et al. }\end{array}$ \\
\hline
\end{tabular}




\begin{tabular}{|c|c|c|}
\hline & $\begin{array}{l}\text { (form2). } \\
\text { 3. The employees here are constantly checked for rule } \\
\text { violations (form3). } \\
\text { 4. Strong penalties are given for violating procedures (form4). }\end{array}$ & $(2003)$ \\
\hline Specialization & $\begin{array}{l}\text { 1. In this organization activities are subdivided into separate } \\
\text { jobs (spec1). }\end{array}$ & $\begin{array}{l}\text { Damnanpour } \\
(1991) ; \\
\text { Child } \\
(1972) ; \\
\text { James and } \\
\text { Jones (1976) }\end{array}$ \\
\hline $\begin{array}{l}\text { Incentives and } \\
\text { Rewards } \\
\text { systems }\end{array}$ & $\begin{array}{l}\text { 1. Excellent team performance pays off in the organization } \\
\text { (incent1). } \\
\text { 2. Even teams that do an especially good job are not recognized } \\
\text { or rewarded by the organization (incent } 2 \text { ). } \\
\text { 3. This organization recognizes and reinforces teams that } \\
\text { perform well (incent3). }\end{array}$ & $\begin{array}{l}\text { Lurey and } \\
\text { Raisinghani } \\
(2001) ; \\
\text { Shaw and } \\
\text { Schneier } \\
(1995)\end{array}$ \\
\hline
\end{tabular}

${ }^{\mathbf{R}}$ indicates reverse coded items 


\section{Appendix IV Descriptive Statistics for Measured Items}

\begin{tabular}{|c|c|c|c|c|c|c|c|c|}
\hline Item & $\mathbf{N}$ & Minimum & Maximum & Mean & $\begin{array}{l}\text { Std. } \\
\text { Error }\end{array}$ & $\begin{array}{c}\text { Std. } \\
\text { Deviation }\end{array}$ & Skewness & Kurtosis \\
\hline \multicolumn{9}{|c|}{ Items related to communication } \\
\hline com1 & 192 & 1.00 & 5.00 & 4.1823 & .05687 & .78806 & -1.114 & 1.775 \\
\hline com2 & 192 & 1.00 & 5.00 & 4.1615 & .05815 & .80572 & -1.030 & 1.353 \\
\hline com3 & 192 & 2.00 & 5.00 & 4.0260 & .05548 & .76873 & -.534 & .067 \\
\hline com4 & 192 & 1.00 & 5.00 & 3.4688 & .06963 & .96486 & -.423 & -.561 \\
\hline com5 & 192 & 1.00 & 5.00 & 3.8854 & .06123 & .84840 & -.662 & .311 \\
\hline com6 & 192 & 1.00 & 5.00 & 3.7677 & .05571 & .77196 & -.533 & .536 \\
\hline com7 & 192 & 1.00 & 5.00 & 3.5573 & .06031 & .83563 & -.374 & -.191 \\
\hline com8 & 192 & 2.00 & 5.00 & 3.9104 & .04415 & .61175 & -.362 & .807 \\
\hline com9 & 192 & 1.00 & 5.00 & 2.8125 & .07146 & .99013 & .287 & -.812 \\
\hline \multicolumn{9}{|c|}{ Items related to conflict resolution } \\
\hline cr1 & 192 & 1.00 & 5.00 & 3.7792 & .05445 & .75445 & -.566 & .707 \\
\hline cr2 & 192 & 1.00 & 5.00 & 3.6844 & .06202 & .85936 & -1.088 & 1.639 \\
\hline cr3 & 192 & 1.00 & 5.00 & 3.6469 & .05894 & .81664 & -.658 & .513 \\
\hline cr4 & 192 & 1.00 & 5.00 & 3.4740 & .06382 & .88433 & -.402 & -.320 \\
\hline cr5 & 192 & 1.00 & 5.00 & 3.5365 & .05654 & .78348 & -.419 & .042 \\
\hline $\operatorname{cr6}$ & 192 & 1.00 & 5.00 & 3.5688 & .06535 & .90552 & -.699 & .210 \\
\hline $\mathrm{cr} 7$ & 192 & 1.00 & 5.00 & 3.2219 & .06494 & .89988 & -.153 & -.835 \\
\hline cr8 & 192 & 1.00 & 5.00 & 2.7104 & .06750 & .93529 & .535 & -.665 \\
\hline cr9 & 192 & 1.00 & 5.00 & 3.6688 & .06137 & .85035 & -.850 & .743 \\
\hline \multicolumn{9}{|c|}{ Items related to Supportiveness } \\
\hline sup1 & 192 & 2.00 & 5.00 & 4.0938 & .04502 & .62376 & -.590 & 1.600 \\
\hline sup2 & 192 & 2.00 & 5.00 & 4.1302 & .04484 & .62137 & -.490 & 1.193 \\
\hline sup3 & 192 & 2.00 & 5.00 & 4.0260 & .04334 & .60048 & -.596 & 1.908 \\
\hline sup4 & 192 & 2.00 & 5.00 & 3.9057 & .05534 & .76680 & -.400 & -.061 \\
\hline sup5 & 192 & 2.00 & 5.00 & 3.9635 & .05241 & .72626 & -.359 & -.010 \\
\hline sup6 & 192 & 1.00 & 5.00 & 3.8385 & .05954 & .82499 & -.596 & .331 \\
\hline sup7 & 192 & 1.00 & 5.00 & 3.7802 & .05833 & .80822 & -.538 & .323 \\
\hline
\end{tabular}




\begin{tabular}{|c|c|c|c|c|c|c|c|c|}
\hline Item & $\mathbf{N}$ & Minimum & Maximum & Mean & $\begin{array}{c}\text { Std. } \\
\text { Error }\end{array}$ & $\begin{array}{c}\text { Std. } \\
\text { Deviation }\end{array}$ & Skewness & Kurtosis \\
\hline \multicolumn{9}{|c|}{ Items related to production capability } \\
\hline pc1 & 192 & 2.00 & 5.00 & 4.1068 & .05195 & .71981 & -.864 & 1.304 \\
\hline pc2 & 192 & 2.00 & 5.00 & 3.9036 & .05360 & .74274 & -.676 & .732 \\
\hline pc3 & 192 & 1.00 & 5.00 & 3.8516 & .05790 & .80222 & -.816 & 1.223 \\
\hline pc4 & 192 & 1.00 & 5.00 & 3.8281 & .06287 & .87108 & -.932 & .857 \\
\hline pc5 & 192 & 2.00 & 5.00 & 4.0599 & .05611 & .77750 & -.797 & .655 \\
\hline \multicolumn{9}{|c|}{ Items related to control capability (performance and standardization) } \\
\hline $\operatorname{cop} 1$ & 192 & 1.00 & 5.00 & 4.0927 & .05588 & .77436 & -1.071 & 2.195 \\
\hline cop2 & 192 & 1.00 & 5.00 & 3.9177 & .06457 & .89466 & -.755 & .445 \\
\hline cop3 & 192 & 1.00 & 5.00 & 3.5417 & .07067 & .97928 & -.422 & .121 \\
\hline cop4 & 192 & 1.00 & 5.00 & 3.5260 & .07252 & 1.00488 & -.401 & -.203 \\
\hline cop5 & 192 & 1.00 & 5.00 & 3.8042 & .06551 & .90767 & -.808 & .789 \\
\hline $\cos 1$ & 192 & 1.00 & 5.00 & 3.4948 & .07348 & 1.01815 & -.572 & .017 \\
\hline $\cos 2$ & 192 & 1.00 & 5.00 & 3.3271 & .07177 & .99449 & -.332 & -.146 \\
\hline $\cos 3$ & 192 & 1.00 & 5.00 & 3.4714 & .07350 & 1.01840 & -.448 & -.150 \\
\hline $\cos 4$ & 192 & 1.00 & 5.00 & 3.6661 & .06751 & .93543 & -.536 & .158 \\
\hline $\cos 5$ & 192 & 1.00 & 5.00 & 3.6693 & .06954 & .96360 & -.618 & .337 \\
\hline $\cos 6$ & 192 & 1.00 & 5.00 & 3.6833 & .06526 & .90428 & -.672 & .501 \\
\hline $\cos 7$ & 192 & 1.00 & 5.00 & 3.6302 & .07659 & 1.06133 & -.680 & .019 \\
\hline $\cos 8$ & 192 & 1.00 & 5.00 & 3.9635 & .06538 & .90590 & -.782 & .384 \\
\hline \multicolumn{9}{|c|}{ Items related to IT infrastructure capability } \\
\hline it1 & 192 & .00 & 5.00 & 3.8880 & .06883 & .95375 & -1.667 & 4.581 \\
\hline it2 & 192 & .00 & 5.00 & 3.4089 & .08366 & 1.15920 & -.887 & .992 \\
\hline it3 & 192 & .00 & 5.00 & 3.6781 & .06938 & .96142 & -.825 & 1.435 \\
\hline it4 & 192 & .00 & 5.00 & 3.6797 & .06822 & .94523 & -1.323 & 3.474 \\
\hline it5 & 192 & .00 & 5.00 & 4.0156 & .05695 & .78917 & -1.190 & 3.384 \\
\hline it6 & 192 & .00 & 5.00 & 3.8281 & .06747 & .93486 & -1.030 & 1.938 \\
\hline it7 & 192 & .00 & 5.00 & 3.6208 & .06924 & .95948 & -.874 & 1.804 \\
\hline it8 & 192 & .00 & 5.00 & 3.4750 & .08019 & 1.11111 & -.864 & 1.247 \\
\hline it9 & 192 & .00 & 5.00 & 3.2875 & .09153 & 1.26832 & -1.148 & 1.242 \\
\hline it10 & 192 & .00 & 5.00 & 3.7885 & .07542 & 1.04500 & -1.312 & 2.413 \\
\hline
\end{tabular}




\begin{tabular}{|c|c|c|c|c|c|c|c|c|}
\hline Item & $\mathbf{N}$ & Minimum & Maximum & Mean & $\begin{array}{l}\text { Std. } \\
\text { Error }\end{array}$ & $\begin{array}{c}\text { Std. } \\
\text { Deviation }\end{array}$ & Skewness & Kurtosis \\
\hline \multicolumn{9}{|c|}{ Items related to team performance } \\
\hline prod1 & 192 & 1.00 & 5.00 & 4.1240 & .05227 & .72433 & -1.122 & 2.638 \\
\hline prod2 & 192 & 1.00 & 5.00 & 3.6010 & .06290 & .87154 & -.651 & .078 \\
\hline prod3 & 192 & 1.00 & 5.00 & 3.5646 & .06569 & .91021 & -.615 & -.037 \\
\hline prod4 & 192 & 2.00 & 5.00 & 4.0688 & .05849 & .81044 & -1.032 & 1.098 \\
\hline prod5 & 192 & 2.00 & 5.00 & 4.0312 & .04949 & .68573 & -.729 & 1.327 \\
\hline prod6 & 192 & 2.00 & 5.00 & 3.9323 & .05627 & .77972 & -.551 & .174 \\
\hline proc1 & 192 & 1.00 & 5.00 & 3.7057 & .06663 & .92330 & -.783 & .282 \\
\hline proc2 & 192 & 1.00 & 5.00 & 3.6729 & .06585 & .91239 & -.421 & -.181 \\
\hline sat1 & 192 & 1.00 & 5.00 & 4.0417 & .05567 & .77144 & -.694 & .840 \\
\hline sat2 & 192 & 1.00 & 5.00 & 3.7563 & .05925 & .82103 & -.488 & .467 \\
\hline sat3 & 192 & 1.00 & 5.00 & 3.7771 & .05782 & .80124 & -.616 & .800 \\
\hline sat4 & 192 & 1.00 & 5.00 & 3.7302 & .06191 & .85787 & -692 & .927 \\
\hline
\end{tabular}




\section{Appendix V Interaction Term Analysis with Procedure, SIMPLIS Code and Starting Values}

\section{Two step Ping (1995) procedure}

1. First thing is centering the variables ( $X$ and $Z)$.

2. Then add the variables (all X's and all Z's)

3. Next step is to do the product term (XZ)

4. Import the data in Lisrel.

5. First run the measurement model i.e. a model of $\mathrm{X}$ and $\mathrm{Z}$ only.

6. Put the values of theta and lambda in the formula for calculating the lambda and theta values for the product (interaction) term. Use the spreadsheet given by Ping (1995) to calculate the starting values.

7. Using the starting values for the structural model which includes interaction term.

8. Once that is done, run the structural model and get the estimates and standardized path coefficients.

Sample LISREL SIMPLIS Code for the Ping (1995) Procedure (two steps) (Adapted from Cortina et al., 2001)

\section{Step 1: Initial run: Model excludes latent product}

1) Observed Variables: Y X1 X2 Z1 Z2

2) Covariance Matrix From File sample.COV

3) Sample Size 300

4) Latent Variables: $X Z$

5) Relationships:

6) $X 1 X 2=X$

7) $\mathrm{Z} 1 \mathrm{Z} 2=\mathrm{Z}$

8) $Y=X Z$

9) LISREL OUTPUT: $A D=O F F$ IT $=100$

10) End of Problem

\section{Step 2: Model includes latent product and set values from Step 1}

1) Observed Variables: Y X1 X2 Z1 Z2 XZ

2) Covariance Matrix From File sample.COV

3) Sample Size 300

4) Latent Variables: X Z interaction

5) Relationships:

6) $X 1 X 2=X$

7) $\mathrm{Z} 1 \mathrm{Z} 2=\mathrm{Z}$

8) $\mathrm{XZ}=($ starting value $) *$ interaction 
9) $\mathrm{Y}=\mathrm{X} Z$ interaction

10) Set the Error Variance of $X Z$ to (starting value)

11) Set the Correlation $X$-interaction to 0

12) Set the Correlation Z-interaction to 0

13) LISREL OUTPUT: $\mathrm{AD}=\mathrm{OFF} \mathrm{IT}=100$

14) $\mathrm{PD}$

15) End of Problem

\section{Sample spreadsheet template}

This spreadsheet calculates the loadings (lambda), measurement error variances (theta) and variances (Phi) of a latent variable (LV) interaction and its related $\mathrm{LV}$ quadratics using modified Ping (1995) formulae (i.e., using averaged indicators for $\mathrm{X}$ and $\mathrm{Z}$. The values inside the cells are just the sample values. Actual values for all the 12 interaction term analysis are prrovided following the sample analysis.

The APA citation for this EXCEL template is Ping, R.A. (2003). "An excel template for calculating Ping 1995, j. marketing res., loadings and measurement error variances." [on-line paper]. http://home.att.net/ rpingir/TMPLTJMR.XLS.

INSTRUCTIONS on using the Template:

1. Bold faced values are required and should be entered from the linear-terms-only measurement model (see Ping 1995). The other values are optional.

2. Optional italicized values are error attenuated covariances for $X=(x 1+\ldots+x n) / n$ and $\mathrm{Z}=(\mathrm{z} 1+\ldots+\mathrm{zm}) / \mathrm{m}$, and should be entered from SAS, SPSS, etc.

3. The phi's for $\mathrm{XX}, \mathrm{XZ}$ or $\mathrm{ZZ}$ should be used first as starting values. If the structural model converges and produces admissible parameter estimates, the phi's for $\mathrm{XX}, \mathrm{XZ}$ or $\mathrm{ZZ}$ should then be used as fixed values to be consistent with the assumptions underlying LV Interaction and Quadratic estimation.

Note: Occasionally this second estimation does not converge or the parameter estimates are inadmissible with fixed phi's for $\mathrm{XX}, \mathrm{XZ}$ or $\mathrm{ZZ}$. In this event, the parameter estimates from the first estimation using the phi's for $\mathrm{XX}, \mathrm{XZ}$ or $\mathrm{ZZ}$ used as starting values should be reported with a comment that the model would not converge with the phi's for $\mathrm{XX}, \mathrm{XZ}$ or $\mathrm{ZZ}$ fixed. 
This table gets the values from running the measurement model for $\mathrm{X}$ and $\mathrm{Z}$ for unstandardized lambda and theta coefficients

\begin{tabular}{|c|c|c|c|c|c|c|c|c|c|c|c|c|c|}
\hline $\mathrm{X}$ & 1 & 2 & 3 & 4 & 5 & 6 & 7 & 8 & 9 & 10 & "Avg." & Sum & SumSq \\
\hline lambda & 0.7900 & 0.8800 & 1.0000 & 0.8700 & 0.9400 & & & & & & 0.8960 & 4.48 & 4.0390 \\
\hline theta & 0.1600 & 0.1300 & 0.1000 & 0.1200 & 0.1000 & & & & & & 0.0244 & 0.61 & 0.0769 \\
\hline$Z$ & & & & & & & & & & & & & \\
\hline lambda & 0.9200 & 0.9000 & 1.0000 & 0.7800 & & & & & & & 0.9000 & 3.6 & 3.2648 \\
\hline theta & 0.2700 & 0.2400 & 0.0700 & 0.2400 & & & & & & & &
\end{tabular}

This table shows the correlation among the two variables

\begin{tabular}{|l|c|c|}
\hline \multicolumn{2}{|c|}{ Correlation } & \\
\hline & $X$ & $Z$ \\
\hline$X$ & 1.0000 & \\
\hline$Z$ & 0.9123 & 1.0000 \\
\hline
\end{tabular}

This Table shows the unstandardized Phi Coefficients

\begin{tabular}{|c|c|c|c|c|c|}
\hline Phi & $X$ & $Z$ & $X X$ & $X Z$ & $Z Z$ \\
\hline$X$ & $\mathbf{0 . 5 1 0 0}$ & & & & \\
\hline$Z$ & -0.3700 & $\mathbf{0 . 8 5 0 0}$ & & & \\
\hline$X X$ & -0.38925 & 0.34600 & 0.52020 & & \\
$X Z$ & 0.34600 & 1.37787 & -0.37740 & 0.57040 & \\
\hline$Z Z$ & 1.37787 & 1.37174 & 0.27380 & -0.62900 & 1.44500 \\
\hline & (cf. Ping 1996) & & (cf. Kenny \& Judd 1984) & \\
\hline
\end{tabular}

This table Starting Values for the interaction term XZ

$\begin{array}{lc} & \mathrm{XZ} \\ \text { lambda } & 0.80640 \\ \text { theta } & 0.03903 \\ \text { reliability } & 0.93362 \\ \text { AVE } & 0.65957\end{array}$

\section{References}

Ping, R.A. (1996), "Latent Variable Regression: A Technique for Estimating Interaction and Quadratic Coefficients," Multivariate Behavioral Research, 31 (1), 95-120.

Kenny, D.A., and Judd, C.M. (1984), "Estimating the Nonlinear and Interactive Effects of Latent Variables," Psychological Bulletin, 96, 201-210. 
Starting values analysis

1. Communication (X) and Production Capability (Z) Interaction Model

Unstandardized lambda and theta coefficients

$\begin{array}{lcccccc}\text { X } & 1 & 2 & 3 & 4 & 5 & 6 \\ \text { Lambda } & \mathbf{1 . 0 0 0 0} & \mathbf{0 . 7 6 0 0} & \mathbf{1 . 2 6 0 0} & \mathbf{1 . 1 8 0 0} & \mathbf{1 . 1 8 0 0} & \mathbf{0 . 7 9} \\ \text { Theta } & \mathbf{0 . 3 7 0 0} & \mathbf{0 . 4 4 0 0} & \mathbf{0 . 3 2 0 0} & \mathbf{0 . 2 4 0 0} & \mathbf{0 . 3 4 0 0} & \mathbf{0 . 2 1} \\ \quad \mathrm{Z} & & & & & & \\ \text { Lambda } & \mathbf{1 . 0 0 0 0} & \mathbf{1 . 2 2 0 0} & \mathbf{1 . 2 8 0 0} & \mathbf{1 . 4 2 0 0} & & \\ \text { Theta } & \mathbf{0 . 3 2 0 0} & \mathbf{0 . 3 5 0 0} & \mathbf{0 . 4 3 0 0} & \mathbf{0 . 2 0 0 0} & & \end{array}$

\section{Correlation}

$\begin{array}{ccc} & X & Z \\ X & 1.0000 & \\ Z & \mathbf{0 . 4 0 0 0} & 1.0000\end{array}$

Unstandardized Phi coefficients

$\begin{array}{ccc}\text { phi } & \text { X } & \text { Z } \\ \text { X } & \mathbf{0 . 2 5 0 0} & \\ Z & \mathbf{0 . 0 9 0 0} & \mathbf{0 . 2 0 0 0}\end{array}$

Starting values and reliability of the interaction term

$\begin{array}{lc} & \text { XZ } \\ \text { lambda } & \mathbf{1 . 2 6 4 8 5} \\ \text { theta } & \mathbf{0 . 0 4 1 9 5} \\ \text { reliability } & 0.70343 \\ \text { AVE } & 0.23298\end{array}$

\section{Communication and Control (performance) Interaction Model}

Unstandardized lambda and theta coefficients

\begin{tabular}{lcccccc}
\multicolumn{1}{r}{$X$} & 1 & 2 & 3 & 4 & 5 & 6 \\
$\begin{array}{l}\text { lambda } \\
\text { theta }\end{array}$ & $\mathbf{1 . 0 0 0 0}$ & $\mathbf{0 . 7 4 0 0}$ & $\mathbf{1 . 2 3 0 0}$ & $\mathbf{1 . 1 6 0 0}$ & $\mathbf{1 . 1 9 0 0}$ & $\mathbf{0 . 7 8}$ \\
\multicolumn{1}{r}{$\mathrm{Z}$} & $\mathbf{0 . 3 6 0 0}$ & $\mathbf{0 . 4 5 0 0}$ & $\mathbf{0 . 3 3 0 0}$ & $\mathbf{0 . 2 4 0 0}$ & $\mathbf{0 . 3 3 0 0}$ & $\mathbf{0 . 2 1}$ \\
$\begin{array}{l}\text { lambda } \\
\text { theta }\end{array}$ & $\mathbf{1 . 0 0 0 0}$ & $\mathbf{1 . 3 4 0 0}$ & $\mathbf{1 . 1 0 0 0}$ & $\mathbf{0 . 8 0 0 0}$ & & \\
& $\mathbf{0 . 2 5 0 0}$ & $\mathbf{0 . 1 8 0 0}$ & $\mathbf{0 . 5 4 0 0}$ & $\mathbf{0 . 6 0 0 0}$ & &
\end{tabular}

\section{Correlation}

$\begin{array}{ccc} & X & Z \\ X & 1.0000 & \\ Z & 0.3300 & 1.0000\end{array}$


Unstandadized Phi Coefficients

$\begin{array}{ccc}\text { Phi } & \text { X } & \text { Z } \\ \text { X } & \mathbf{0 . 2 6 0 0} & \\ \text { Z } & \mathbf{0 . 1 0 0 0} & \mathbf{0 . 3 5 0 0}\end{array}$

Starting values and reliability of the interaction term

$\begin{array}{cc} & X Z \\ \text { lambda } & \mathbf{1 . 0 7 7 6 7} \\ \text { theta } & \mathbf{0 . 0 5 2 5 8} \\ \text { reliability } & 0.70041 \\ \text { AVE } & 0.23769\end{array}$

3. Communication and Control (standardization) Capability Interaction term

Unstandardized lambda and theta coefficients

$\begin{array}{lcccccc}\text { X } & 1 & 2 & 3 & 4 & 5 & 6 \\ \text { lambda } & \mathbf{1 . 0 0 0 0} & \mathbf{0 . 7 5 0 0} & \mathbf{1 . 2 3 0 0} & \mathbf{1 . 1 7 0 0} & \mathbf{1 . 1 8 0 0} & \mathbf{0 . 7 9} \\ \text { theta } & \mathbf{0 . 3 6 0 0} & \mathbf{0 . 4 4 0 0} & \mathbf{0 . 3 3 0 0} & \mathbf{0 . 2 4 0 0} & \mathbf{0 . 3 4 0 0} & \mathbf{0 . 2 1} \\ \mathrm{Z} & & & & & & \\ \text { lambda } & \mathbf{1 . 0 0 0 0} & \mathbf{1 . 2 0 0 0} & \mathbf{1 . 0 4 0 0} & \mathbf{1 . 0 2 0 0} & \mathbf{0 . 9 8} & \mathbf{0 . 6 8} \\ \text { theta } & \mathbf{0 . 4 7 0 0} & \mathbf{0 . 2 1 0 0} & \mathbf{0 . 2 6 0 0} & \mathbf{0 . 3 4 0 0} & \mathbf{0 . 5 8} & \mathbf{0 . 5 6}\end{array}$

\section{Correlation}

$\begin{array}{ccc} & X & Z \\ X & \mathbf{1 . 0 0 0 0} & \\ Z & \mathbf{0 . 1 5 0 0} & \mathbf{1 . 0 0 0 0}\end{array}$

Unstandadized Phi Coefficients

$\begin{array}{ccc}\text { phi } & X & Z \\ \text { X } & \mathbf{0 . 2 6 0 0} & \\ \text { Z } & \mathbf{0 . 0 6 0 0} & \mathbf{0 . 5 7 0 0}\end{array}$

Starting values and reliability of the interaction term

$\begin{array}{lc} & X Z \\ \text { lambda } & \mathbf{1 . 0 0 6 4 0} \\ \text { theta } & \mathbf{0 . 0 5 1 3 6} \\ \text { reliability } & 0.75066 \\ \text { AVE } & 0.20939\end{array}$


4. Communication and IT Infrastructure Capability Interaction term

Unstandardized lambda and theta coefficients

\begin{tabular}{lcccccr} 
X & 1 & 2 & 3 & 4 & 5 & 6 \\
lambda & $\mathbf{1 . 0 0 0 0}$ & $\mathbf{0 . 7 6 0 0}$ & $\mathbf{1 . 2 3 0 0}$ & $\mathbf{1 . 1 7 0 0}$ & $\mathbf{1 . 1 7 0 0}$ & \multicolumn{1}{c}{0.79} \\
theta & $\mathbf{0 . 3 6 0 0}$ & $\mathbf{0 . 4 4 0 0}$ & $\mathbf{0 . 3 3 0 0}$ & $\mathbf{0 . 2 4 0 0}$ & $\mathbf{0 . 3 4 0 0}$ & $\mathbf{0 . 2 1}$ \\
$\mathrm{Z}$ & & & & & & \\
lambda & $\mathbf{1 . 0 0 0 0}$ & $\mathbf{1 . 2 9 0 0}$ & $\mathbf{1 . 1 9 0 0}$ & $\mathbf{1 . 1 3 0 0}$ & $\mathbf{0 . 8 5}$ & $\mathbf{1 . 1 3}$ \\
theta & $\mathbf{0 . 5 4 0 0}$ & $\mathbf{0 . 7 3 0 0}$ & $\mathbf{0 . 4 0 0 0}$ & $\mathbf{0 . 4 2 0 0}$ & $\mathbf{0 . 3 6}$ & $\mathbf{0 . 4 1}$
\end{tabular}

Correlation

$\begin{array}{ccc} & \mathrm{X} & \mathrm{Z} \\ \mathrm{X} & \mathbf{1 . 0 0 0 0} & \\ \mathrm{Z} & \mathbf{0 . 0 9 0 0} & \mathbf{1 . 0 0 0 0}\end{array}$

Unstandadized Phi Coefficients

$\begin{array}{ccc}\text { phi } & X & Z \\ \text { X } & \mathbf{0 . 2 6 0 0} & \\ \text { Z } & \mathbf{0 . 0 3 0 0} & \mathbf{0 . 3 7 0 0}\end{array}$

Starting values and reliability of the interaction term

$\begin{array}{lc} & \text { XZ } \\ \text { lambda } & \mathbf{1 . 1 2 0 3 0} \\ \text { theta } & \mathbf{0 . 0 4 9 5 3} \\ \text { reliability } & 0.71143 \\ \text { AVE } & 0.16346\end{array}$

5. Conflict Resolution and Production Capability Interaction term

Unstandardized lambda and theta coefficients

$\begin{array}{lcccccc}\text { X } & 1 & 2 & 3 & 4 & 5 & 6 \\ \text { lambda } & \mathbf{1 . 0 0 0 0} & \mathbf{1 . 3 9 0 0} & \mathbf{1 . 2 2 0 0} & \mathbf{1 . 1 1 0 0} & \mathbf{1 . 0 4 0 0} & \mathbf{0 . 9 7} \\ \text { theta } & \mathbf{0 . 3 2 0 0} & \mathbf{0 . 2 6 0 0} & \mathbf{0 . 3 0 0 0} & \mathbf{0 . 4 8 0 0} & \mathbf{0 . 3 5 0 0} & \mathbf{0 . 5 7} \\ \mathrm{Z} & & & & & & \\ \text { lambda } & \mathbf{1 . 0 0 0 0} & \mathbf{1 . 2 3 0 0} & \mathbf{1 . 2 9 0 0} & \mathbf{1 . 4 4 0 0} & & \\ \text { theta } & \mathbf{0 . 3 2 0 0} & \mathbf{0 . 3 5 0 0} & \mathbf{0 . 4 3 0 0} & \mathbf{0 . 2 0 0 0} & & \end{array}$

\section{Correlation}

$\begin{array}{ccc} & X & Z \\ X & 1.0000 & \\ Z & \mathbf{0 . 4 0 0 0} & \mathbf{1 . 0 0 0 0}\end{array}$


Unstandadized Phi Coefficients

$\begin{array}{ccc}\text { phi } & X & Z \\ X & \mathbf{0 . 2 5 0 0} & \\ Z & \mathbf{0 . 0 9 0 0} & \mathbf{0 . 2 0 0 0}\end{array}$

Starting values and reliability of the interaction term

$\begin{array}{lc} & \mathrm{XZ} \\ \text { lambda } & \mathbf{1 . 3 9 0 8 7} \\ \text { theta } & \mathbf{0 . 0 5 0 1 8} \\ \text { reliability } & 0.70554 \\ \text { AVE } & 0.22741\end{array}$

6. Conflict Resolution and Control (performance) Capability Interaction term

Unstandardized lambda and theta coefficients

$\begin{array}{lcccccc}\text { X } & 1 & 2 & 3 & 4 & 5 & 6 \\ \text { lambda } & \mathbf{1 . 0 0 0 0} & \mathbf{1 . 3 7 0 0} & \mathbf{1 . 2 3 0 0} & \mathbf{1 . 1 1 0 0} & \mathbf{1 . 0 4 0 0} & \mathbf{0 . 9 7} \\ \text { theta } & \mathbf{0 . 3 2 0 0} & \mathbf{0 . 2 7 0 0} & \mathbf{0 . 2 9 0 0} & \mathbf{0 . 4 7 0 0} & \mathbf{0 . 3 5 0 0} & \mathbf{0 . 5 7} \\ \mathrm{Z} & & & & & & \\ \text { lambda } & \mathbf{1 . 0 0 0 0} & \mathbf{1 . 3 6 0 0} & \mathbf{1 . 1 0 0 0} & \mathbf{0 . 8 0 0 0} & & \\ \text { theta } & \mathbf{0 . 2 6 0 0} & \mathbf{0 . 1 8 0 0} & \mathbf{0 . 5 4 0 0} & \mathbf{0 . 6 1 0 0} & & \end{array}$

Correlation

$\begin{array}{ccc} & X & Z \\ X & 1.0000 & \\ Z & 0.3100 & 1.0000\end{array}$

\section{Unstandadized Phi Coefficients}

$\begin{array}{ccc}\text { phi } & X & Z \\ X & \mathbf{0 . 2 5 0 0} & \\ Z & \mathbf{0 . 0 9 0 0} & \mathbf{0 . 3 4 0 0}\end{array}$

Starting values and reliability of the interaction term

$\begin{array}{lc} & X Z \\ \text { lambda } & \mathbf{1 . 1 9 2 8 0} \\ \text { theta } & \mathbf{0 . 0 6 1 7 5} \\ \text { reliability } & 0.69163 \\ \text { AVE } & 0.22206\end{array}$


7. Conflict Resolution and Control (standardization) Capability Interaction term

Unstandardized lambda and theta coefficients

$\begin{array}{lcccccc}\text { X } & 1 & 2 & 3 & 4 & 5 & 6 \\ \text { lambda } & \mathbf{1 . 0 0 0 0} & \mathbf{1 . 3 8 0 0} & \mathbf{1 . 2 3 0 0} & \mathbf{1 . 1 2 0 0} & \mathbf{1 . 0 4 0 0} & \mathbf{0 . 9 8} \\ \text { theta } & \mathbf{0 . 3 2 0 0} & \mathbf{0 . 2 7 0 0} & \mathbf{0 . 2 9 0 0} & \mathbf{0 . 4 7 0 0} & \mathbf{0 . 3 5 0 0} & \mathbf{0 . 5 7} \\ \mathrm{Z} & & & & & & \\ \text { lambda } & \mathbf{1 . 0 0 0 0} & \mathbf{1 . 2 0 0 0} & \mathbf{1 . 0 4 0 0} & \mathbf{1 . 0 2 0 0} & \mathbf{0 . 9 8} & \mathbf{0 . 6 8} \\ \text { theta } & \mathbf{0 . 4 7 0 0} & \mathbf{0 . 2 1 0 0} & \mathbf{0 . 2 6 0 0} & \mathbf{0 . 3 4 0 0} & \mathbf{0 . 5 8} & \mathbf{0 . 5 6}\end{array}$

Correlation

$\begin{array}{ccc} & X & Z \\ X & 1.0000 & \\ Z & \mathbf{0 . 1 5 8 0} & \mathbf{1 . 0 0 0 0}\end{array}$

\section{Unstandadized Phi Coefficients}

$\begin{array}{ccc}\text { phi } & \text { X } & Z \\ \text { X } & \mathbf{0 . 2 5 0 0} & \\ \text { Z } & \mathbf{0 . 0 6 0 0} & \mathbf{0 . 5 7 0 0}\end{array}$

Starting values and reliability of the interaction term

$\begin{array}{lc} & \text { XZ } \\ \text { lambda } & \mathbf{1 . 1 1 0 0 0} \\ \text { theta } & \mathbf{0 . 0 6 0 5 0} \\ \text { reliability } & 0.74997 \\ \text { AVE } & 0.20090\end{array}$

8. Conflict Resolution and IT Infrastructure Capability Interaction term

Unstandardized lambda and theta coefficients

$\begin{array}{lcccccc}\text { X } & 1 & 2 & 3 & 4 & 5 & 6 \\ \text { lambda } & \mathbf{1 . 0 0 0 0} & \mathbf{1 . 3 8 0 0} & \mathbf{1 . 2 3 0 0} & \mathbf{1 . 1 1 0 0} & \mathbf{1 . 0 3 0 0} & \mathbf{0 . 9 8} \\ \text { theta } & \mathbf{0 . 3 2 0 0} & \mathbf{0 . 2 7 0 0} & \mathbf{0 . 2 9 0 0} & \mathbf{0 . 4 8 0 0} & \mathbf{0 . 3 5 0 0} & \mathbf{0 . 5 7} \\ \mathrm{Z} & & & & & & \\ \text { lambda } & \mathbf{1 . 0 0 0 0} & \mathbf{1 . 2 8 0 0} & \mathbf{1 . 1 9 0 0} & \mathbf{1 . 1 4 0 0} & \mathbf{0 . 8 5} & \mathbf{1 . 1 2} \\ \text { theta } & \mathbf{0 . 5 4 0 0} & \mathbf{0 . 7 4 0 0} & \mathbf{0 . 4 0 0 0} & \mathbf{0 . 4 2 0 0} & \mathbf{0 . 3 6} & \mathbf{0 . 4 1}\end{array}$

Correlation

$\begin{array}{ccc} & \mathrm{X} & \mathrm{Z} \\ \mathrm{X} & \mathbf{1 . 0 0 0 0} & \\ \mathrm{Z} & \mathbf{0 . 1 3 1 5} & \mathbf{1 . 0 0 0 0}\end{array}$




\section{Unstandadized Phi Coefficients}

$\begin{array}{ccc}\text { phi } & X & Z \\ X & \mathbf{0 . 2 5 0 0} & \\ \text { Z } & \mathbf{0 . 0 4 0 0} & \mathbf{0 . 3 7 0 0}\end{array}$

Starting values and reliability of the interaction term

$\begin{array}{lc} & \text { XZ } \\ \text { lambda } & \mathbf{1 . 2 3 0 0 9} \\ \text { theta } & \mathbf{0 . 0 5 8 3 1} \\ \text { reliability } & 0.71092 \\ \text { AVE } & 0.15643\end{array}$

9. Supportiveness and Production Capability Interaction term

Unstandardized lambda and theta coefficients

$\begin{array}{lcccccc}\text { X } & 1 & 2 & 3 & 4 & 5 & 6 \\ \text { lambda } & \mathbf{1 . 0 0 0 0} & \mathbf{1 . 0 8 0 0} & \mathbf{1 . 8 7 0 0} & \mathbf{1 . 7 1 0 0} & \mathbf{1 . 4 2 0 0} & \mathbf{1 . 6 5} \\ \text { theta } & \mathbf{0 . 2 6 0 0} & \mathbf{0 . 2 1 0 0} & \mathbf{0 . 1 4 0 0} & \mathbf{0 . 1 6 0 0} & \mathbf{0 . 4 2 0 0} & \mathbf{0 . 3 1} \\ \mathrm{Z} & & & & & & \\ \text { lambda } & \mathbf{1 . 0 0 0 0} & \mathbf{1 . 2 2 0 0} & \mathbf{1 . 3 4 0 0} & \mathbf{1 . 4 8 0 0} & & \\ \text { theta } & \mathbf{0 . 3 3 0 0} & \mathbf{0 . 3 6 0 0} & \mathbf{0 . 4 2 0 0} & \mathbf{0 . 1 9 0 0} & & \end{array}$

\section{Correlation}

$\begin{array}{ccc} & X & Z \\ X & \mathbf{1 . 0 0 0 0} & \\ Z & \mathbf{0 . 4 4 5 3} & \mathbf{1 . 0 0 0 0}\end{array}$

\section{Unstandadized Phi Coefficients}

$\begin{array}{ccc}\text { phi } & \text { X } & Z \\ X & \mathbf{0 . 1 3 0 0} & \\ \text { Z } & \mathbf{0 . 0 7 0 0} & \mathbf{0 . 1 9 0 0}\end{array}$

Starting values and reliability of the interaction term

$\begin{array}{lc} & \text { XZ } \\ \text { lambda } & \mathbf{1 . 8 3 3 3 0} \\ \text { theta } & \mathbf{0 . 0 3 8 3 1} \\ \text { reliability } & 0.73647 \\ \text { AVE } & 0.25152\end{array}$


10. Supportiveness and Control (performance) Capability Interaction term

Unstandardized lambda and theta coefficients

$\begin{array}{lcccccc}\text { X } & 1 & 2 & 3 & 4 & 5 & 6 \\ \text { lambda } & \mathbf{1 . 0 0 0 0} & \mathbf{1 . 0 7 0 0} & \mathbf{1 . 9 0 0 0} & \mathbf{1 . 7 1 0 0} & \mathbf{1 . 4 6 0 0} & \mathbf{1 . 6 8} \\ \text { theta } & \mathbf{0 . 2 6 0 0} & \mathbf{0 . 2 2 0 0} & \mathbf{0 . 1 4 0 0} & \mathbf{0 . 1 6 0 0} & \mathbf{0 . 4 2 0 0} & \mathbf{0 . 3} \\ \mathrm{Z} & & & & & & \\ \text { lambda } & \mathbf{1 . 0 0 0 0} & \mathbf{1 . 3 8 0 0} & \mathbf{1 . 1 0 0 0} & \mathbf{0 . 8 0 0 0} & & \\ \text { theta } & \mathbf{0 . 2 6 0 0} & \mathbf{0 . 1 6 0 0} & \mathbf{0 . 5 5 0 0} & \mathbf{0 . 6 1 0 0} & & \end{array}$

Correlation

$\begin{array}{ccc} & X & Z \\ X & 1.0000 & \\ Z & \mathbf{0 . 4 4 5 0} & 1.0000\end{array}$

Unstandadized Phi Coefficients
phi
X
$\mathrm{X}$
0.1200
$\mathrm{Z} \quad \mathbf{0 . 0 9 0 0}$
0.3400

Starting values and reliability of the interaction term

$\begin{array}{lc} & X Z \\ \text { lambda } & \mathbf{1 . 5 7 2 9 0} \\ \text { theta } & \mathbf{0 . 0 4 5 9 4} \\ \text { reliability } & 0.73892 \\ \text { AVE } & 0.25406\end{array}$

11. Supportiveness and Control (standardization) Capability Interaction term

Unstandardized lambda and theta coefficients

$\begin{array}{lcccccc}\text { X } & 1 & 2 & 3 & 4 & 5 & 6 \\ \begin{array}{l}\text { lambda } \\ \text { theta }\end{array} & \mathbf{1 . 0 0 0 0} & \mathbf{1 . 0 8 0 0} & \mathbf{1 . 9 2 0 0} & \mathbf{1 . 7 3 0 0} & \mathbf{1 . 4 6 0 0} & \mathbf{1 . 6 9} \\ \mathrm{Z} & & 0.2200 & \mathbf{0 . 1 4 0 0} & \mathbf{0 . 1 6 0 0} & \mathbf{0 . 4 2 0 0} & \mathbf{0 . 3} \\ \begin{array}{c}\text { lambda } \\ \text { theta }\end{array} & \mathbf{1 . 0 0 0 0} & \mathbf{1 . 2 1 0 0} & \mathbf{1 . 0 4 0 0} & \mathbf{1 . 0 2 0 0} & \mathbf{0 . 9 8} & \mathbf{0 . 6 9} \\ & & & & & & \\ \end{array}$

Correlation

$\begin{array}{ccc} & X & Z \\ X & \mathbf{1 . 0 0 0 0} & \\ Z & \mathbf{0 . 3 4 4 0} & \mathbf{1 . 0 0 0 0}\end{array}$

\section{Unstandadized Phi Coefficients}

$\begin{array}{ccc}\text { phi } & \text { X } & \text { Z } \\ \text { X } & \mathbf{0 . 1 2 0 0} & \\ \text { Z } & \mathbf{0 . 0 9 0 0} & \mathbf{0 . 5 7 0 0}\end{array}$


Starting values and reliability of the interaction term

$\begin{array}{lc} & X Z \\ \text { lambda } & \mathbf{1 . 4 6 5 2 0} \\ \text { theta } & \mathbf{0 . 0 4 3 5 8} \\ \text { reliability } & 0.79536 \\ \text { AVE } & 0.23222\end{array}$

12. Supportiveness and IT Infrastructure Capability Interaction term

Unstandardized lambda and theta coefficients

\begin{tabular}{|c|c|c|c|c|c|c|}
\hline $\mathrm{X}$ & 1 & 2 & 3 & 4 & 5 & 6 \\
\hline lambda & 1.0000 & 1.0800 & 1.9100 & 1.7300 & 1.4400 & 1.67 \\
\hline $\begin{array}{r}\text { theta } \\
\mathrm{Z}\end{array}$ & 0.2600 & 0.2200 & 0.1400 & 0.1600 & 0.4200 & 0.31 \\
\hline lambda & 1.0000 & 1.2900 & 1.2000 & 1.1400 & 0.85 & 1.13 \\
\hline theta & 0.5400 & 0.7300 & 0.4000 & 0.4200 & 0.36 & 0.41 \\
\hline
\end{tabular}

\section{Correlation}

$\begin{array}{ccc} & X & Z \\ X & \mathbf{1 . 0 0 0 0} & \\ Z & \mathbf{0 . 1 8 9 8} & \mathbf{1 . 0 0 0 0}\end{array}$

\section{Unstandadized Phi Coefficients}

$\begin{array}{ccc}\text { phi } & X & \mathrm{Z} \\ \mathrm{X} & \mathbf{0 . 1 2 0 0} & \\ \mathrm{Z} & \mathbf{0 . 0 4 0 0} & \mathbf{0 . 3 7 0 0}\end{array}$

Starting values and reliability of the interaction term

$\begin{array}{lc} & X Z \\ \text { lambda } & \mathbf{1 . 6 2 1 2 9} \\ \text { theta } & \mathbf{0 . 0 4 2 8 2} \\ \text { Reliability } & 0.74094 \\ \text { AVE } & 0.17063\end{array}$




\section{Appendix VI Alterative Models for Social Capability}

\section{Model 1}

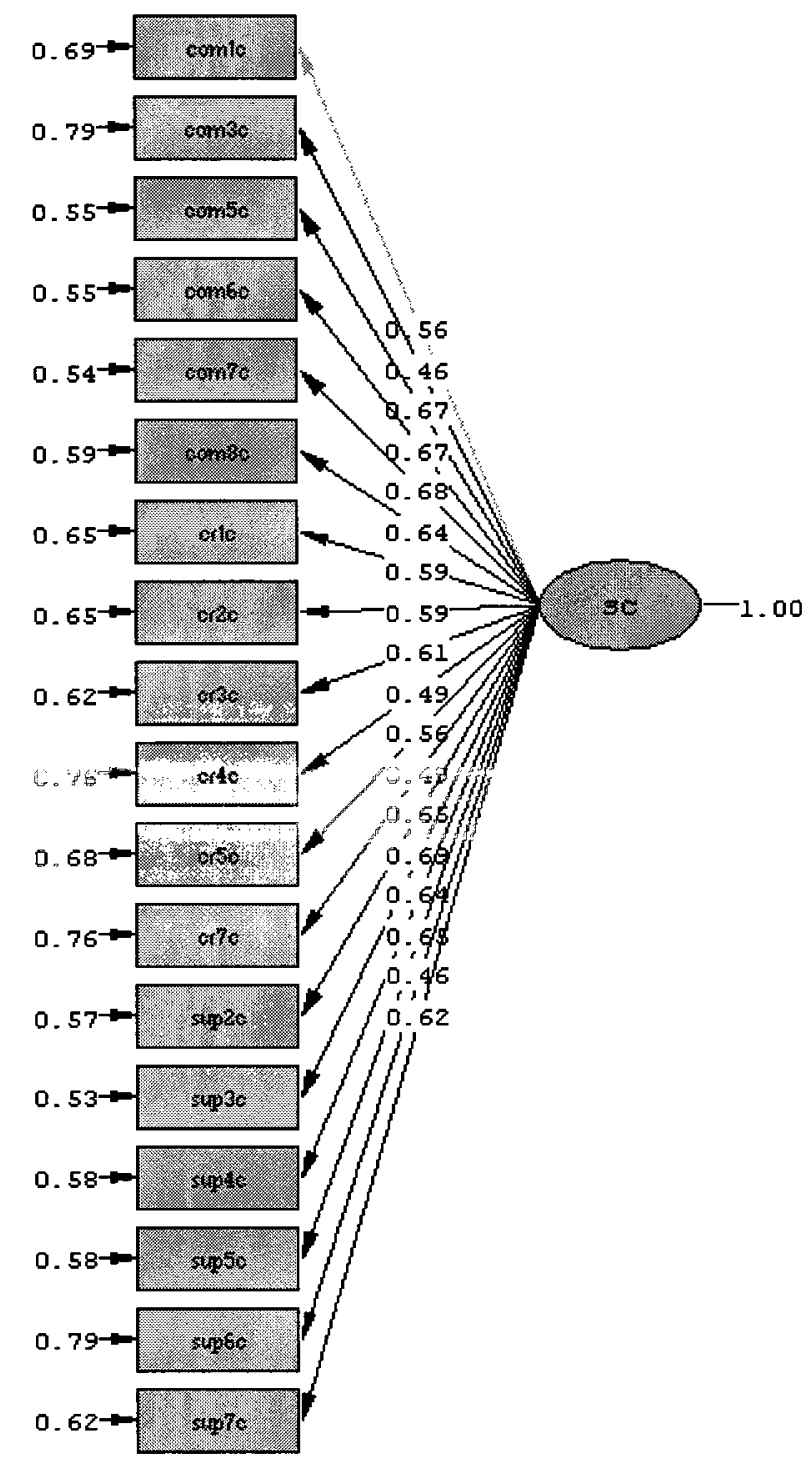

Chi-square $=696.21, \mathrm{~d} f=135, \mathrm{p}-\mathrm{value}=0.00000, \mathrm{RMSEA}=0.148$ 


\section{Model 2}

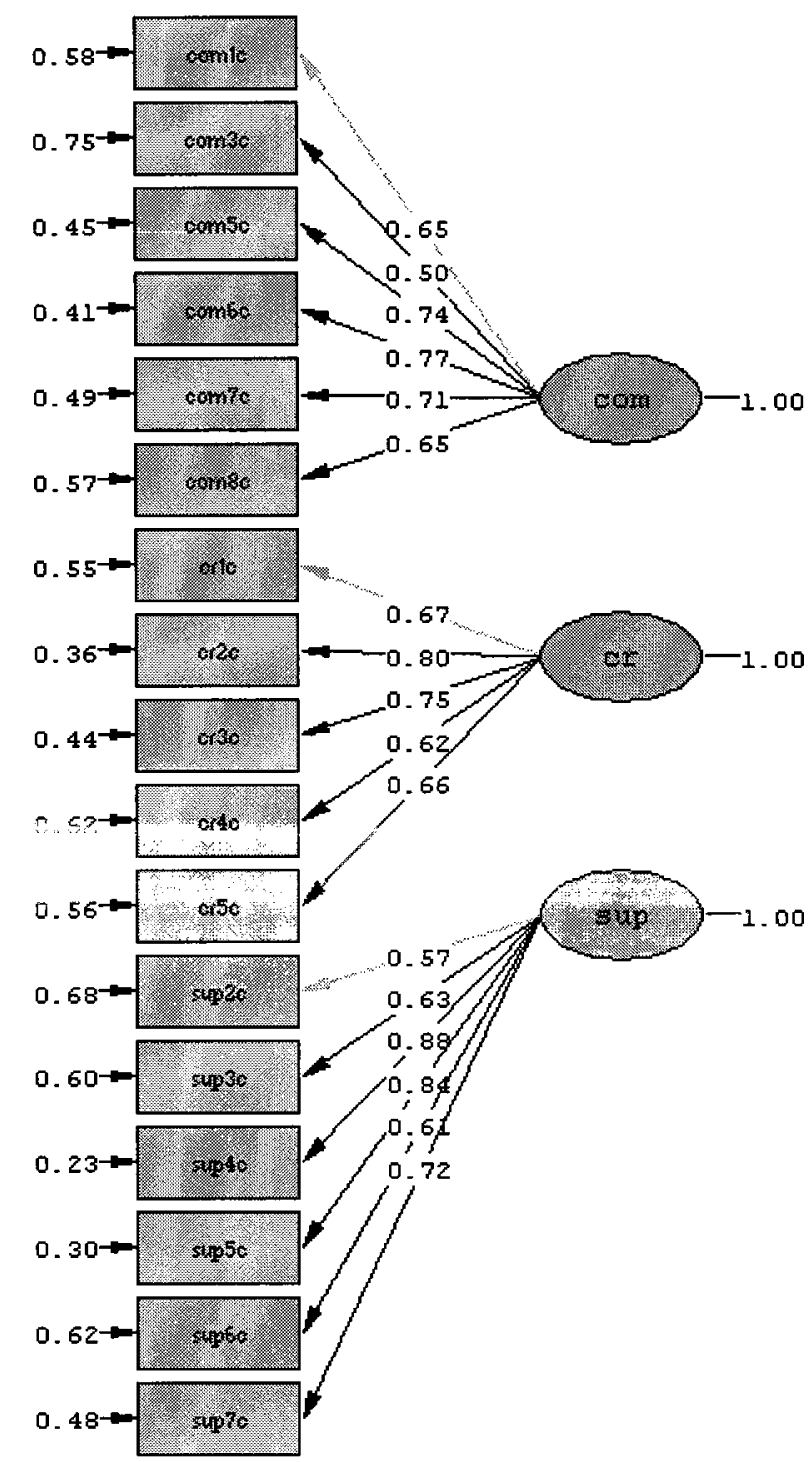

Chi-Square=366.82, df=119, P-value=0.00000, RMSEA=0.104 


\section{Model 3}

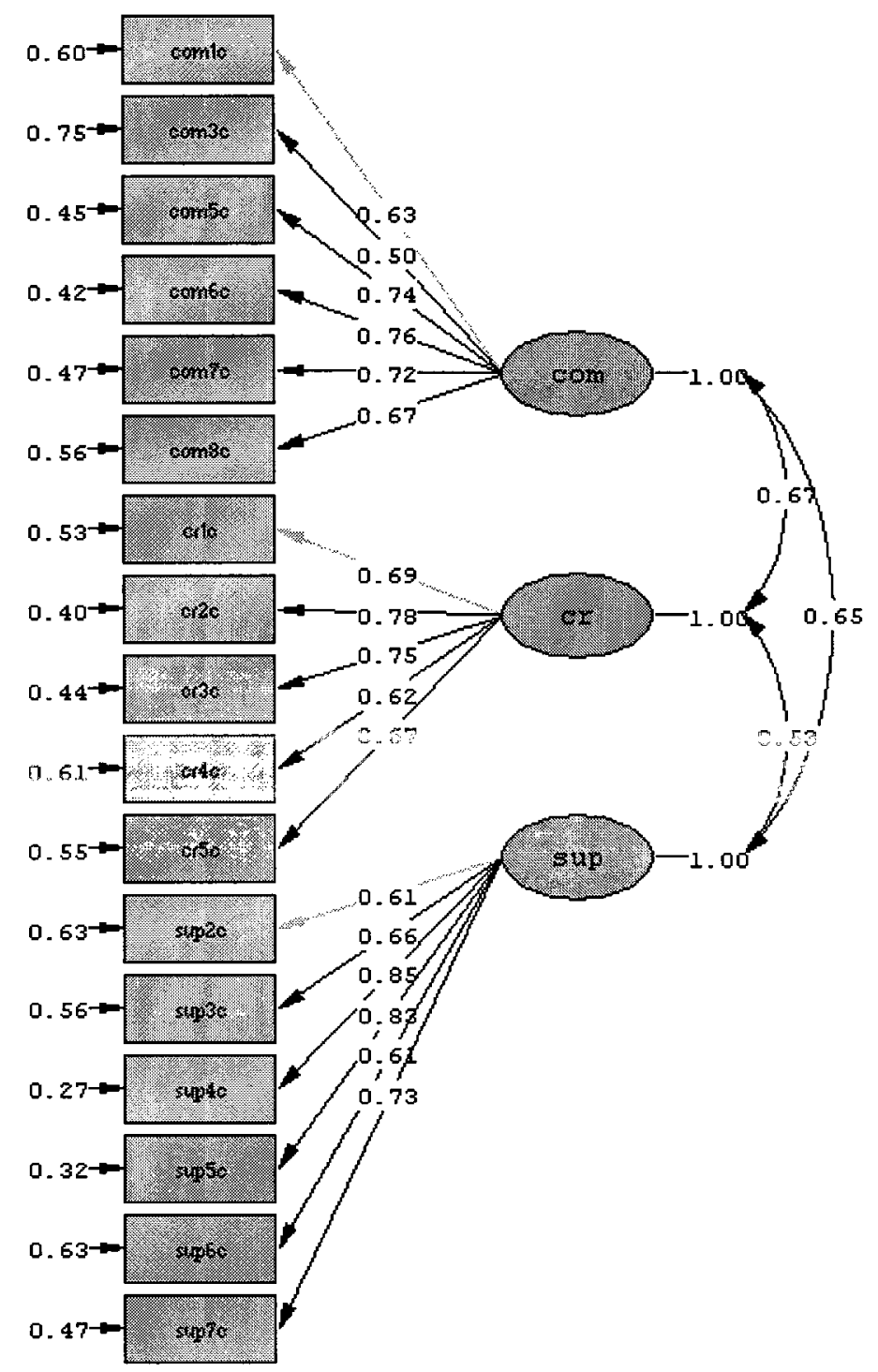

Chi-square=229.17, df=116, P-value=0.00000, RMSEA=0.071 


\section{Appendix VII Alternative Models for Technical Capability}

\section{Model1}

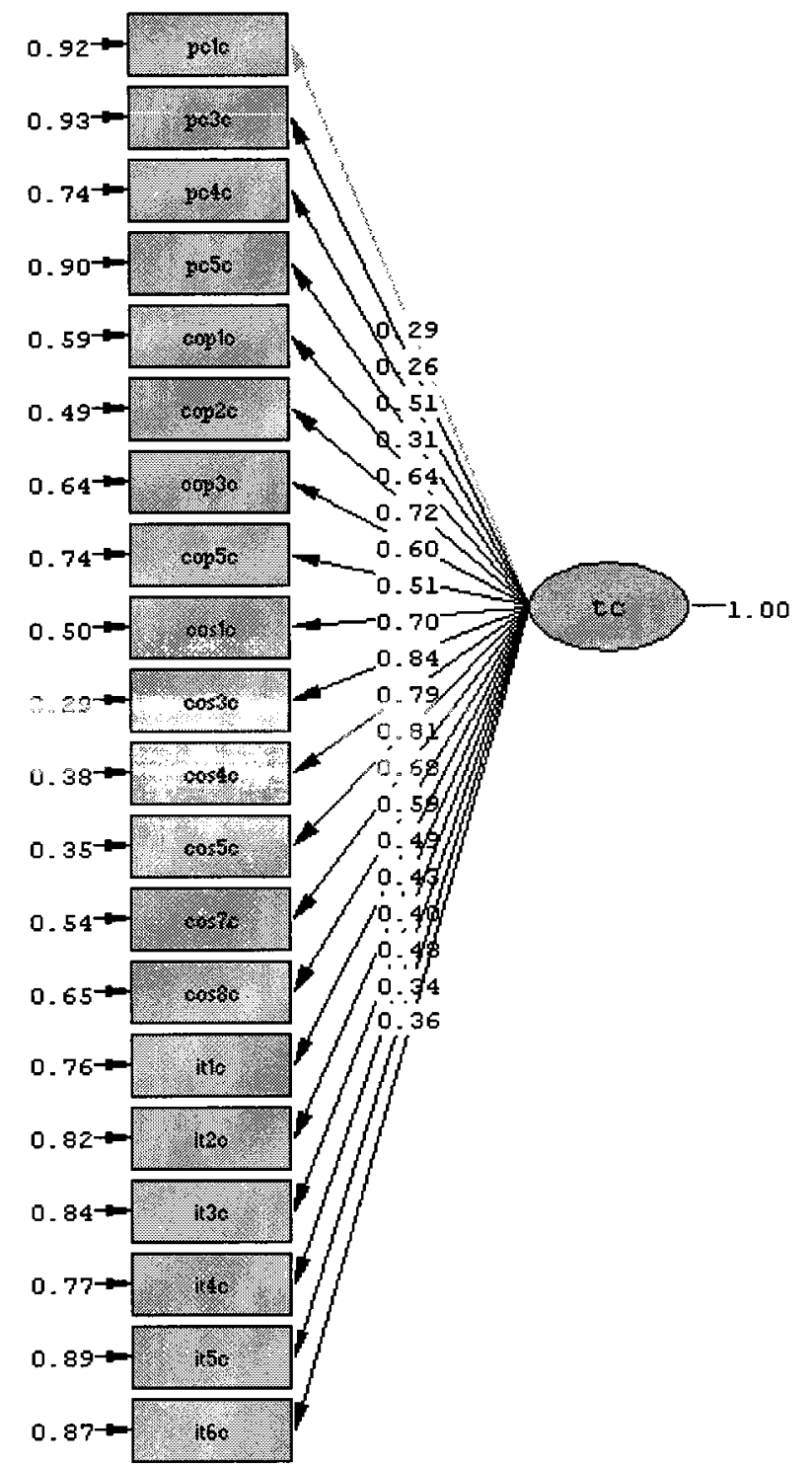

Chi-Square=1036.49, $d f=170$, P-value=0.00000, RMSEA=0.163 
Model 2

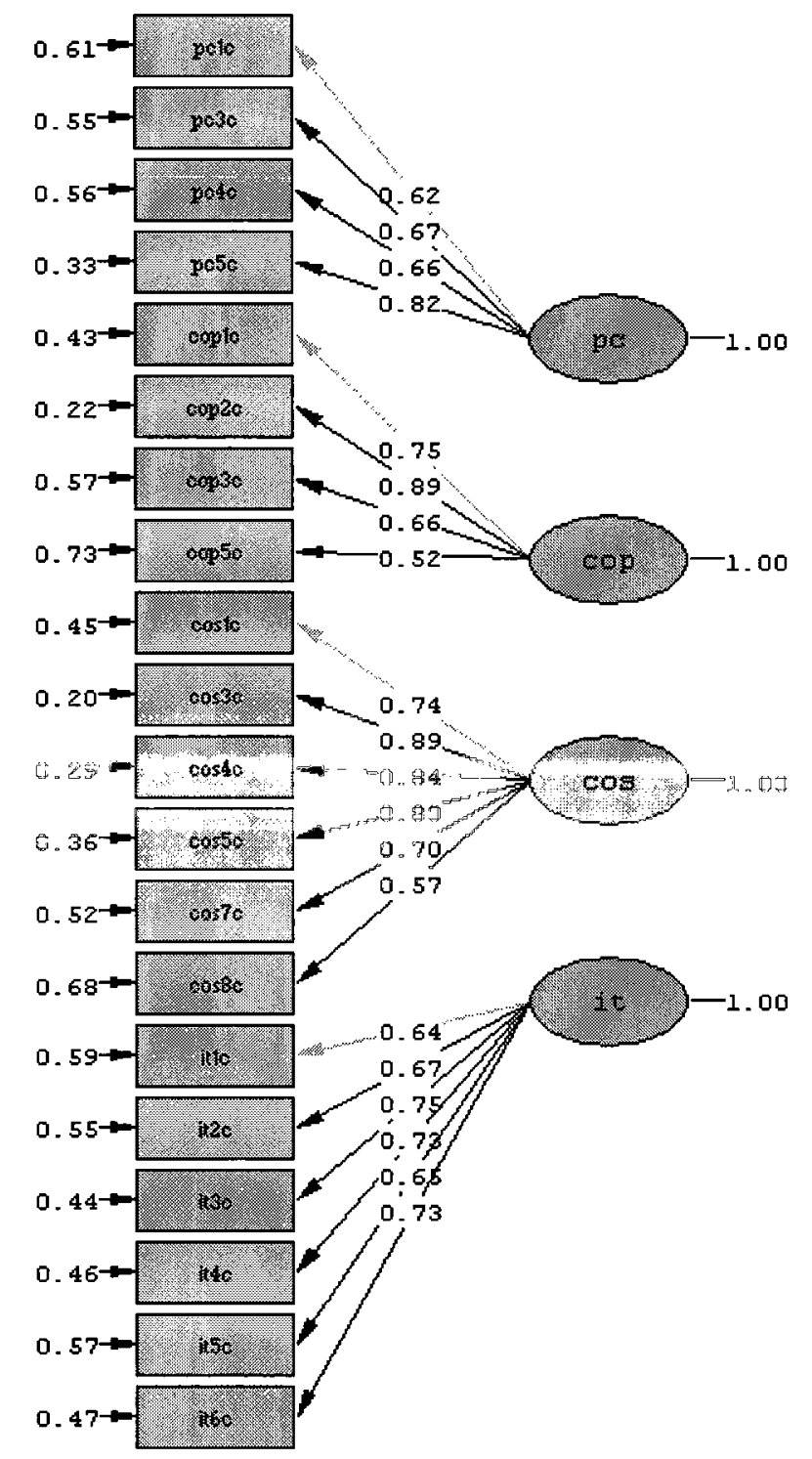

Chi-square $=500.88, d f=170, P-v a l u e=0.00000$, RMSEA $=0.101$ 


\section{Model 3}

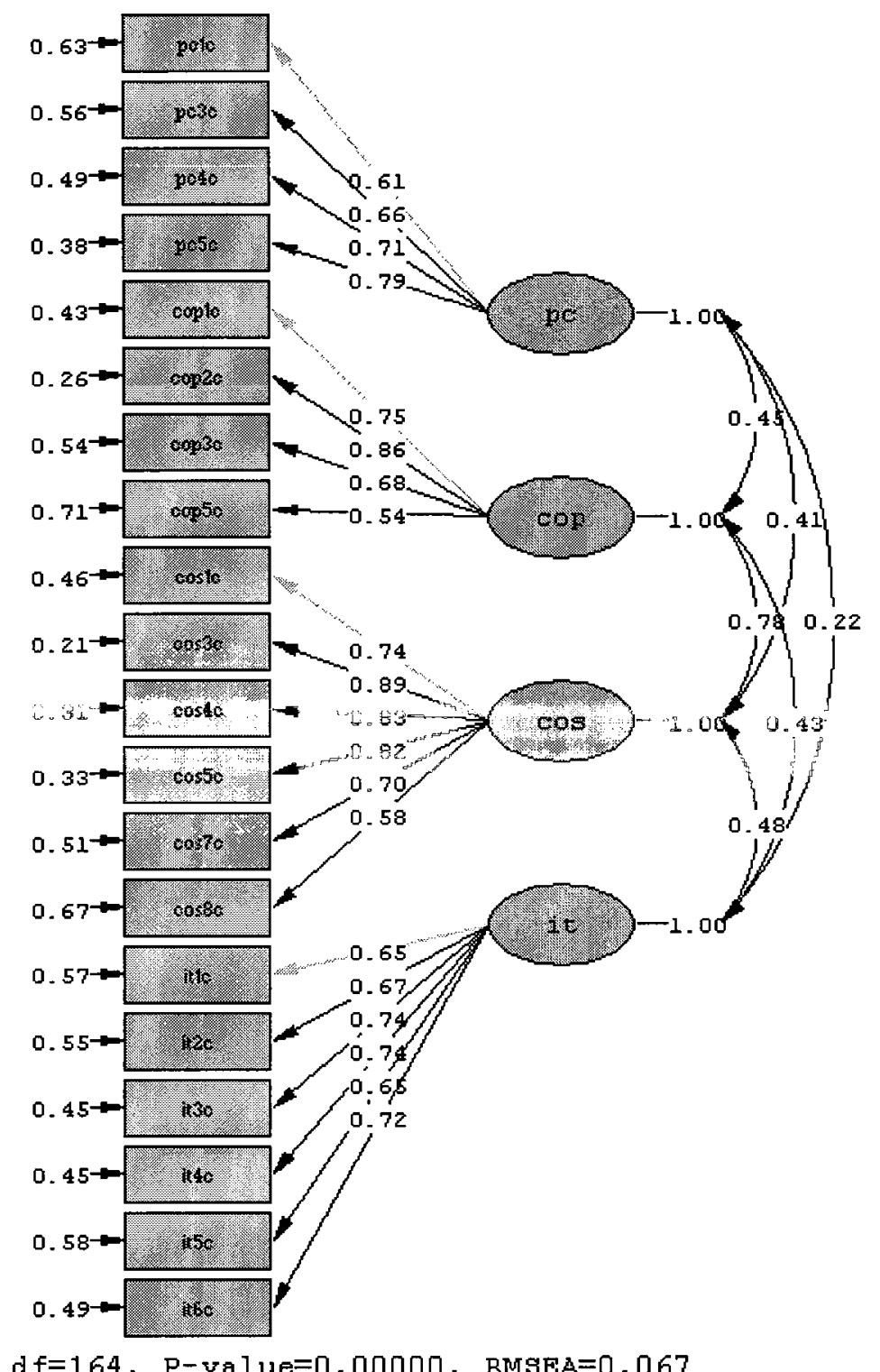

Chi-Square $=306.26$, df $=164, P$-value $=0.00000$, RMSEA=0.067 


\section{Appendix VIII Team Satisfaction Analysis using Profile Deviation}

\section{Descriptive Statistics}

\begin{tabular}{|l|l|l|l|}
\hline & $\mathrm{N}$ & Mean & Std. Deviation \\
\hline Team satisfaction & 154 & 3.8729 & 0.66275 \\
\hline
\end{tabular}

Table: Ideal Profile values for social capability dimensions in the two groups

\begin{tabular}{|c|c|c|c|}
\hline $\begin{array}{l}\text { Mean }>4.20 \\
154 \text { cases }\end{array}$ & \multicolumn{3}{|c|}{ Team Satisfaction } \\
\hline \multirow{3}{*}{$\begin{array}{l}\text { Low Technical } \\
\text { Capability }\end{array}$} & \multicolumn{3}{|c|}{ No. of high performing teams $=15$} \\
\hline & com & cr & sup \\
\hline & 3.99 & 3.70 & 4.40 \\
\hline \multirow{3}{*}{$\begin{array}{l}\text { High Technical } \\
\text { Capability }\end{array}$} & \multicolumn{3}{|c|}{ No. of high performing teams $=31$} \\
\hline & com & cr & sup \\
\hline & 3.98 & 3.78 & 4.34 \\
\hline
\end{tabular}

